Florida International University FIU Digital Commons

\title{
Crossing Boundaries to Education: Haitian Transnational Families and the Quest to Raise the Family Up
}

Tekla Nicholas

tnich002@fiu.edu

DOI: $10.25148 /$ etd.FI14040880

Follow this and additional works at: https:// digitalcommons.fiu.edu/etd

Part of the Educational Sociology Commons, Inequality and Stratification Commons, Race and Ethnicity Commons, and the Social and Cultural Anthropology Commons

\section{Recommended Citation}

Nicholas, Tekla, "Crossing Boundaries to Education: Haitian Transnational Families and the Quest to Raise the Family Up" (2014). FIU Electronic Theses and Dissertations. 1230.

https://digitalcommons.fiu.edu/etd/1230 


\section{FLORIDA INTERNATIONAL UNIVERSITY}

Miami, Florida

CROSSING BOUNDARIES TO EDUCATION: HAITIAN TRANSNATIONAL

FAMILIES AND THE QUEST TO RAISE THE FAMILY UP

A dissertation submitted in partial fulfillment of

the requirements for the degree of

DOCTOR OF PHILOSOPHY

in

COMPARATIVE SOCIOLOGY

by

Tekla C. Nicholas

2014 
To: Dean Kenneth G. Furton

College of Arts and Sciences

This dissertation, written by Tekla C. Nicholas, and entitled Crossing Boundaries to Education: Haitian Transnational Families and the Quest to Raise the Family Up, having been approved in respect to style and intellectual content, is referred to you for judgment.

We have read this dissertation and recommend that it be approved.

Sarah J. Mahler

Jean Muteba Rahier

Chantalle F. Verna

Alex Stepick, Major Professor

Date of Defense: March 27, 2014

The dissertation of Tekla C. Nicholas is approved.

Dean Kenneth G. Furton

College of Arts and Sciences

Dean Lakshmi N. Reddi

University Graduate School

Florida International University, 2014 
C Copyright 2014 by Tekla C. Nicholas

All rights reserved. 


\section{ACKNOWLEDGMENTS}

After writing this dissertation I am more aware than ever that I am deeply privileged to have had the opportunity to attain the level of education I desired. Although an academic degree is treated as a personal accomplishment, it represents the efforts of a family, a community, and a society. I owe my gratitude to many people who have made my education possible and who have contributed along the way.

I first must thank the contributors to the dissertation research who so generously shared their stories and their time with me. I regret that they must remain unnamed because they have truly been partners in my efforts to produce this dissertation. I thank the pastors, their wives, and all the families of Salvation Church who welcomed me when I began my fieldwork and who have been relentlessly encouraging throughout my research and writing. It is to them that I dedicate this dissertation.

I am deeply grateful to Dr. Alex Stepick, who has been a wonderful teacher, advisor and mentor. His research and writing deepened my interest in the Haitian immigrant community in South Florida and led me to the topic of this dissertation. Dr. Stepick exemplifies socially-engaged scholarship, encouraging students in research that illuminates and addresses societal inequities and problems. He always displayed a great interest in my research and facilitated relationships with other scholars with overlapping interests. I thank him for encouraging me to follow the empirical evidence as I developed my theories about the incorporation of Haitian immigrants. I must also thank Carol Stepick for the encouragement, advice, and cautionary tales she offered.

I have also been fortunate to benefit from a wonderful dissertation committee. Dr. Sarah Mahler has contributed a great deal as a teacher and mentor, who, with her purple 
pen, constantly pushed me to improve. As the leader of Team Mahler, she fostered an environment of collegiality and support among her graduate students that was so helpful in the early stages of the dissertation. I have also been privileged to learn from Dr. Jean Muteba Rahier, whose writing has inspired me with its emotion and authenticity. As Director of Africa and African Diaspora Studies, Dr. Rahier has created a fertile environment for scholarly thought and research. Dr. Chantalle Verna has been a guiding light, providing useful critiques and words of encouragement throughout my work on the dissertation. Her gentle comments encouraged me to think more broadly about the context of my research.

I also wish to thank Sophia Louis-Ridore who provided invaluable assistance in scheduling interviews and many other aspects of data collection, as well as Ireshah Andre and Santiague Deprez, who helped with many hours of interview transcription.

Finally, I wish to thank the family and friends who have contributed in many ways along my journey. In particular, I thank my parents, Ed and Tekla Hallanan, who were enthusiastic about my research but who did not live to see it completed. The intellectual curiosity and passion for learning that lead me to write this dissertation were planted and nurtured by them. My sisters, Sharon Hallanan and Marian Wilson, also contributed support and advice. Among many graduate school colleagues who helped to shape and sharpen my ideas, I want to thank Sharon Placide and Francisco Sastre for their critiques, suggestions, encouragement, and friendship as we made our way through the $\mathrm{PhD}$ program together. The deepest thanks and love must go to my husband, Bob Nicholas, who has been a constant comfort and a steadfast partner, holding down the fort while so much of my time and attention has been devoted to completing this dissertation. 
Throughout my graduate program I have enjoyed the support of the FIU Department of Global \& Sociocultural Studies including a teaching assistantship and funding for academic conferences. I also thank Africa and African Diaspora Studies (AADS), the Graduate \& Professional Student Committee (GPSC), and The Peace Research Institute Oslo (PRIO) for funding to present my work at academic conferences. These opportunities to share my research and discuss emerging theory throughout the process of the dissertation research and analysis were vitally important to the development of the ideas presented in this dissertation.

I have been privileged to live in a society that made these educational opportunities possible and to be among those to whom the society's great benefits are extended. This research has brought this privilege into sharp focus and I am grateful to have had this opportunity. 


\title{
ABSTRACT OF THE DISSERTATION \\ CROSSING BOUNDARIES TO EDUCATION: HAITIAN TRANSNATIONAL FAMILIES AND THE QUEST TO RAISE THE FAMILY UP
}

\author{
by \\ Tekla C. Nicholas \\ Florida International University, 2014 \\ Miami, Florida \\ Professor Alex Stepick, Major Professor
}

Nearly 175, 000 Haitian immigrants have settled in South Florida since the 1970s. Their lives are often lived transnationally with persistent connections and obligations to family members in Haiti. Yet, traditional theories of immigrant assimilation focus on the integration of immigrants into host countries, giving little consideration to relationships and activities that extend into migrants' countries of origin. Conversely, studies of transnational families do not explicitly address incorporation into the receiving country. This dissertation, through the experiences of Haitian immigrants in South Florida, reveals a transnational quest to raise the family up through migration, remittances, and the pursuit of higher levels of education. I argue that familial duties and obligations, which have cultural foundations in the Haitian lakou, structure the activities of Haitian transnational families as they pursue socioeconomic advancement through migration and education. With the support of transnational families, many students cross boundaries to academic achievement and improve their opportunities for socioeconomic mobility in the US. With higher levels of education, these individuals contributed to a more favorable incorporation into the United States for their extended families, as well. 
The data were collected through participant observation and 78 in-depth interviews documenting the migration histories of 27 Haitian immigrant families in South Florida. This dissertation contributes to the existing literature on Haitian immigrants in the United States and to an understanding of the transnational dimensions of immigrant incorporation more broadly. 
CHAPTER

PAGE

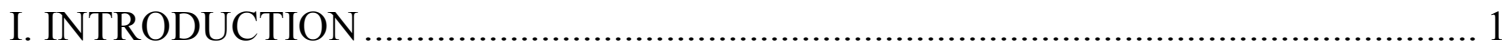

Preliminary Research and the Research Topic ................................................... 1

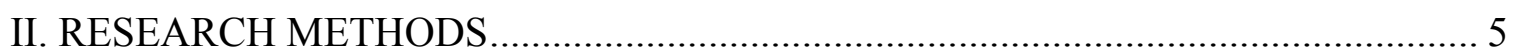

Participant observation in the Haitian community.............................................. 5

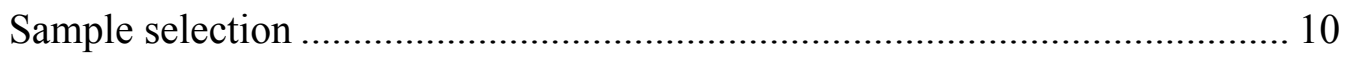

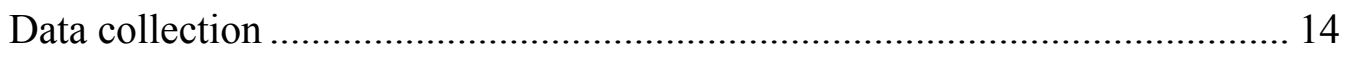

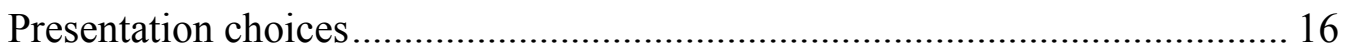

III. HAITIAN MIGRATION TO THE UNITED STATES ……………………….......... 21

IV. IMMIGRANT INCORPORATION IN THE UNITED STATES............................. 28

The Assimilation Paradigm.......................................................................... 28

Boundaries as a Framework for Immigrant Incorporation ................................ 41

V. A TRANSNATIONAL APPROACH TO IMMIGRANT INCORPORATION .......... 55

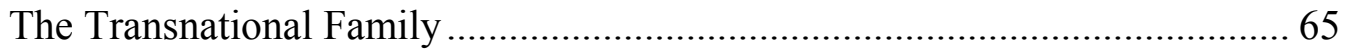

Haitian Immigrant Families and Transnational Obligations............................. 98

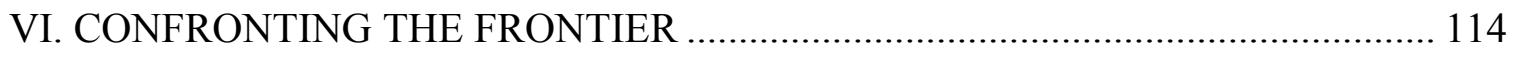

VII. EDUCATION and the TRANSNATIONAL GENERATION ……...................... 133

Tipa Tipa: Making Progress Step by Step …………………........................ 143

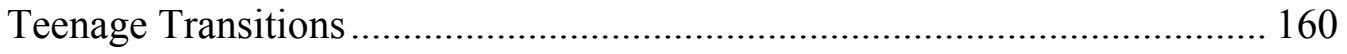

Crossing Boundaries to Higher Education..................................................... 200

Haitian Immigrants in South Florida and Education ....................................... 216

VIII. Familial Relationships and Obligations …………............................................... 220

The Logic of the Lakou............................................................................ 220

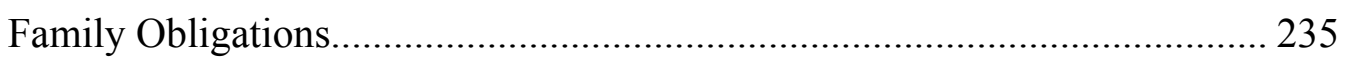

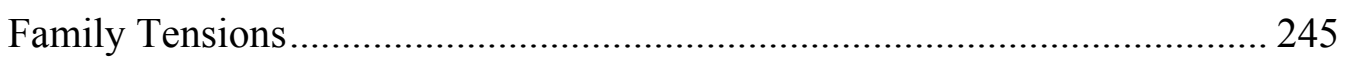

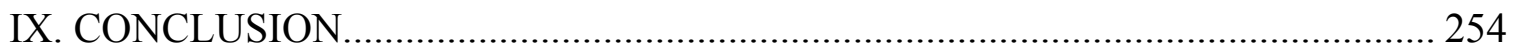


REFERENCES

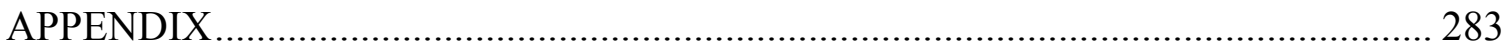

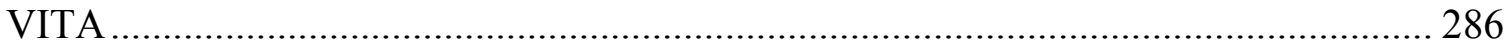




\section{LIST OF FIGURES}

FIGURE

PAGE

Figure 1. Occupations of Salvation neighborhood Haitians ...................................... 8

Figure 2. Industry of employment for neighborhood residents 16 years and over ........... 10

Figure 3. United States Coast Guard Interdictions of Haitians, 1982-2012 ................... 23

Figure 4. Haitian immigrants in South Florida by year of entry and citizenship............. 25

Figure 5. Age distribution of Haitian-born persons in South Florida .......................... 217

Figure 6. Educational attainment of Haitian immigrants in South Florida .................... 218

Figure 7. School enrollment of Haitian immigrants in South Florida .......................... 219 


\section{INTRODUCTION}

\section{Preliminary Research and the Research Topic}

In the fall of $2004 \mathrm{I}$ began a research project to examine parent - child communication in regard to education in the South Florida Haitian community. Having steeped myself in the recent "children of immigrants" literature, I felt prepared to begin my research. I expected that my findings would reveal some of the phenomena that had been discussed in the literature, although I hoped that my qualitative approach would lead to a more detailed and nuanced understanding the processes involved. Prepared to encounter evidence of adversarial attitudes toward education, parent - child dissonance, and the likelihood of negative assimilation outcomes suggested by previous research (Portes and Rumbaut 2001, Portes and Zhou 1993, Stepick et al. 2001), I began my research.

I wanted to spend some time immersing myself in the community I would study before formally beginning my fieldwork. I contacted a Haitian man who had previously invited me to his church. I explained that my return to school for a graduate program was leading me in the direction of research in the local Haitian community. I wanted to get to know Haitians, not just as individuals, but as members of families. I thought the church was the best public space to get to know people this way. He welcomed me to come to church with him, introduced me to the pastors who led the church, and I began to attend services regularly. This was a large Protestant congregation of Haitian immigrants and their children. With services that combined Haitian Kreyòl, French, and English, during the first year I was fortunate to have translation provided by a volunteer from the congregation or a student who was assigned to help. Eventually, after additional study in 
an intensive summer language program, I understood all but some of the more obscure cultural references, - usually in the form of a joke that went over my head - which would quickly be explained by someone sitting nearby.

Happily, the church was an ideal place to get to know Haitian families, as I had hoped. My language limitations led me to first become familiar with the high school students in the congregation. I was assigned to their Sunday school class because, while the adult classes were conducted in Haitian Kreyòl, the teens primarily communicated in English. They often served as my translators for the worship service, and it was this group that would become the focus of my initial research project.

Not only was the church a good place to meet Haitian families, but it turned out to be a good place to learn about educational experiences and attitudes, as well. The topic of education came frequently from the pulpit, and Sunday school discussions among high school students often revolved around school experiences or relationships with their parents. As my formal research was about to begin, the opportunity for reciprocity, the basis of engaged and ethical fieldwork, emerged. In one of our first conversations, a pastor of the church remarked that he hoped I would find a way to be useful to the community. Soon that opportunity presented itself. I became involved in tutoring a number of students from the church.

The Florida Comprehensive Assessment Test (FCAT) had just reached the stage of full implementation. The exams had been given for several years, but now students who had completed high school without passing both FCAT reading and math exams would not receive a high school diploma. They received, instead, a certificate of completion. In addition, students at the third grade level who did not pass their FCAT 
exams would not be promoted to fourth grade. These standardized tests of math and reading were taking a heavy toll on students in the church.

I volunteered to tutor students who were adversely affected by their FCAT scores. Soon I was regularly visiting Haitian families in their homes to talk about educational concerns and to tutor students in math and reading. Well immersed in the academic issues and family interactions regarding education in Haitian immigrant families, I was sure my research would contribute to understanding the sources of some of these problems and the ways parents reacted to them (see Nicholas 2008; Nicholas, Stepick, and Dutton Stepick 2008). Nevertheless, my first interview introduced me to a phenomenon that I was not expecting, and one that would turn out to be common to many of the Haitian immigrant families I have encountered.

Daniel, the child of barely literate Haitian farmers, explained that his parents came to the United States to work so that they could afford to keep their children - he and his three siblings - in school in Haiti. He did not see them for fifteen years, but because of their sacrifices he arrived in the South Florida with a Haitian high school diploma, and a determination to continue with college in the United States. With their continued support, he completed Bachelor's and Master's degrees and now works in Florida's public education system. He is now in a position to make his parent's lives much more comfortable, and they share in the higher status Daniel has achieved.

Over and over I encountered similar stories in which migration and family obligations combined to profoundly affect educational outcomes. Many of the Haitian parents I interviewed had more education than the literature on Haitians and Haitian immigrants in South Florida had led me to expect. They were not from wealthy or even 
middle class families in Haiti; their family migrations had begun in an effort to escape from poverty. Most of these Haitian parents of American-born teens revealed that their own parents had little to no formal education. They recounted family migration stories that were remarkably similar in the transnational educational pathways they displayed. Migrants, with very little education themselves, left Haiti to work abroad and sent money back to support their families. Remittances were used to fund children's educations in Haiti, which resulted in large advances in the level of education within the family. When these more educated family members migrated themselves, they became a resource that benefitted the rest of the family. These stories explained a transnational process "to raise the family up," a phrase that they commonly used, which combines migration and transnational distribution of resources and opportunities. The extended family relationships of Haitians were central to this enterprise.

My desire to examine these phenomena more closely led to this dissertation research. I will argue in this dissertation that the incorporation of Haitian immigrants needs to be understood through a transnational perspective. As I will demonstrate, many Haitian immigrant families change the nature of their incorporation through transnational extended family processes that increase access to educational opportunities. Educational attainment has become an important factor in contemporary theories of immigrant incorporation. My analysis employs a framework of boundaries and boundary-work to examine how transnational family processes that increase opportunities for individual family members to further their education affect the incorporation into the United States of these individuals and for their extended families, as well. 


\section{RESEARCH METHODS \\ Participant observation in the Haitian community}

\section{Salvation Church}

My original research site and the center of my participant observation in the Haitian community was a large evangelical Protestant church that I will call Salvation Church, situated in a concentrated Haitian community in Broward County, Florida. The Church is a hub of religious and social activity for local Haitian immigrant families. More than 1,000 congregants gather for the Sunday morning service. In addition, the church holds religious services several times a week, Bible study, several choirs, an orchestra, and other religious activities. It is also the site of non-religious activities including a nursing education program, annual health fair, and other community service ventures.

Since its establishment as a small storefront ministry that served a handful of Haitian immigrant families, Salvation Church has grown dramatically to become a large Haitian community center. The church has been at its current location, led by a team of Haitian immigrant pastors, since 2000. Salvation Church is associated with a major mainstream American Protestant religious organization that has a strong missionary presence in Haiti. The church members are diverse in terms of their places of origin within Haiti and in their socioeconomic status in the United States. Most are working class - employed in janitorial or landscaping services, restaurants, health care facilities, and factories - to middle class, with common occupations including teaching, nursing, and public safety. The congregation includes immigrants who arrived during the early phase of Haitian migration to South Florida in the late 1970s and it continues to welcome 
recently arrived immigrants on a regular basis. The church strives to accommodate the needs of this diverse group. For example, while sermons are typically given in Haitian Kreyòl, PowerPoint presentations are used to deliver the main points in English for church members who have been raised primarily in the United States. When the message is primarily directed toward the youth of the congregation, the linguistic delivery is reversed.

Salvation Church is located at the vertex of three census tracts with substantial populations of Haitians. The congregation includes families from Dade, Broward, and Palm Beach counties, with a large proportion residing in the immediate neighborhood. Church members who do not live in the neighborhood often lived there previously or have family members nearby.

\section{The Neighborhood}

The area surrounding Salvation Church is an ethnically and racially mixed working class neighborhood. Bounded to the east and west by railroad tracks, a major interstate highway bisects the neighborhood from north to south. From east to west a busy local street is lined with ethnic shops and restaurants that display the mix of Caribbean and Latin American cultures that coexist here. About 35\% of the 21,000 residents of the three census tracts that comprise this neighborhood are Haitian immigrants or their children, according to US Census Bureau, 2006-2010 American Community Survey. This is the largest and most densely populated Haitian neighborhood in Broward County. 
Although the majority of residents are black, the racial composition of the focal neighborhood is quite mixed: $56 \%$ black, $32 \%$ non-Hispanic white, $10 \%$ Latino (mostly Puerto Rican and Mexican) and 2\% Asian (U.S. Census Bureau, 2006-2010 American Community Survey). The neighborhood has a significant immigrant population; $42 \%$ of the neighborhood residents are foreign-born. Many of the native-born are the children of these immigrants who were born in the US.

This neighborhood, like many others in South Florida, has experienced a steady influx of immigrants over the course of several decades. More than $40 \%$ of the immigrants in this neighborhood arrived in the United States since 2000. Thirty percent (30\%) arrived during the 1990s. It is not surprising, therefore, that many residents report that they cannot speak English very well. Forty three percent of neighborhood residents (age five and older) speak only English, but only 1\% of Haitians fall into this linguistic category. Fifty one percent of the Haitian population speaks English less than very well (U.S. Census Bureau, 2006-2010 American Community Survey).

Despite its large immigrant population, the neighborhood does not display a distinct ethnic character. What is evident, instead, is that the residents are people who work hard for a living. In the early morning, men and women head to work in the uniforms of maintenance workers, security guards, and health care aids. Men carrying neatly folded aprons ride small bikes to work at the local grocery store, and women walk along the road in the distinctive garb of fast food chains. In the evenings, trucks and vans pull to the side of the road and men pile out, tired and soiled from a long day of landscaping or construction. 
Figure 1. Occupations of Salvation neighborhood Haitians

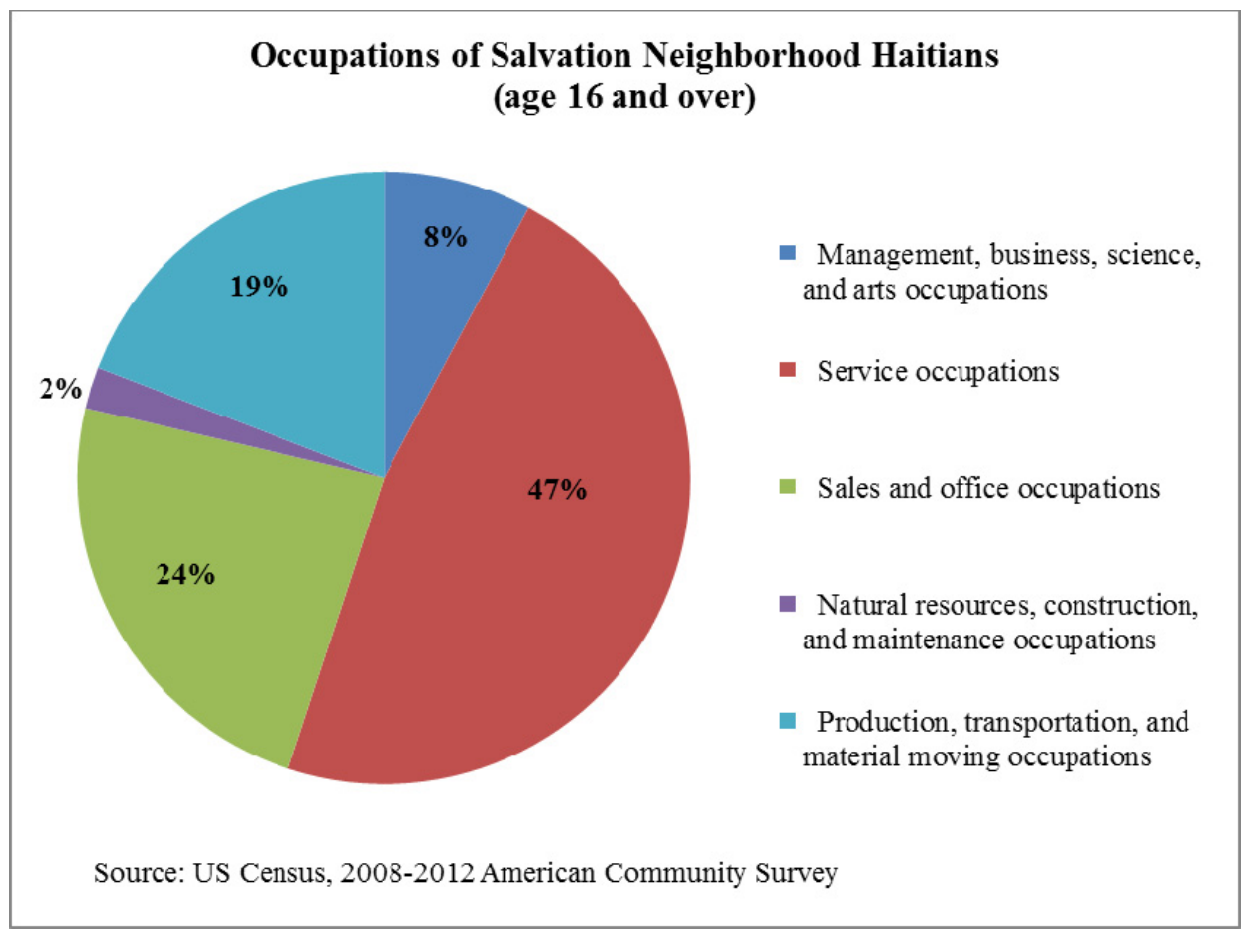

The neighborhood is divided into numerous small housing developments. While all are modest, the economic differences between them are evident at a glance. Homes range from single-family ranch style residences with flourishes of recent renovations to dilapidated apartment buildings. Most of the homes were built in the 1960s and 1970s, with median values of about $\$ 100,000$ (U.S. Census Bureau, 2008-2012 American Community Survey). There is a broad range of incomes among neighborhood households, from very poor to solidly middle class. The modal earning category is \$50,000 - \$74,999 per family (U.S. Census Bureau, 2006-2010 American Community Survey). But about one quarter of the households in this neighborhood reported an annual income below the poverty level. Among the foreign-born residents, Haitians who were not citizens had the highest rate poverty. 
During my time as a participant in this community, the effects of the national economic boom, bust, and the subsequent period of recession have been apparent. Home ownership is highly valued among Haitians, and families in this community tended to prioritize purchasing a home, pulling together resources from relatives to make a down payment. Families who had purchased very modest, older homes in the 1980s and 1990s were able to sell at much higher prices in 2000s. They took advantage of the vigorously promoted mortgage offers to move into more affluent neighborhoods.

Some families did well in this economic transition, but, overall, the community was hit very hard by the subsequent real estate bust that hit 2008. Property values suddenly and dramatically declined. Financial strategies that had been planned on the basis of increasing real estate prices were no longer viable. Like many others across the US, this community experienced high rates of mortgage defaults, foreclosures, and endless negotiations for loan modifications (Olorunnipa 2011).

These troubles were compounded by the effects of the recession on employment. Many local Haitians employed in the service sector with hourly positions had prospered during the economic boom with steady employment and opportunities for overtime work or part-time second or third jobs. Suddenly, hours were cut, overtime was eliminated, and extra part-time workers were laid off. Today, in 2013, the economic situation of the community has stabilized but times are much tougher than before. Even the college educated professionals of the community have faced job insecurity. Many work in the public schools where budget cuts have been substantial. 
Figure 2. Industry of employment for neighborhood residents 16 years and over

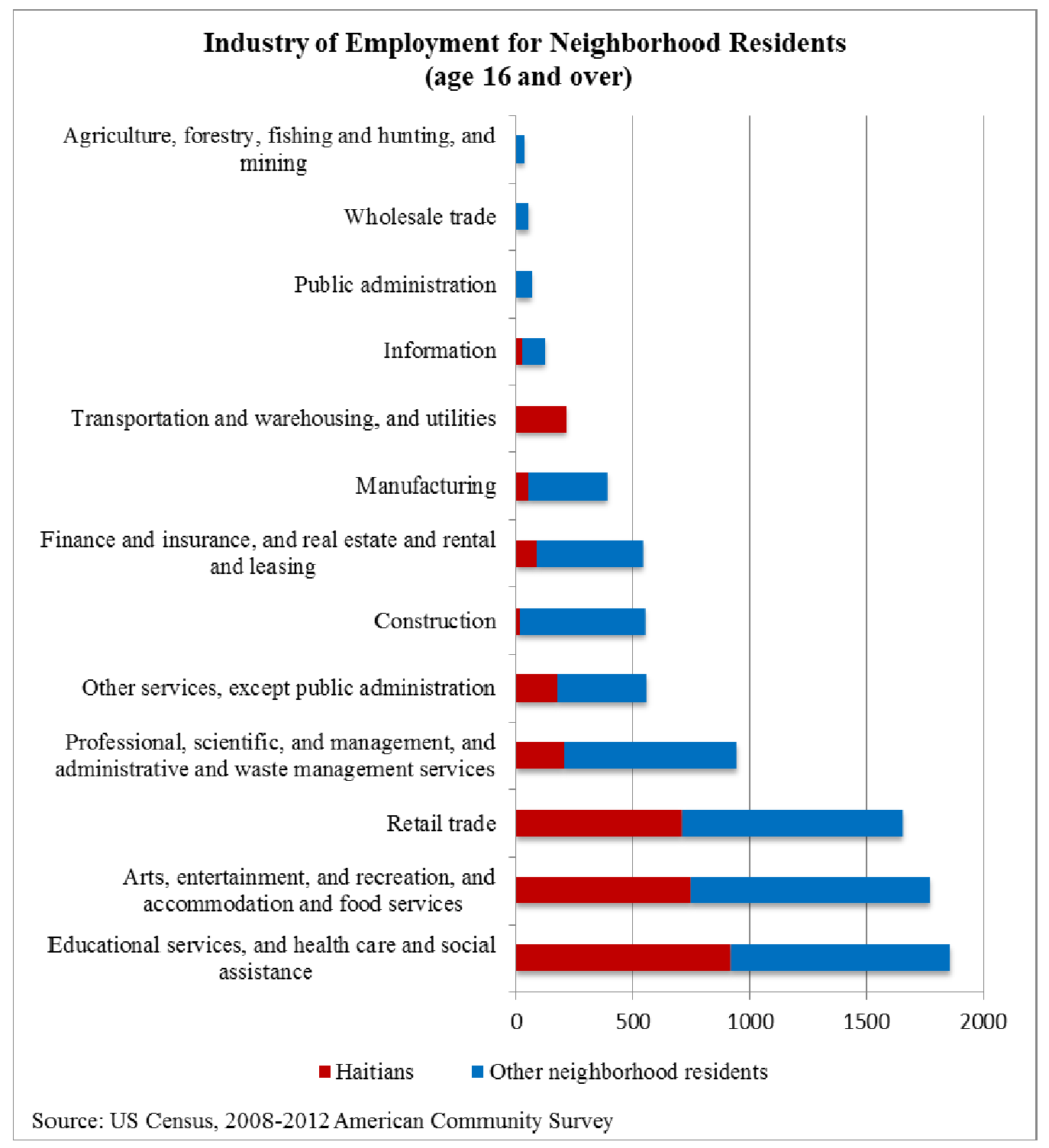

\section{Sample selection}

As mentioned previously, this research project was carried out to better understand the transnational process through which Haitian families endeavored to increase the level of education achieved by members of the family. The project began with families I already knew well from the Salvation Church community. From preliminary studies of these families it was evident that, in addition to a transnational 
perspective, the research required a broad, emic, definition of family. From all my interaction in the Haitian community, it was clear that "family" had to be understood as extended, transnational, and inclusive of social relations that were not bounded by biological ties. In other words, family had to be defined as those who considered themselves to be part of the network of social duties and obligations that incorporate individuals into a Haitian family. The cultural foundation, ideologies, and practices associated with Haitian notions of family will be discussed in Chapter 5 .

To understand whether the transnational processes being studied could be observed more broadly, I purposively sought out families beyond those I had come to know already through research and social interaction. I reached out to church families I did not know well and then extended the search to include Haitian families from outside the church community. I made these contacts by requesting interviews with Haitians whom I met in my day to day activities, at the grocery store, during a taxi ride to the airport, and at restaurants. These brief encounters led to interviews with Haitian immigrant families throughout South Florida, from Palm Beach County to Miami. I was able to meet family members who visited from other parts of Florida, New York, Boston, Canada, and Haiti, and collected stories from several members of each family.

\section{Definition of Terms:}

Transnational family - a group of related individuals who are separated across national boundaries for substantial periods of the time, but who continue to define themselves as a family and maintain a sense of connection to one another (Bryceson and Vuorela 2002: 3) Frontiering migrant - an immigrant who establishes residence in an area where no other close relatives already reside (Bryceson and Vuorela 2002: 11) 
Trailing migrant - an immigrant who follows earlier family members to a particular area, often with their assistance

\section{$\underline{\text { Research sample criteria }}$}

Families selected for the research sample met the following criteria:

Frontiering migrant(s):

- had origins in a rural area of Haiti (but rural-to-urban migration may be a part of the migration history).

- had a demographic profile that included low levels of human capital - little to no English, limited education (no more than primary), limited job skills (no profession or skills that were highly sought by US employers).

- migrated to the US, leaving at least some children or siblings of school-age in Haiti.

\section{Trailing migrants:}

- were identified by the frontiering migrant as "family members" who came to the United States after them. 
Table 1. Frontiering migrants' demographic characteristics and migration information

\begin{tabular}{lcc} 
Frontiering migrants & $\mathrm{n}=27$ & $\%$ \\
\hline Female & 12 & $44 \%$ \\
$\quad$ Male & 15 & $56 \%$ \\
Age at migration & & \\
$\quad$ Average & 27 & \\
$\quad$ Range & $19-45$ & \\
Decade of migration & & \\
1970s & 10 & $37 \%$ \\
$1980 \mathrm{~s}$ & 8 & $30 \%$ \\
$1990 \mathrm{~s}$ & 7 & $26 \%$ \\
$2000 \mathrm{~s}$ & 2 & $7 \%$ \\
Educational attainment at migration & & \\
none & 4 & $15 \%$ \\
$1-4$ years & 15 & $56 \%$ \\
5-6 years & 8 & $30 \%$ \\
Education in the US & & \\
none & 25 & $93 \%$ \\
vocational training & 2 & $7 \%$ \\
\hline
\end{tabular}

The importance of thinking of family beyond the nuclear, biologically-related, coresident household unit was reinforced over and over. Although they may have been physically distant for much of the time, commitments to people who were considered to be family were always present. Phone calls from Haiti frequently brought both family news and requests for funding. On a Saturday visit to a Haitian household it was not unusual to be greeted at the door by a woman holding a cellphone to her ear whispering, "It's Haiti. My niece need money for her school." Large boxes were loaded with goods of all kinds - clothes, shoes, kitchen utensils, diapers for babies or adults, food products,

\footnotetext{
${ }^{1}$ Total exceeds $100 \%$ due to rounding.
} 
medical supplies - and sent to Haiti to be distributed to various family members.

Households had frequent changes of membership as nieces, nephews, aunts, uncles, grandparents, or friends would come to stay for a few weeks or a few years. Family was defined by sprawling networks of care-taking and obligation.

\section{Data collection}

In addition to participant observation and countless informal conversations with Haitian immigrants in South Florida, from June 2011 through June 2012, I engaged in 78 semi-structured interviews for this project, including members of 27 families. Through these interviews, migration and education histories were collected on a total of 27 frontiering migrants and 172 trailing migrants.

The interviews were usually carried out in the home of the contributor (as I refer to the Haitian immigrants who provided their family migration stories for this research) or another family member. A few interviews were conducted at Salvation Church or at public libraries to coordinate with other activities. Most interviews ran from two to $2 \frac{1}{2}$ hours and many individuals were willing to talk more - in person or on the phone - as the work progressed and additional questions came to mind. Occasionally, this resulted in a sort of spontaneous family focus group, with several family members contributing memories and stories to the narrative.

The data collection began with a family migration history, charting all the places an individual migrant had lived and the age at which each move occurred. I then retraced the life history with the contributor, asking with whom they lived in each location (see sample interview guide in Appendix 1). I documented the movements of the individual contributor and other family members to develop a full understanding of the transnational 
configurations of the family at different points of the contributor's life course. I then asked about the educational pathways of the contributor and other family members. The data regarding education, employment, and remittances are based on the reports of the contributors. For reliability, the information was gathered from several members of each family and, if discrepancies occurred, they were investigated further until a family consensus could be reached. Questions were posed broadly to allow the contributors to bring forth the facts, issues, and themes that were most important to them. Probes were used to reveal needed information that was not included in the responses to the broader questions.

Table 2. Trailing migrants' educational attainment in Haiti and the US

\begin{tabular}{|l|c|c|c|c|}
\hline Trailing migrants & \multicolumn{2}{|c|}{$\mathrm{n}=172^{2}$} & \multicolumn{2}{l|}{} \\
\hline $\begin{array}{l}\text { Level of education } \\
\text { US equivalents) }\end{array}$ & \multicolumn{2}{|c|}{ at time of migration } & at time of interview \\
\hline None & -- & -- & -- & -- \\
\hline Elementary & 41 & $24 \%$ & 15 & $9 \%$ \\
\hline High school, no degree & 21 & $12 \%$ & 12 & $7 \%$ \\
\hline High school degree & 95 & $55 \%$ & 41 & $24 \%$ \\
\hline Technical certification & -- & -- & 22 & $13 \%$ \\
\hline Some college & 10 & $6 \%$ & 15 & $9 \%$ \\
\hline Associate's degree & -- & -- & 15 & $9 \%$ \\
\hline Bachelor's degree & 5 & $3 \%$ & 38 & $22 \%$ \\
\hline Master's degree & -- & -- & 7 & $4 \%$ \\
\hline Doctoral degree & -- & -- & 5 & $3 \%$ \\
\hline
\end{tabular}

${ }^{2}$ Educational outcomes include the highest level of education achieved at the time of the interview by all trailing migrants 18 or older identified by contributing families $(n=172)$. Interviews were conducted with 51 individual trailing migrants. 
The interviews were all conducted in English, with occasional bursts of "Kringlish," as the teenagers call the composite language they often speak with their parents. I offered the option of conducting the interview in Haitian Kreyòl with the assistance of a translator. I did not feel that my language skills were sufficient for conducting interviews completely in Kreyòl on my own. But each contributor chose to participate in English. Some explained to me that "when you are in America you should speak English." Instead, the contributors who thought they might need help with the interview arranged to have a family member nearby to explain anything they could not communicate well in English.

Most interviews were digitally recorded and transcribed. A few contributors preferred not to have their interviews recorded; in those cases, notes were handwritten. All contributors were given pseudonyms that were used in all documents, including this dissertation, in order to maintain confidentiality. Although I transcribed most of the interviews myself, I had assistance with this task from two Haitian-American college students. I assigned transcriptions to my assistants only with the permission of the contributor. All interview transcripts were handled securely with encryption software.

\section{Presentation choices}

I struggled to choose the right words to refer to the Haitian immigrants who shared their stories with me. They are not "subjects" of or "participants" in an experiment. This dissertation is about their lives; their lives are not about my research. "Respondents" or "interviewees" suggests that they are defined by my questions and questioning. Instead, I think of them as my cultural teachers and contributors to this project. They contributed their time and their personal stories, which form the principal 
source of the data. As they did so, they taught me about their family relationships and the obligations they fulfill. Each contributor gave me a deeper understanding of their Haitian homeland and its culture in order to teach me about their experiences as immigrants seeking better lives for themselves and their families. Sometimes it seemed evident that they were speaking not only to me, but were hoping to reach out through me to a wider audience of people who do not know Haitians well. I have tried to let those voices be heard in this text.

Another choice involved the presentation of the quoted material. The recorded interviews were transcribed as they were heard, with very little alteration of patterns of speech, word choices, or grammar. Quotes included in this dissertation are intended to help convey the natural speech of the contributor. The fluency with which Haitian immigrants speak English affects their opportunities for jobs and schooling, their willingness to participate with native English speakers, and the ways they are perceived by others both within and outside of the Haitian immigrant community. By presenting their speech as I heard it, I add this piece of context to their personal migration narrative.

I struggled to present detailed ethnography while also respecting my ethical obligation to the contributors and their families to keep their identities confidential. In order to examine extended family interactions, contributors' narratives included information about family members who were not interviewed themselves. To maintain confidentiality of those who spoke to me and to avoid identifying individuals who might not want to be discussed, I chose to focus on specific parts of the transnational process separately, obscuring some characteristics of family members who did not directly participate in the research. 
For each of the educational pathways I will discuss, I chose several individual cases that exemplified some of the key characteristics and variations among the total group for that pathway. The individual cases were chosen, first, because the stories were an excellent representation of the pathway under discussion. In addition, the individual had to be very comfortable with being written about and having their words published. For many contributors, this was not the case. They were happy to talk to me about their family migration and education histories, but had concerns about their migration statuses being compromised or that they might be endangered if other people were jealous about their educational or financial successes. Many families included individuals with insecure immigration statuses; others were afraid that their permanent residence status or even citizenship could be revoked if their migration stories were publicly discussed. The contributors have lived through coups, political violence, and the potential for arbitrary vengeance by a government. These concerns had to be respected first and foremost. I will present a few extended families, from which many members contributed directly, more fully in order to examine broad family processes in greater detail.

The purpose of this research is to examine a process that is not well documented or understood. I took a grounded theory approach to the research, beginning with questions about a phenomenon observed empirically and allowing the range of interview questions to evolve with my growing understanding of the phenomenon. Grounded theory is an iterative process; analysis occurs throughout data collection, and future questions are adapted as knowledge deepens or gaps become evident.

Transcribed interviews were coded, first through a process of open coding in which the text was analyzed closely for categorical possibilities. As data accumulated, 
significant categories and themes were identified. A constant comparative approach was used to examine these categories, and memos were kept throughout the process to record emerging understandings and nagging questions, alike. I sought out the dimensions of each category and analyzed the patterns that appeared among them. To assist in these efforts, I used the qualitative data analysis software, MAXQDA. Major coding categories used in the dissertation include:

- Educational boundaries in Haiti

- Educational boundaries in the US

- Educational outcomes

- Occupational outcomes

- Family obligations

- Family assistance

- Transition to US

In addition, the following variables were used in the analysis:

- Year of migration

- Highest level of education (Haiti, US)

- Frontiering or Trailing

- Family members in US at migration (none, few, many)

- Number of siblings

- Number of children

To set the context for my research, I will first provide some of the needed background and related literature. The next chapter will provide background on Haitian 
migration the United States and, particularly, to South Florida. Following that, I will discuss theories of immigrant incorporation and the framework of boundaries and boundary-work that is most useful to the analysis of my data. 


\section{HAITIAN MIGRATION TO THE UNITED STATES}

Haitian migrants have come to the United States since the Caribbean nation gained its independence from France in 1804. But their numbers were so few until recent decades that they were barely noted in the history of American immigration. Prior to 1960, most Haitian immigrants were professionals and political exiles from the Haitian elite. After Francois "Papa Doc" Duvalier came to power in 1957 upper class migration increased, and by 1964 the Haitian middle class joined the anti-Duvalier exodus. From 1950-1970 nearly eight percent of the Haitian population emigrated. In particular those with money, education, and professional, business, or trade skills found it possible to seek opportunities elsewhere (Catanese 1999). Most Haitian immigrants, prior to the 1970s, made their new lives in the northeastern U.S. or the French-speaking regions of Canada. Haitians generally avoided the southern U.S., where racial segregation persisted (Stepick 1998).

The 1970s, however, marked a change in the nature of Haitian migration as Papa Doc was succeeded by his son Jean-Claude "Baby Doc" Duvalier. The economic deprivation, political repression, and brutality that characterized this period led to increased migration from rural Haiti, as well as the urban centers (Laguerre 1984). The typical immigrant was now more likely to be poor and uneducated. Population pressures, land depletion, and poverty drove migration to the urban areas of Haiti, or off the island to the Bahamas, Canada, or the United States. By 1977 Haitians began regularly to arrive on the shores of Florida, often attempting the 700 mile voyage in small vessels that were barely seaworthy. It is estimated that up to 70,000 Haitian refugees arrived by boat from 
1977-1981, with an additional 5,000-10,000 entering South Florida by plane (Stepick 1992).

This influx of dark-skinned immigrants, many of whom were poor and uneducated, set off a strong negative reaction in the United States, particularly among Florida residents (Mitchell 1994, Stepick 1992). By the time of their arrival, Florida's long history of racial segregation was no longer sanctioned by law, but still characterized social relations in this southern state. Not only did Haitians face racial prejudice in the communities in which they settled, but they also drew the attention of the federal government which took action to keep them from reaching American shores and to remove them if they did. In spite of the turmoil in their country, Haitians were seen only as economic refugees. The US Immigration and Naturalization Service (INS) ${ }^{3}$ increased efforts to control Haitian immigration including imprisonment, denial of work permits, and rejection of claims for asylum (Charles 2006; Lawless 1986). In 1981 the Reagan administration began a program of interdiction to intercept migrants before they ever left Haitian waters. In the first ten years of this program, nearly 23, 000 Haitians were interdicted at sea, only 11 of whom were deemed eligible to apply for asylum in the US (Wasem 2005).

\footnotetext{
${ }^{3}$ The INS was disbanded by the Homeland Security Act of 2002. The Department of Homeland Security (DHS) now handles responsibilities that once fell to the INS through three federal agencies: Customs and Border Patrol (CBP), Immigration and Customs Enforcement (ICE), and US Citizenship and Immigration Services (USCIS). http://www.uscis.gov/history-and-genealogy/our-history/agencyhistory/post-911
} 
Figure 3. United States Coast Guard Interdictions of Haitians, 1982-2012

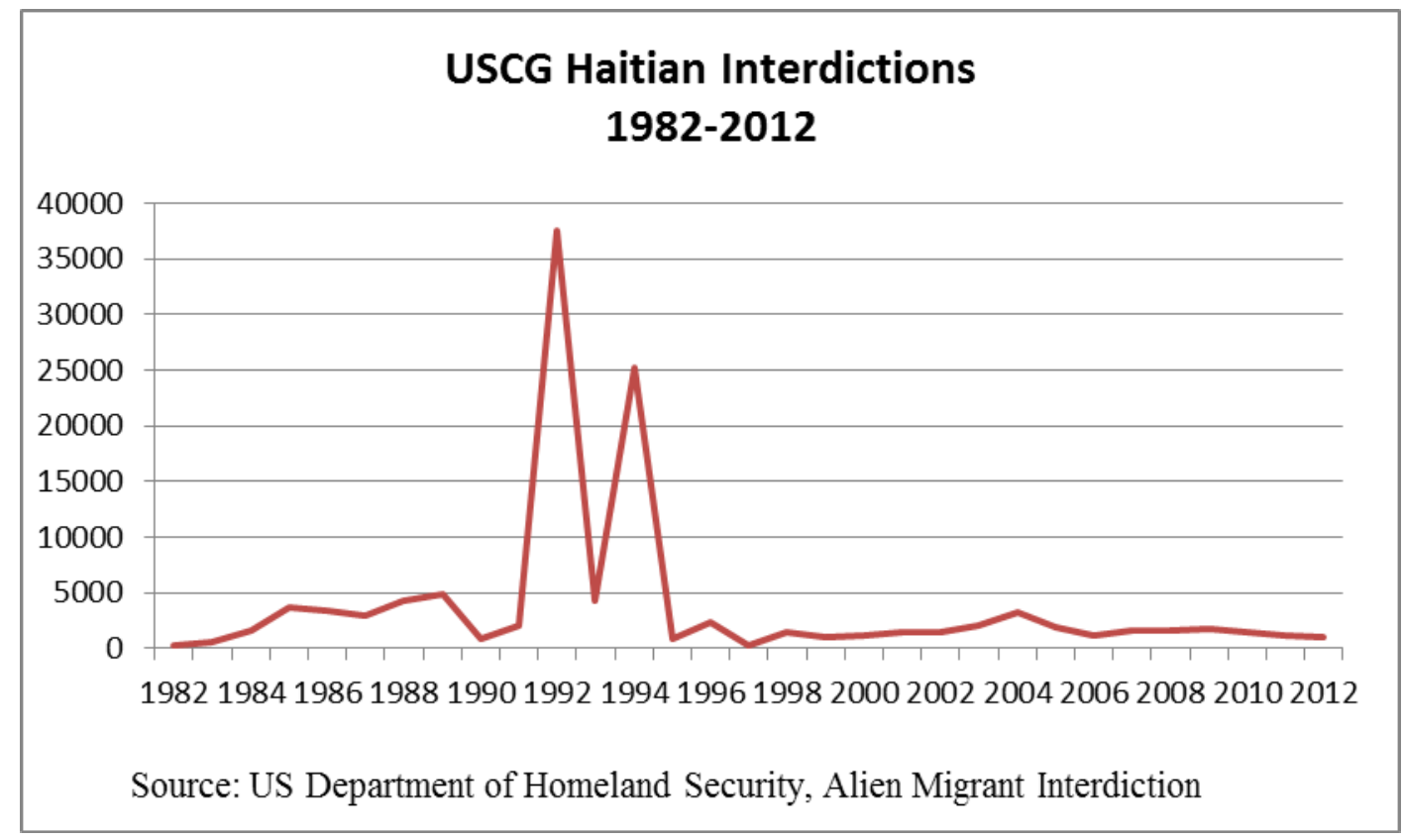

Following the 1991 coup that ousted the democratically elected Haitian President Jean Bertrand Aristide, the Haitian exodus increased. But this unstable political situation undermined the US assertion that Haitians were primarily economic migrants. As a result, the US sought to process Haitian claims for asylum at the US naval base in Guantanamo, Cuba, where it could more readily deny them and prevent applicants from disappearing into the US mainland. Nevertheless, many Haitians were able to prove persecution. Yet their success would be met by another type of US resistance. After more than 10,000 Haitian asylum-seekers were admitted into the US, then-President George H.W. Bush ordered that Haitians intercepted at sea would be immediately returned to Haiti without further processing (Charles 2006, Lawless 1986, Mitchell 1994,Wasem 2005). Although the U.S. interdiction program brought a sharp decline in the numbers of Haitian immigrants after 1981, Haitian migration to Florida continues at a steady pace (Stepick and Portes 1986). 
Many Haitians who reached the US have been subject to imprisonment at Krome detention center in Miami or other prison-like facilities, where some were held for more than a year awaiting release or deportation. In addition, the Centers for Disease Control (CDC) included Haitians on a list of high risk groups for Acquired Immune Deficiency Syndrome (AIDS), again enforcing a stereotype of Haitians as carriers of disease. As Stepick notes "In the public mind, all Haitians were black boat people who were disease ridden, desperately poor, and pathetic" (1992:65). Haitians were often treated as illegal immigrants by INS even after the Immigration Reform and Control Act (IRCA) of 1986 provided opportunities for many undocumented Haitians to regularize their legal status.

The US government has consistently implemented measures to reject Haitian claims of asylum and exclude them from the United States. Critics have pointed to egregious disparities between the treatment of Haitian and Cuban asylum-seekers (Joppke 1999, Stepick 1982, 1992, Stepick and Portes 1986, Wasem 2005). This political and social climate constitutes the type of negative context of reception associated with poor assimilation outcomes among the children of immigrants (Portes and Rumbaut 2001, Stepick 2001).

Haitian immigrants to South Florida came, overwhelmingly, from the last wave of migration that began in the mid-1970s. Many spoke little English when they arrived and had little schooling. They began to arrive in Florida where they were met with prejudice and legal obstacles to immigration (Stepick and Portes 1986). Despite these difficulties, Florida's Haitian population more than doubled from 1990-2000, to 267,689 (Stepick, Dutton Stepick, Kretsedemas 2001:5). Migration to North America has increasingly become part of the survival strategy for Haitian families, and South Florida has been a 
key destination. In addition, as a Haitian community has become established in Florida, immigrants from the earlier wave of Haitian migration have relocated from the northern sites they first settled. Of the 813,186 persons of Haitian ancestry living in the United States in 2010, more than 270,000 reside in the South Florida counties of Miami-Dade, Broward, and Palm Beach where they comprise approximately five percent of the population (US Census, 2006-2010 American Community Survey). About two thirds are first generation immigrants, born outside of the US.

Figure 4. Haitian immigrants in South Florida by year of entry and citizenship

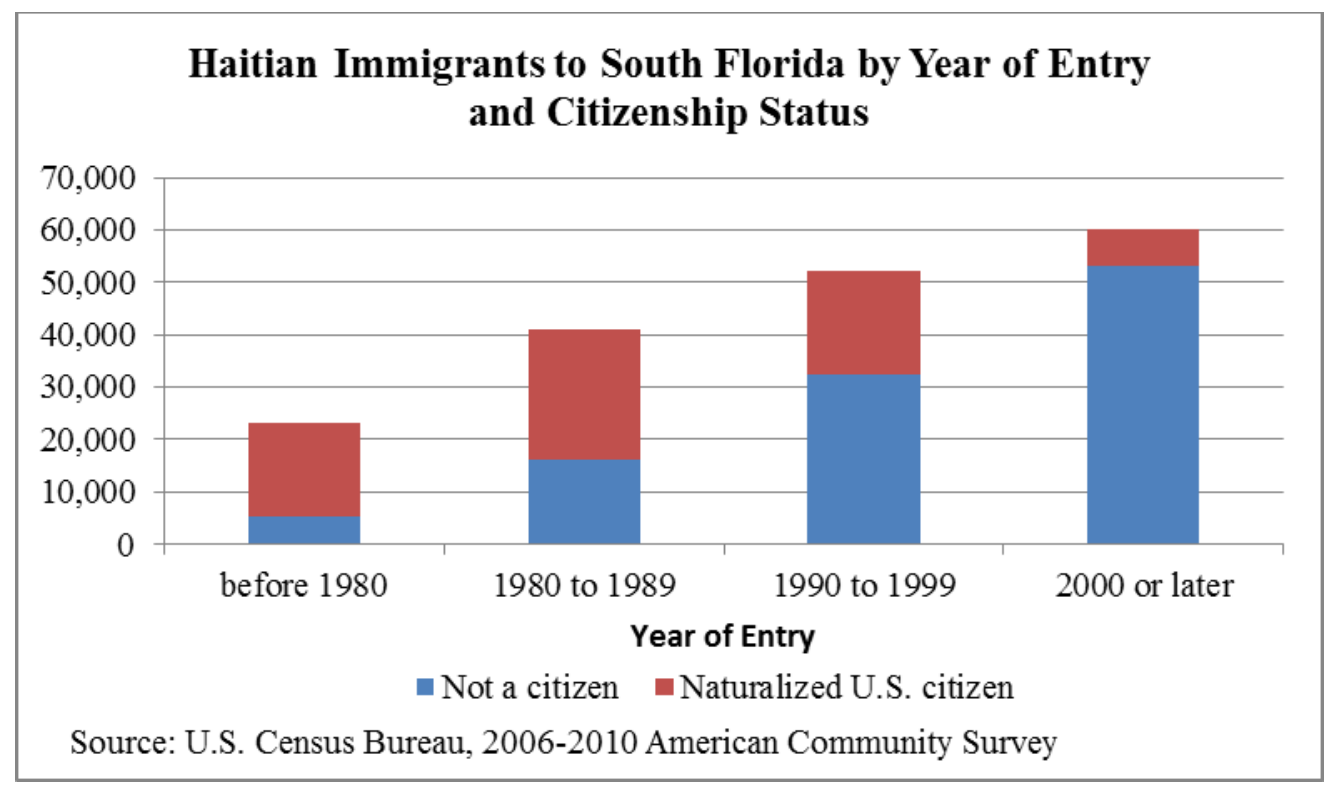

This research is focused on immigrant families from Haiti who settled in South Florida since the 1970s. The impacts of ethnic and racial prejudice and the disadvantages of low levels of education and other types of human capital on the incorporation of Haitian immigrants to the US have been documented (Portes and Rumbaut 2001, Stepick 1892, Stepick et al. 1992, Stepick et al. 2001). But over the course of several decades, 
Haitian immigrant families have established chains of migration and engaged in transnational activities that were not considered in these analyses.

Building upon an extended period of participant observation among Haitian immigrant families in South Florida, in-depth interviews and family migration histories were used to explore the transnational strategies that Haitian families have employed to negotiate the disparate economic and educational opportunities available in Haiti and in the United States. I examined the ways that resources were transmitted between parents and children, and how they were distributed across other lines of kinship. Guided by a framework of boundaries and boundary-work, this research demonstrates how transnational relationships and activities affected the incorporation of Haitian immigrants into the United States. I focus on educational attainment and occupational status as measures of socioeconomic incorporation into the United States.

This dissertation is intended to contribute to the existing literature on Haitian immigrants in the United States and to an understanding of the transnational dimensions of immigrant incorporation more broadly. For this reason, I do not approach the research from a diasporic perspective. Arguing for a transnational approach to analyzing processes of immigrant incorporation, I bridge the separate literatures that focus on immigrant assimilation and incorporation and on transnational families. As I will discuss in the next chapters of the dissertation, traditional theories of immigrant assimilation have tended to focus on the integration of immigrants into "host" countries, giving little consideration to the impact of relationships and activities that extend into migrants' countries of origin. Studies of transnational families, on the other hand, have focused on family relationships 
and processes but not explicitly on how this affects their incorporation into the countries to which they have migrated. My research examines the relationship between transnational family processes and immigrant incorporation outcomes. It takes an approach that is both transnational and intergenerational in order to better understand migration and incorporation into the receiving society as family endeavors. In the next chapter, I will discuss some of the theoretical frameworks that have guided the social science of immigrant incorporation, laying the foundation for the contribution I hope to make with this research. Then, I will discuss the literature on transnational families that contributes useful concepts and findings to my analysis of the transnational family processes found among Haitian immigrant families in South Florida. 


\section{IMMIGRANT INCORPORATION IN THE UNITED STATES}

Since its inception, the United States has been shaped by immigrants and their children. However, the ways that newcomers have been incorporated are quite varied. Some have been welcomed, others marginalized or even excluded. And the trajectories of the incorporation of those admitted have differed as well. A tension exists between contradictory notions of America, on one hand, as a nation that welcomes and affirms equal opportunity to all comers and, on the other, a society with persistent hierarchies based on race and ethnicity (Joppke 1999). After half a century of immigration policy reforms that reflected the abstract liberal ideals and also served to significantly increase the flow of immigrants into the US, a nativist backlash has been evident. Nearly 40 million foreign-born persons resided in the United States in 2010, comprising 13\% of the total population (Grieco et al. 2012). More than half of this population arrived in the US since 1990. Consequently, many Americans express concern over the effects this large population of immigrants will have upon American society.

\section{The Assimilation Paradigm}

The academic study of immigrant incorporation in the United States gained prominence with the Chicago school of sociology in the early $20^{\text {th }}$ century. Robert Park, Ernest Burgess, W.I. Thomas and their students were engaged in understanding the lives of the immigrant groups residing in their city. This research began at the turn of the century and focused primarily on the immigrants of European origin who had settled in the Chicago area. Occurring within a political environment that sought to rapidly 
"Americanize" newcomers, these scholars studied and developed theory regarding the processes that led immigrants to this end (Alba and Nee 2003, Stepick et al. 2003).

The term "assimilation" has often been used to identify the process by which immigrants become incorporated into American society. Defined as to "make like" or "be absorbed into," ${ }^{4}$ assimilate is something that immigrants are often compelled to do. Early $20^{\text {th }}$ century ideas regarding assimilation are often linked to this definition from Robert E.

Park and Ernest W. Burgess, two of the founding scholars of the Chicago school, in The Introduction to the Science of Sociology"

Assimilation is a process of interpenetration and fusion in which persons and groups acquire the memories, sentiments, and attitudes of other persons or groups, and, by sharing their experience and history, are incorporated with them in a common cultural life. [1921: 735, quoted in Gordon 1964: 62]

Although assimilation is described as a process, it is the outcome of incorporation into a common cultural life that defines it. Park later provided this more nuanced definition of "social assimilation" in the Encyclopedia of the Social Sciences:

The name given to the process or processes by which peoples of diverse racial origins and different cultural heritages, occupying a common territory, achieve a cultural solidarity sufficient at least to sustain a national existence. ... In the United States an immigrant is ordinarily considered assimilated as soon as he has acquired the language and the social ritual of the native community and can participate, without encountering prejudice, in the common life, economic and political. ... This implies among other things that in all the ordinary affairs of life he is able to find a place in the community on the basis of his individual merits without invidious or qualifying reference to his racial origin or to his cultural inheritance. [1930: 281, cited in Gordon 1964: 63]

\footnotetext{
${ }^{4}$ The Oxford Desk Dictionary and Thesaurus, American Edition. 1997. New York: Berkeley Books.
} 
Park's definition starts off from a position of a minimal requirement for a common political identification along with competence in the linguistic and social norms of the United States. Immigration scholars seemed to view their role as one of reassuring doubters that in fact, over time, immigrants did become real Americans. This approach reflected political and social expectations for Anglo-conformity that dominated the era and shaped US policies for immigration and naturalization (Alba and Nee 2003, King 2000). Incorporation into the nation's economic structure is specifically noted as an expected result of this process.

The focus of these early immigration scholars was on European immigrant groups who, over two or three generations generally became integrated into the dominant American society. Although a "melting pot" metaphor has been widely used for this process, the immigrant ingredients were selected through restrictive immigration policies and processed with a goal of their becoming unnoticeable and having little impact on the final product (King 2000). In the quote above, Park makes clear that prejudice and discrimination can restrict the ability of the immigrant to be judged by his abilities and can impede the process of assimilation. Through this definition, Park establishes that the outcome of assimilation requires some parity of opportunity. Over time, immigrant groups of European origin became part of American society as ethnic prejudices diminished. But the continued marginalization of black Americans was not explicitly incorporated into the assimilation theories of this era.

As the period of sharply limited immigration was coming to an end, the social incorporation processes that occurred under these conditions were modeled in the classic assimilation theory framed by Milton Gordon (1964). Gordon outlined a series of 
conditions that lead immigrant groups eventually, but not inevitably, to full assimilation into the host society. He noted that these adaptations would not take place in all groups at the same pace. Further, he acknowledged that for some groups widespread discrimination could limit the educational and employment opportunities necessary for social mobility. Assimilation was largely regarded to be a one-way process in which immigrants adapted to a "core society" and its culture, without having much impact on the host country itself. He incorporated seven sub-processes to be used as variables through which the assimilation of groups could be analyzed and compared.

In his model, Gordon noted that groups such as Native Americans and African Americans might not be allowed complete access into American society; however, immigrant groups were generally expected to assimilate over time into the American mainstream. Clearly, the framework for Gordon's analysis presented "American" as racially white and assumed that immigrants would be white, as well. Even as American civil rights protests gained momentum, the racially bifurcated nature of American society in the 1960s was not explicitly analyzed in Gordon's model. Instead, the experience of white European immigrants served as a model for the influential social science theories of immigrant incorporation and assimilation of this era (Alba 1999, King 2001, Omi and Winant 1986, Pierre 2004).

Gordon's work was published just as American society entered a period of turbulent change in which groups that had been marginalized contested established boundaries on many fronts. These social and political struggles brought significant change to US immigration policy, to the society into which immigrants entered, and to the ways that social scientists viewed immigrant incorporation. Seen as a framework that 
was associated with Americanization ideologies that discounted the value of the various cultural components found throughout the nation, the assimilation paradigm eventually fell out of favor.

\section{Civil Rights, Multiculturalism, and the Hart-Cellar Amendment}

The 1950s and 1960s were decades marked by challenges to the established racial order of the US. Black Americans, Latinos, and Native Americans engaged in struggles for civil rights and legal reforms while ethnic groups who had been able to enter the "mainstream" celebrated their "symbolic" ethnicity (Gans 1979). The idea of the "melting pot" in which ethnic groups would eventually dissipate into a homogeneous American culture gave way to a more pluralistic notion of American society.

In Beyond the Melting Pot (originally published in 1963), Glazer and Moynihan put forth a view of a persistent ethnic factionalization of America. They suggested that

it is not the temporary upsetting inflow of new and unassimilated immigrants that creates a pattern of ethnic groups within the nation, but rather some central tendency in the national ethos which structures people, whether those coming in afresh or the descendants of those who have been here for generations, into groups of different status and character. [Glazer and Moynihan 1970: 290-291]

Glazer and Moynihan argued that "the notion that the intense and unprecedented mixture of ethnic and religious groups in American life was soon to blend into a homogeneous end product has outlived its usefulness, and also its credibility" (1970: xcvii), asserting instead a pluralist society with persistent ethnic groups as the likely model for America. This conclusion reflected a belief that because the "melting pot" failed to render a homogeneous outcome in the course of a lifetime, it was not a reasonable model of the process of "Americanization." They argued that "cultural 
pluralism" was no more likely than the melting pot, as old world languages and cultural traits would surely dissipate. Ethnic groups, nevertheless, would persist but with a new culture forged in the US, making them "something they had not been, but still something distinct and identifiable" (1970: 15).

In later editions they admitted that the passage of time seemed to be proving them at least partly wrong. By the end of the 1960s the religious split between Protestants, Catholics, and Jews had softened considerably (the assimilability of non-Judeo-Christian religions was still unfathomable), but ethnic identities persisted. Race had become the most polarizing aspect of social division as the civil rights movement gained momentum and faced the backlash of white resistance. Subsequent research and analysis of immigrant incorporation focused on the racial components of immigrant integration.

After the Hart-Cellar Act of 1965 abolished the national origins quota system that had governed US immigration law since 1924, the population of the US began a substantial demographic shift (Joppke 1999, King 2000). In addition to the intended easing of restrictions on European immigration, the new policy led to increased immigration from Asia, Latin America, and the Caribbean. Immigrants from these regions were viewed as racially "other" from the Euro-American "white" core society of the United States.

Immigration to the US had been at historic lows in the three decades leading up to the 1960s. Fewer than 10 million foreign-born persons resided in the US in 1970, but over the next thirty years this segment of the population tripled (Gibson and Lennon 1999). Particularly since 1990, the US experienced unparalleled growth in both the number of immigrants and the percent of the population they represent. Over the last 
twenty years the foreign-born population in the US has nearly doubled, and almost 40 million immigrants now live in the US (US Census, 2010 American Community Survey). In addition, immigration policy reforms opened the door to parts of the world that had previously been restricted, thus changing the demographics of the immigrant population. Demographic changes have come at a remarkable pace because of the multiplier effect of the family reunification preferences included in the law.

Currently, more than one million new immigrants are legally admitted to the US each year. There are a variety of categories through which they are admitted, but the majority comes as family sponsored immigrants. Nearly 750,000 legal permanent residents were admitted on the basis of family reunification in 2009 alone (Monger 2010: 3). Ironically, the family reunification policy was intended to preserve the existing ethnic balance by minimizing restrictions on groups already established in the country; but by the time of its implementation Europeans no longer sought migration to the in US in large numbers. Instead, the nations with the greatest numbers of immigrants admitted through family reunification in 2009 include Mexico, China, Philippines, India, the Dominican Republic, Cuba, Vietnam, Colombia, South Korea, and Haiti (Monger 2010: 4).

For many immigrant groups, this policy has facilitated a chain of migration as earlier migrants apply for their family members to join them in the US. Haitians have avidly pursued family reunification in the United States. From 2005-2009 more than 80,000 Haitians have been admitted to the US as family-sponsored immigrants, representing $69 \%$ of all legally admitted Haitians during that period (Jeffries and Monger 2008: 4, Monger 2010: 4). In addition, nearly 55,000 Haitians with approved petitions for migration were awaiting their visas as of January 2010 (Wasem 2010: 12). 
Hundreds of thousands more people seek entrance to the US annually, even though they lack legal authorization. US immigration policies intended to selectively constrain migration fail to prevent a substantial amount of "illegal" migration; an estimated 10.8 million unauthorized immigrants reside in the US (Hoefer et al. 2010: 1). Haitians comprise the $11^{\text {th }}$ largest national origin population of unauthorized immigrants, estimated at about 76,000 in 2000 (INS Office of Policy and Planning: 9).

The dramatic increase of the immigrant population brought renewed interest in understanding the impacts of this diverse group on American society. There have been notable disparities in the outcomes of different national origin groups. More recent theories have attempted to explain these patterns of incorporation into US society. Scholarly analyses became more directly concerned with the impact of factors such as race, class, and education on the incorporation of immigrants. With a focus on these differences, migration scholars took a critical approach to the idea that immigrants would, could, or should assimilate.

\section{Separate Paths}

Herbert Gans' 1992 essay, "Second Generation Decline: Scenarios for the Economic and Ethnic Futures of the Post-1965 American Immigrants," ushered in an era of pessimistic predictions regarding the children of immigrants. Although it was a purely speculative essay, it set forth questions that led to more than a decade of focus on the academic achievement of the children of immigrants by framing potential negative outcomes in terms of success at school. 
Indeed, second-generation decline is likely to produce an early convergence between the present American poor and some secondgeneration poor, for if immigrant parents are unable or unwilling to enforce strict school - and homework - discipline, if language problems cannot be overcome, or if the youngsters, especially those who have difficulty in school early on, see that their occupational futures are not promising, they may begin to get low grades, reject schooling, and eventually drop out or get themselves pushed out of the school system. [Gans 1992]

In conclusion Gans paints a stark portrait of a devolution-into-the-underclass scenario, exhorting "The cities cannot stand a cohort of immigrants' children who will join very poor blacks, Hispanics, and Anglos on the corner or in the lines of the welfare agencies" (1992: 189).

The potential future outcomes of the children of immigrants raised in Gans's (1992) article became formalized into what has perhaps become the contemporary canon of the immigrant incorporation literature, the segmented assimilation theory. Whether in support or contradiction, studies of immigrant incorporation over the past decade have been framed by this model. Unequal access to American society is at the heart of segmented assimilation theory.

\section{Segmented Assimilation}

Segmented assimilation theory incorporates the effects of unequal opportunities into likely pathways for the children of immigrants growing up in different circumstances (Portes et. al. 2005, Portes and Rumbaut 2001, Portes and Rumbaut 2005, Portes and Zhou 1993, Zhou 1997, Zhou and Xiong 2005). While some will be able to access opportunities for economic and social advancement in the United States, others will not fare as well. The types of resources a family brings into the immigration process financial resources, education, skills, and social status - coupled with the context of their 
reception in the new country - government policies, racial stratification, and labor market conditions - interact to create the mode of incorporation that the immigrant family will experience. Portes and Zhou have argued that "the central question is not whether the second generation will assimilate to American society, but to what segment of that society it will assimilate," noting that existing structures of stratification shape the incorporation of immigrants (2005:1). They suggest that immigrant youth and the children of immigrants, particularly racial minorities, who grow up in impoverished inner cities are at risk of assimilating into the lowest strata of American society. A concentration of marginalized groups in the inner cities exposes immigrant families who settle there to high rates of crime, illegal drug use, and adversarial attitudes toward middle-class values. This puts the second generation at greater risk of adopting the undesirable behaviors that surround them. In addition, contemporary migrants face labor markets that provide only low wage jobs for those with limited education, eliminating opportunities that may have existed for migrants in earlier eras (Portes et. al., 2005; Portes and Rumbaut, 2001; Zhou 1997). In light of this, segmented assimilation theory posits that the children of immigrant parents who have meager financial resources, low levels of education, and sparse social networks, are often raised in underprivileged urban settings, where they may assimilate into an American underclass. Their socioeconomic outcomes include the possibility of "downward assimilation," actually declining in socioeconomic status in subsequent generations.

While racial and ethnic discrimination may shape these outcomes, a process of selective acculturation strategically employed by immigrants may give them some measure of control over the way their integration proceeds (Gibson 1997, Portes and 
Zhou 1993, Portes et al. 2005, Rumbaut 1997, Zhou 1997, Zhou and Xiong 2005). Some families find ways to resist the forces that tend to lead children toward undesirable outcomes. Following Gibson (1988), who documented promising academic achievement among the children of Punjabi immigrants in California who limited their children's acculturation, Zhou (1997) suggests that a path of selective acculturation can protect immigrant youth from some of the negative aspects of urban life in the United States, even when faced with limited parental resources and racial prejudice. By maintaining strong ethnic relations, including the retention of their parents' language, the children of immigrants may avoid negative influences. She suggests that this is accomplished through participation in ethnic communities in the host country. This argument suggests an underlying assumption that assimilation into the disadvantaged segment of society is at least to a certain extent a matter of agency, rather than of structural constraints.

The incorporation of Haitian immigrants into American society played an important role in the construction of the segmented assimilation theory. They have been associated with racial marginalization and the potential negative outcome, "downward assimilation" (Portes et. al. 2005, Portes and Rumbaut 1996, Portes and Rumbaut 2001, Portes and Zhou 1993). This theory brought needed attention to the disparate treatment of immigrant groups by emphasizing the "context of reception," which for Haitians has been decidedly unwelcoming (Portes et. al. 2005, Portes and Rumbaut 2001, Portes and Zhou 1993, Stepick et al. 2001). Unfortunately, as Alex and Carol Stepick (2010) have pointed out, analyzing immigrant incorporation outcomes by national origin group tends to create the impression that it is something inherent to the group, rather than their shared structural impediments that lead to negative outcomes. 
Segmented assimilation theory makes clear that racial prejudice and discrimination affect the lives of immigrants and their children. However, the argument seems to shift to one of personal agency when Portes and Zhou (1993) suggest that immigrants who are poor and black and reside in the inner city are likely to develop adversarial attitudes toward "mainstream values." Critical race theorist, Mary Romero criticizes this aspect of segmented assimilation theory, arguing that "an underlining assumption is that racial pride (which does not embrace Whiteness) and cultural identification with communities of color are the causes of low academic achievement and lack of social mobility" (2008: 25). Romero contends that the sociological literature on immigration ignores the structural impediments imposed by routine maintenance of racial boundaries in the US (2008:26). Neckerman and colleagues (1999) have countered this formula with a claim that middle class minorities may provide a "minority culture of mobility" that may help others to navigate obstacles to attaining middle class status. Others have identified less pessimistic outcomes among Haitians (Konczal and Haller 2008, Nicholas et al. 2008).

Kasinitz, Mollenkopf, and Waters (2002) argue that the premises of the segmented assimilation theory are that the current racial boundaries of the US will remain as they are. They, along with others such as Alba and Nee (2003) call attention to the potential for these boundaries to shift. They argue that a new and more diverse "American mainstream" may emerge from the incorporation of immigrants from Latin America, the Caribbean, Africa, Asia, and other parts of the world. 
The model proposed by Milton Gordon emphasized the integration of immigrants and other minorities into primary group relationships and intermarriage as a critical indicator of assimilation. But as immigrant incorporation theories developed in the era of multiculturalism, an emphasis on socioeconomic parity emerged (Alba and Nee 2003). Quantifiable variables such as education, occupation, and income could be analyzed to determine the extent to which a given group's status resembled that of the majority. "Assimilation" could be demonstrated when the socioeconomic distribution of the group was similar to the distribution found among white, native-born Americans (Alba and Nee 2003).

By examining these variables across generations, several studies have differed with some of the pessimistic conclusions reached by segmented assimilation proponents in regard to the incorporation of contemporary immigrants. Farley and Alba (2002) found that even though outcomes differed by national origin, most of the second generation exceeded parental levels of education, occupational status, and income. Waldinger and Feliciano's (2004) analysis of Mexican labor force participation concluded that the American-born children of Mexican immigrants achieved higher levels of education and greater stability of employment than the first generation. Their levels of employment approached those of native-born whites and consistently exceeded those of African Americans.

Because of the relatively short period of large-scale migration from Haiti, it is difficult to determine how this immigrant group will fare over several generations. At this point, outcomes are mixed. A 2005 update to the Children of Immigrants Study found that Haitians performed significantly better than expected in terms of educational 
outcomes. Unfortunately, their academic achievements did not translate into higher earnings, rather Haitians earned $\$ 16,000$ less per year on average than other ethnic groups (Portes et al. 2005). ${ }^{5}$ So while there is no evidence of a substantial rejection of education among Haitian youth, their economic outcomes appear, nevertheless, to be depressed.

\section{Boundaries as a Framework for Immigrant Incorporation}

The process of immigrants becoming part of a receiving society has primarily been framed as a process of "assimilation." Variants of this concept, from the models of the Chicago School to the pathways outlined in segmented assimilation, have been used to provide more nuance to the examination of the interactions between groups. At the foundation of each of these is the human process of categorizing people into groups of "us" and "other." A framework of boundaries and boundary-work allows for a detailed examination of this process and how it shapes the outcomes of groups who come to live together.

Boundaries and the processes of boundary-work that define, maintain, and sometimes alter them have become useful concepts for social analysis in a variety of disciplines. Anthropologists, sociologists, political scientists, historians, and social psychologists have all found ways to apply boundary concepts to their work (Lamont and Molnár 2002). This suggests that the boundary concept captures an essential human process that can be applied in a multitude of contexts. Boundary processes are relational,

\footnotetext{
${ }^{5}$ West Indians, also a primarily black immigrant group, had similar results.
} 
used to establish differences including class, race, gender, nationality and other collective identifications (Lamont and Molnár 2002). But boundaries are not only drawn to establish a group identity; boundary work is a process by which inclusion and exclusion are defined and defended in order to make claims to rights and resources.

The study of immigrant incorporation is, at its core, a study of borders and boundaries. Controlling the US borders, both in a physical sense - the rules governing migration - and in a political sense - the qualifications for legal residence and citizenship - are an enduring legacy of codified social norms that clearly define the outer limits of the potential for social inclusion (Alba 2005). Most studies of immigrant incorporation, however, are concerned with the boundary processes that occur within particular national borders and the stratification systems they produce. These processes range from the production and maintenance of social boundaries that exclude newcomers from full integration into a society to the ways that immigrant groups change to fit within these boundaries (assimilation). Rather than changing to fit in, some groups make efforts to fortify boundaries in resistance, making their differences more distinct. Alternatively, the boundaries themselves may change or soften to include groups that were once shut out of the dominant core of a society. Furthermore, groups who were once excluded may participate in defending social boundaries against the inclusion of additional groups of newcomers.

While social strata are drawn across numerous characteristics - including wealth, occupation, education, religion - for purposes of immigration scholarship ethnicity and its associations with its phenotypic component, race, have been of primary importance (DeWind and Kasinitz 1997, Lee 2004). Historically, decisions regarding who is eligible 
for admission to the US have been largely (but not exclusively) based on race and national origin. Likewise, analyses of immigrant incorporation generally reflect this method of classifying people.

\section{Ethnic Boundaries}

The concept of boundaries in migration literature is traced to Fredrik Barth (1969) who used the term to explain the social construction of ethnicity. Barth established that social boundaries persist despite mobility and contact of groups across physical borders they do not exist merely due to the geographic segregation of groups of people, as primordialist notions of ethnicity once implied. Ethnic boundaries occur because groups of people define themselves by their differences, not that they are dissimilar in some essential way. Because of this, Barth argued, the essential question for social science was to investigate "the ethnic boundary that defines the group, not the cultural stuff in encloses" (1969: 15).

Barth used the boundary concept to explain the persistence of ethnicity in societies that included groups from varied regional origins. Contact itself does not diminish a sense of difference between groups. In fact, social hierarchies can highlight and perpetuate ethnic distinctions. Barth asserted that boundaries were not drawn exclusively by the dominant groups in a society. The work of boundary construction and maintenance comes from both sides, as groups define themselves in opposition to others and simultaneously sanction individuals who deviate from the established norms. 


\section{Boundaries and Immigrant Incorporation}

The concept of assimilation has dominated the study of immigrant incorporation. Alba and Nee argue for a definition of assimilation as "a decline in the social salience and consequences of categorical memberships for a group or some of its members."

(2003:166). For immigrants, this occurs when association with a particular ethnic group makes little difference in a person's social inclusion, educational opportunities, or employment outcomes.

A boundary framework permits analysis of varied sites of difference and inequality (such as gender, wealth, education, and race). Thus, it provides greater explanatory power cross-culturally where markers of difference may vary (Alba 2005). In the study of immigrant incorporation, for example, race is often thought to be the most significant social boundary in the US, but religion may be a more powerful site of difference in a European context (Alba 2005, Zolberg and Woon 1999). This is particularly useful in an examination of transnational processes, such as those analyzed in this dissertation, in which participants encounter boundaries in each locale but the criteria used to define the boundaries in each may be quite different.

Regardless of the specific characteristic that is emphasized in producing social distance, the processes of defining difference and producing social stratification can be compared in terms of boundary-work. Although each group attempts to construct boundaries in ways that benefit its members and align with their self-concept, the dominant group has an advantage in determining how boundaries are defined (Alba 2010). Boundary concepts bring focus to the ways the more powerful groups in a 
society—however they are defined: by race, wealth, gender, citizenship — defend their position of privilege and other groups maneuver for desired resources and status.

Boundary-work is the process by which social barriers are erected, maintained, negotiated, and transformed. Gieryn (1983) is credited with the term "boundary-work" used in the realm of science to rhetorically privilege particular actors and practices with authenticity (Lamont and Molnár 2002:179). Through boundary-work, the members of a group guard its defining characteristics as they identify and exclude those who do not meet the criteria for belonging. Patrolling the boundaries is done through the deployment of symbols that assign meaning and value to these defining characteristics.

Boundaries are not fixed; they change over time and respond to technological, economic, or socio-political changes in a society (Shibutani and Kwan 1965, Alba and Nee 2003). Due to the fluidity of such boundaries, for example, the currently perceived "majority" population of the United States is mostly composed of groups other than the Anglo-Protestants who once defined the American mainstream population (Alba 1999).

It is the process of changing boundaries that creates assimilation, either by groups becoming more similar or by differences becoming less important. Individuals may cross boundaries, but these demarcations may also blur or shift allowing the incorporation of those once on the outside into the "core," thus broadening the range of traits considered "mainstream" (Alba and Nee 2003, Omi and Winant 1994, Shibutani and Kwan 1965, Wimmer 2008, Zolberg and Woon 1999).

The concept of boundaries is a useful tool for analyzing how immigrants are incorporated into a receiving society. Historically in the US, there has been a clear shift of boundaries in regard to European origin groups. The Irish, for example, were once 
maligned and stereotyped as a separate and deficient "race" (from the perspective of the dominant Anglo reference). Today, Irish ancestry has become inconsequential in regard to access to schooling, employment, place of residence, and other determining of life outcomes. A social boundary that once existed has shifted. Persons of Irish heritage have joined the "mainstream" of American society, for members of which ethnicity has no significant negative consequences. To enact this shift of boundaries, the Irish had to either assimilate by eliminating cultural practices that resulted in exclusion or by changes in the attitudes of the dominant group toward the cultural practices of the Irish. The ethnic group can change to blend in with the mainstream, or the mainstream can relinquish its rejection of aspects that formerly marked a group as "other." In addition to boundaries that are formed against cultural practices, boundaries arise in relation to stereotyped notions of the ethnic group. Negative perceptions of the group often remain resilient until a substantial proportion of the group provides contradictory evidence. When this has occurred, the meaning of the ethnic label no longer justifies denial of resources or privileges.

Zolberg and Woon (1999) (expanding on Bauböck 1994), identified a three-stage process by which outsiders become insiders. The first step involves boundary crossing. This occurs when minority individuals adapt to the dominant society in ways that permit their inclusion but have no notable effect on the general separation of the groups. Boundary crossing is seen as being psychologically hazardous in that it requires an individual to identify with a group where co-ethnics may not fit in or be accepted. By incorporating into the dominant group, where they also risk rejection, individuals become more socially distant from minority group peers. 
Boundary blurring occurs when the separation between groups becomes less distinct and there is no longer a clear dichotomy of "us" and "them." Blurry boundaries allow a sense that individuals can be members of both the minority group in the majority simultaneously (Alba 2010: 167). Alba suggests that this can be an intermediate step in the process of boundary change. He cites the social changes that led to diminishing differences between Jews and Catholics and the dominant American Protestant mainstream as examples of the gradual changes that first reduce the distinctiveness of groups and then render their differences less salient. In these cases, as the groups became more similar in terms of education, occupation, and residential proximity, religion became less important in defining social inclusion. Thus, the boundaries between them became blurrier.

Boundary shifting marks the changing of the criteria for inclusion that either makes once-salient differences unimportant or, conversely, ascribes priority to distinctions that once seemed insignificant (Alba 2005, Zolberg and Woon 1999). Boundaries may shift with the erosion of the original boundary and absorption of the once-excluded group into the dominant group. For example, immigrants of southern- and eastern-European origins who were once considered racially distinct from the dominant Anglo-American group eventually were included among the population defined as "white" (Jacobson 1998, Roediger 2005, Zolberg 2006). Boundary crossing and blurring can lead to boundary shifting toward greater inclusion, but this result is by no means guaranteed. Instead, the result can be a more determined effort to maintain the distinction between the groups and a reactive fortification of boundaries. Nativist backlashes occurred throughout American history as racial boundary lines changed. 
This general boundary framework emphasizes the broad process of changes to social inclusion and the potential for the erosion of boundaries that exclude an ethnic group from incorporation into the mainstream of society. But boundary blurring does not necessarily occur when groups come together. A factor in the potential for a boundary to become blurry is how it has been institutionalized as part of the cultural web of norms and expectations (Alba 2010). In the US, race, defined mostly by skin color and a cluster of other physical features, often has the qualities of a "bright" boundary, one that is clear, unambiguous, and resistant to blurring. For much of US history, race, particularly whether or not one was considered "white" has been a distinct social boundary that produces unequal access to resources. Opportunities for education, employment, place of residence, and even entertainment have been unequally distributed on the basis of race. This history of unequal treatment has produced symbolic boundaries - disparate associations of people and the meanings given to race - that justified the existing social boundaries. While some of the social boundaries based on race have eroded, symbolic boundaries based on racial stereotypes assign meaning to one's race that goes beyond its phenotypic dimension. Because they are deeply institutionalized, changes to bright boundaries often require collective action by the minority group. In the US, for example, the civil rights movement was necessary to erode the legal foundations behind longstanding racial boundaries, such as the Jim Crow laws, in the US (Alba 2010).

\section{Stigma}

At their extreme, boundary processes include the deployment of stigma and creation of pariah groups. The exclusion of these groups from society is based upon 
behaviors or characteristics that are rejected by the larger society and are often associated with the breaking of established taboos (Barth 1964: 31). Negative stereotypes applied to immigrants or other minority groups can have this effect on their incorporation. Jaynes argues, "The association of poverty and oppositional behavior with any minority group threatens that group with the 'underclass' stigma and discriminatory treatment" (2004:114). This label creates powerful incentives to fortify boundaries against its contamination and justifies prejudice. Persistent stereotypes of American minorities as suffering from a "culture of poverty" or belonging to an "underclass" influence perceptions of black immigrants by native and immigrant whites. In addition to being painted with this stigma themselves, black immigrants often seek to distance themselves from native-born black Americans. By emphasizing their foreignness, some immigrants construct boundaries against African Americans and their perceived stigma (Placide 2010, Waters 1994, Zephir 1996).

\section{Institutionalizing Inequality}

Boundary concepts are also useful to analyze the social structures that produce and perpetuate inequality. Pierre Bourdieu employed the concepts of cultural capital and habitus to explain the reproduction of established power structures through the institutionalized practices of schools. Habitus comprises one's "habits and dispositions," both the behaviors and mental frameworks that are acquired subconsciously through social interaction (Bourdieu 1984, 1986). Although the components of habitus are learned socially, these habits and dispositions become embodied and are, thus, perceived to be characteristics of the individual that can be used to assess them personally. 
Cultural capital results when certain behaviors and dispositions become value laden and then used in the process of social stratification. Cultural capital is achieved through boundary work, where dominant groups have the power to define "us" and “other." Bourdieu and Passeron (1972, translation 1977) analyzed the processes by which schools reproduced the inequalities within French society. They argued that schools assessed students on the basis of their competent performance of the habitus of the dominant class. Therefore, the system of academic credentialing justified and institutionalized the perpetuation of hierarchical French class structures. In the US context, and particularly in relation to immigrant incorporation, ethnic boundaries, rather than class structures, are the basis for analysis. But the consequences of ethnic boundaries can be assessed by socioeconomic outcomes and whether ethnic association or national origin affects these outcomes.

The concept of cultural capital incorporates the idea that one's habitus and the certifications that represent performance of the habitus of dominant group are resources for inclusion into social groups or employment. Similarly, Douglas Massey integrates boundary concepts with various forms of capital in ways that make the connections between boundary-work and socioeconomic outcomes clear. As Massey notes, "Stratification does not just happen. It is produced by specific arrangements in human societies that allow exploitation and opportunity hoarding to occur along categorical lines" (2007: 242). Ethnic or class associations can be a resource deployed symbolically to draw or maintain boundaries to resources and benefits.

Lamont and Lareau (1998) point out that cultural capital can be used toward different types of boundaries. Some may mark cultural practices as "prestigious" - those 
that assign one to an elite social group - or simply "respectable" - a less exclusive set that draw a boundary that distinguishes the middle class from those who fall below that status. It is this boundary to respectability that is invoked with the term "underclass." This term suggests more than poverty; it carries associations with an undesirable habitus, one that falls short of the boundaries of what is "respectable." As such, it identifies a stigmatized segment of society and justifies inequitable treatment and exclusion.

The power of exclusion, Lamont and Lareau (1988) argue, is the essential dimension of cultural capital. "In particular, it is a power of legitimating the claim that specific cultural norms and practices are superior, and of institutionalizing these claims to regulate behavior and access to resources" (Lamont and Lareau 1988: 159). As the educational system incorporates the cultural values of the dominant group as a means to assess students, it serves to validate these norms. Through these practices, Bourdieu and Passeron (1977[1970]) explain, the dominant group wields the power of "symbolic violence" through which they impose meanings on the cultural elements of others (Lamont and Lareau 1988:159).

For Haitians, the concept of symbolic violence is useful in understanding the widespread denigration of Haitian culture and stereotyped notions of what it is to be Haitian. One example of this is the depiction of Haitian Vodou. This religion emerged in Haiti from the combined influences of varied religions of Africans who were forcibly brought to Haiti and the Roman Catholic beliefs and practices of the French. These practices have been exoticized and laden with characterizations as primitive and savage. In the US, through the lens of the dominant worldview of Christianity these practices are often viewed as Satanic, creating a powerful stigma (Lawless 1992). 


\section{Social and Symbolic Boundaries}

Lamont and Molnár (2002) distinguish between social and symbolic boundaries to clarify the interaction between ideas about a group and the group's access to resources. Symbolic boundaries are mental frameworks that establish the categories through which people understand similarity and difference. They are comprised of the contested meanings of cultural practices and materials that are used to make claims for status. Symbolic boundaries are the culturally determined bases for assessing whether an individual is one of "us" or "other."

Whereas symbolic boundaries are produced in the realm of meaning, social boundaries are material. Social boundaries are "objectivized forms of social differences manifested in unequal access to and unequal distribution of resources (material and nonmaterial) and social opportunity" (Lamont and Molnár 2002:168). Symbolic boundaries can justify the social inequities that then become social boundaries. For example, stereotypes that depict a minority group as unintelligent can make it seem sensible to put fewer resources for college-bound students in schools that serve that group. Symbolic boundaries do not, themselves, produce social boundaries, but they are necessary foundations for creating and sustaining structural inequality (Lamont and Molnár 2002:169).

\section{Boundaries and Education}

This dissertation will focus on the education of Haitian immigrants, viewing education both as a resource unequally distributed due to social boundaries and as a means for crossing social and symbolic boundaries to equitable incorporation in the 
United States. The educational system powerfully defines and maintains boundaries. It is indeed one of the most important means of creating and reproducing a society's structural inequities. For an individual, achieving higher levels of education provides a means for crossing other boundaries. Educational achievement is a social resource that operates both in the symbolic realm, contributing to a more favorable habitus and producing status, and in the material realm, increasing cultural capital and opportunities for socioeconomic mobility. Furthermore, when a group achieves overall greater education, the group's symbolic capital and the meaning of the domain of education as a site of boundary work is altered. An immigrant group that has been stereotyped as uneducated carries a stigma; but as levels of education among its members come to parity with the rest of the society, lack of education loses its potency as a basis for excluding the group.

For many families in Haiti there are substantial boundaries to achieving desired levels of education. Lack of education has been a symbolic resource for boundary-work against Haitians. Whether or not individual Haitian immigrants are well-educated, they are subject to the association of their ethnic group with stereotyped notions of illiteracy and backwardness.

Among Haitians, the extended family helps to overcome some of geographical and financial boundaries to education, and migration is one strategy for generating financial resources that can help "to raise the family up." As I will demonstrate, Haitian immigrant families can change the nature of their incorporation into the US through transnational extended family processes that increase access to educational opportunities.

While this phenomenon is interesting and compelling in and of itself, it is also an important contribution to the debate within the social sciences regarding the 
incorporation of the large group of immigrants who have come since the Hart-Cellar Act of 1965 led to increased immigration from Asia, Latin America, and the Caribbean. Immigrants from these regions have been viewed as racially "other" from the EuroAmerican "white" core society of the United States. Because Haitians are black immigrants, most of whom have few socioeconomic resources, the achievement of equitable incorporation by Haitians would imply crossing boundaries of foreign origins, class, as well as the particularly bright boundary of race.

It is within the context of the larger question of the potential for the equitable incorporation of Haitians into the United States that I approach the dimension of education. Educational boundaries include both the boundaries to education - the obstacles to equitable access to quality schooling, as well as the boundaries of education - the limitations in a society that are associated with an individual's level of education. I will develop this argument considering the social boundaries defined by Lamont and Molnár as "unequal access to and unequal distribution of resources... and social opportunities.” In addition, I will consider symbolic boundaries, “conceptual distinctions... to categorize objects, people, and practices" (Lamont and Molnár 2002: 168). If "Symbolic boundaries can be thought of as a necessary but insufficient condition for the existence of social boundaries" as Lamont and Molnár (2002: 169) have argued, then a change in the symbolic meaning of a given ethnicity should serve to erode the justification for inequitable treatment. Interplay between these two types of boundaries is at the heart of the analysis presented here. 


\section{A TRANSNATIONAL APPROACH TO IMMIGRANT INCORPORATION}

Assimilation theories dissect the process by which immigrants and their offspring become integrated into the new society and its cultural practices. But they tend to assume a process that occurs within the geographic boundaries of the receiving state. The outcomes of immigrant incorporation are generally seen as dependent upon the opportunities and constraints encountered in the new country and the individual characteristics of the migrant. This process has been compared to a transplanted tree, struggling to survive in new surroundings, completely severed from the environment to which it had been adapted. Oscar Handlin established this trope in 1951 with his American immigration history, The Uprooted:

Emigration took these people out of traditional, accustomed environments and replanted them in strange ground, among strangers, where strange manners prevailed. The customary modes of behavior were no longer adequate, for the problems of life were new and different. With old ties snapped, men faced the enormous compulsion of working out new relationships, new meanings to their lives, often under harsh and hostile circumstances. ... The immigrants lived in crisis because they were uprooted. (Handlin 2002 [1951]: 5-6)

But it has become quite evident over the last few decades that the old metaphor, "the uprooted," does not adequately describe the contemporary immigrant experience (Fouron and Glick Schiller 2002, Glick Schiller et al. 1995). ${ }^{6}$

Research on immigrant populations revealed that a "container model of society" was not sufficient for examining the ways that many migrants lived their lives (Wimmer and Glick Schiller 2003: 582). Earlier migration scholarship tended to focus on the

\footnotetext{
${ }^{6}$ Nor would a contemporary immigration scholar generalize immigrants as "men".
} 
integration of immigrants into "host" countries, with little consideration of the impact of continuing relationships that extended into their homelands. Society was portrayed as interchangeable with the nation-state, discrete and bounded, and immigrant integration was defined by activities and relationships within those boundaries. ${ }^{7}$

But a transnational frame looks beyond the national "box" and brings into view immigrants' on-going relationships and activities that span national borders. Advocating for this expanded view of immigrants' lives, Glick Schiller, Basch, Szanton Blanc (1995) explain:

Transnational migration is the process by which immigrants forge and sustain simultaneous multi-stranded social relations that link together their societies of origin and settlement. In identifying a new process of migration, scholars of transnational migration emphasize the ongoing and continuing ways in which current-day immigrants construct and reconstitute their simultaneous embeddedness in more than one society.

As immigrants often maintain active ties to their homelands-whether social, economic, or political - a transnational frame is necessary to understand their experience of incorporation. In this age of rapid communication, international travel, and globalized mass media, the process of assimilation in the sense of acquiring the language, behaviors, and values of a new society can begin even while an individual remains in the country of origin. In particular, it might be expected to have this socializing effect on individuals who expect to travel themselves to the US. This type of analysis requires a transnational

\footnotetext{
${ }^{7}$ For an excellent discussion of the conceptual distortions created by such "methodological nationalism" see Wimmer and Glick Schiller 2003.
} 
approach to study relationships and activities that cross national borders while considering the economic, social, and political contexts of each locale involved.

\section{Transnationalism - What is it?}

In the 1960s, the term "transnational" was often associated with phenomena of multisited corporate structures that spanned national boundaries (Glick Schiller et al. 1995). By the next decade it was used to describe practices and institutions that superseded or were unconstrained by the nation-state. Migrants, of course, always crossed borders, but ideas that the nation-state would inevitably relinquish its hegemony in the structure of global affairs entered the migration literature framing the analysis of their continued ties to their homeland in new ways.

In several books and articles in the early 1990s, Glick Schiller and colleagues proposed that the study of contemporary immigrants must consider the persistent ties to their home societies. They suggested that this avenue of scholarship identified "a new process of migration" and that immigrants might be "best understood as transmigrants" (1995:48). By contrasting immigrant lives that are vitally connected to people, practices, and institutions of their homeland to the trope of "the uprooted," they framed these persistent connections as something new. Further, they suggested that these enduring ties challenged the existing global order dominated by nation-states, instead arguing that social structures need not be bound to political structures, even as they are shaped by them. This vein of scholarship has emphasized the distinction between assimilative tendencies and the structures that support enduring connection to the homeland. Immigrants who participated - whether through travel, commerce, religious affiliation, remittances, or simply interpersonal communication - in activities that crossed national 
boundaries were seen as a challenge to the nation-state. Asserting equivalence to a grassroots political movement, immigrant cross-border activity was described as "transnationalism from below" (Smith and Guarnizo 1998). ${ }^{8}$

Although transnationalism among immigrants was characterized as something new in the early writings of Glick Schiller and her colleagues, other scholars have demonstrated that forms of transnational activity are evident among migrants of previous eras as well (Foner 2005, Morawska 2001, Portes et al. 1999). But technological advances have certainly changed the nature of transnational relationships. Rapid forms of communication, the reach of global media, and the potential to travel quickly from one country to another make the possibility of maintaining transnational ties much more feasible today. Nevertheless, access to advanced technology is still limited by economic means and the reach of infrastructure. Modern communications technologies, such as cell phones and internet, are not available in many poor, rural areas or may be too costly (Mahler 1998, 2001, Pribilsky 2004, Sassen 2000). The ability to travel is limited by economics and geography and in addition may be curtailed by a migrant's legal status or a family's ability to secure necessary visas (Landolt and Da 2005, Parreñas 2005, Pribilsky 2001).

\section{Transnational Ties: Access to Resources, Opportunity, and Status}

Researchers have come to different conclusions about the most important of the reasons that immigrants maintain transnational ties. As with reasons for migrating, they

\footnotetext{
${ }^{8}$ See Mahler 1998: 66-73 for discussion of this concept.
} 
are complex and multifaceted. While for some scholars evidence of transnational affiliations has been applied as a critique of the nation-state and evidence of its declining hegemony, for migrants themselves a relationship to the nation-state is often not their primary attachment, identification, or concern (Olwig 2003:790). This political perspective on transnational activity overlooked the quotidian transnationalism of many immigrants who simply maintain relationships and activities from their pre-migration lives, becoming embedded, simultaneously, in both societies. But some of the key rationales for transnational practices include maximizing access to resources, opportunity, and status.

The concept of reactive transnationalism, a strategy in response to racial or ethnic marginalization in the host society, is one such response (Itzigsohn \& Saucedo 2002). Glick Schiller et al. (1995) have argued that "immigrant transnationalism is best understood as a response to the fact that in a global economy contemporary migrants have found full incorporation in the countries within which they resettle either not possible or not desirable" (Glick Schiller et al. 1995: 52). Immigrants who find themselves excluded or relegated to the bottom of the social hierarchy may reject full incorporation into the host society, resisting assimilation by emphasizing an on-going attachment to their homeland. Fouron and Glick-Schiller find that the children of Haitian immigrants in the U.S. "see connection with Haiti as a way to escape racial barriers and the restriction of economic opportunities they increasingly are facing in the United States" (2002: 197). And Espiritu and Tran (2002) have suggested that second-generation Vietnamese experiences with racism and exclusion contribute to a "symbolic 
transnationalism" that may have little to do with a physical crossing of national borders but provides a psychological salve.

This understanding of transnationalism as a response to negative experiences in the host society led, at first, to a characterization of transnationalism as a challenge to the presumptions of assimilation and eventual incorporation of immigrants into the host society (Basch et al. 1994, Kearney 1991). However, such conclusions have given way toward a view that transnationalism and assimilation may be concurrent and even complementary (Itzigsohn \& Saucedo 2002, Levitt and Glick Schiller 2004, Morawska 2003, Portes 2003).

For some immigrants and their children, transnational pursuits may not be a resistance of assimilation but rather an attempt to renegotiate the terms of their incorporation into the host society. Robert C. Smith $(2002,2006)$ suggests that the process of assimilation itself creates an impetus for undertaking transnational activities. He concluded that transnationalism among the Mexican immigrant youth he studied was a reaction to the discrimination they faced in the US and a way to distinguish themselves as "not black" and "not Puerto Rican," thus resisting placement in what were perceived to be the lowest social categories. He argued that "rather than squashing transnationalism, assimilative pressures actually foster it by giving the second generation a reason to want to redefine their Mexican-ness in a new context" (2002:148).

These activities can be characterized as a transnational pursuit of status. Whereas an immigrant's material resources may not be sufficient to elevate his or her status in the US, remittances, participation in hometown associations, and display of consumer goods can change the way he or she is perceived in the homeland. Luin Goldring concluded that the 
Mexican transmigrants she studied "participate in the modification of their social landscape" including the ways they are themselves perceived and the image of their ethnic group as well (1998:167). She attests,

[T]ransnational social fields, and localities of origin in particular, provide a special context in which people can improve their social position and perhaps their power, make claims about their changing status and have it appropriately valorized, and also participate in changing their place of origin so that it becomes more consistent with their changing statuses and expectations. [1998: 167]

Building upon these ideas, Sheba George (2005) emphasizes both the extended family and the church as important arenas for transnational claims of social status among transnational Keralite Indians. She points out the value of leadership positions in transnational churches in enhancing the status of otherwise marginalized immigrant men. But George further elaborates that those who enjoy a privileged place within the traditional hierarchies may strive to limit these innovative claims to status. She also found that gender- and class-based stigmas were employed within the transnational social field to deflect these immigrants' efforts to advance their social standing. An immigrant's quest for social mobility faces challenges from within the ethnic group as well as those they encounter in the native population of the host society.

While some migrants seek transnational opportunities to access resources and build status when they encounter boundaries to the benefits of the host society, for others transnational activities may be facilitated by full incorporation into the host society. At least in terms of political and business activities, immigrants who are more thoroughly incorporated into the host society have also been found to be more likely to be engaged transnationally (Itzigsohn \& Saucedo 2002, Portes 2003). This type of "resource- 
dependent transnationalism" requires not only financial resources, but also the necessary access to communication and transportation technologies and the ability to navigate the economic structures in each location. In these cases, successful integration into the host society may offer economic and political advantages as well as greater freedom to travel. In fact, status as a permanent legal resident or citizen in the US provides valuable mobility resources that can be utilized to facilitate the migration of other family members.

\section{Transnational social fields and extended families}

The concept of the "transnational social field" is useful for studying lives that regularly involve cross-border activities and communication. In the early transnational migration literature, with its concerns about potential political transformation, the social field concept was used to stress the intersections of migrants with the two or more states in which they were embedded (Glick Schiller, Basch, and Szanton Blanc 1995).

However, more recent analyses have focused on social relationships and, in particular, the distribution of power within them. Synthesizing the ways the concept had been used in their own earlier work, as well as others, Levitt and Glick Schiller define social field as "a set of multiple interlocking networks of social relationships through which ideas, practices, and resources are unequally exchanged, organized, and transformed" (2004: 1009). This later definition drops the focus on the societies into which the social field is embedded and, instead, emphasizes the activities associated with social relationships and explicitly notes their inequalities and potential for change. The concept of a social field invites sports analogies, emphasizing inequalities and 
competition for both social and material resources. But appropriately framing the amorphous concept of "social field" may vary depending on cultural context.

Studies of transnational life among Latin Americans tend to define the social field in terms of the natal village to which migrants remain connected through both familial and civic or religious ties. Researchers such as Robert Smith $(1998,2006)$ and Luin Goldring (1998) who have studied transnationalism from the Mexican context have emphasized hometown associations as an important site of transnational activity and status building. Smith provides a compelling argument that the socio-political history of Mexico has made the local community the important source of "meaning-creating" and therefore is a useful unit for analysis of transnational activity (1998: 201-205) Similarly, Levitt (2001) emphasized the "transnational village" as a social unit of analysis of transnational relationships and activities in her study of transnational Dominicans. This type of community, which "emerges when large numbers of people from a small, bonded sending community enact their lives across borders" (Levitt 2001: 213), includes both migrants who maintain relationships in their homelands and those who never leave but still are affected by material resources and ideas transmitted from abroad. She emphasizes the role of social remittances - including social capital, roles, and behaviors - in creating changes across the social field that are dependent upon maintaining transnational relationships. Levitt argues that transnational communities mediate between individual activities and those of states and other institutional actors such as religious organizations.

Notions of transnational community or hometown associations rely on a spatially rooted social field based on relationships of physical proximity in the homeland. They arise from a history of connections between resident families who cooperate in various 
social, religious, economic, or political undertakings. However, in the study of Haitian migrants, the extended family is the essential social unit and core of transnational activity (Brown 1991, Glick Schiller and Fouron 1999, Fjellman and Gladwin 1985, Laguerre 1984, Richman 2005, Stepick et al. 2001). The historic origins of Haitian communal life center on the family compound, the lakou, and relationships with kin living elsewhere (Arthur and Dash 1999, Herskovitz 1971, Laguerre 1982) For Haitians, a family centered approach to the study of transnational activity is appropriate because of the cultural context that emphasizes familial duties and obligations. The extended family, not the hometown nor the individual, is viewed as the primary social unit among Haitians. I use the term "extended family" to emphasize the expansive, multi-generational nature of this fundamental social unit; but, for Haitians, this is simply "family." The metaphor of a tree is often employed, indicating that individuals, like branches, may grow and usually nourish and contribute to the strength of the tree but sometimes may be weak and fall off or need to be cut off to maintain the health of the tree as a whole (personal fieldnotes). But the family itself is the essential entity to which each individual is subject. I will discuss the Haitian lakou and concepts of family in more detail later in this chapter.

The incorporation of Haitian immigrants needs to be understood through a transnational perspective. As I will detail in this dissertation, Haitian immigrant families change the nature of their incorporation through transnational family processes.

Because I will examine immigrant incorporation in terms of educational attainment, my analysis will demonstrate how transnational family processes that affect opportunities for individual family members to further their educations affect the 
incorporation into the United States of these individuals and of their extended families, as well.

\section{The Transnational Family}

As technological advances have changed the way immigrants live their lives, increasing opportunities for communication and travel, transnational approaches to the study of migration have emerged. A transnational perspective is necessary to understand the lives of contemporary immigrants whose lives in the US do not stand apart from the connections to family and community in their homelands, nor from the associated financial obligations, social reciprocities, or political alliances they engender (Glick Schiller, Basch, and Szanton Blanc 1995, Glick Schiller and Fouron 2001, Landolt and Da 2005, Levitt and Glick Schiller 2004, Mahler and Pessar 2006). Transnational immigrants live complex and multifaceted lives that weave together aspects of economics, culture, kinship and identity across the two, or perhaps more, countries in which their families reside.

Transnational relationships have often been analyzed in terms of the amorphous concept of the "social field" (Glick Schiller, Basch, Szanton Blanc 1995, Levitt and Glick Schiller 2004). ${ }^{9}$ Because my research will focus, in particular, on Haitian immigrants, I argue that the extended family — the multigenerational, network of bilateral relatives and fictive kin defined by Haitians as family — is the appropriate unit for the study of their transnational activities and relationships. The historic origins of Haitian communal life

\footnotetext{
${ }^{9}$ Some of the difficulties with this term are discussed in Mahler 2007.
} 
center on the family compound, the lakou, and relationships with kin living elsewhere in a cultural context that emphasizes familial duties and obligations (Arthur and Dash 1999, Herskovitz 1971, Laguerre 1984). For Haitians, family is the essential unit that governs social relations, including those that span national borders. (Brown 1991, Glick Schiller and Fouron 1999, Fjellman and Gladwin 1985, Laguerre 1984, Richman 2005, Stepick et al. 2001).

Family separation has always been a part of the migration process and it can take many forms. Unmarried young men and women have historically migrated and either returned later to their homelands to start families or permanently settled and started families in their new land. Some leave families behind and intend to return after an extended period of wage labor in the United States. Pribilsky suggests that the migrants he studied in the Andes may be seen as "commuters who endure lengthy commutes (3000 plus miles) and long work shifts (between 2 and 6 years at a time)" (2001:255). But many immigrants come to the US to settle permanently. US policies for family reunification provide opportunities for immigrants to request visas for family members to join them, although the process may take many years. In the interim, families of immigrants to the United States often have lives shaped by their anticipation of a future in the US as well as by the realities of the country in which they live.

This type of family separation comports well with notions of a nuclear family in which young adults leave the households of their parents to marry and create independent familial units. Men leaving families behind to migrate for seasonal employment, or migrating first and planning to send for their families at a later time, has been generally seen as a migration strategy that is difficult on family life but one that does not 
fundamentally undermine the structure of the family. However, as women with children are increasingly becoming part of the migrant population the conflict between woman as mother, homemaker, and caretaker, and woman as breadwinner has become an important topic for research. Much of this literature (which will be discussed in greater depth later in this section) emphasizes the emotional difficulties of parent-child separation, the burdens placed upon women, and the detrimental effects on the children reared in such circumstances. But other studies, particularly those of societies in which the extended family is the primary social unit and child-fostering is a normative family practice, demonstrate that flexible family formation is part of a general strategy for maximizing access to resources. However, even as many family members may be involved in the transnational family, benefits and resources are distributed disparately and costs are unequally borne among them. "Not everyone within a family network or even within a household may benefit to the same degree and tensions abound as men and women, those at home and those abroad, define their interests and needs differently" (Glick Schiller et al. 1995).

In this section I will discuss the literature that introduces important concepts used in the study of transnational families. These include some of the factors that create the impetus for or sustain transnational separations and the ways that familial relationships are managed and maintained. I will discuss benefits and costs that are experienced by members of transnational families, as well as the conflicts that are frequently inherent in transnational relationships. 


\section{What is a Transnational Family?}

Transnational migration has been defined as "the process by which immigrants forge and sustain simultaneous multi-stranded social relations that link together their societies of origin and settlement" (Glick Schiller et al. 1995: 48). Furthermore, studies of transnational relationships and activities emphasize the ways that immigrants "construct and reconstitute their simultaneous embeddedness in more than one society" (Glick Schiller et al. 1995: 48). Studying immigrant life from this perspective requires a consideration of not only the nature of relationships that span national borders, but also how the socio-cultural, economic, and political realities of each location affect migrants and, through transnational relationships, affect individuals who reside elsewhere.

To distinguish familial bonds from other types of transnational relationships, Bryceson and Vuorela define transnational families as "families that live some or most of the time separated from each other, yet hold together and create something that can be seen as a feeling of collective welfare and unity, namely 'familyhood', even across national borders" (2002: 3). Notably, this definition is founded not in specific set of blood-relations, but rather on feelings that bind a collective that may include distant or even fictive kin.

Migration always causes family separation of some kind. Even when a nuclear family of parents and their children migrates together, grandparents, aunts, uncles, cousins and other relatives are left behind (Bryceson and Vuorela 2002). While some transnational relationships may weaken or even disintegrate, modern communication and transportation technologies have made the maintenance of a sense of "familyhood" much more feasible. 


\section{Access to Resources in Two Places}

Migrants relocate to seek opportunities—-they may be economic, social, or political—but a family that maintains a transnational existence may attempt to maximize those opportunities by taking advantage of resources in two or more locales. A transnational perspective is necessary to examine how economic conditions and the employment and educational opportunity structures in each locale affect individual and family resources and how these factors figure in to family decision-making.

A primary impetus for migration and the creation of transnational families is economic opportunity. This includes labor migration for jobs in low-wage industries such as agriculture, construction, and janitorial services. But many immigrant workers also come from the highly educated sectors of their home countries, seeking employment in medical, high-tech, and academic fields, or in the upper levels of multinational companies (Bryceson and Vuorella 2002). ${ }^{10}$ Transnational families also result when children are sent abroad for schooling (Vuorella 2002, Waters 2005). International educational opportunities can be seen as part of a longer term project of improving economic outcomes. In a transnational family, particularly those originating in countries where wage employment is scarce or very poorly remunerated, family income may be increased by seeking employment opportunities in other locales. Each location may provide opportunities that are disparately advantageous according to age, gender, level of

\footnotetext{
${ }^{10}$ Bryceson and Vuorela (2002) point out that the term "migrant" is mostly associated with sojourners from the lower end of the socio-economic scale, while the more privileged who, nevertheless, cross borders to pursue opportunities for financial and social gain, are thought of somewhat differently.
} 
education, occupational training, or linguistic skills. Immigrants can access different opportunities in each place, creating greater financial security for the family (Alicea 1997, Glick Schiller et al. 1995, Glick Schiller and Fouron 1999, Schmalzbauer 2004). Studies of migration often emphasize aspects such as "push-pull factors," giving the impression that it is a reaction to extreme conditions. However, Karen Fog Olwig has pointed out that in areas where opportunities are quite limited, such as on the Caribbean islands where she conducted her fieldwork, "travel to another place, in order to take advantage of social and economic opportunities not available locally, was natural when one reached a certain age. It was quite simply necessary in order to progress in life, given the limited opportunities available locally" (2003:799-800). Such choices are not dissimilar to the relocations undertaken by residents of larger nations; however, Americans, for example, have many options within their own country that those born in small, island nations must cross national borders to access. But while it is not unique to transnational migrants to relocate for work or other opportunities, members of transnational families do face special challenges because they straddle different societies with varied and sometimes conflicting cultural norms.

Income production is one aspect of the equation, but family obligations, costs of child care, quality of life, and access to education are other important factors for transnational families as they consider their living arrangements. Even among more privileged families who do not struggle for subsistence, a transnational lifestyle may afford some family members access to higher wages, greater physical security, or enhanced educational or business opportunities. The logic of the transnational family can be compared to that of a corporation that strategically pursues the disparate advantages of 
different countries, locating various segments of their business where they can be most profitable (Bryceson and Vuorela 2002). Multi-sited families can also minimize risk. By keeping a stake in the homeland, migrants can facilitate a return if they lose their employment or wish to retire where the expenses will be lower and they have a greater social support network (Glick Schiller et al. 1995, Glick Schiller and Fouron 1999). As it has become increasingly possible to sustain relationships across borders, families strategize for their greatest advantage.

\section{Immigration Policies and Transnational Families}

One factor that places special importance on the social unit of the family - not only for Haitians but for all migrants to the US - is the family preference policy for allocation of immigrant visas. Immigration policies of the state shape migrants' opportunities for employment, education, social services, political inclusion, and sponsorship of other family members. The immigration policies of the US make the immigrant family the source of migration resources and, therefore, central to transnational relationships (Parreñas 2005).

The majority of new immigrants to the United States each year is admitted through family reunification policies that provide preferential entry to close family members of citizens and permanent legal residents. Of the more than one million new immigrants legally admitted to the US each year, the majority comes as family sponsored immigrants. Nearly 750,000 legal permanent residents were admitted on the basis of family reunification in 2009 alone (Monger 2010: 3). For immigrants from Haiti, this policy has facilitated a chain of migration as earlier migrants apply for their family 
members to join them in the US. From 2005-2009 more than 80,000 Haitians have been admitted to the US as family-sponsored immigrants, representing $69 \%$ of all legally admitted Haitians during that period (Jeffries and Monger 2008: 4, Monger 2010: 4). In addition, nearly 55,000 Haitians with approved petitions for migration were awaiting their visas as of January 2010 (Wasem 2010: 12). Qualifications based on age, marital status, and citizenship are among the factors that shape family migration strategies.

There are long backlogs for family reunification visas and this process can mean that family members are separated for years or even decades. Married children of US citizens who have been approved for family sponsored preference admissions typically wait nine years to receive their visas, with even greater delays for migrants from Mexico and the Philippines because the number of applicants far exceeds national origin limits. Backlogs for siblings of US citizens are longer still, at about 11 years after the petition is approved (Wasem 2010: 12). But despite these long periods of separation, it is clear that many thousands of immigrant families make this choice and anticipate that there will be a beneficial outcome eventually.

In addition to immigrants who pursue legal admission to the US, hundreds of thousands more seek entrance annually without legal authorization. US immigration policies intended to selectively limit migration fail to prevent a substantial amount of "illegal" migration; an estimated 10.8 million unauthorized immigrants reside in the US (Hoefer et al. 2010: 1). Other migrants are stuck in protracted states of contingent status, attaining legal residency on a temporary and fluctuating basis (Mahler 1995, Parreñas 2005). Transnational families are also created and transformed in this way, but they experience different structural incentives and constraints. Immigrants in such situations 
face substantial obstacles to physically reuniting their families. Migrants who lack legal documents cannot cross the border freely to make return visits to family in their homelands (Adler 2000, Mahler 1995, Parreñas 2005). They are not eligible for many social services nor are they legally authorized to work. These obstacles often mean that only part of the family will attempt to migrate. And for families who live together in the US with undocumented members, there is the possibility that they will be separated by deportation.

So, both the processes of legal and unauthorized migration to the United States result in many transnational families. Families respond to these situations in different ways, depending on long-term family goals, the specific ways they are affected by immigration policies, and the social resources available to them, in addition to the economic calculation they make (Adler 2000). These factors help to determine who will migrate, how long they will stay, and if or how other family members will follow. A transnational analysis of the conditions of their migration helps to bring to light the ways that immigration policies affect not only the individual migrant, but the family as a whole.

\section{Social Remittances}

In addition to the economic remittances that generally characterize transnational family relationships, and the mobility resources that contribute to maintaining these bonds, there are transfers of information and ideas. A transnational perspective facilitates the analysis of how social resources are shared across borders of country and culture and the impact they have on migrants' strategies, plans, opportunities, and outcomes. 
Social capital, as characterized by Pierre Bourdieu (2001), is the sum of the benefits one derives from relationships with others. Social capital can be parlayed into economic benefits such as personal loans, hospitality, and employment opportunities, but also it can generate cultural capital either as information or prestige or access granted through one's association with others. Framing this more specifically in terms of transnational processes, Peggy Levitt refers to these benefits as social remittances (1998, 2001).

Ideas, beliefs, and values are transmitted through transnational social networks. Among other things, they include expectations for appropriate age and gender roles, norms of familial obligations, and modes of social interaction and participation in public life, that may be changed by exposure to the behaviors characteristic of the country of immigration (Levitt 1998: 931). These social remittances can create changes in the home country that affect people who do not migrate themselves. But they can also affect the incorporation of later migrants by acquainting them with cultural norms and behaviors of the receiving country before they travel there themselves. This is one of the ways that the incorporation of individual immigrants may be affected by the link in the family migration chain that they occupy.

The value of social remittances from earlier migrants may vary depending on the extent to which they adapted to the receiving country (Levitt 1998: 931). Immigrants who limit their social interaction to the ethnic community acquire most of their knowledge of the receiving society through observation, the media, and the reports of other members of the ethnic community. Consequently, their social remittances are modest. But migrants 
who actively pursue the social and cultural knowledge that enhances their integration and opportunities for success in the new land are most able to provide valuable social remittances to their transnational networks. Another type of social remittance considered by Levitt is the status a person acquires in the host country or through transnational activities. ${ }^{11}$ This capital may be an asset that results from admirable accomplishments; on the other hand, it might be a detriment for individuals who have not lived up to expectations.

While Levitt (2001) emphasizes the ways that social resources can be part of the remittances transmitted transnationally, some scholars believe that migration itself puts a drain on social capital. Coleman (1990) and Putnam (2000) each have argued that migration and its disruption of family and community relationships have a deleterious effect on the social capital of the migrants and their social networks. Others argue that spatial unity is not necessarily a requisite for family support and that a static view of the family limits an understanding of the potential for developing social capital in diverse family forms (Landolt and Da 2005; Parreñas 2005, Evergeti and Zontini 2006).

Even so, as Portes and Sensenbrenner (1986) point out, there are costs associated with being embedded in an ethnic community and the social capital that belonging can generate. Among some groups, access to social capital may require the individual to remain apart from, or actively reject, the mainstream society. In so doing, some social capital may limit the kinds of integrative activity that Levitt (2001) indicated would add

\footnotetext{
${ }^{11}$ She refers to this type of social remittances as social capital, creating some confusion with the other, broader, uses of the term by Bourdieu (2001), Coleman (1990), Putnam (2000) and others.
} 
value to a migrant's social remittances, and might even squelch academic achievement and occupational aspirations (Portes and Sensenbrenner 1986). Transnationalized criminality and participation in gangs are among the most extreme outcomes of such negative types of social capital. There are some indications that youth who migrate during their teenage years may be at particular risk (Smith 2006: 268). And the costs and benefits generated by social ties are not equally distributed, possibly exacerbating gendered or generational disparities (Zontini 2009). Another significant cost of the social relationships that generate social capital is that economically successful members of a group may be besieged by requests for assistance from those who are less well off. "Hence," Portes and Sensenbrenner argue, "cozy intergroup relationships of the sort frequently found in solidarity communities can give rise to a gigantic freeriding problem" (1986: 126).

The interpretation of an individual's duties in a communal social structure as an embattled position of protecting one's assets from the demands of "freeriders" demonstrates the sharp disjuncture between communalist and individualist worldviews. Values and behaviors associated with individualism (as discussed previously) may be among the aspects of cultural capital acquired by immigrants and included in the social remittances transmitted to the homeland. While this aspect of transnational relations has yet to be studied explicitly, the tension between individualist and collectivist values is evident in the subtext of analyses of transnational familial relationships (Levitt 2001, Glick Schiller and Fouron 2001, Richman 2005).

Social capital is vital to the migration process, as it is used to access the economic resources for migration as well as a critical source of information, assistance, and 
connection to additional social resources (Evergeti and Zontiti 2006). Social remittances in the forms of information about the receiving country, including the transmission of cultural norms, language skills, and practical knowledge such as what qualities are prized by potential employers are passed along transnationally (Levitt 2001). Beyond the utilitarian values of the knowledge and skills that are derived from social capital, Pessar and Mahler (2003) point out that the imagining, planning, and strategizing for migration or other transnational endeavors are important, but little studied, aspects of transnational life. All these factors may have an impact on the ways that immigrants are incorporated into the US.

\section{Managing Family Relationships}

In a transnational family, whether the initial migrants go abroad for a temporary period of employment or schooling or they emigrate to settle permanently, the experiences of the initial, "frontiering" migrants will likely be quite different than those of family members who follow (Bryceson and Vuorela 2002: 11). Like the pioneers who settled the western frontiers of the United States, the first family members to establish residence in a new land travel into largely unknown territory with no established networks for support. Beyond the notion of venturing into new physical spaces, frontiering suggests the encounter with new cultural norms and values and the persistent clash of cultural environments that characterize transnational families. Divergent gender norms and variation between generations produce conflict in transnational situations in which some family members, with varying levels of enthusiasm, engage and adapt to the new frontier. They maintain relationships with kin in the homeland who have little or no 
familiarity with these cultural practices. In each location, family members will vary as some eagerly seek out and absorb the ways of the host culture and others maintain staunch resistance and defend their traditional homeland practices and values. The transnational family will encounter new frontiers in many aspects of social, cultural, and economic life, and these are important components of their incorporation into the receiving country.

The material dimensions of transnational family relationships are most often the impetus for migration and a major factor in the on-going interactions among family members. Many migrants send regular remittances and often sacrifice to send as much money as possible to relatives at home (Glick Schiller and Fouron 2001, Mahler 1995, Richman 2005, Schmalzbauer 2008). The Migration Policy Institute estimates that $\$ 414$ billion in remittances were transferred globally in 2009; that sum includes only cash transmitted through formal means and misses the substantial quantities of money and goods remitted outside of channels such as banks and money transfer services. But family members in the homeland also play an economic — albeit generally unquantifiedrole in the maintenance of the family. Although they are sometimes characterized as merely "eating up" migrants' remittances (Richman 2005: 41), kin networks at home are often relied upon to maintain small businesses, build homes and make other investments for the migrants, and above all to care for children and elderly relatives left behind (Glick Schiller and Fouron 2001, Levitt 2001, Richman 2005).

The nature of familial relationships is altered by a transnational distribution of labor, in which income is primarily generated abroad and remitted to kin who remain in the homeland. Levitt argues, "Migrants' power increases as their family's economic 
dependence on them grows" (2001: 89). But this power shift is not unproblematic.

Migrants may become resentful of the dependency of those left at home, even as those distant kin serve to validate migrants' claims to enhanced status based on the remittances they provide. This attitude may also evolve as a migrant becomes acculturated to more individualistic norms of the US (an example of the kind of cultural frontiers that are crossed by some family members and not others in a transnational family). A participant from Levitt's study of the Dominican village of Miraflores explained,

In the U.S. everyone has to work. It would be very difficult for you to have your brother living in your house for a year without contributing anything. Maybe for a week, but not for a year. Here it used to be different. If my brother isn't working and he doesn't have work, then I have to support him because I work. I have to do this because he is my family. ...

In the U.S., your responsibility to your family changes. You don't have to feel obligated to support anyone who just doesn't feel like working. The same family hardly shares at all, although they are Dominicans, although they are brothers. [Levitt 2001: 91-92]

Contests over the amounts, frequency, and uses of remittances reflect the changing power dynamics within a transnational family (Glick Schiller and Fouron 2001, Levitt 2001, Richman 2003, 2005).

But while migrants tend to hold the upper hand in terms of financial capital, those at home often exercise "moral capital" over the migrant in their judgments of remittances, withholding some of the power the migrant might otherwise claim as the dominant material provider of the family (Carling 2008). Family members left behind may be both appreciative of the money and goods sent to them but also complain that remittances are not enough or come too infrequently (Carling 2008, Levitt 2001, Richman 2005). In this way, Jørgen Carling (2008) argues, relatives in the homeland retain "moral capital" that 
may be deployed as a counter to the power generated by the superior financial resources of the migrant. Moral capital of non-migrants is their socially recognized expectation of remittances and use of complaints to denigrate the contributions from abroad. By minimizing what is received or framing it as less than expected, receivers undermine the hierarchical aspect of remittances (Brown 1991, Carling 2008, Richman 2005).

Established social hierarchies may also be renegotiated in transnational families, as structural inequalities result in members having disparate access to resources of various kinds. (Bryceson and Vuorela 2002, Carling 2008, Landolt and Wei 2005, Parreñas 2005, Pessar and Mahler 2003, Schmalzbauer 2008). "Not everyone within a family network or even within a household may benefit to the same degree and tensions abound as men and women, those at home and those abroad, define their interests and needs differently" (Glick Schiller et al. 1995). Roles of and relationships between siblings change when some become senders and others receivers of remittances from abroad (Glick Schiller and Fouron 2001, Levitt 2001). And traditional bearers of status in the homeland may exercise their moral capital in ways that limit the extent to which migrants can convert their earning power into social status (George 2005).

Males and females encounter new gender norms after migrating, which may substantially alter their relationships. Some studies have found that because of the gendered differences in the ways that individuals experience migration, women often prefer to settle permanently in the host country where they have the opportunity for greater independence, while men who experience a decline in status desire to return to their homelands (Goldring 1998, Mahler 1998). But reactions to new gender ideologies and their component opportunities, responsibilities, and expectations are varied as 
individuals adapt to their particular social and economic circumstances. While immigrant males who struggle economically may yearn for the privilege of traditional patriarchal gender roles they enjoyed in their homeland, men who have been more successful in their post-migration ventures often do not share those feelings (Smith 2006). Similarly, women's reactions to the gender roles they encounter in migration are more complex than a simple preference for greater independence. Women do not necessarily desire to give up the role of homemaker and status as the primary family caretaker (Alicea 1997, Smith 2006). Traditional patriarchal family roles, such as those documented by Nazli Kibria (1993) among Vietnamese immigrants, while placing considerable constraints on women are also a source of benefits derived through the obligations of husbands and children. So the impact of migration on gender roles is quite varied.

Nevertheless, exposure to varied gender expectations produces changes in the families of migrants and throughout the homeland society, too. These changes may be even more difficult to manage when spouses are separated transnationally. In a study of Ecuadorean transnational families, Kyle (2000) documented that separation of spouses led to significant marital dissolution over a course of years as both communication and remittances dwindled. Women's roles and practices changed as men left the village, including in ways that both prepared them and made them more likely to migrate themselves. And these changes impact migrants' children, as well. Youth who grow up in transnational circumstances are exposed to multiple gender ideologies - for example, male stereotypes of Mexican "macho ranchero," white middle-class career man, hardworking immigrant, American rapper, Mexican gangster (Smith 2006: 123-124) which must then be negotiated in concert with their attempts to fulfill the aspirations of 
their immigrant parents (Smith 2006: 126). Pessar and Mahler (2003) have articulated some of the complexities of the relationships between geographic scales, social location, and power hierarchies in their "gendered geographies of power" framework. The role of gender in transnational relationships cannot be viewed alone, but rather as one aspect of the complicated social field that migrants negotiate. It is part of the calculus of duties and obligations that connect transnational families.

The ways that relationships with particular members are selectively tended in transnational families has been termed relativizing by Bryceson and Vuorela (2002). Specifically, relativizing "refers to the variety of ways individuals establish, maintain or curtail relational ties with specific family members" (Bryceson and Vuorela 2002:14). Included in this are material exchanges, such as remittances and child care, but also the maintenance of communications, transmission of ideas and practices, and sponsorship of subsequent migrants. Leah Schmalzbauer expands on this definition, emphasizing the emotional realm: "Forms of relativizing may be used as a strategy to cope with the emotional difficulties of being geographically distant from family members, to manage the guilt of leaving children behind, or to defend family loyalty to non-blood kin with whom members may feel closer than they do to blood relatives" (2004: 331). So not only do migrants decide how to distribute resources, but they actively shape the nature of transnational family relationships in a variety of ways.

Like the distribution of remittances, various forms of communication help to sustain cherished family relationships. Regularly scheduled phone calls (Parreñas 2005), letters with small gifts (Erel 2002), photos and videos of the migrant's life abroad (Pribilsky 2001) may help maintain feelings of familyhood. Haitian emigrants send 
cassette tapes that will be played as the family gathers together (Richman 2005). These are forms of relativizing meant to bridge the physical distance in a transnational family.

But regular communication does not always happen. Access to advanced technology is not uniformly available; it is limited by economic means and the reach of infrastructure. Modern communications technologies such as cell phones and internet are not available in many poor rural areas or may be too costly for frequent use (Mahler 1998, 2001, Pribilsky 2004, Sassen 2000). Likewise, the ability to travel is limited by economics and geography and may also be curtailed by a migrant's legal status or a family's ability to secure necessary visas (Landolt and Da 2005, Parreñas 2005, Pribilsky 2001).

While some gaps in communication between members of a transnational family are due to constraints of resources, others occur as forms of relativizing, as migrants choose how much information to share about their situations in the receiving country. Communication with family back home is often meant to disguise the harsh realities of the migrant's life (Brown 1991, Goldring 1998, Levitt 2001, Mahler 1995, Richman 2005, Schmalzbauer 2008). Consequently, those left behind often imagine a life in the US that is much more prosperous than in reality. Communications may also diminish when a migrant feels unable to meet the financial expectations of family members in the homeland (Brown 1991, Glick Schiller and Fouron 2001, Mahler 1995, Richman 2005, Schmalzbauer 2008). Some migrants withhold communication from spouses to exercise their relative power and discipline them for real or perceived transgressions (Kyle 2001, Pribilsky 2004). Contact may be strategically limited as a way to create emotional distance, avoid disapproval, or manipulate power relations. 
Another part of the process of relativizing is the distribution of mobility resources (Carling 2008). Immigrants with legal status to petition for family preference visas wield a great deal of power as gatekeepers of future migrations. These mobility resources can become a source of conflict as they are selectively distributed (Carling 2008). The choice of the next migrant affects educational opportunities, the ways that remittances will be distributed, and which family members will qualify for future family preference visas.

Where family-related migration is the norm, the gate-keeping role of emigrants is central to their relations with non-migrant relatives. On the one hand, they may facilitate migration of relatives in return for past favors. On the other hand, emigrants can use their power to keep nonmigrant relatives in the country of origin to oversee construction, take care of children or provide other services, even when those nonmigrants are desperate to leave. [Carling 2008: 1471]

Migrants may use their mobility resources to sponsor family members who can be helpful to them personally in the receiving country as childcare providers or extra income earners for the household. Or they may hope to shift the responsibility for remittances onto another family member (Glick Schiller and Fouron 2001). Another strategy is to sponsor a new migrant who is best equipped to advance academically or professionally in the receiving country, with the possibility of bringing both social and economic rewards to the extended family.

\section{Children as "Pivotal Points" in Family Migration Strategies}

Children in transnational families, whether left in the home country, brought along with the migrant parent, sent for after a period of separation, or born in the new country, play an important role in the choices made. Orellana and colleagues argue that "the presence of children is central to the families' decision-making processes, and children fundamentally shape the nature and course of families' migration experiences" 
(2001: 587). They connect branches of the family (including fictive kin) through child care, the distribution of remittances, the webs of duties and obligations that are intended to persist well into the future (Glick Schiller and Fouron 2001, Orellana et al. 2001, Whitehouse 2009). Children's needs, as well as their abilities to contribute to the family welfare, play an important role in adult's migration decisions. The birth of a child can postpone migration plans while the responsibilities of child-rearing may also provide the financial tipping point that motivates the move. In particular, providing for children's educations is an important motivating factor in many parents' migration decisions (Dreby 2005, Pribilsky 2004, Waters 2005).

But these decisions and processes are shaped by the particular contexts of migration both in homeland and new land, as well as factors such as the family's social class and the age and gender of the child.

[T] he legal positioning of children and of parents; patterns of economic dependence and divisions of labor by age and gender; beliefs and practices entailed in bringing up children and (from the child's perspective) growing up-enter into the complex dynamics of family migration [(Orellana et al. 2001: 578]

For example, age limits for family preference visas, rights of children as a consequence of their place of birth, cultural norms regarding care-taking roles and responsibilities, ideas about the age at which children should begin to contribute to the family's material well-being, as well as the age until which their parents should support them, will vary in accordance with the laws and customs of the locale and the class positioning of the family. 
Additionally, children must be viewed as part of a strategy for the welfare of the entire family and prospects for their future.

In seeking opportunities for the future of their children, families are also strategizing to improve their collective conditions. The individualistic focus of traditional Western views of child development tends to neglect the collective interests of families and to ignore the tight links that may connect children to larger family networks. [Orellana et al. 2001: 587]

Traditional approaches to understanding the incorporation of immigrants into the United States tend to define family as discrete units of parents and their offspring, and agency conceived of in strictly individual terms. This may obscure the kinds of intergenerational, extended family projects for collective goals that are commonly described in research on transnational families. One example that provides clear evidence of the strategic planning that enters into such migration decisions and the important role of children is that of Korean "parachute kids." These young people are sent to US during their high school or even elementary years in the hopes that they will gain admission into American universities. The tough competition for coveted spots in top Korean universities motivates some parents to seek alternative options in the US that might deliver both academic credentials and family prestige (Orellana et al. 2001, Waters 2005). Orellana and colleagues describe this as "part of a long-term transnational strategy for economic advancement" (2001:575) that can pave the way for future transnational business ventures. Through their American educations, these students participate in a family project of accumulation of capital in many forms (Waters 2005). They build human capital in the forms of education and preparation for prestigious occupations, social capital through establishing international networks of relationships and earning an elevated status in their homelands, symbolic capital by deploying their acculturation into 
American society and its material trappings, and mobility resources by helping to facilitate the migration of other family members.

Similarly, Moldenhawer (2005) documented transnational Pakistani families in Denmark "utilizing education strategically as a social mobility medium by amassing increased sources of income and job opportunities (economic capital)" (2005:62). Enhanced education, made available by migration to Denmark, not only represented future economic resources for the family, but also improved the family's status both in the host country and in the homeland, as well. This enhanced status could be further parlayed into greater prestige by facilitating an advantageous marriage.

Parents weigh long-term and short-term opportunities and consequences, the available resources in each location, as well as social and emotional factors. Whereas affluent Korean families employ long-term strategies to maximize the opportunities for their children and for the social and economic placement of the family as a whole, less fortunate migrants may have choices that are more constrained by day-to-day concerns for food, shelter, and safety.

\section{Parent-Child Separation}

Transnational families experience a number of challenges as a result of family separation. Most difficult, perhaps, is when parents and children must live apart for long periods. The increasing prevalence of this type of household is evidenced by a 2007 paper produced by The United Nations Children's Fund (UNICEF), "The Impact of International Migration: Children left behind in selected countries of Latin America and 
the Caribbean." But the consequences of this aspect of transnational family life are presently under debate.

Although regular communication and visits have been made possible by technology, migrants often find that financial difficulties limit family contact to a much greater degree than they had anticipated (Mahler 1998; Sassen 2000). Access to the advantages of technology is unequally available, limited not only by economic status, but by geographic location, as well. Migrants from areas that lack modern infrastructure are much less able to maintain regular transnational communication (Parreñas 2005, Pribilsky 2001). And migrants who lack legal documentation are unable to travel freely; they often choose to forego visits home in order to avoid further illegal and risky border crossings (Adler 2000).

Family separations may be emotionally difficult on both parents and children (Dreby 2009, Erel 2002, Levitt 2001, Moran-Taylor 2008, Pribilsky 2004, Schmalzbauer 2004, Suarez-Orozco et al. 2002). Siblings are separated in some cases, as some children migrate along with a parent while others are left in the home country. Or while some children may have been left in the homeland when their parents migrated, other children may be born and raised in the host country with full citizenship. Siblings raised in different countries may not share a culture or even a language. Such separations may be painful and provoke jealousies within the family. Not only do children suffer from the absence of their parent, but they often become attached to their caretakers and experience a similar grief when they are sent to the US to rejoin their parent. Reuniting, perhaps years later, parents and children may have become virtual strangers and experience ambivalent feelings about living together again (Erel 2002, Moran-Taylor 2008, Olwig 
1999, Schmalzbauer 2004, Suarez-Orozco et. al. 2002). And in some cases parents leave children behind and fail to maintain financial support and eventually cease contact (Moran-Taylor 2008).

Even when parents migrate with their children or reside in the receiving country with children born after they arrived, sometimes it is deemed necessary to send children back to the homeland for some period of time (Levitt 2001, Matthei and Smith 1998, Orellana et al. 2001). This strategy is often undertaken, or threatened, when children begin getting into trouble or become difficult to handle in the US. Their parents may feel it beneficial for the children to develop a better sense of how privileged they are in comparison to the conditions in the country of origin. Some immigrant parents feel they are not properly able to care for their children because they work long hours and lack the extended family support they might have relied upon in their homeland (Levitt 2001, Orellana et al. 2001). If the family is undocumented, parents may send the child back to lessen fear of deportation or because opportunities, such as obtaining financial aid for college, may be unavailable to them. Others find it financially untenable to raise their children in the US on modest wages and believe they can provide for them better by sending remittances that will go much further in their country of origin. In addition, some immigrants feel it is important for their children to learn the customs and culture of the homeland and, especially in societies where interpersonal relationships are considered a critical resource sending a child back is part of a strategy to build and enhance social networks (Whitehouse 2009).

Regardless of how the family divided, familial roles tend to be changed by transnationalism. The literature suggests that women maintain the primary responsibility 
for childrearing, with aunts and grandmothers caring for children left behind when mothers migrate (Alicea 1997, Parreñas 2005). When fathers are left in charge, households are characterized as less stable, with less favorable outcomes for children. However, it seems that far too little attention has been paid to transnational households in which the father is the primary caregiver to provide sufficient evidence for analysis.

Although transnational caretaking is a responsibility that falls disproportionately to women, it also affects children who are called upon to care for siblings or take on other household tasks in the absence of a parent (Alicea 1997, Parreñas 2005, Schmalzbauer 2004). These responsibilities may have a negative impact on a child's school performance (Parreñas 2005) or may even prevent some children from attending school (Alicea 1997). An older child may themselves be sent abroad in hopes that he or she will earn enough to support the family or to send younger siblings to school (Zontini 2004). While the literature suggests some differences in familial responsibilities along the lines of gender and birth order, these have not been explicitly studied and analyzed to date.

But although a number of scholars have emphasized the negative consequences that may be associated with parent-child separation, others, particularly those who work in regions with well-established practices of extended family child-fostering and cultures of migration, point out that that such separations are not especially traumatic or unusual in all contexts.

\section{Child-fostering and Cultures of Migration}

Olwig (1999) emphasizes the cultural context and its norms of social and familial relationships in understanding the impacts of parent-child separation in circumstances of 
migration. She explains that "Caribbean family relations" are far more extensive than the Western model of the nuclear family and are established and maintained through patterns of reciprocity.

In Caribbean family networks all social and economic rights and obligations are not concentrated in smaller autonomous nuclear family units, but are rather placed in wider webs of relations where relatives outside the immediate family may play a prominent part. Thus, in a family network any relative may contribute towards the economic support for a child. Likewise, a child may be cared for by relatives other than the mother, and it may even be regarded as highly functional that older relatives, who are not able to engage in gainful employment, concentrate on child rearing. From this point of view it is therefore impossible to say anything about the social and economic welfare of the child on the basis of knowledge about the parent-child unit as such. What counts is whether the networks of relations are doing their job, and these relations may well extend beyond the household to relatives in distant migration destinations. [Olwig 1999:267]

Children in the Caribbean cultural context, like others where extended family and child-fostering are common, are not merely dependents. They can be the sources of both domestic and commercial labor, the conduits for parental remittances, and an investment for future emotional and material needs.

Since children often live with grandparents, migrants have a double incentive to send support to the home. If children are cared for by other relatives or non-relatives, these substitute parents become, to a certain extent, parental figures for the children and the substitute-parents will expect some form of economic support from the children later in life. Children are therefore not just an economic and social responsibility for those who care for them, but also a potential source of income for those who assume parental responsibility for them, as well as an investment in future flows of support from their grateful charges. [Olwig 1999:267]

Patterns of child-fostering have been long-established among Garifuna women in Belize (Matthei and Smith 1998). This facilitates particular types of labor migration. 
Women without documentation often accept employment as live-in domestic workers that would make it difficult to migrate with and care for their own children. Fortunately, women who remain in Belize are often eager to take in migrants' children, as this provides a stream of remittance income. One Garifuna woman explained the value of such relationships saying, "Even a little job in the States can support two families," meaning both the migrants' own family and the family of the caretaker in Belize. In addition, caring for a migrant's children establishes transnational social networks that can facilitate eventual migration for the caretaker herself or for her family members.

Similarly, among Central American and Mexican families, Orellana and her colleagues (2001) report that "other mother's children" (cites Dill 1994) are not necessarily seen as a burden. Remittances sent from parents working abroad are often sent to the caretaker and augment the household income. In addition, children provide household labor in the form of chores and child care and may also contribute as wage earners (Orellana et al. 2001).

The economic reasons for transnational parent-child separation may be enmeshed in the transmission of homeland values that dictate norms of filial obligation. In a study of families who had migrated from Mali to the Republic of Congo, Whitehouse found that "parents ... put the social reproduction of their home community before their right to raise their own children" (2009: 86). They viewed the Congolese host society as morally inferior and corrupting. Consequently children were ideally sent back to their parents' home villages to be raised by relatives, and to be socialized into local norms and values. It is in the home villages where children are enculturated into systems of familial obligations that will require them to provide for their parents as they age. One of his 
participants explains the divergent values systems of the Congo (host society) and West African home villages:

Congolese children, they depend on their parents for food, right up to 25 years of age. ... But for us [Malians], already from the age of ten or so, a child says 'I must feed my father and my mother.' There's the big difference. West African children work for their parents. Children here work for themselves. [Whitehouse 2009:89]

Whitehouse points out that because child-fostering is quite common in West Africa regardless of parents' migration status, it may not be associated with some of the negative emotional consequences observed in other cultural contexts.

In sum, while there are strong arguments that the negative consequences of transnational parent-child separation are too great, there is no definitive consensus. In particular, it seems that normative traditions of child-fostering serve to minimize adverse outcomes. One particular area of concern for scholars who study transnational parentchild separation is the impact this circumstance has on educational opportunity and achievement.

\section{Impacts on Education}

The ways that transnational family life affects children's educational outcomes is an important issue in the studies of transnational families. However, at this point there is no comprehensive theory on this topic. What is evident from the variety of case studies is that a child's education may be enhanced by an increase in family earnings; but, on the other hand, the disruption to family life, poor supervision by caretakers, additional responsibilities for siblings, and emotional distress may lead to negative outcomes. 
Cultural contexts, homeland education systems, and socioeconomic class position of the family seem to have an impact on educational outcomes. In general, children's opportunities for education are increased due to cash remittances. In areas where access to school is limited by ability to pay for tuition or supplies, remittances may make the difference between achieving some schooling or none at all, or persisting beyond elementary school (Dreby, 2005, Glick Schiller and Fouron 2001). For the children of migrants who would have gone to school anyway, remittances may be spent for private schools or more sophisticated supplies (Schmalzbauer 2008). And immigrant hometown associations may fund new or improved school facilities (Levitt 2001). But many scholars note the potential for negative academic outcomes in transnational families.

Some students suffer academically because their educations are frequently disrupted by moving between transnational locations. Peggy Levitt (2002) tells of Eduardo who was shuttled back and forth between the US and Dominican Republic throughout his youth, relocated each time he got into trouble. With each move he became less able to successfully negotiate his surroundings. He had mastered neither English nor Spanish and was not fully acculturated in either society. By age eighteen, the result of his transnational upbringing seemed to be "social and economic marginality in both settings" (Levitt 2002: 127).

Levitt argues that large-scale migration that has turned Miraflores in the Dominican Republic into a transnational village has impacted education in contradictory ways. Money from villagers who work abroad has substantially improved the physical structures of the schools and the children of migrants have many amenities to enhance 
their schooling. But despite these advantages, children of migrants may put less stock in education, instead focusing on their own eventual migration.

Noting a similar problem, Joanna Dreby (2005) believes that even though financing their children's education is a primary motive for parental migration, it is generally a counterproductive strategy. In her study based in Oaxaca, Mexico, Dreby found that many children whose parents had migrated discontinued their schooling early. She concluded that the emotional burden of separation from their parents combined with a growing culture of migration resulted in students who became focused on migrating themselves instead of education.

But planning for their own future migrations does not always mean that student will devalue education. In the Andean community he studied, Jason Pribilsky (2001) found that the educational focus for the children of migrants had been affected by their families' transnational lives. Remittances improved the opportunities for schooling, however, migrant fathers emphasized that their children should acquire English language skills to prepare them for their own futures as migrant workers in the US. Even more than this, the influx of remittances reduced Ecuadorian families' dependence on their children's labor and allowed a greater emphasis on education. The nature of childhood was being redefined as extended years of education became a more viable option.

The increased opportunity for education can also re-orient young people's perceptions of their class status. In Leah Schmalzbauer's (2008) study of Honduran youth left behind while their parents worked in the US, remittances provided for private school educations that would have otherwise not been possible. The students came to see themselves in contrast to young people with fewer resources who became involved with 
gangs and other negative outcomes. They also avoided the dangers of urban poverty in the US that befall many young people who migrated with their parents. Unlike the studies previously discussed, Schmalzbauer reports that the youth she studied did not plan to migrate for work as their parents had done. They have not developed a "culture of migration" and believe they will be able to remain in Honduras and maintain desirable lifestyles. She fears that their expectations of good jobs as a result of the educational opportunities made possible by their parents' remittances (most attended private schools) will not be met if they remain in their homeland. She argues that they have become a "remittance bourgeoisie" (adopting the term introduced by Smith 2006); they have become accustomed to a privileged lifestyle only made possible by their parents' labor abroad. However, their parents are living in poverty in the US. Schmaltzbauer notes, "It is theoretically important to determine whether over time the aspirations of transnational youths will match the opportunity structures in which their lives are rooted, how their aspirations and expectations will evolve, and what impact remittances will have on this evolution" (2008: 345).

The outcomes of youth raised transnationally may not be easily discerned until they reach adulthood. Georges Fouron's personal account of his transnational endeavors to achieve upward mobility through education demonstrates the complexity of the process (Glick Schiller and Fouron 2001). His journey required creative and strategic interpersonal negotiations and use of both legal opportunities and extra-legal loopholes and required many years of effort to ultimately achieve the level of academic and occupational success he sought. In the process, he acquired a dense network of reciprocity through which his eventual success would become a resource for others. 
For young people who grow up where opportunities for school and employment are severely limited, as they are in Haiti, education often comes at a great cost to students and their families, as well.

\section{Conclusion}

Studies of migration now emphasize a transnational approach, making clear that a bounded study of immigrant incorporation in the receiving country misses a substantial and important part of many immigrants' lives. A transnational lifestyle is simply a lived reality for innumerable families in the US and across the globe. Some of these families are parted for temporary periods of labor migration, while others may aim for a permanent migration that nevertheless necessitates long periods of family separation.

The transnational family, as a vital unit in the maintenance of transnational ties and the distribution of transnational resources, must be examined as part of the full range of social processes that affect the incorporation of immigrants. Transnational families share both material and social resources in ways that disparately affect individual family members as they try to balance familial obligations with their individual goals and desires. As immigrants often maintain active ties to their homelands, a transnational perspective is necessary to understand their experiences of incorporation, and the transnational family is central to this endeavor. 


\section{Haitian Immigrant Families and Transnational Obligations}

Haitian families are extended and flexible and, both within Haiti and in the transnational context, they provide important networks for support and social mobility. These are vital networks that must be tended in ways that vary, depending upon social and material resources. In this chapter I will discuss the traditional notion of family in the Haitian countryside and the ways it is affected by migration. In particular, I will examine the ways that the Haitian family provides resources for survival and social mobility but also levies substantial demands upon its members.

Any discussion of such generalized normative practices relies on broad stereotypes that, while providing useful cultural context, fail to do justice to the variation found in real life. This section, nevertheless, is intended to demonstrate the ways that traditional behaviors and beliefs that are characteristic of rural Haiti provide the cultural basis for current patterns of transnational activity.

\section{Haitian Family Structure}

The flexible structure of extended family is the key social unit in Haitian culture, central to both economic and spiritual life. "For Haitians family is fundamental. Haitians put family first and they define family as the large extended family, including distant cousins and occasionally people who are not actually related by kinship" (Stepick et al. 2001:6). Melville Herskovitz observed, 
The word "family" as employed in Haiti can be understood only in terms of a broader meaning than is given it in Europe and America, where it describes only the most immediate relationship group. Though in Haiti this type of organization, consisting of mother, father, and children, lies at the base of its structure, the Haitian "family" includes a wide range of relatives, direct and collateral, on the sides of both parents. The immediate family is thus but a part of a larger group, to which it is in many ways subordinate. [1971:123]

The extended family structure that facilitates the transnational Haitian migration pattern is rooted in the culture of rural Haiti.

In the Haitian countryside, the typical form of social organization is the lakou (Arthur and Dash 1999; Herskovitz 1971). Traditionally, portions of a rural landholder's property were allotted to his sons. Each son built a home on the family land as they began to marry, where he and his wife would raise children of their own. In the lakou, these individual homes are clustered around a common area. Each household has distinct economic concerns, but this living arrangement accommodates a lifestyle in which many tasks, including food preparation, child care, social and religious activities are carried out with some degree of interdependence. This extended family group is a critical part of Haitian economic subsistence.

The lakou is a source of communal support, but it is also the site for enforcing behavioral expectations and social norms. Traditionally, the eldest male heads the extended family, and he is consulted in both secular and spiritual matters. The head of the lakou has the authority to withhold family support for transgressions. Returning to the Haitian metaphor of the family as a tree, bad branches must be removed for the health of the rest. The seriousness of such a sanction was clear to Herskovitz, who noted, "a man thus punished forfeits the outstanding economic advantage of belonging to his 
relationship group, the right to call on the members of his family for aid when he is in trouble" (1971:127). Haitians turn to members of their extended families for the essential social "safety net," of financing, protection, health care, and other needs. Family is an essential resource in all aspects of Haitian life, and the threat of exclusion is a powerful incentive for compliance.

Family responsibilities are enforced by a moral code that emphasizes that one must "do for" one's family members (Glick Schiller and Fouron 2001). A person is obligated to help less fortunate family members; at the same time, it is wise to provide what favors one can to those better off in order to maintain the relationship and ensure assistance when needed. Religion provides what Clifford Geertz refers to as "a model of and a model for society" (1973:93), both establishing and reinforcing norms of social behavior. For Haitians, the prototype for the morality of family can be found in Haitian Vodou, the traditional religion of Haiti. This belief system emphasizes the interconnection between humans and the spirits, or $l w a$, in ways that model the family relationship. One must "feed" the spirits and in turn they will protect those who serve them (Brown 1991, Richman 2005). Failure to uphold these responsibilities will result in harsh punishments in the form of illness or misfortune. In addition, Vodou reinforces the notion of family as the essential social unit, as it is through one's ancestry that spirits are inherited. In the traditional lakou, the family joins together for rituals to serve their common spirits. These values pervade Haitian culture, even among those who don't practice the traditional religion.

According to Herskovitz 1971), the traditional lakou is patrilocal and headed by the landholder. However, while age and gender roles still structure authority and 
responsibility, Richman suggests that the traditional form has declined. Whereas the lakou was once the family's center of activity and authority, it may now be reduced to "a nursery and a nursing home for migrants" (Rouse 1992: 28 cited in Richman 2005). The decline of Haiti's agrarian subsistence base has led to substantial migration to the country's urban centers and beyond its national borders, as well. Social roles have been altered in the process. Nevertheless, the traditional family structure of rural Haiti is an important foundation to the study of the Haitian family in its contemporary transnational context. The extended family continues to be the hub of a network of duties and obligations governed by mores of interdependence.

Michel Laguerre (1982) documented the re-creation of the lakou in the urban context, as Haitians have left the countryside to seek economic opportunities in Port-auPrince or the smaller cities of Haiti. Laguerre argues that Haitians retain the traditional understanding and expectations of the lakou as a spatial and religious community despite the urban setting, as he documents the persistence of interdependence among individual households of relatives and fictive kin. Laguerre noted the efforts among these extended family communities to establish a migrant abroad in order to generate remittances and arrange for future emigrants.

Despite the erosion of the lakou as a spatial entity due to the excessive division of land and other social and economic factors that have drawn many Haitians further and further from ancestral homes in the countryside, its structures are culturally embedded. What remains is a logic of extended family relations through which individuals contribute to and benefit from economic resources of their kin. While inheritance rules and land 
rights structure the traditional lakou, in its landless form, the relationships themselves are the basis of communal wealth and status.

\section{Children}

Children in Haiti are considered a gift from God. Large families bring prestige and help to extend social ties. They are also important to the family's economic survival (Schwartz 2003). In rural Haiti, as soon as they are old enough, boys go to the field with their fathers and girls help their mother with her tasks of cooking, caring for younger children, and taking goods to market (Herskovits 1971). Children are considered essential for running errands, fetching water, and collecting firewood, and the many other tasks required to run a household in the countryside (Schwartz 2003). They will help to provide for their parents in old age, especially their mothers. The proverb, "Petit se richès fanm pov" ("Children are the riches of poor women"), is an essential truth of Haitian life (Richman 2005: 286). Karen McCarthy Brown asserted that, "for Haitian women, even for those now living in New York, children represent the main hope for a financially viable household and the closest thing there is to a guarantee of care in old age" (Brown 1991:244).

Children are critical links in the social relationships of the extended family. Childcare is important in maintaining social networks. In Haiti, children may be sent to live with wealthier relatives who will support them and perhaps send them to school in exchange for domestic labor, a relationship known as restavek. These relationships may be mutually beneficial. However, they are sometimes exploitive situations in which the child is virtually a household servant given meager sustenance in return (Brown 1991, 
Cadet 1998, Herskovits 1971). Whether exploitive or benign, the web of reciprocal obligations is expanded and strengthened by sending children into extended family homes. This also includes godparents, who take on many responsibilities, often in regard to the education of the child, and are thus drawn into the family network (Laguerre 1982). Godparents may expect a return on their investment as they age and build bonds of reciprocity between their own extended families and that of the child.

\section{The Family in Migration}

Haitian migrants receive help from and sustain obligations to their extended families. The extended family, created by bonds between spouses, children, siblings, and more distant as well as fictive kin, plays an important part in the survival strategies of Haitians who migrate to the United States. This mutable family structure allows Haitians to adopt a transnational approach, linking members residing in Haiti, Canada, the Bahamas, the United States, and elsewhere in a web of support and obligation. The flexible nature of Haitian families facilitates chain migration, the sequential migration of family members, as resources permit.

The Haitian concepts of marriage and children allow households to form and reconfigure quite freely within established social norms. Marriage, for Haitian immigrants, is subject to change in the migration process. Spousal roles and power dynamics are affected by differences in legal status, earning power, and level of assimilation (Laguerre 1984). Husband and wife are often unable to migrate together. The initial migrant may be either spouse, but in rural areas it is more likely to be the man who migrates first. After becoming established, he may bring his spouse to the US. When the 
original migrant is the woman, the relationship is dramatically changed by his dependence on her when he is able to join her.

The prevalence of common-law marriage in Haiti complicates the family unification process. Only legal spouses are recognized by the United States for immigration purposes. "A migrant who has engaged in a consensual union, which is protected by folk laws in Haiti and thus achieves a certain stability, may find it easier to marry someone else here than to sustain the relationship" (Laguerre 1984:74). Unmarried migrants may meet a potential spouse in the US or may return to Haiti to marry. As in other immigrant groups, marriage to a US citizen or permanent resident is sometimes contracted in order to obtain legal residency status (Laguerre 1984, Stepick 1998). However, for Haitians, whose traditional conjugal practices include the possibility of a man maintaining multiple common law relationships, this does not preclude maintaining a union in Haiti or even sending for the Haitian spouse.

Multiple families may be part of the migration strategy. A man may try to maintain a family in Haiti as well as one in the United States. Some continue to keep multiple households in the US, spending some time, eating some meals, and sleeping part of the time in each, as he would in Haiti. He provides a certain amount of support for children he has fathered. "While he lives with one woman and their children, he may also regularly visit another with whom he has children to whom he provides support" (Stepick 1998:28). By exercising various marriage strategies migrants extend social ties and expand family networks.

Defining family ties and obligations is further complicated by spouses maintaining separate and sometimes competing familial obligations. Each spouse 
maintains ties with his or her own kin and is subject to demands for financial assistance and obligations to help subsequent migrants (Glick Schiller and Fouron 2001, Laguerre 1984, Richman 2005).

Children also play a role in expanding family networks and maintaining ties. In migration, children are frequently left behind until their parents have the money or the legal status to be able to send for them. Relatives or godparents will take them in, caring for them in exchange for their help with domestic chores. Even children born in the United States to Haitian immigrants may be sent to Haiti for a time to save childcare costs. Children of immigrants are also sent to Haiti to spend time with family and absorb Haitian culture and values (Laguerre 1984, Stepick 1998). The extended family feels a responsibility for children and through their care reinforces reciprocal assistance.

The links reinforced by children are not always based on raising a migrant's offspring in Haiti. Immigrant families may send for a niece, nephew, or godchild to stay with them in the US, extending the migration chain to another branch of the family network (Glick Schiller and Fouron 2001, Laguerre 1984, Stepick 1998). Haitian immigrants try to recreate the flexible extended family in their new country by allowing children to circulate freely between the homes of relatives. Kin-like bonds are established between unrelated Haitian families who help to care for each other's children. Shared childcare, both in the US and in Haiti, is an important way in which Haitians reinforce their social ties.

The economic and social links that connect migrants to their home country are augmented by spiritual connections. While not all Haitians or Haitian immigrants maintain the practice of Vodou, it nevertheless is a fundamental component of Haitian 
culture. The cultural foundations of Vodou tie the migrant to the land of his ancestors. Vodou spiritual practices, traditionally found throughout rural Haiti, extend the network of "family" to those who gather for ceremonies and rituals, as well as to the ancestors. "In traditional rural Haiti, Vodou ceremonies draw together one's family, both immediate and extended, and help individuals cope with the experiences of growing up, becoming ill, getting cured, and eventually dying" (Stepick 1998:86). In the immigrant experience, Vodou rituals draw together a reconstituted spiritual family and provide an avenue for building new "family" ties (Brown 1991).

Vodou requires the maintenance of a family's connection with their ancestors. They must be remembered and "fed" (Brown 1991, Richman 2005). The graves of the ancestors, and sacred places important to the practice of Vodou, pull migrants to return to their villages. Migrants visiting Haiti to participate in Vodou rituals and celebrations maintain the web of transnationalism. Ritual goods for Vodou ceremonies are transported on trips from Haiti, maintaining ties to the homeland through other travelers (Brown 1991, Brown 1999, McAlister 1998). These spiritual ties reinforce the transnational web. Among Protestant converts, contributing to and participating in mission work in Haiti similarly sustains transnational connections.

Spiritual practices reinforce family cohesion through ritual duties and obligations, as well as by exerting a pull on the migrant to return to his homeland. A never-ending relationship with the ancestors connects family members. Family is central to Haitians, and it is key to their migration strategy and success. The flexible and expansive concept of the family allows Haitians to widely distribute social and economic resources. Family 
dynamics, including social, economic, and spiritual relationships extend across borders to create the transnational Haitian migrant family.

\section{A Migrant's Obligations}

Migration has become an important part of the economic strategy of Haitians. As migration to North America has become commonplace throughout Haiti, a culture of migration has taken hold and young people often have their sights set on a future outside of Haiti (Glick Schiller and Fouron 2001, Richman 2005). It is difficult to find adequate employment in Haiti, even for those with skills and education. Cheap imports have undermined the Haitian agricultural sector and nearly eliminated the demand for skilled trades such as shoe-making and tailoring (Richman 2005). Consequently, remittances from the United States have become a significant part of the Haitian economy and the wages of each migrant help to sustain many family members back home (Stepick 1998).

The selection of a migrant is a serious consideration that has financial repercussions for the whole family. During the 1970s and 1980s many families for whom migration to North America had not previously been possible or desirable began to make the journey and established a transnational presence (Richman 2005). The emergence of the kanntè, or sailboat, as a viable, albeit dangerous, method of travel from various areas of Haiti to the US or the Bahamas opened the possibility of migration to large numbers of Haitians.

Plans for migration are often family enterprises. The family selects the person most likely to be able to earn enough money to send for others. Family members pool resources to fund the travel of the migrant, selling some land or livestock if necessary. 
Social resources are important considerations in the plans for where the migrant should settle. Efforts are made to connect with any relative or family friend who could provide a place to stay or leads for finding work (Glick Schiller and Fouron 2001, Laguerre 1984, Stepick 1998).

The family plan might be for the migrant to send remittances for a period of time and then return home. But he or she is now more likely to be a link in a chain migration, responsible for establishing a place to live and earning the necessary money to send for the next family member. In this way, "family ties both promote and activate migration (Fjellman and Gladwin 1985:305)". The chain of Haitian migration is created from these extended family connections. Each migrant in turn paves the way for another. The migration chain may extend from Haiti to US and include other members in the Bahamas or in Canada (Fjellman and Gladwin 1985). Networks develop to provide support and assistance. The initial migrant will often pay the passage of the next family member chosen, providing a place to stay and helping to find employment. As more family members migrate they will assume responsibility for remittances, relieving the economic burden of the early migrant. By hosting new arrivals the immigrant earns a central place in the new network forming in the US (Laguerre 1984, Stepick 1998).

The obligation to help new migrants insures additional sources of remittances for relatives in Haiti. It extends the web of family and reinforces the migrant's position within it. Bringing new migrants into one's household forges strong ties and reciprocal obligations. Both the economic and moral dimensions of these expectations reinforce the transnational family ties that may extend across several countries. 
The Haitian family is a resource buttressed by a moral code. Glick Schiller and Fouron identified two of its essential components: "Those who have more are obligated to help those who have less" and "A person's humanity is defined by their acts of helping others" (Glick Schiller and Fouron 2001: 66). Helping others is an obligation, not a gift or a charitable act, in particular, in regard to family. Glick Schiller and Fouron argue that "family can be experienced as a series of 'debts' that must be paid and can be collected" (2001: 77). Further,

support from family members is an obligation. Indeed, the primary family value is obligation rather than love. This does not mean to say that there are no deep emotional bonds among Haitian family members. Rather, it is to observe that with or without love, there is obligation.

[Glick Schiller and Fouron 2001: 77]

A migrant is expected to send remittances to relatives remaining in Haiti. This is both an economic and moral obligation (Brown 1991, Glick Schiller and Fouron 2001, Richman 2005, Stepick 1998). To support one's family is the reason for migrating, and therefore, with this opportunity, a migrant must do all he or she can to alleviate the suffering of those left behind (Glick Schiller and Fouron 2001). Family and neighbors in Haiti will judge the migrant by the remittances he or she sends. But many Haitian immigrants earn low wages and must live very frugally to save the money expected at home. Despite the financial difficulty, Haitian immigrants almost universally send money and goods to Haiti (Brown 1991, Catanese 1999, Stepick 1998). The obligation exists regardless of the migrant's circumstances. Migrants are expected to work harder, if necessary, to support those who rely on their remittances (Glick Schiller and Fouron 2001). There is a strong moral responsibility for migrants to send generous remittances. 
Migration and the distribution of remittances affect power relations within a family; but these are not simply economic calculations, nor do such shifts go uncontested. Migrants fortify family connections with remittances and are rewarded with respect and status. But at the same time, social conventions aim to minimize the hierarchical nature of the exchange (Brown 1991, Glick Schiller and Fouron 2001, Richman 2005). Recipients may refuse to acknowledge or even denigrate the support they receive (Richman 2005). Or the migrants themselves may carefully frame their giving as goods accidently left behind or as payment for services such as minding a vacant house. In addition to social consequences, the threat of supernatural sanctions buttresses the moral imperative for generosity (Brown 1991, Richman 2005). Too much success may bring accusations that the gains were a product of sorcery or could provoke a curse as a result of jealousy.

While Haitian families see migration of at least some family members as a strategy for improving their economic circumstances, scholars do not always agree on the nature of the overall outcome. Two works, in particular, have illustrated the complexities of familial duties and obligations in the Haitian transnational context. Karen Richman's Migration and Vodou (2005) explores the social, economic, and spiritual dimensions of the impact large-scale migration has had on the village of Ti Rivyè she studied for two decades. At the center of her analysis was a Haitian migrant agricultural worker she met in Florida, nicknamed Little Caterpillar. She documents his very difficult life, both in terms of the economic challenges he faced as a migrant worker in the US and the social pressures of navigating his transnational obligations. In the end, Little Caterpillar dies convinced that, despite his efforts to be generous, his affliction was due to sorcery 
directed at him because of his material gains. Richman frames the transnational projects of the residents of her research site of Ti Rivyè as a largely futile effort:

[I]t's main activity seems to be producing low-cost labor for export, consuming migrants' wage remittances, and reabsorbing the migrant workers when they are spent (or deported). [2005: 120]

However, such transnational projects also account for Georges Fouron's journey from an apparent dead-end in Haiti to a successful professional career in the US, documented by Nina Glick Schiller and Fouron in Georges Woke Up Laughing (2001). Fouron's story demonstrates at every turn the necessity of familial resources to bring his individual aspirations and endeavors to fruition. In the process, he was incorporated into a wide web of obligations both to those who had helped him and to those who had less than he. These obligations have become extended and intergenerational, as the reciprocating generosity is often directed toward a child or other family member of the person to whom a debt is owed. As a result, he provides financial assistance to a wide range of family and others in Haiti and has been called upon to assist subsequent migrants to the US in a variety of ways. He feels the weight of their expectations as he tries to provide the best possible future for his own children in the US.

While these books provide substantial ethnographic detail of Haitian transnational families and the complexities of the duties and obligations they entail, neither explicitly sets out to analyze the role of these practices in the incorporation of immigrants into the US. Still, they make clear that belonging to a transnational social field has an impact on a migrant's incorporation into the United States. There are potential advantages in having received both economic and social remittances while still in Haiti and having family 
members to rely once in the US. But there are also substantial costs in belonging to a Haitian transnational family.

The research I present in this dissertation is intended to examine the transnational strategies and activities of Haitian families who have migrated to South Florida and to analyze how these have affected their incorporation into American society. Family members left behind when their relatives migrate often have lives shaped by their anticipation of a future in the US. While these separations may be painful, they also provide transnational spaces in which some families are able to benefit by accessing the different resources available in each country of residence. Not only do young people in Haiti put to use the social remittances from frontiering migrants as they imagine and strategize for their futures, but the remittance income they receive helps them to renegotiate the terms of their eventual incorporation to the US. In particular, remittances allow at least some of the children who grew up in Haiti while their parents or siblings worked in the US to achieve levels of education, or to enjoy a higher quality of education, that would otherwise have been unlikely or even impossible. Entering the US under these circumstances changes the terms of their incorporation and may produce more favorable outcomes than earlier migrants experienced.

In the next chapters I will present the migration experiences of families who contributed to this research. First, I will present the migration stories of the frontiering generation, the earliest migrants in each family. These migrants did not receive remittances prior to their migration and they came to the US without the benefit of already established family members to support and assist them. I will consider how these circumstances and the migrant's level of education affected his or her incorporation into 
South Florida. I will then turn to the "transnational generation," trailing migrants whose educations in Haiti were funded by remittances. Several distinct pathways of incorporation were found among these migrants, to be discussed in Chapter 7, Education and the Transnational Generation. The chapter contains three sections in which I present distinct incorporation pathways, focusing on the types of boundaries encountered in each. I will discuss the ways remittances affected the education that young people in Haiti achieved prior to migrating and how education affected their subsequent incorporation into the US. Tipa Tipa, will present the incorporation of adult migrants who made modest socioeconomic advances in the US after receiving remittances that supported their educations in Haiti. In the following chapter, Teen Transitions, I will discuss the particular challenges faced by young people who migrated as teenagers. The final chapter of this section, Crossing Boundaries to Higher Education, will discuss transnational pathways that led trailing migrants to completing college in the US. Following the chapters on transnational pathways to educational attainment, I will discuss the ways that resources and benefits were distributed within these Haitian transnational families and the function of the extended family in establishing security for individuals as they grow older in Chapter 8, Familial Relationships and Obligations. 


\section{CONFRONTING THE FRONTIER}

In a transnational family, whether the initial migrants go abroad for a temporary period of employment or schooling or they emigrate to settle permanently, the experiences of the "frontiering" migrants will likely be quite different than those of family members who follow (Bryceson and Vuorela 2002). As did the pioneers who settled the western frontiers of the United States, the first family members to establish residence in a new land travel into largely unknown territory with no established networks for support.

In this section I will profile several of the frontiering migrants I interviewed to understand Haitian migration as a transnational family process. I will discuss the level of education they arrived with, the boundaries to educational and occupational opportunity they experienced, and how that affected their incorporation into the United States. These individuals were among the first in their families to come to the United States. Most had a friend or relative in Florida whom they were able to contact before coming, but they had no relatives close enough or well enough established in the US to offer them financial support. These migrants arrived in the US with no English language skills and no familiarity with American culture. They came with the intention of providing financial support for parents, siblings, spouses, and children left behind in Haiti and dreams of a more secure and prosperous life.

I selected the stories of Carleton, Annelle, and Philomene because these stories capture experiences repeated frequently among the frontiering migrants I interviewed. Carleton and Annelle both came to South Florida in 1979, during the early years of what would become a large-scale migration of Haitians. Their stories reflect some of the 
gendered aspects of incorporation into the United States frequently reported by frontiering migrants. Philomeme came much later, in 1994. Nevertheless, she is a frontiering migrant because she was the first in her family to come to the US. I include her story to demonstrate the similarities and differences of frontiering migrants who came earlier and those who arrived after a substantial Haitian community had become established in South Florida. Through their stories, I examine the limits of their educational opportunities in Haiti and the impact of level of education on socioeconomic incorporation into the United States.

\section{Carleton}

Carleton came to Miami in 1979. At 34 years of age he had only a few years of primary education and no knowledge of English. He had struggled to learn in primary school and his father decided it was not worth it for him to continue. "In Haiti," he said, “your parents have to send you to school. If they don't send you, you can't go." Sending a child to school is an investment decision in the Haitian context. For most parents, even modest school fees represent a substantial portion of their incomes. Families often must sell assets such as property or livestock or seek contributions from relatives at the beginning of each school year. Haitian families tend to be large, so sometimes a decision must be made as to which child to invest in for education while the others are kept home.

Carleton worked as a driver in Haiti. He drove a bus and eventually saved enough money to buy a car. He made up a sign and went into business as a driver for hire. I wondered why he wanted to come to the US if he already had a car and a little business

of his own. "I wanted to change my situation. I sold the car to get money to leave for my 
family." When Carleton states that he wanted to "leave for my family" he expresses his deeply-felt obligation to provide financially for many family members. In Haiti, when a family member had a financial need, such as paying for school fees, they would make requests for contributions from various family members. Carleton had some assets and income-producing work, so he was expected to help pay for the schooling of nieces and nephews as well as to provide general support for the living expenses of his mother, his girlfriend, and her daughter.

Carleton felt that his situation in Haiti was not secure and the future was uncertain. He wanted to earn enough to marry his girlfriend and to support her and her young daughter, while helping his mom and siblings as well. A member of his extended family had recently come to Miami. Carleton wanted to join him.

Carleton explained that although he had one relative, a "cousin," who provided a place to stay, he had no one to help him at all to find a job, learn English, or anything else he needed to do. He was really all on his own and very lonely. He moved into a small apartment with his cousin and a number of other immigrants. The other men in the apartment would leave early for work— 6 or 6:30 in the morning — and then he was all alone, "No job, no food, no family."

"It wasn't like now," he explained. "Now you can find a Haitian person on every corner. 1979 not too many Haitian people in Miami and nobody to help you." To find a job he just went out to the street and asked a few men if they had any job for him. Sometimes he would get some work in construction. His first steady employment opportunity was a nighttime job with a company that was running cable lines. He used the jackhammer to break concrete. But after a couple of months the company moved to 
another state. They offered him a job if he wanted to relocate, but he told his boss he wanted to talk it over with his cousin. His cousin told him it was a bad idea: "No, you have no family there." Even though his cousin provided very little support, it was unthinkable to go somewhere where he would have no family connection at all. So he told his boss no, and after the company moved he had no job again.

He was next able to get work in construction, at first in labor positions that required no special skills, earning $\$ 3.50 / \mathrm{hr}$. But as he learned on the job, he became the best on the work crew and was given more responsibility. He issued tools and equipment to the workers, maintaining the logs where they signed tools out and checked them back in. His pay went up to $\$ 4.50 /$ hour. Eventually he went to work for another construction company. He was very hard-working and enthusiastic about his work. "I always rush to work." He became a foreman and supervised the work crew. Carleton's employment history demonstrates the differences that even a modest education like his could make. He had the reading and writing ability necessary to keep simple logs, which exceeded the abilities of some of the workers he supervised. His bosses were English-speakers, and Carleton had absorbed enough English to handle the necessary business communications with them. He tried some English classes but found it too hard and quit. His limited education made him feel very uncomfortable in the classroom setting. Carleton had internalized his father's assessment that he was not bright enough for more schooling. But the workers he supervised were Haitian, as well, so his language skills did not prevent him from rising to a minor supervisory position.

Even though he didn't earn much money when he first came to the US, Carleton found that it was not too hard to send some back to Haiti. He lived very simply, and 
"things don't cost too much then; not like today." He explained that he only spent about \$20-\$25 a week for food. He would pay somebody and they would cook for him. “Because I'm a man; I can't make my own food." He remembers, "Twenty-five cents for a soda, $\$ 4$ or $\$ 5$ for a whole case of bananas, $\$ 50-\$ 75$ a month for a room. You could rent an apartment for $\$ 450$ and share with 5 people. Even electric bill, maybe $\$ 8$ or $\$ 10$ per month." He said he would earn about $\$ 140$ per week and could send $\$ 40$ of that to Haiti. Because of the cost differences between the US and Haiti, this was a substantial remittance. The primary recipients of Carleton's remittances were his mother, his girlfriend, and his older brother, who was tasked with receiving the money and distributing the remainder to Carleton's siblings and others he might designate.

Despite his satisfaction with his economic progress, he made clear that confronting the frontier of a new culture without family support was very difficult. He described his life when he arrived in the US:

First, I was very sad. You don't understand nothing. Sometimes you say, 'Wow, why did I come here?' You have no mom or brother or nobody to help you. You sleep on the sofa bed. You can't sleep until everybody else goes to bed. Last one to take shower. No food for you.

He became quite emotional at this memory. His wife smiled and shook her head, suggesting that he was being overly dramatic. He responded, "When people come with family they have everything for free." He explained how different life was for trailing migrants in comparison to the difficulties faced by the first in a family to come to the US. People who came later had a place to stay, food in the refrigerator, someone to cook their meals. They would be able to go to school or take English classes to get a better job. He 
had nobody and no help. But that actually motivated him when he was able to find work. “That's why you want to work very hard. To get something for my life."

He turned back to his wife, "That's why you don't have a bad situation. Because you had somebody make opening for you." He continued to tell us about how difficult his first weeks in the US had been. "For 3 months I eat only banana and bread. Maybe I got some piece of cheese I put inside my bread." These were things he could pick up from the store on the corner when he came home from work. But being without family put him in a very marginal position. He explained that the person who rented the apartment would have the bedroom and that was for his family. Then maybe some other family member would rent the second bedroom. But Carleton, who was just an unrelated renter, had no place to call his own. He could not go to sleep until everyone else had retired to the bedrooms and he could finally pull out the sofa bed. Then in the morning he closed up the bed and there was no space that was his alone. When he came home from work-long, hot days of construction - he had to wait until last to take his shower. He never felt comfortable and at home. It was the experience of being alone in this new frontier that affected him the most. For Carleton, this was just not a normal way to live.

Having been raised in a culture characterized by dense social ties and familial reciprocity, frontiering migrants had no comprehension of what it would be like to be alone in a new country. In Haiti a person's most valuable assets were family and friends. These migrants had lost all of the benefits of their social networks while they felt their obligations more intensely than ever. Without the support and protection of family, frontiering migrants often found themselves in situations that ranged from uncomfortable to humiliating or even dangerous. 


\section{Annelle}

Annelle was adopted as a small child into a Haitian missionary family. She was able to complete her primary schooling, but it was quite difficult. She walked long distances to school and without electricity it was hard to study in the evening. Still, she was unhappy when she could not continue into middle school "I feel ashamed. I feel sad when I saw my friends go, but I can't." Her adoptive parents had many children to support on an income that depended on donations from church members.

Annelle moved to the capital, where some relatives were living, and worked for a time in a sewing factory. After she married and had a daughter, an uncle gave her some money to get a passport. She began to travel back and forth to different islands, buying and re-selling clothes and other merchandise. She was able to pull together the money for each trip from various relatives and would repay them when she sold her goods. She was eventually able to get a visa to travel to the US.

When I'm coming, I'm coming for one week, for two weeks, but I buy, go to everywhere, Hialeah, downtown Miami, and I buy something, shoes and sneakers, pants, clothes, and I buy some things to resell. [After several trips to the US] I decide to stay here definitely.

Like Carleton, Annelle had the difficult experience of confronting the new

frontier alone. She came to Miami in 1979 with no advance preparation and no family or friends to welcome her. Haitian immigrants often expect that life in the US will be easy because of the abundance of consumer goods, food, and modern technologies. They are not aware of the cost of living in this land of plenty, and they are used to relying on the support of extended family and friends. Annelle came to the US completely unprepared for the financial realities of beginning a life alone in a new country. 
When I decide to stay here I don't have any money. When I come here, always I remember I have my clothes. I went to the [travel] agency, my agency friendly for so many years when I travel. I buy ticket all the time. And I ask them, 'I'm going to buy a ticket and I'm not going to come back. I'm gonna send the ticket, the half ticket back and to reimburse me the money because I don't have any money to leave for my daughter.

And when I decided to stay here definitely, I come here with twenty dollars. Twenty dollars. Twenty dollars and ten cents, nickel, twenty five cents. My uncle give it to me. And I have clothes I put in the suitcase, that's it and I come here.

But when I come here, it was very hard for me. It was very hard for me. I do something I'm not supposed to do. I do something because my situation. When I came here I don't have any place to live. And I find a guy, he like me, so I take him. I take him. But I know I do something I'm not supposed to do. And I take him almost after a year, I'm pregnant. I got baby, and he support me. And when [my son] is born, the money ends. At that time, after that God start to punish me. I pay the price. I pay the price, I pay. Always I feel guilty.

Alone in Miami, Annelle felt that she had to move in with a man she had met to establish some security for herself in the new country. She is ashamed, feeling that she set aside her values in order to gain some economic stability. For women who came to the United States alone, finding a man to live with was often the first step toward building a "family" in the new country. Norms of Haitian social relations require that a man provide economically for a woman in exchange for housekeeping and her sexual fidelity. Most Haitian man, as Carleton mentioned in the previous section, rely on women for food preparation. Among frontiering migrants gender roles are disrupted. In Haiti, a man can eat at the house of his mother, sisters, wife, or girlfriend. Haitian men alone in the United States may pay to eat in a someone's home, take meals with a girlfriend, or take a "wife" (sometimes even if he has a wife back in Haiti). 
Annelle wished that she could take English classes and continue her education, but she needed to work as many hours as she could to earn money to support her family back in Haiti. Annelle's story demonstrates the limits that low levels of education put on Haitian immigrants to the US.

It was still hard for me. When I come, I'm not able to go to school. I like to go to school, but I leave my parents in Haiti, I leave my daughter in Haiti, and I don't have any good education, but I start to work full time, part time, three dollars fifty. When I came my first job is three dollars fifty, in Miami. Sewing in the factory. I loved that because when I was in Haiti I worked in the factory and I sewing on all kind of machine. I know [how to do that]. But three dollars fifty to take care of yourself, to take care of parents in Haiti, no way for me to go to school. That's why I keep working.

Despite her very limited academic foundations, Annelle was eventually able to advance from the factory job by completing a vocational training course. Her poor English skills made her hesitant to try, but encouraged by a friend, she enrolled in and managed to complete a training program for nursing assistants.

I got my friend call me he say got a school open for nursing assistant. "Are you able to go?" I say, "I'm not speak English. Why do you want me to go to school? What I'm gonna do? What I'm gonna learn? What I'm gonna say?" I don't want to go because I'm not speaking English. I'm not listen, I'm not hear, I'm not ... What you want me to do? Just pay my money for nothing? He said to me "Let's go. I tell you, let's go."

I know my English always not good. I'm try, read newspaper, watch $T V$, but I'm not learn. The teacher talked to everybody in the class, and when she talked to me I said nothing. She called me Mrs. Nothing! (Laughs) But I know, I read. I read. If I read something I decide the answer to the question. But it's hard for me to answer you when you say something to me. It's too fast. 
And when I go, after three and a half months I'm graduate. (Laughs) Yes! I got my nursing assistant diploma, certificate. And I'm start to work six dollars. Six or six fifty. I went to the agency, I start to work. And after I go to the nursing home for six dollars. Six, six fifty. At this time it's overtime. At this time you find people give you private jobs. They pay you ten dollars an hour for the private. But not now. Now the things is different. It's not easy. Take care of the kids to go to school, to work full time or two jobs, is not easy.

I have a nursing assistant course, but I would like to do more. I would like to do more but now I can't keep too much in my mind. I like to have a better job. I work at [an adult care facility]. And now I do activities with the dementia people. That's a tough and hard job. It's not easy. Five days a week you sitting with those people, screaming, refuse to sit down, spitting on you, curse you out. But I love them. I have to do it. Thanks God I have patience. Oh yes, I pray God please give me more patience.

Taking home less than $\$ 300$ per week, Annelle has cared for elderly patients in South Florida for the last 30 years. She has learned quite a bit of English, but other than the nursing assistant training she struggled through years ago she has not been able to advance from the elementary education she completed in Haiti. The desire to do so hasn't left her, however. She continues to think about trying an adult education course of some kind.

\section{Philomene}

Many frontiering migrants, like Annelle and Carleton, arrived in South Florida in the 1970s or early 1980s, as conditions in Haiti worsened under Jean Claude "Baby Doc" Duvalier. After Jean Bertrand Aristide, Haiti's first democratically elected President, was deposed in a 1991 coup, migration to the US surged again. During the subsequent period of political violence and economic conditions that dramatically worsened as the US and the international community increased sanctions against the military regime, many more families sought to establish a frontiering migrant abroad. Philomeme arrived in the US in 
1994. Her story illustrates both similarities to the experiences of earlier fromtiering migrants and differences due to the presence of a more established Haitian community in South Florida. Philomene grew up in Cap Haitian, the second largest city in Haiti, located along the country's northern coast. She was the youngest of eight children, living with her mother who supported them as well as she could by cooking and selling food. Her father contributed little to the family by the time she was growing up. "My dad wasn't there; he didn't live in the same house."

As the frontiering migrant of her family, Philomene did not receive remittances for her education as a child in Haiti. She and her siblings all attended school at some point, but none were able to continue on to secondary school. They were enrolled sporadically, depending on how much money was available each semester. Some of the boys ended up with very few years of education; but even though they were not attending school, they were not able to find work to help keep the other children enrolled.

I went to elementary and like middle school. [My school] was big. It had all classes, same like the school down the street. It was a public school, because we didn't have a lot of money to pay. In Haiti there's a lot of private schools, but if you don't have good money you can't go.

Some [of my siblings] went and some didn't. The oldest, they went to school. But some went and then they left the school so quick. Sometimes there was no money. Even for public school you need to pay, you need to pay. But you don't pay the same as private school. My sister stayed in school longer. But my brothers left school early. Another one stayed but another one left. When some grew up they helped [the family financially], but not when they were young. No. There was no work.

Philomene came to Miami in 1994 when she was 20 years old. She was married with a young son. With less than six years of schooling and no employment prospects in Haiti she hoped that she could do more for herself and her family abroad. 
1994. Yes, there was a lot of trouble in Haiti then. Aristide. There was trouble. That's why I came then. I wasn't thinking about [coming to the US] when I was little. But when I was older my brother found someone to buy a visa for me. He has someone he was close to, some friend, he gave him some money to come to here. He didn't send me just to go and help [the family], but you need to help. You have to find a good job. You have to change.

Coming in the 1990s, after so many other Haitians had already migrated to South Florida, Philomene was able to make arrangements to stay with a family she had known slightly in Haiti. She came with her son, leaving her husband behind.

Before I came I called some friends. I told them I was coming because I got a visa and I told them to come get me at the airport. When I was in Haiti, these people came to my house. They came to visit when they went to Haiti. They came to my house and they were very nice.

The daughter she was very nice when she was in Haiti. But when I came here, whooo, she was no good! She was no good. She told me, "When you're coming to America for the first time, even if you have a husband, you need to get a boyfriend. I have a boyfriend for you." I said, "Me?" I said, "What?" I said, "That's my boyfriend over there (indicating her son). Don't play with me! I don't play with trash like that." I see this man, he came and sat down. She said "That's the man I got for you." I said, "Don't play with me like that. I'm a Christian. Don't play with me." I stayed for two weeks and then I left there. I couldn't eat. I didn't know what to feel because it's the first time that I came [to another country]. I prayed, I pray, pray, God help me. Even if these people were good, I don't know why you have to do this to me in this house. I cried and cried. So that's why I say when you first come here, it's not easy. It was very hard.

Women who came to the US alone, even if they were married, were often subject to an expectation that they would exchange sex for housing or protection. Sometimes this led to a love relationship and cohabitation or marriage, but others simply expected a sexual "payment." Philomene encountered this expectation when she accepted the offer of a room with a family she had met in Haiti. The woman who offered her a place to stay when she first arrived expected Philomene to "take a boyfriend," and establish a sexual 
relationship with a man who would reciprocate with money or material goods for the household.

Philomene was miserable during her first few months in the United States. But she was able to improve her living conditions more rapidly than the frontiering migrants who had come prior to 1980 . She made contact with other immigrants who had come from her hometown in Haiti and was able to rent a room in another home after a few weeks. A Haitian community was already established in South Florida that provided job referrals and information and advice about life in the US. Through these contacts she pursued and received a legal grant of asylum.

Philomene arrived in 1994 and, despite President Clinton's determination to continue the repatriation of Haitians, she was granted asylum in a hearing in Miami and was able to bring her husband to join her a short time later. Once her husband was with her, even though she earned only $\$ 3.50 /$ hour (which was below the federal mimimum wage) and he earned just a little more in his factory job, they were able to rent a room and then after a few months they were able to rent half of a duplex and settle into a more comfortable life. Philomene uses the history of her housing situation to illustrate the trajectory of her socioeconomic status in the US.

When I first came, I stayed [with the family I knew] for two weeks. After that, I didn't really like this place to live, so I found a place with [someone else I knew]. I stayed for one month. After that, my husband found a job and I rented a room. I moved. After that, I got a duplex. I lived over there with two rooms. After that, when I was pregnant with my daughter, I rented a house. After that, I bought this house.

Philomene's migration experience began in very small and unsatisfactory rooms in the homes of acquaintances where she was uncomfortable and unhappy. But as she 
worked and saved and was able to bring her husband to contribute to supporting the family, she transitioned to housing over which she had more control. Eventually she was able to achieve greater security for her family by buying her own house. Of all the things we discussed in the interview, this seemed to be the most important to her. Buying a home was her American dream. Having a home of her own also allowed her to begin to bring some of her older nieces and nephews to the US, as well.

It's been good for me to come here. Because I didn't have any work in Haiti. Even sometimes people in Haiti they finish all their school and they never find a job. They just sit around the family gives them food. Being able to have a job; that's what is good here.

She is not so sure she should have brought her son with her, though. He benefitted from access to free public schools, but they lived in poor neighborhoods where she feels he was influenced by friends who were getting into trouble.

For a long time it was better if you left your kids in Haiti. If you left them there and you would send money. Send your kids to school. Yeah, that's better. There's good control. But anyway I tell God thank you. But you know my oldest son, if I knew the situation would be like that, I would have left him in Haiti. Even though he has a job now, and everything is good, it was not good to bring him here. I even tell him, if I knew things would turn out like that I would have left you in Haiti. That makes him mad. He says, "You would leave me in Haiti? In that country where people would kill me? That's what you said?" I tell him "Yes, you have to be good. You can't behave like that."

A long time ago when I lived in Haiti, you couldn't do whatever you want. But Haiti changed now, they like here. If you have kids now, you're not going to send them to Haiti now. Because in all countries ... [she motions with her hands to show that there are problems everywhere]. 
It is a difficult choice whether to bring young children to the US or to leave them behind. Philomene's son, Wisner, insists that he got into trouble and did not finish school because his father moved out and did not support him as he grew older.

That's why I'm like that. I get depressed. I don't have a dad to help me. I get depressed. Everybody has a dad to talk to or go somewhere. I don't have anyone.

Currently her two teen-aged daughters are doing well in school. However, they are attending schools with poor records of academic achievement. Her youngest son, still in elementary school, has struggled ever since kindergarten to perform at grade level, particularly in reading and language arts.

Their situation exemplifies the debate over the incorporation outcomes of the children of Haitian immigrants. By American standards, Wisner's failure to graduate from high school is not viewed as part of a trajectory of upward mobility. Yet, without his mother's migration he would likely have shared her experience of leaving school in Haiti well before achieving a high school education. Instead, he completed eleven years of schooling, reads, writes, and speaks effectively in English, and currently works at a full time job. He has moved to the midwest where he joined his cousin doing semi-skilled labor in agriculture. His hourly earnings are more than double those of his parents.

Philomene's siblings all remain in Haiti, but her migration has brought about a substantial improvement to their condition. All her nieces and nephews have been able to stay in school and expect to complete high school. Three of her sister's children have followed Philomene to the US where they now work and also contribute to the needs of 
the family in Haiti. With the help of remittances, her sister has been able to buy a house in Cap Haitian and now runs a small store from it.

Every year I'm supposed to send money for the kids' school. The kids can get a better education when I send money. They can finish high school. They don't have to leave school and go look for some work. My sister, she has a big house. She has a shop in her house because her kids send money. And I send some. She got a big, big house over there.

Philomene's adjustment was easier than Carleton's for two reasons: first, because she was able to gain a legal status that allowed her to bring her husband to the US and for both of them to work legally. In addition, the fact that a Haitian community was already established in South Florida gave her ready access to job referrals and information and advice about life in the US. People advised her of the process of applying for asylum and helped her to contact someone to advocate for her and to facilitate the process. She was immediately hired onto a restaurant cleaning crew, a job she didn't like but one that provided the soup she relied on for subsistence in her first few weeks in the US. With her modest education, cleaning is the only kind of work Philomena has done in the United States. But she feels content now and has held her current job for many years. She likes it because the work is very steady. When business is slow they don't cut back her hours and when things are good she is able to get overtime. She gets up at 4:30 each morning to attend a prayer service before she begins her workday, and she returns home at 4:30 in the afternoon. Like many other Haitian migrants, Philomene works in the mainstream American economy but in a niche that is often dominated by immigrants of providing services to people of a higher socioeconomic status. 
When frontiering migrants tell their stories, they emphasize their lack of English and limited education as boundaries to economic opportunity in the United States. They do not generally seek social incorporation outside of the Haitian community. The symbolic boundary they felt most strongly was that of "family" vs. "outsider." A family member had to be met with generous support but someone who was not family was not entitled to that support and could even be taking advantage of or mistreated. For Philomene, being able to obtain legal residency status and bring her husband to the United States meant she could improve her material circumstances substantially, even though she was only able to obtain low-paid janitorial work. Consolidating family allowed her to achieve more security and to begin to work toward owning a home. Carleton also made constituting a family in the United States a top priority. He described his determination to get his wife to the United States. Crossing boundaries of legal status allowed many frontiering migrants to bring spouses or other family members to the United States and to create much greater security for themselves.

The frontiering migrants had come to the United States because they perceived the boundaries to socioeconomic mobility to be more permeable in the US than in Haiti. In Haiti, even if one had education, to get a job he or she had to "know somebody." Social relationships were necessary to cross boundaries to employment. In the US, Haitian immigrants also utilized social relationships, when possible, to find jobs, but they did not feel that employment opportunities were bounded in the same ways.

In addition to earning money to send to Haiti, frontiering migrants sought opportunities to bring family members to the United States. The early migrants were able to regularize their status in the US after the Cuban-Haitian Adjustment Act or the 
Immigration Reform and Control Act of 1986 (IRCA). Frontiering migrants who came in the 1990s sought opportunities to apply for asylum. When they were able to apply for family reunification visas they saw an opportunity to make progress - as a family - in the United States. Frontiering migrants were generally unable to advance much in terms of education, occupation, or income, themselves. But as they brought additional family members to the US they strategized to move trailing migrants into a position that would offer better opportunities. These strategies included investments in education in both the US and Haiti. By doing this, they not only increased the financial resources of the family for use both in the US and in Haiti, but they began to seek upward social mobility, as well.

Frontiering Haitian migrants typically enter the US with few social or economic resources and have tremendous responsibilities to provide for family members in Haiti. They provide vital financial resources to support family members who remain in Haiti. Frontiering migrants create more advantageous conditions for the trailing migrants who follow them when they provide remittances that allow for higher levels of education, information about life in the US, mobility resources to facilitate the migration of other family members (such as funds for travel or family-based visas), and support for them when they arrive.

The frontiering migrants discussed in this chapter fit the characterizations of labor migrants, having low levels of education or occupational training. Among Haitians, however, they would not be considered to be particularly poorly educated, as most of them read and write, albeit at a very basic level. It is often because they have some education that they were encouraged by their families to seek work abroad. Conditions in 
Haiti simply provided them very few opportunities for employment, and their obligations to contribute to the family welfare motivated their migrations to the US.

By taking a transnational perspective, we can understand the implications for immigrant incorporation differently. Frontiering migrants began to send money to family members in Haiti as soon as possible. They sought out ways to bring others to create more favorable conditions for themselves and to generate more financial resources for the family in Haiti. Like Philomene, many migrants measured their progress by their housing, moving up from a crowded house or apartment where they had no security, to renting their own apartment or house. As they did so, their incorporation into the United States became more comfortable and secure.

Frontiering migrants tended to remain in low-skilled, menial jobs. They limited their interactions outside of the Haitian community, lacking confidence in their ability to speak English. Nevertheless, the remittances they sent to family members in Haiti helped others to overcome obstacles to education. They set the stage for more highly educated trailing migrants have a more favorable incorporation into the United States. In the next chapter I discuss the role of age at migration and education in defining generation in the children of immigrants literature. I introduce the concept of the "transnational generation" of trailing migrants who were educated transnationally. In addition, the chapter will include background on education in Haiti to provide a foundation for my research on the transnational educations of Haitian immigrants to be presented in subsequent chapters. 


\section{EDUCATION and the TRANSNATIONAL GENERATION}

The concept of generation has been important in the immigration and assimilation literature and theory. Assimilation has been understood as a process that occurs over generations. The immigrant, or "first generation," has the difficult task of learning a new culture and incorporating to the extent they can into a new society. First generation immigrants are unlikely to fully assimilate; however, they are generally conceived of as being highly motivated to endure the challenges of incorporating into a new country in order to secure a better future for their children. The children of these immigrants who are born in the new country are considered to be the "second generation." Ruben Rumbaut (2004) identified the substantial difference in the assimilation process for immigrants who come to the new country as young children and, therefore, experience early acculturation through schooling and growing up among children in the new country. This group of immigrants who come to the new country before the age of 12 has been referred to as the 1.5 generation. Rumbaut has further argued that a more fine-grained analysis detects substantial differences among children coming during different phases of development. In particular, he details the different phases of education and language acquisition that affect immigrants of different ages: 1.75 generation who migrate at an early enough age to begin their schooling in the new country, have not yet learned to read and write in the homeland, and are able to acquire the language of the new country with virtually no "foreign" accent; 1.5 generation who arrive from ages 6-12, who began their education in another country but who spend substantial portions of their youth in US schools; 1.25 generation who begin their US education in secondary schools or may enter the workforce without further schooling in the new country. Oropesa and Landale (1997) 
found significant differences among the "decimal' generations in a study of English proficiency among Latino immigrants. Rumbaut empirically tested the effect of these generational subsets on the educational attainment of immigrants aged 25-39 using CPS data from 1998-2000 (Rumbaut 2004: 1186). Among low socioeconomic status immigrants, the 1.0 generation and 1.25 generations had low rates of high school completion ( $49 \%$ and $59 \%$, respectively) and college graduation ( $9 \%$ of each cohort). Seventy six percent of the 1.75 cohort graduated from high school and $15 \%$ earned a college degree. Among the 1.75 generation, $85 \%$ were high school graduates and $24 \%$ graduated from college. These results demonstrate a distinct disadvantage among immigrants who arrived in their teens or later.

In my analysis of the transnational generation, I begin with this understanding that the age of migration has a profound effect on the incorporation of immigrants, particularly when educational attainment is used as a measure of incorporation outcome. But I argue that we must consider, further, how family migration has affected the educational opportunities of later migrants. In a broad fashion, the placement of migration within the historic pattern of immigration from a particular country—such as whether a migrant came during the exodus of relatively privileged Haitians during the dictatorship of "Papa Doc" Duvalier or from the flight of the economically struggling Haitians that began in the mid-1970s-is well-established as historical "waves" of migration that are important to the analysis of the incorporation of a national-origin group.

This research demonstrates that it is not only the age of a migrant and, therefore, the point in their educational development that affects their incorporation outcomes, but 
that the content and quality of the education that young immigrants arrive with profoundly affects their ability to make academic progress in the new country. The impact of family members having already migrated affects the educational foundations of later migrants because in Haiti (and many countries from which the contemporary flow of migrants to the US come): 1) money remitted to family left behind is used for education, and 2) education systems are such that ability to pay for schooling makes a substantive difference in the ability of students to attend school or the quality of school they attend.

\section{The Difference Remittances Make - Education in Haiti}

Although Haitian leaders have asserted the importance of education since the country declared its independence, the reality has been that education in Haiti has been a scarce resource with access limited by area of residence and ability to pay. As a social and symbolic boundary, education plays a powerful role in perpetuating the country's social divisions. With a privileged elite controlling much of the country's wealth and a small middle class, the majority of Haitians struggle economically. According to the World Bank, 80\% of Haitians live in poverty, defined as less than \$2 US per day, and more than half of the population suffers extreme poverty, which is less than \$1 US per day ${ }^{12}$. For these families opportunities for education is seen as a pathway out of poverty, but access to schooling remains limited.

\footnotetext{
${ }^{12} \mathrm{http} / / / \mathrm{www} . w o r l d b a n k . o r g / e n /$ country/haiti/overview
} 
The 1987 Haitian Constitution declared that

Education is the responsibility of the state and its territorial divisions. They must make schooling available to all, free of charge, and ensure that public and private sector teachers are properly trained. [Hadjadj 2000]

Primary schooling is compulsory; however no mechanisms to ensure this have ever been implemented in Haiti. The government of Haiti has declared its intentions to educate all students, however in reality it falls far short of this goal. Few students have access to low cost public schooling, which has the capacity to serve only about $10 \%$ of Haiti's school-age population (Salmi 2000). State run schools are limited and cannot begin to handle the task of educating every Haitian child (Hadjadj 2000). Private schools have come to fill this void.

As Frida noted to begin our first conversation, Haiti has some very good schools. Because of the stereotype frequently held by Americans of Haiti as a backward country of illiterates, contributors often took pains to note that excellent schools do exist in Haiti. Frida emphasized that "Haitians are very smart people," and that it was possible to have a high quality education in Haiti. But she continued on to explain that access to these fine schools is limited to those who either have money or social connections.

We have good schools in Haiti. We have good schools, college, university, like here [the US], but they're very expensive. Very expensive. It's not easy like here, after you graduate you just go to a college, just like that. You have to have money. In Haiti, to learn something, oh Lord, it's very difficult if you don't have money. Very, very, very, very difficult. Like nursing, they have free nursing school in Haiti - it's not free but you don't pay a lot of money - but you have to have somebody close to you in that position. You have to have a friend, a brother, someone like that so you can get in. You have to have a friend. You need connections. 
The boundaries to good schools, according to Frida, can only be crossed with financial or social capital. Furthermore, she feels that the process for admission into Haiti's schools is one of the ways that the educated elite of the country takes advantage of the Haitian people.

For example, in Haiti if they need 300 students for the school, they collect 3000 students and all of them paid to apply. And they need only 300. You see? They get the money from all of the students, they take their money and they know they need only 300 !

As Laurent explained to me, there is simply not enough public schooling in Haiti to accommodate the needs of the population. So while in theory schooling is free, most students must rely on private schools.

In Haiti school is tuition free ... Unfortunately there are not enough state schools, the schools run by the government. And for that reason the private schools have taken over. And if you want to go to school at all, you have either to stay on a list - and it was very difficult since the demand is high and the offer is low, so people for this reason had to go to private schools. So private school is not a luxury in Haiti as it is here. If you have to have an education, the choice is not great. You don't have a lot of choice, much choice to go to a state run school.

[If you can't go to private school], you might not be able to get an education. That's the downside of the situation. But theoretically it's tuition free. So that's the reality. Sometimes you pay if you want to go to a private school. There, the access is easier than the public schools.

Although public schooling is free in theory, students are required to pay for uniforms, books and materials, and other school fees. Even small fees put schooling beyond the means of many Haitian families. There has been an expansion of public schooling for primary education in recent decades, but the quality is not perceived to be good. 
Raphaella contrasts the public schools of her neighborhood in Port-au-Prince to the private school she attended.

In Haiti the public school is just open for the poor people. They do have some expenses, like you have to buy uniforms, stuff like that. Probably $\$ 40$ every trimester, 40 Haitian dollars [200 Haitian gourdes, approx. $\$ 4$ - \$5 USD]. On the contrary, for my [private] school, my secondary school, I have to pay US money to get in. So the public school is not like this country's public school, how people would be so proud to say I go to the school. In Haiti, some students who go to public school, they would not feel good to say that they go to public school. Some of them hide it. Because public school is like, you see students, like, there would be ashy, they would usually be kids who live in people's house as maids, and then they would go to public school at night. Or delinquent kids.

Most Haitians have little chance of attending the good schools that do exist in Haiti. Boundaries to education in Haiti reproduce the inequities in Haitian society. Sharp class divisions are reinforced by the availability of high quality schooling to families who can pay or who have social connections to the elite stratum of the population.

But money is not the only thing that puts school out of reach for many Haitian children. In the countryside, schools are widely dispersed and students walk long distances to attend. In this way, schooling also serves to reinforce the boundaries between Haitians of the countryside and the cities. Rural origins and lack of education are conflated in the symbolic representations of the Haitian peasantry. In the past few decades it has become more common for a child to be sent to stay with a relative who lives nearer to the city in order to send him or her to school. Children may also be sent to live with an urban family where they will work as household servants in the hope that they will be sent to school with the other children of the household. But these children 
carry the stigma of their rural and impoverished origins, as was evident in Raphaella's statement above.

For children who live far from schools, the burden of a long walk of two to three hours each day reduces the chances that they will complete their schooling. When poverty, illness, and malnutrition are factored in, the pursuit of education in the countryside often becomes too great. While primary school enrollment reached $74 \%$ in Port-au-Prince in 1982, when many of the frontiering migrants were arriving in Florida, it was only at $32 \%$ in the Haitian countryside (Haggerty 1989). Likewise, dropout rates, which were high throughout the country (over 50\%), were much worse in rural areas where $80 \%$ of students stopped attending school before completing six years of primary education. Because school attendance is often sporadic in the countryside and the quality of schools may be poor, students frequently repeat grades. The combined effects of dropouts and repetition results in the majority of rural primary school students attending grades 1 or 2, with less than half combined in the higher four grade levels (Haggerty 1989). The majority will not stay in school through all six levels. In fact, fewer than half of the schools in rural Haiti offer a full six-year primary education (Hajadj 2000)).The average student completes less than four years of schooling.

Enrollments in primary education in Haiti made significant strides in the 1980s and continued to grow through the 1990s. Much of the increase in student enrollment has been due to the expansion of private schools, which accounted for $92 \%$ of new enrollments (Hadjadj 2000). Private institutions enroll $80 \%$ of students, and the Haitian government exercises no oversight over most of these schools. In 2003 only $8 \%$ of Haiti's private schools operated with government certification (Demembynes, et al. 
2010). Schools vary widely in quality. There are well-established institutions, including religious and non-sectarian schools that provide a rigorous curriculum. On the other hand, much of the growth in private schooling has been from institutions opened by entrepreneurs and run for profit with untrained teachers and sparse materials (Wolffe 2008). Protestant schools predominate, educating more than half of all students (Hadjadj 2000). This expansion of schools coincides with an exponential increase in remittance dollars from abroad, much of which is allocated towards education.

The post-1970 wave of Haitian migration to the United States ushered in an exponential increase in remittances sent back to Haiti. In 1971, the World Bank estimated that Haitians received about $\$ 18$ million in remittances. As the influx of Haitians to the US grew, remittances rapidly increased, topping $\$ 100$ million by 1980 . By 2000 , remittances exceeded $\$ 500$ million and currently top $\$ 1$ billion annually (Orozco 2006:6).

More than half of Haiti's population lives on less than $\$ 1$ per day, and those in rural areas (2/3 of the population) are most likely to be extremely poor. (Sletten and Egset 2004). Remittances are a vital source of income in rural Haitian communities. While food is the primary use of the funds, $74 \%$ report using the money for education, making this the second most common use of remittances (Orozco 2006). More than half of the households receiving remittances have no other source of income, and the primary recipients are the children of immigrants. Orozco (2006) estimates that a quarter of remittance dollars are spent on education. Those who receive remittances not only have more access to schooling, but they also are more likely to be able to receive adequate nutrition and medical care, and thus can ameliorate some of the obstacles to academic persistence. The Inter-American Development Bank Haiti Remittance Survey 2007 found 
that Haitians who received remittances from abroad were much more likely to have completed high school than their peers who did not.

It is a matter of course among Haitian families in the US that they will begin to receive requests to cover educational expenses as the beginning of the school term approaches. In my research of Haitian immigrant families, each family reported that having a family member abroad made a critical difference in the ability of the children and youths to persist in school or to access higher quality schooling.

The remainder of this chapter is divided into three sections throughout which I will examine the educational and occupational trajectories of the transnational generation of the contributing families. This group of immigrants remained in Haiti as part of a transnational family in which at least one relative had migrated to South Florida. I will consider how this transnational relationship affected the educational attainment of these individuals and what impact it had on their own expectations for the future. I discuss the ways that the education in Haiti of young people who would later migrate to the US themselves was affected by the remittances they received from family members. I will then discuss how the incorporation of these Haitian immigrants was affected by the level and quality of education they were able to receive in Haiti prior to migrating to the US. In sum, in this section I analyze how the experiences of the transnational generation affected their subsequent incorporation into the United States, considering what educational and occupational opportunities they had and how they differed from those of the frontiering migrants.

In the next section I will examine some of the stories of the family members of frontiering migrants whose educations benefitted from remittances. All of these cases 
involve substantial periods of family separation. While some of the frontiering migrants were able to secure a legal and financial status that allowed them to visit Haiti and return to the US or to bring their children to Florida for occasional visits, many others did not have the freedom to travel. They were often separated from children, siblings, and other family members in Haiti for a decade or longer. But the children who stayed in Haiti and received remittances, whether they saw their parents or not, were able to attend school more consistently and in higher quality institutions than they would have been able to otherwise.

The parents of the transnational generation migrants I will discuss in this chapter had no more than a few years of schooling themselves. Providing for the educational expenses of children or siblings and increasing their academic opportunities was a primary reason for migration to the United States. I will discuss the ways that family separation and remittances affected the educations of children left in Haiti and how these transnational relationships contributed to their potential for upward mobility. I will also discuss the ways that the migration experiences of the transnational generation differed from those of their frontiering parents who had struggled when they arrived in the United States with no family to support them. The transnational generation enjoyed a much more advantageous incorporation into the United States than the prior generation had experienced. With higher levels of education, they were able to access opportunities in the United States that the frontiering migrants could not. Transnational family ties were vital to the educational opportunities this generation was able to pursue. Through the next three sections I will discuss several varying incorporation pathways. 


\section{Tipa Tipa: Making Progress Step by Step}

For all the contributing families, having a family member in the United States resulted in more funding for education. Remittances allowed the family members who remained in Haiti to cross financial and geographic boundaries to education. At a minimum, when a single migrant had many children to support, this might mean that children could simply stay in school longer or attend more consistently. Families who were able to pool remittances from several sources moved to urban areas where older children had access to secondary education that wasn't available in rural communities or smaller towns. With remittances, young people who were raised in Haiti were able to cross geographic and financial boundaries to education.

The frontiering generation arrived in the US without having benefitted from relationships with family members who migrated earlier. They had not received remittances to help them stay in school. Nor were their migrations facilitated by family members waiting to receive them in the US. In this chapter I begin to discuss the family members who trailed behind the frontiering migrants. They received remittances that funded more years of schooling. But the trailing migrants I discuss in the first section of the chapter still would not achieve the levels of education they hoped for. They, like the frontiering migrants, had obligations to the family that they hoped to fulfill by migrating to the United States.

To raise the family up each individual must balance their individual goals with their obligations to the rest of the family. Often this tension took the form of curtailing educational aspirations in order to produce income for households in the US as well as for family in Haiti. At some point, the migrant's priority becomes investing in younger 
siblings, nieces, nephews, or his or her own children. Still feeling the tug of their own academic goals, these migrants explain, "I lost my time." Eventually, the role they play to raise the family up is to invest in the academic progress and assist the migrations of other family members.

In this chapter I will introduce Frida and Jean-Luc, whose stories illustrate some of the common elements of this phase of the transnational family migration narratives of the contributors.

\section{Frida}

Frida grew up in Cap Haitian, along Haiti’s northern coast. Like many contributors, she was born to parents who had attended only a few years of school in the countryside. Her parents moved closer to the city to raise their family where there were more possibilities for work and schooling. Frida was the fourth of seven children in her mother's household.

Our father died when I was a child, a baby. Only my mother was living with us. My mother was raising seven children. There's three boys and four girls. I was number four. There were two brothers, then a sister, and then me.

Left to support seven children, Frida's mother worked as a seamstress. Because they lived in an urban area, the family had access to educational facilities and all the children attended school when they were young. But Frida's mom did not earn enough to keep seven children in school. As the younger children reached school age, the older siblings had to leave school to help support the family.

My brothers, they didn't finish high school. They didn't stay in school. You know when you're older, in Haiti that the way it is. When you're older 
even if you could continue high school you have no choice; you have to go to work to help the other kids. You have to work for the family. So the older brothers had to go to work to keep the younger kids in school. In Haiti that the way it is. The older help the younger.

Because their father died, Frida's older brothers left school to help provide for the younger children. They were obligated to do so because they were older, but also because as males they were expected to fill the economic role of the father, or eldest male in the family.

Yes, because they were boys they had to provide for the family. Because our father died when we were kids, so they had no choice.

Frida explained that when her brother came to the United States it made things much easier for the family back in Haiti. With remittances coming in to support the household, living conditions for the family improved and Frida was able to stay in school.

It used to help us a lot. It would be easier for us to live, to pay for school, to eat, to do whatever we want. When my brother started sending money it helped. We could get a better education.

Due to her brothers' support, Frida stayed in school for fourteen years. Nevertheless, Frida did not manage to graduate from secondary school. Eventually her own family responsibilities would become an obstacle to her education. After Frida's three older siblings migrated to the US, their mother's health began to decline. As the eldest of the siblings remaining in Haiti, Frida became responsible for running the household, caring for her ailing mother, and supervising the younger children. She continued in school but was no longer making good progress. Then, after she had spent a couple of years in the US, Frida's older sister became seriously ill and returned to the 
family home in Haiti. With the added responsibility of nursing her sister, Frida could not manage to keep up with her studies and left school without graduating.

Fourteen years I think I stayed in school. Yes, 14 years. I did my high school but I didn't graduate. Because one of my sisters got sick and came back to Haiti. At that time I was in school and it got to be too much for me. I couldn't focus on my school. And so I did my high school but I didn't graduate. I can't deal with all those problems at the same time. To study, to take care of her, to take care of my mother, it was too much for me. So I went from kindergarten to high school.

Frida benefitted from the sacrifices of her brothers. They left school in their early teens and eventually migrated to the US to raise the family up. It was due to their financial support that Frida had been able to stay in school into her high school years. But once the heavy burden of family caretaking responsibilities fell to her, these obligations curtailed her ability to advance academically. Among Haitian contributors, obligations to provide for the family, whether through economic activity or household care-taking, are deeply felt and enforced by a powerful moral code.

Education is a primary focus of investments to raise the family up. It has the potential of increasing earning potential and is a source of status in itself. Another key investment for a family's socioeconomic advancement takes the form of mobility resources. These are the resources required for migration, such as visas, transportation, travel arrangements, and funding. Each migrant's story includes an acknowledgement of the individual(s) credited with making the trip possible. As observed among the frontiering migrants, once a migrant has become established in the US, he or she often prioritizes arranging the migration of others for companionship and support, to share living expenses, and to increase the income production of the family. In addition most 
migrants hope to generate more mobility resources to facilitate the migration of other family members.

Frida explains the roles of the siblings in her family's migration story and the ways that their obligations to one another have both increased her opportunities and curtailed her abilities to pursue them. Her oldest brother was the first to migrate. He eventually financed the migration of the second brother, who then arranged for Frida to come to the United States.

When [my oldest brother] first came here [to the US] he worked as a cook in a restaurant. He sent money back for the family. He used to take care of us. He sent money to take care of the family. The second one, he came after 10 years, and he's the one who sent money for me to come here. The second one, the one who died. The first brother paid for the second brother to come to the United States. Then the second brother paid for me to come.

I think when I came here I was 33 years old, something like that. I was already an adult when I came here. To get a better life. I think everybody who came, they came to get a better life. Because in my country there are no jobs. There are a few jobs, but not so many like here.

When her brother was able to bring her to the US, Frida felt it was the best way to bring more resources to the family. Her younger sister would take on the household responsibilities of cooking, cleaning, and caring for the infirm, while Frida would add more income to the pool of remittances. She hoped that she would also have the opportunity to continue her education. Frida lived with her brother and took English classes, but she needed to begin working right away to provide for her mother and her sister who, in addition to having health issues of her own, now had a child who was ill, as well. 
I left my mom in Haiti and I came. It was very hard [to be separated from the family]. Because you were all raised together. But you have no choice with the situation. You have no choice. To get better life, to help other people, to help my mom... Because everything is very expensive in Haiti. For doctors, for healthcare, you have to have money to pay for everything. It's very hard with this situation, so you have no choice.

When I came here I went to school to learn English. In Haiti we learn to speak English but not too much. We studied it in school. In all schools in Haiti, we study English, Spanish, French. Even though it's not too much, you study that. When I came here I went to school because I wanted to graduate from high school to be a nurse. But the time didn't allow it. Because it was too much for me. When I came here, I had my older sister she was sick. She had a son and her son was sick also. I was the one who took care of both of them. And my brother, too; my brother who died. He's the one who helped me to take care of both of them. It was difficult for me. It was very, very, very difficult to take care of them. I went to school, sometimes I went to work, because you have no choice. Because when you come here, you have your own life, you have to work.

My first job, I think I was working at the restaurant. One of my friends helped me get a job there. After the restaurant, I used to work at a dry cleaner. I did the customer service. I used to work at [a grocery store] as a cashier for four years. Then I left there, but if I knew I would not have left there because it's a good, good job. They have good benefits. It's a good company. I worked there for four years. After that I went to school to learn nursing assistant. And I'm still working as a nursing assistant. That's the job I have now.

Frida completed the certification for nursing assistants, and she has worked steadily in a nursing home for more than ten years. The sacrifices of her brothers allowed her to achieve the level of education necessary to secure employment that required training and certification. But her own familial obligations prevented her from going further. When I asked if she liked her work, she responded:

I do it. I do it (laughs). I like to help elderly people. I like to work in nursing. But I can do better than that. I can do better if I go to school. But I'm okay to help people because they can't help themselves. Like even myself, if I was in the hospital and I pee on me, I do on me, I need someone to help me. So I feel okay to help them. But I would like it better if I was an LPN, and if I continue my school I can be. 
It is a constant regret for her that she has not continued her schooling to a higher level. Even today, although she is in her 50's, Frida continues to hope that she will eventually complete a high school degree and enroll in a nursing program. Still, she feels that earning money for the family must be her top priority.

I can't finish my high school diploma. No. It's my fault. I still want to go! First when I came it was very difficult for me. Because I had to work for my sister and my nephew. They were sick. And they're still sick. So that's why I can't finish my high school. I can't go on to be what I want to be. So many responsibilities for me. I can't. But after a few more years, if I want to go I can. But, it's me. (She laughs) It's no good, I know. But it's me. If I could finish my school, I could be a nurse. But it's me.

Frida continues to send money to support her family in Haiti and is bringing more family members to the US. She explains that she provides more to those who don't have parents to help them.

Yes, I still do it. I have my niece, from my sister who died. I'm the one who support them. Only one of them I support, the other one they had their mom and their dad, so the one I support more lost her mom. I send money to Haiti.

It is my responsibility to help them. As long as I'm alive, I can help push them. To help them, to feed them. To help them until they can take responsibility for themselves, I have to help them. Even their dad, because he just came. Until he can find a job... But he can't go to rent a house now. It's very hard. So this is my responsibility, to help them.

Frida explains that she can focus all of her efforts on her nieces and nephews because she has no children of her own. If she were also trying to raise her own children it would be very hard to provide for her extended family to the extent that she does now. 
I love the children and that's why I help with them. If I had my own children, my own family, it would really be hard. It would really be hard because I couldn't take care of all of them. Every day I tell them that. You are so lucky because I don't have children. So I could pay their school in Haiti before they came here. If I had my own children, I couldn't do that. I could help them, but not too much. They are very lucky.

Frida's story helps to illustrate the duties and obligations between siblings in a Haitian transnational family. She was able to benefit from remittances sent by her older siblings to stay in school longer and to attend higher quality schools than they had been able to do. But when family members became ill, the caretaking responsibilities became too great for her to be able to finish high school. Since coming to the US, she continues to wish she could complete a GED and enroll in nursing school. But not only does she still have to care for others in the family who are ill, she now has the obligation (and desire) to provide for her young nieces and nephews.

The focal points of family investments are in providing education for family members who are in school and arranging for the migration of those who are best suited for employment in the United States. In Frida's family, because her older brothers had the responsibilities of the senior males of the family, they began the migration to support the others. Frida has not achieved her educational goals but believes that it is now time to invest in the next generation. In a later chapter I will discuss the ways that returns on these familial investments are realized.

Tipa tipa, step by step, contributing families sought to increase the levels of education achieved by family members in order to improve their socioeconomic status. Like Frida, Jean-Luc was able to stay in school because of remittances sent from the 
United States. He was able to complete his secondary education and arrived in the US as a high school graduate.

\section{Jean-Luc}

Jean-Luc's parents never attended school. They didn't read or write. They supported themselves and their seven children by farming in the mountainous northern region of Haiti. As the children got older, their father, Willie, decided to go to the United States to work so that he could keep them in school. But he refused to bring his children to the US. He did not like the way he saw the kids growing up in poor immigrant homes in Miami.

My dad when he came, he said he's not going to bring his kids to the United States. Because the way he saw the kids with their parents, maybe some of them, they don't listen and they do things and end up in jail. So he said he's not going to bring us here. For us, to help us grow up, he need to come because by himself he could not afford all of us. He always sent money to us to go to school.

Altogether, we are seven. Two girls and five boys. I'm the second. I have an older sister, and then I'm next. I'm the oldest boy.

As the oldest male child, in his father's absence, Jean-Luc fulfilled the role of the head of the household.

Even if they are older than me, they listen to me. Because my dad he used to travel a lot and we used to live with my mom. And because I'm the oldest brother, I represent my dad. I was like the man of the house. Anything my mom needed, maybe talking to the other kids if they're not listening, she would say she was going to wait for me. I told her "No, you don't need to do that because you are the mom. You don't need to wait for me." But that's the way it was. 
Unlike Frida's older brothers who had to leave school to support the family, JeanLuc was able to complete high school because of the remittances Willie sent from the Florida. Despite having a high school education, Jean-Luc was unable to find work in Haiti.

When I used to live in Haiti I wasn't working. I tried. For maybe six months I have a little experience working. But I was thirty-something and since I was born I could never do anything, just stay with parents to take care of you. There's just no work. No, no, no, nothing.

Willie's refusal to bring his children to the United States once they had completed their schooling caused a rift between him and his sons. Willie had sent money to help his brother arrange for one of his brother's sons, Jean-Luc's cousin Ralph, to come to the US. It is a common migration strategy to help a niece or nephew to migrate in order to establish a resource for an adult sibling's family to obtain visas and to eventually to shift the responsibility for remittances to that branch of the family. But it is unusual for their migration to be prioritized over financing the migration of one's own child. Jean-Luc had accepted that his father did not want to bring him to the US when he was young, but as an adult with no prospects for work in Haiti, he was determined to migrate himself.

You know, every Haitian who come to the United States, well some of them have opportunities, they have money. They come maybe to study. But most of us, we come for economic problems. Because you know even if you finish working in Haiti, you learn something, even if you finish college, to get a job you should have something they call, um, a step father or something. Somebody has to help you. And for women, if I'm in charge of the job and a woman wants a job, then I tell her that she should be my girlfriend. That's what most of them used to do in Haiti. That's why so many people, they don't want to stay in Haiti. They come here to get the best economic situation to help the rest in Haiti. 
After his cousin, Ralph, came to Miami and started working, Jean-Luc asked for help so that he could migrate, too. For Jean-Luc, marriage was the life event that propelled his migration. He married late in the summer of 1999 and boarded a boat for the United States two months later.

[My cousin] brought me money. He went to Haiti and he gave me a part, and my brother gave me a part, and I paid somebody and I came here. It cost about \$5,000 to come in a boat, US money. I tried one time, I went to the embassy to ask for a visa. They said I'm not qualified and after that I never tried. When I came here and I started working, I applied for political asylum and I was qualified. And I applied for my wife, and she came.

I was so happy. I knew my dream would be changed because I saw that some people who had lower education, lower economics than my family, they came here and I saw how much progress they made. And I thought if I came here too, my situation would be changed.

Jean-Luc emphasizes, in his migration story, that it was his cousin-not his father-who helped him to migrate. It is clear that he considers his father's choices to be a breach of the proper order of familial obligations. Jean-Luc moved into his cousin's home and lived there until his wife was able to join him two years later.

Jean-Luc explains his incorporation into the US in terms of his employment history.

For my first job, I had a friend who put shoes in boxes and clothes to send to Haiti. And he took me every day to see if he could help me. And he paid me $\$ 30$ a day. That was his little business. He's still doing that.

I stopped doing that after I got my papers, my work permit. Then my cousin referred me to a restaurant. And I started doing dishes. The first day, it was so terrible for me. I was working and I have water (tears) coming from my eyes because this is not job I was looking to do. I finished my school and I heard some people talking about that (having to work at menial jobs below their abilities), but now I'm doing it. 
They gave me a job interview first. My English wasn't good. I didn't hear (understand) that the boss told me to read the menu. Maybe he was going to start me as a cook. But I didn't hear him when he told me to read. You know when I first came I didn't hear English that good. And he went to my cousin and said I didn't know how to read. I said, 'I didn't understand what he said. It's not because I don't know how to read. I know how to read!' So he sent me to the dish room.

It was a humiliating experience for Jean-Luc to be sent to work as a dishwasher.

He was aware that this work was associated with lack of education and was the lowest position in the restaurant. Having completed a high school education, he was ashamed to be working in the dishroom and he was furious at being thought of as someone who could not read. He was determined to be recognized as a man who belonged on the other side of this symbolic boundary.

Jean-Luc had many advantages that would allow for a more favorable incorporation into the US than the frontiering migrants experienced. He arrived with a high school education, was granted legal status as an asylee, and was able to live with a cousin who helped him to find work and settle into the new country. Even before he came to the US, Jean-Luc and his cousin would practice speaking English together. Nevertheless, he found his language skills to be an obstacle to the kind of work he was seeking.

Getting a work permit allowed Jean-Luc to cross the boundary to legal employment. He was able to move up from packing boxes for shipment to Haiti to a restaurant job in the mainstream economy. But his poor English skills relegated him to the bottom rung of restaurant work. To cross the boundary to better pay and higher-status work Jean-Luc knew he had to improve his English. 
By the time Jean-Luc arrived in 1999, English classes had become widely available in South Florida. After paying a small registration fee, he was able to take English classes at a local technical school. In contrast to frontiering migrants who were often intimidated by classroom learning and had many obstacles to attending classes, Jean-Luc thrived in the classroom setting. For six months he attended English classes each evening, from seven o'clock to nine o'clock, after his shift at the restaurant. As his English improved, Jean-Luc sought a job that would take him out of the dishroom and that was commensurate with his level of education.

I had another friend and he said, okay, because I know how to read, he's going to refer me to another job. By that time I went to school and I could hear a little bit of English. I went to the other restaurant and they started me with more money and they hired me to cook, to do prep, everything like that.

But they give you different jobs and they never give you a raise. Then after, because I had a work permit, I went to another place to find another job.

Having legal employment status allowed Jean-Luc to seek out better options. Unlike the frontiering migrants, who tended to remain in low-paying jobs once they achieved stable employment, Jean-Luc felt empowered to pursue upward mobility. As he developed more skills in the workplace, he sought higher-paying jobs and better working conditions.

After the restaurant, I went to do deliveries. I worked for a party supply store. Anything you want to make a party: tables, chairs. I made the deliveries. Sometimes they would send me by myself and sometimes they would send me with a driver. But I didn't like the way the supervisor acted. He was Spanish, and he dealt with Spanish people better than Haitian people. So I didn't like that and I looked for another job. 
I went to a dealer who did car detail. I worked at dealer for maybe one year, and then I had another friend who referred me to a factory. They build doors and windows. And I've been working there for 10 years. That's the job that I have now. It was better pay and more respectful.

Jean-Luc intended to continue his education. He began to take classes at a community college but by that time he had two children and it was too difficult to coordinate the household schedules. He still yearns to advance into a skilled trade.

Yeah, I'm thinking if I could do mechanic, or plumbing maybe. I think that's something I will do. I was thinking about getting my license for driving a truck. I tried so many times to get the license, but I never passed the test. And I keep trying, you know. But sometimes it's hard. You know, I want to study but I don't have someone to encourage me. And sometimes I get the book and I keep reading, maybe sometimes I fall asleep... (Laughs). I have the website and I go to practice. But when you go to the $D M V$, some of the questions are the same and some of them they change. You know, after you go there so many times you know they're not going to give you the same questions. Every time they change it. They change it.

Like Frida, Jean-Luc still aspires to advance in education or vocational training, but at this point in his life he finds it difficult to do so. He must continue to work hard to meet his financial responsibilities and, despite his desire, it is hard to find the energy to study at the same time. Many of the trailing migrants who came to the US as adults with a high school level of education continue to seek out opportunities to advance vocationally. Because it is so hard for a working adult with children to find time to take classes, they often have a history of programs that were begun but not completed. Online courses or programs that can be pursued independently through the mail are popular alternatives. But studying in English is usually more difficult and time-consuming than expected, and exams that are worded differently than the study materials can be baffling. 
Recognizing that "I lost my time" for higher education, Jean-Luc invested in the education of his brother, Marc. He hoped that Marc would be the one to raise the family up to a level that Jean-Luc would not be able to achieve.

I have another brother who went to the Dominican Republic. He went to study to be a doctor. And I was the one, and my dad, who helped him economically. Yes, I used to send money for his school in the Dominican Republic every few months. We had to send for his college and to pay rent for the house, money to eat, things like that.

After that he got his girlfriend in New York who tried to bring him here. And he stopped his studies. He went for three years and then he came to the United States, to New York. I told him he needed to continue, to study. I told him if he didn't want to continue to study to be a doctor - I know it's difficult, it's a lot of money - he needs to learn another thing.

I realized that even if he came [to the US] it would be better for him [to have finished his schooling]. Because if he graduated it would be easy for him to come here and maybe take a test and then maybe get into the program. And now I lost money for nothing.

Efforts to raise the family up by investing in others often fail to achieve the desired outcome. But they do increase the level of education within the family, step by step. Jean-Luc's hopes now are that his children will be the ones to finish college and go to medical school.

You know, I didn't get a lot of education. I want [my children] to be... I expect them to be successful. To get more education. To finish high school and go to college. And to learn something so they are not the same like me, doing a hard job like me and my wife do.

I always tell them I want them to be ... I tell my son I want you to be a doctor. My daughter too, I want you to be a doctor. My son says no he doesn't want to be a doctor because he's scared of blood or something like that. I say I want you to be a pediatrician because you like kids. If you will help kids, this will be great. You will make a lot of money. Sometimes maybe you could be tired of thinking, not tired of lifting. I'll try to do the best I can to see it happen. 
If they can get higher and higher, I will be more happy. I want people to say these are Jean-Luc's kids and they're very successful. I always pray for them, for God to make them strong, give them a strong life, give them a good education.

\section{Tipa Tipa}

The stories of Frida and Jean-Luc illustrate a step up from the conditions of the frontiering migrants in the quest to raise the family up through migration, remittances, and education in a Haitian transnational family. Their incorporation into the United States reflects the transnational family endeavor to achieve socioeconomic mobility. As the recipients of remittances, this group of migrants entered the US with substantially higher levels of education than did the frontiering migrants in their families. They were able to cross financial boundaries to education that would not have been possible without the support of family members in the United States. Transnational families strive to cross the structural boundaries that limit educational opportunities in Haiti along class lines. The educational opportunities they had in Haiti raised individual aspirations and selfconcepts. They crossed symbolic boundaries by becoming relatively highly educated among Haitians, despite their inability to turn their academic achievements into gainful employment.

These migrants came to the United States with more information than frontiering migrants had about what to expect when they arrived. However, they were frustrated by the limits to their academic achievement. They all had hoped to continue their educations once in the United States. Despite having more knowledge about life in the United States, these trailing migrants still underestimated the social and economic challenges they would face. The need to produce income to support themselves and to provide for other 
family members became a boundary to continuing to the levels of education they desired. They had lost their time. This phrase reveals a symbolic boundary to educational persistence. There is a point in life at which a family member is expected to relinquish their personal aspirations to focus on raising the family up through others.

Still, they were able to cross many boundaries that frontiering migrants could not. Because they benefited from the remittances sent by earlier migrants, this group of Haitian immigrants achieved a more favorable incorporation into the United States. The low wage earnings of frontiering migrants provided for their schooling in Haiti. As a result, these trailing migrants came to the United States with higher levels of education and were prepared for better jobs than the frontiering migrants who paved the way for them. Their migrations were facilitated by relatives who provided money, housing, support and assistance in learning the American culture and finding jobs. They took classes to improve their English and became comfortable working in the mainstream economy among multiethnic coworkers. They could participate in their children's school events and communicate with their children's teachers. These are all substantial boundary crossings in comparison to the incorporation of frontiering migrants.

These trailing migrants then became resources for other family members. Once they began to work in the United States, they sent remittances to family members who remained in Haiti. These remittances, like those of the earlier migrants, were intended in large part to provide funding for education. As they settled into their new lives, they hosted other new migrants and helped them to find jobs or to continue their schooling. Furthermore, these trailing migrants became resources for the frontiering migrants or other family members with less education or English ability. As they did so, they created 
a more favorable condition of incorporation for these migrants, as well. The net resources of financial, human, and social capital enjoyed by each family increased substantially as trailing migrants with more education became established in the United States. The ways that resources were distributed in transnational families will be discussed further in Chapter 8 .

The trailing migrants discussed in this section had hopes of continuing their educations in the US, but because of their obligations to others, they prioritized employment over education. In contrast, trailing migrants who came at an earlier age, during their middle or high school years, were expected to raise the family up by continuing their educations. Teen incorporation narratives emphasize immigrant experiences in American schools. Although the eventual incorporation outcome for some of these young migrants is yet uncertain, their stories illustrate the obstacles faced by trailing migrants who arrived in South Florida before they completed high school. In the next section of this chapter I will analyze the boundaries to incorporation that teen trailing migrants encountered and the resources that allowed some of the immigrant youth to cross these boundaries.

\section{Teenage Transitions}

Young people in Haiti must cross geographic and financial boundaries to education. If they live in the countryside, students will need to travel to larger towns or cities to continue with secondary schooling. A student may be sent to stay with a relative who lives in an urban area or the whole family may relocate as children get older to have better access to schools. Most Haitian teens are unable to cross the boundaries to the 
equivalent of a US high school degree._For many contributing families, remittances allowed children to attend more expensive, higher quality schools.

Migrating to the US is a way for young people to evade the boundaries to education in Haiti, but they encounter boundaries of a different nature in the United States. To understand the composition of those boundaries in greater detail, it is useful to examine the stories of immigrant youth who arrived in South Florida during their teenage years.

Migrants who come to the United States as teenagers are often grouped together as "children of immigrants" or "immigrant children." By the more precise generational categories suggested by Rumbaut (2004), they are the 1.25 generation. His analysis found that immigrant youth who arrive in the US as teens had educational and occupational outcomes very similar to those of the 1.0 generation, who migrated as adults. Rumbaut suggests that, "in general, the 1.25 cohort comes across as a distinctive and seemingly vulnerable one" in contrast to children who migrate at younger ages (2005: 1191). He argues that teen migrants "may undergo a comparatively more problematic adaptation, which should be taken into account in studies of the incorporation of the new second generation" (Rumbaut 2005: 1191).

In this section, I discuss some of the particular challenges experienced by contributors who migrated during their teen years. However, I examine these boundaries within the fuller context of the student's experiences as part of a transnational family. I consider how remittances and family relationships affect educational trajectories that span Haiti and the United States. Students who migrate during their teen years contend 
with different boundaries to education in each country. The students and their parents are well aware of the financial and geographic boundaries to education in Haiti. With remittances, they make every effort to cross them. When young people come to continue their educations in the United States, however, they do not anticipate the boundaries they will face. They are aware that every child in the US can attend public schools, where they pay no tuition fees and transportation is provided. The clear social boundaries that limit educational resources along class lines in Haiti and reproduce the social hierarchies of their homeland are not as evident in the United States. Without the financial and geographic hurdles they experienced in Haiti, contributors believed that academic achievement in the United States was only limited by the personal effort of the student; the only obstacle to education was a student who was "lazy." But, in fact, students found academic achievement in the United States to be much more challenging that they had expected.

In this chapter I examine teen transitions through a framework of boundaries that reveals the obstacles to academic achievement these trailing migrants faced. An individual student's ability to cross the boundaries they encountered varied with the resources transnational ties provided. Among this group of 1.25 migrants there are different educational pathways and, thus, different incorporation outcomes that can be understood by examining the transnational processes involved. I selected the stories of four trailing migrants to illustrate the educational pathways found among contributors who migrated to South Florida during their teen years. In other chapters I emphasize the stories of contributors who migrated decades earlier in order to include their occupational 
outcomes. But in this chapter, I wish to examine students' school experiences more closely; therefore I present the stories of young Haitian immigrants - William, Evangelique, and Raphaella - who still attend or recently completed school. In addition, I included the experiences of Coralie, who migrated as a teen in 1980, to compare the experiences of students of these two periods in the Haitian migration to South Florida.

\section{Boundaries to a High School Diploma}

\section{William}

William is really happy to have come to the United States because he says, "In Haiti it's too hard." He was not always able to go to school in Haiti. "Every semester you have to pay money. If you did not have the money you could not return to school." $\mathrm{He}$ would call his father in the US and ask for the money needed to pay the tuition for his younger siblings and himself. William had no idea how difficult life was for his father in the United States. He didn't understand that when his dad did not send the money it was because he didn't have any money to send. William always heard that there was a tree with money in the US and everyone was rich.

Although he was 17 when he came to the US, William had only completed the six levels of primary education in Haiti. He came from a town along the central coast of Haiti, where there was not access — even if he had been able to afford it — to the highquality schools found in Port-au-Prince. Nevertheless, his opportunities have been far greater than those of many of his 15 siblings. He doesn't have close relationships with his older sisters and brothers because they are from his mother's earlier marriage and don't have a father in the US to send money for them. This disparity, according to William, 
provokes a great deal of jealously within the family. When he was living in Haiti, William worried that because they envied his economic advantages these siblings might try to kill him. Because of this fear, he avoided socializing with them. He didn't eat at their houses, as he would be expected to do in an extended Haitian family. The educational opportunities that having a father abroad have provided to Williamcompleting six years of schooling by age 17—seem grossly insufficient from an American point of view. However, his story highlights that this advantage is so great from the perspective of the sending context that he incurs tremendous jealousy. Without remittances, his siblings did not have the opportunity that William had to cross the educational boundaries that reproduce economic disparities in Haiti.

When he came to the United States, William found school to be very difficult. He did not speak any English and, despite having completed only six levels of school in Haiti, because of his age he was placed in the $11^{\text {th }}$ grade. His insufficient academic preparation presents a boundary to his progress in high school. He was enrolled in the ESOL program at Edison Senior High School, but three years later he still struggles with the English language. His progress has been limited because he hates to speak in English. The other students laugh at him because of the way he speaks, so he prefers to keep quiet. He tries to learn English by watching cartoons and listening to rap music. William struggled through the interview, but he was determined to continue in English, even though a friend was available to translate. He kept his head down, avoiding eye contact, as young people in Haiti are required to do when addressing an adult.

William has very modest circumstances in the US. He lives with his father and younger sister in a poor section of Miami among many other Haitian immigrant families. 
His father works in construction and encourages him to persist in school and get all the education he can. William really hated going to school, not being able to speak English, and at one point he wanted to give up. But his father explained to him, "In America when you have an education you can have a good life. With no education you will be like me, working hard." Still, even with this difficult transition, he feels life is better in the US than in Haiti. "You have more opportunities." He can go to school, unlike in Haiti where he could not go if his father did not send the money.

But with his limited academic foundations, William's ability to earn a high school diploma in the US is questionable. He is 20 now and, although he completed his high school courses, he has not been able to pass the FCAT exams required to earn his degree. ${ }^{13}$ There is a clear gap between "completing" and "graduating" from high school. Without a high school diploma, William will encounter substantial boundaries to a favorable incorporation into American society. He is taking classes at a local technical school to earn a GED. He needs the academic certification because he hopes to join the Navy. He sees this as his best path to upward mobility because military service offers educational benefits and the possibility that he will eventually be able to go to college. Ultimately, he would like to be a firefighter. He has been told that he can train for this in the Navy and then have good career when he returns to civilian life.

${ }^{13}$ The Florida Comprehensive Assessment Test (FCAT) is a set of exams required in Florida's public schools for promotion in selected grades and for high school graduation. Beginning with assessments of math and reading, at full implementation the exams included science and writing, as well. From 1998 to present the specific requirements of the FCAT have varied due to staged implementation and then transition to revised assessment programs. 
The remittances William received from his father were enough to help him cross some of the boundaries to education in Haiti. But he came to the United States without the level of academic preparation expected for his age. Insufficient academic foundations (in terms of the standards of the host country) create a formidable boundary to upward mobility. Despite his determination and the resources provided to help immigrant youth, it is entirely possible that he will not be able to achieve his academic goals. But this is a consequence of the systemic boundaries he faced, both in the US and in Haiti, not his attitude toward education. It is difficult to know if William might have been able to advance more easily if he had come to the US earlier, but his father, as the sole frontiering migrant of the family, did not feel that he was in a position to take on the dayto-day care of his children while trying to earn enough to support them. He is, however, continuing to support William and urging him to persist in school, believing that an investment in more education is the best route to upward mobility for the whole family.

William hopes to be able to bring his mom and his younger sisters to live with him in the US someday. "Life is too hard in Haiti." He feels a responsibility to do well and advance in American society so that he can take care of them. He smiles when he thinks about his mom, and he calls her every day. But he hasn't seen her since he left three years ago. He doesn't have the money to go back to visit his family in Haiti.

\section{Boundaries to Higher Education}

Nearly all contributors believed that if they graduated from high school in the United States they would have the opportunity to go to college. They were not aware, though, of the complex financial aid systems they would have to navigate to be able to 
continue with higher education. Parents, who are often highly suspicious of requests for disclosure of personal information, must provide financial documentation. Students may need an adult to co-sign for student loans. And most options for financial aid are limited to US citizens or permanent residents. Evangelique's story demonstrates the substantial boundaries she crossed to graduate from high school, only to encounter a seemingly unbreachable boundary to post-secondary education.

\section{Evangelique}

Evangelique has a large group of siblings, ranging from 4 to 35 years of age, who share a father but resulted from his relationships with several different women.

I have 11 siblings. I have in total seven brothers. The oldest one, my sister, I think she's 35. My dad has a lot of kids. My mom has six kids and my dad has 11 kids. My mom has two girls and four boys.

Her youngest siblings are the children of Esther, who Evangelique refers to as her stepmom. It is through her step-mom that Evangelique had ties to the US before her own migration. Esther's migration was arranged by a cousin several years ago. Esther sent money for the care of her children who remained in Haiti, and her husband, Evangelique's father, was able to build a little business selling soft drinks with the remittances. Although Evangelique was not a direct recipient of these remittances, her schooling in Haiti was paid for by proceeds from the soft drink business. With this transnationally-funded enterprise, life for Evangelique's family became easier.

Evangelique grew up in one of the larger towns along Haiti's central coast, where there was a large public school. Despite being a public institution students paid substantial fees, and many young people were unable to attend school consistently. The 
older children in Evangelique's family did not complete high school, but Evangelique and her younger siblings enrolled in school every year and were making good progress. However, school came to an end for them in January 2010, when Haiti suffered a devastating 7.3 magnitude earthquake. Evangelique's family lived approximately 60 miles north of Haiti's capital city where the quake wrought its most severe destruction, but the schools in her town were too damaged to safely reopen. Her father arranged for Evangelique and some of her siblings to go to Florida so that their schooling would not be interrupted.

Coming to the United States was not something that Evangelique had anticipated. While many young Haitians with relatives in the United States had grown up with the expectation that they would eventually migrate themselves one day, for Evangelique this was a sudden change of plans. Evangelique had a stepmother with ties in the US, but she did not benefit from that the way that her sisters (the biological children of her stepmother) did. Siblings tended not to distinguish between those who shared the same two parents; instead, the closeness of their relationships depended upon whether they were near in age and had been raised together. For parents, on the other hand, these distinctions are quite important. Because of the nature of familial obligations in Haitian culture, a child represents the parent's primary investment for the future and opportunity for socioeconomic mobility. In addition, the nature of the familial relationship determines access to legal mobility resources in the US, such as family preference visas. In many families the benefit of transnational relationships accrues most directly between parent and child, but then extends to siblings, cousins, and other relatives. (The distribution of resources in transnational families will be discussed in more detail in Chapter 8.) 
For Evangelique this meant that, because her transnational connections were through a stepparent, she did not get to go to the US to visit each summer, as her younger sisters did. Nor did she expect to migrate herself to join her stepmother's relatives in South Florida. But when the situation in Haiti became dire following the earthquake in 2010, her stepmother helped to facilitate migration to the US for Evangelique, as well as her own children.

My little sisters used to come here before me because they had visas. They would explain me like everything. They said it was beautiful. And there was school. And there was always food (laughs), and parks, and beautiful clothes. So I wanted to come too. I asked my dad and somehow he got me a visa. And I came here. After the earthquake there was no school in my town so my dad said that Florida would be the best place for us to come so we could go to school. I was going to come here for like two months, but after the earthquake my dad said we can stay because there is no life over there [in Haiti].

The schools in her Haitian town did not re-open the next school year, so it was decided that Evangelique would stay in the US. Evangelique was very excited and continues to overflow with enthusiasm when she talks about coming to the United States.

Oh, I was so excited. Oh my gosh! It was like a dream. I was so happy that I came here. When I was on the airplane, I was like "Oh my gosh, I'm actually here!" I was so excited. It was like a dream come true.

Evangelique's unbridled delight at the opportunity to live in the US belies the very difficult experience she has had here. Although she had to study English in school in Haiti, Evangelique found it very difficult; and because she did not expect to go the US she had no interest in learning the language. With really no comprehension of English at all, her entry into school in Florida was quite traumatic. 
I did have English class in Haiti. But I used to hate English. Because it was really hard! Yeah, when I was in Haiti it was really, really hard for me to learn. Even when I came here, I used to cry every time I go to school. I could never understand what the teacher was saying. I didn't even know how to say hello in English!

Evangelique's step-sisters, on the other hand, had been travelling back and forth for visits to South Florida for some time. By the time they began school in the US, the girls conversed easily in English. And, as elementary school students, Evangelique's young step-sisters would learn many of their foundational academic skills in English in American schools.

It's just elementary school, kindergarten... So they didn't have any problem. They speak English like American kids! When I talk to them they laugh at me because I have an accent [Evangelique has a barelydiscernible accent]. They're like, "Why do you talk like that?" I say, "Talk like what?" "You have this accent." I'm like, "Cause I came here when I was 16. You came here when you were like eight. I can't talk like you guys talk."

In addition to the challenges of learning a new language, nearly all contributors who migrated during their middle or high school years had to contend with bullying and violence at school. For many students, like Evangelique, these hostile environments presented a serious obstacle to their academic persistence.

I actually got jumped the first day I went to school. I actually got jumped by these two girls. I was just looking at them... It was nothing serious, I was just looking. I didn't understand what they said. They just beat me.

So I was afraid to go back to school. Yeah. I spent like two weeks at home. I mean, not home... They dropped me off at school and I'd go somewhere else. I didn't want to get beat up again! And I couldn't understand what they were saying. Even the teachers. Everybody was just sitting there doing their work and I was like, "What am I doing?" 
Fear and confusion characterized Evangelique's early experiences in American schools and challenged her academic progress. Similar experiences were described by nearly every contributor who migrated during their teen years. After the ubiquitous struggle with English, physical and emotional torment in their schools was the boundary to academic achievement most frequently reported. Like Evangelique, most teen migrants did not want to report these humiliating experiences to their parents. Evangelique's solution — to stop attending school—was attempted or at least considered by many students who suffered similar abuse and frustration. Crossing this boundary requires substantial stamina and confidence.

When Evangelique was caught skipping school, she was encouraged by her stepmom to return. Just as William's father had advised him, Evangelique's stepmom explained that returning to school was necessary because upward mobility in the US is only possible through education.

I talked to my stepmom and she said if you want to be somebody in the future you have to go to school. You don't have to hide or stay home all the time. And she said if you don't go to school you'll never learn English. And I woke up the next day and I was ready to go to school.

Although the belief in easy prosperity that some Haitians arrive with - that money grows on trees in America-is soon discovered to be untrue and is quickly relinquished, the faith in the power of education to transform one's life is resilient.

Evangelique entered an ESOL program in which the teachers spoke only English but were very supportive. 
My first ESOL teacher, she was American ... A very nice teacher. I loved her! She really helped me a lot. But she didn't speak Creole. But she showed me everything, like, with a picture so I could understand.

In just three years Evangelique has made excellent progress in English. She speaks fluently, with confidence, and has only a hint of an accent. Like many other immigrants, she found watching TV to be a great way to learn a new language.

I read a lot and I go to libraries a lot. I listen when other people talk. And I watch a lot of cartoons! That really helps, trust me. SpongeBob!

By her senior year of high school she was able to pass the tests to leave ESOL and take classes with the general school population. Although school had been difficult because of the language barrier, once she learned English she had no problems with her classes.

Well, it was a little bit hard when I first came. But then after I got used to it and I started understanding English then it was easy because everything I did in high school I already did in Haiti. It was just the language.

As with many other immigrant students who attended troubled South Florida schools, Evangelique reported that the content of her courses in the US had mostly been covered already in her school in Haiti. Despite having to learn in a new language, she passed all her required exams and graduated with a $3.8 \mathrm{GPA}$. With this promising academic trajectory, Evangelique might seem to be headed to college and incorporation into the American middle class. But after graduating from high school she began to encounter boundaries to her academic progress.

Trailing migrants all struggled financially as they pursued more education in the US, but those who were able to access financial aid of various kinds found it possible—or even economically advantageous - to stay in school. Evangelique enrolled for classes at 
Miami-Dade College and applied for financial aid with the help of a teacher, but in her situation, for reasons she does not understand, she does not qualify for funding.

I've been trying to get into Miami-Dade since I graduated but every time I go there there's always some problem with my papers, my residence card, or the problem I'm having with financial aid. I would be able to go if I had the money, if I had someone to sign for me. My teacher, she actually sat down with me and we filled out the whole thing together. But when the paper came to the mail, there was no money. They said no. And when I went to Miami-Dade, they dropped all my classes. It was a lot of money, so I couldn't pay it. It's a lot. I talked to my mom about it, but she couldn't do anything. She don't have a good job. She can't pay. And my dad is not working now. You can't pay college; it's too expensive.

Despite her plans to stay permanently in her new country, Evangelique has only a temporary legal status in the United States. Because of this, she is not eligible for federal and state financial aid programs. The boundaries set by US immigration policies restrict students like Evangelique from accessing benefits reserved for US citizens or permanent residents.

In addition, Evangelique must contend with the boundaries that exist within her family. Her stepmother did not keep Evangelique as part of her household for long. Instead, Evangelique was sent to live with other relatives of her stepmother's where she was expected to provide childcare and housekeeping services in exchange for her room and board. Although she does not recognize it, Evangelique seems to have lost her time. The family resources are being focused on the stepmother's children, and the family Evangelique now lives with has no interest in helping her to pursue higher education.

Evangelique is the first high school graduate in her family. She has exceeded her parents' levels of education, but without financial aid, she does not have access to the higher education necessary to fulfill her ambition of becoming a nurse. No one is 
investing in her future. Her story illustrates the impact of familial resources on an immigrant student's ability to access higher education. In Haiti, financial resources were a boundary to education at all levels, and, both in Haiti and in the United States, economic factors play a role in the quality of schools a student can attend. Financial boundaries to higher education can be crossed by many low-income students who qualify for financial aid. But, like Evangelique, many immigrant youth have issues of legal status or other complications that make financial aid inaccessible.

Still, Evangelique is very hopeful for her future in the United States.

Yeah! I want to get married and have kids here. And get like a good job here. I mean, I might move to another place, maybe another state, but I'll still be in America. I love America!

Children who migrate when they are of school-age had a particularly difficult transition, not only because they had to learn English very quickly to be able to progress academically, but also because of the cruel treatment they were subjected to in school. The segmented assimilation analysis suggests that students develop an antipathy toward mainstream values, which leads to disengagement from school. In my research I have not encountered students who do not value education or aspire to reach the American middle class. Rather, the environments in which they are placed for schooling are perceived to be so hostile that they might leave school entirely or avoid participating while they are there. Immigrant students reported a great deal of stress and fear related to violence in their schools. They were humiliated by other students who laughed at their accents and poor English. Many felt that some of their teachers did not like Haitian students and did not seem to have much regard for their academic aspirations. 
Many students who came to the US when they were very young and spoke predominantly English nevertheless struggled in school because of their limited vocabularies. Their learning was stunted not only by unfamiliar words but also by a lack of exposure to experiences, stories, and ideas that are commonplace in the childhoods of most American-born children. Particularly amongst boys, these knowledge gaps led students to consider themselves to be "dumb" and unable to succeed in school. Feedback from teachers often reinforced these feelings. Young men recounted the alternative ways they sought success. The most fortunate distinguished themselves in sports; others, who mostly had dropped out of high school, achieved notoriety as the "class clown," by fighting in school, or by flaunting money they earned either through legal or other means. Most of the immigrant students, however, persisted in school and tried hard to overcome the obstacles to their academic progress.

Immigrant youth like William and Evangelique encountered substantial obstacles to academic progress when they came to the US as teenagers. Their stories illustrate the boundaries to upward mobility and the middle-class status to which they aspire.

The financial obstacles to William's schooling in the United States were negligible. There were no tuition or transportation costs, and most of his supplies were provided. The most significant cost was that his family was forgoing William's potential earnings to prioritize his schooling. In a poor family like his, this choice reflects the belief that educated individuals are necessary to raise the family up. William's father believes that this investment will pay off in the elevated socioeconomic status William could achieve with a high school credential. William's father recognizes that education is 
a means for crossing the social boundaries of the US. As he told William, "In America when you have an education you can have a good life." William is aware that he is pursuing "a good life" not only for himself, but for his whole family.

The boundaries to achieving this are substantial. For all Haitian immigrant contributors, English competency was a formidable boundary to their successful incorporation into the US. This boundary works both in the symbolic realm, marking immigrant youth for torment and exclusion by their peers, and as a social boundary, as well. Although immigrant students are helped to transition to learning in English through ESOL classes, educational resources are designed for English-speaking students. William arrived in the US late in his teens when American youth of his age were finishing high school. There was no time to gradually learn the language and then progress with his other studies. Evangelique also experienced this boundary; however, with a stronger educational background she has been able to overcome this obstacle and successfully complete her high school education.

The difference in outcomes of these two students illustrates the ways that an immigrant's education in Haiti affects their incorporation into the US. With a stronger academic foundation, Evangelique overcame her language limitations and graduated from high school. William continues to pursue a GED and has a long-term strategy that eventually leads to college, but he faces formidable academic and linguistic barriers to realizing his dreams. Evangelique crossed these boundaries. She is academically qualified and prepared for college. But, while students can attend kindergarten through high school tuition-free in the US, they face a financial boundary to higher education. Access is 
assured only to those who can pay. Financial aid has become more widely available in recent decades and this boundary represents a significant barrier to a smaller proportion of the US population. But in Haitian immigrant families there may be obstacles to accessing financial aid including issues of legal status, inexperience with complicated forms and bureaucratic systems, fear of disclosing financial information, or parental illiteracy or inability to comprehend English. Even with financial aid, the costs of higher education can become a barrier to completing a college degree. In Haitian transnational families, decisions about where to direct a family's resources can determine whether or not an individual will go to college. In Evangelique's case, transnational ties facilitated her migration, but her tangential relationship to her stepmother's family means that resources will not be directed toward higher education for Evangelique.

Having a high school diploma allows Evangelique to cross social boundaries she will be able to apply for jobs that require a high school degree - and symbolic boundaries - having the status of a "high school graduate" rather than a "dropout" or the intermediate status of a one who holds the certificate of completion awarded to students who finish high school but cannot pass the required exams. But the lack of financial resources for college creates a boundary to her socioeconomic mobility in the US.

Still, many teen trailing migrants have been able to cross the boundaries to completing a high school degree in the US and continuing on to college. The teen transitions of Raphaella and Coralie illustrate experiences that were common among this group of migrants from the transnational generation. They encountered significant boundaries to their academic progress. But the stories of these teen migrants emphasize 
resources developed through transnational family ties that helped them to continue on to higher education.

\section{Raphaella}

As the granddaughter of the frontiering migrant of her family, Raphaella benefitted from the combined efforts of her grandmother and her uncle to insure that she got a good education in Haiti. Grandma Pierre (she prefers the English term "Grandma" to the Haitian Kreyòl "Grann," which she says "sounds too old") left Haiti when the oldest of her eleven children were teens. She was no longer able to keep them all in school with the money she earned butchering pigs and selling meat in the market. Even though some of the older children already had kids of their own, she wanted them to be able to finish high school. Raphaella's mother, Miriel, and most of Miriel's siblings were able to complete high school because of the money their mother sent from Miami.

Raphaella's father died when she was a small child. Since then, her uncle, Antoine, took responsibility for helping to support Raphaella. After he left Haiti to join his mother abroad, Antoine was the one that Raphaella would call when her tuition payment was due.

Without him, I don't know [how my education would have turned out] ... because my mom was a single mother in Haiti. Imagine, her mom is providing for her and now I'm here. So it was a big support for us. Like when I'm going to school, I have to call my uncle and he has to send the money for the whole trimester to pay for the school. To make sure that I get a good education, I go to a private school, stuff like that. He would send money in advance to pay for my school. Books, clothes, everything. And when he would come, he would come with a suitcase with clothing, underwear, everything for us. 
Raphaella's mother, Miriel, was able to finish high school—although not until she was 19 and already a parent—-because of the remittances she received from Grandma Pierre. Raphaella feels sure that she, likewise, would have managed to finish school even without her uncle's help because her mother was working and her grandmother sent money from the United States. But she would have been at a disadvantage compared to some of her cousins who had a father in the US sending remittances if she had not been treated like a daughter by her uncle.

If it was only my mom, I think I would still manage to finish school here, but the level I would be I would not be at the same level. My uncle was supporting me, but my mom was working too. She would buy shoes. Go buy a big box of shoes and go to mache (market) to sell them to bring food to the house. And if [my uncle] was not part of my life, I think because of the fact that I was fortunate enough for my grandma to be here, I would have the education but I would not graduate at the same time I graduated here, or I would not be at the same level that I was in Haiti, or I would not be in the school that I was in Haiti. But I would still be able to get an education because my mom was working.

There are times when my mom couldn't afford it. They would send me home [from school] and my mom would give my uncle a call and he would send the money. So if he was not there, I would probably stay home for the whole year. I would say next year I'll come back. Down again instead of going up. In Haiti, when you're in school you have to pay every semester, every time before the semester starts you would have to pay. And if you don't pay, they would come to the classroom and say, well, you need to have your parents come. And they would give you a receipt, like something that you have to come pay. If your parents don't come pay, when you come to school they don't let you go by with the other students. While you are entering, they just call you into the office and tell you, you have to go. You could not come back until they pay. If they don't pay, you don't come.

Remittances from Raphaella's uncle provided the financial safety net that was needed to keep her in the high quality private school she attended. 


\section{Effects of Quality of Education in Haiti}

Raphaella felt that having a good private school education in Haiti was essential to her academic accomplishments in the US. Overcoming linguistic boundaries in American schools was a significant challenge for her. She explained that only because her education in Haiti had been advanced in comparison to what she encountered in American schools was she able to keep up with the material.

Raphaella arrived in Florida at the age of 13 and began middle school with very little comprehension of English. She tried to improve by watching television shows after school and repeating the phrases she heard.

In Haiti they introduced us to English when you were in secondary school. The things that I understood were like "how are you?" "How old are you?" I can count from 1 to 10. The basic stuff. "What grade are you in?"

[After arriving in the US] I learned English from listening in class. And the TV. You know when you're watching the TV, the captions? I would read the captions. I used to watch that episode, Ranger? Chuck Norris? Texas Ranger! Yeah, yeah, Texas Ranger. Chuck Norris. Every day after school. I would go to the house for 3 to 4, 5 to 7, Chuck Norris. Every day Chuck Norris. And then they would have the captions, everything he would say I would repeat.

By the time I started high school, ninth grade, I still did not speak English but I could write. So then sometimes if I want to explain something I would write it to my teacher.

With so little comprehension of English, Raphaella believes that it is only because she went to a very good school with an advanced curriculum in Haiti that she was able to progress at her grade level in the US. She credits the rigorous memorization that is required by Haitian schools for her ability to retain information from her textbooks even in a language she didn't fully understand. Furthermore, she emphasizes the self-concept 
she developed as a student who was privileged to attend a good, private school. She came to the US with a belief in her academic capabilities and with a conviction that it was possible for her to achieve a higher socioeconomic status through education.

I think once you're from a good school in Haiti, you had a good education, a good base, when you come here even though you don't know the language you will still succeed. You will still make it. You have good study habits and you have the base. The base is like what you learn in the school you were in. It doesn't matter what country you would go to, you would understand.

It's very important. There are some things I learned in primary school in Haiti, I'm learning in college here. To me I felt like I was more advanced in Haiti. So some chemistry that I'm learning in college when I was in Haiti some people would do in secondary school. So I was proud. Coming from that school, I was proud of myself. I didn't know the language but some things they were doing here, to me it was like a piece of cake.

When I first came, the students, when I'm doing math they would come to me. (Laughs) They would want to look at my paper when I'm doing math. Because I have a good background. With math, it doesn't matter what language if you have a good background. I would see the equation; I would solve it. So my math grade was higher. Then the other class requires, like, studying by heart. I would get high grades because I'm used to that. I would just open the book; close the book and study. In history, yes. But with reading, the only way I succeed is because in Haiti we have where you do reading and answer questions; so I was used to that. And I was very good at it, so that's how I made it.

Even though she still struggled with English, Raphaella was able to pass the required standardized tests (Florida Comprehensive Assessment Test, FCAT) in reading and math before her junior year of high school. One of her counselors suggested that she enroll in a vocational program through a dual enrollment option for high school students. She graduated with both a medical administrative certificate and a high school diploma. She did not see vocational training as an alternative to college, however; to Raphaella it 
was an opportunity to better prepare herself for the skills she would need for higher education.

While I was doing vocational I was still applying for college. Because I know I passed the FCAT, I would have a high school diploma. And then the vocational school to help me to know about computer skills, administrative skills, and then that would help me through my college here.

Raphaella credits one of her high school counselors with encouraging her to pursue a college education. He taught her how use the school computer to search for colleges and then how to apply for admission and financial aid. Raphaella feels that it was his guidance that led her into a local college that was a good fit for her.

So in 10th grade year I would go to his classroom... I would just go to the computer looking for colleges. He would give me that opportunity to just look for colleges. He introduce me to that. Every time when I would come to this class would be like, "Go to the computer! Let's go!" So I was looking for colleges. I wanted to go to Barry University and he said, "Raphaella, let's start off with Miami-Dade or Broward College." So I applied by myself. I had financial aid. They paid for me.

She was able to get the financial aid she needed to complete two years at the community college and then transition to a local university. She expects to graduate with a Bachelor's degree after one more semester and hopes to continue on to a graduate program in education.

\section{Coralie}

Like Raphaella, Coralie came to the US during her middle school years. When Coralie arrived in Miami at age thirteen, it had been ten years since she had seen her 
mother. Since she was three years old she had lived in Port-au-Prince with extended family members under the supervision of her grandmother.

My mom at the time had five children. She was happily married, but my father fell sick and died. So as a result she had to leave us behind, just looking for a better education, a better life, primarily for us. So she sacrificed her life and left everything behind and came here so she can work very extremely hard. That way she could take care of us, send us to private school back at home and provide our food, clothing, you know, just the basic necessities.

[My mom] never really made it a priority for us to come until there was some kind of stability. You find very commonly, too, that the dream is to bring the older ones in first and they start working and making things better before you bring the younger ones in, you know, who's not able to work. Plus their focus was work, work, work, work, and it was very common that these people are doing two or three jobs so they wouldn't have really have time for their children at that time.

Like Raphaella, Coralie credits the very good private school education she

enjoyed in Haiti with propelling her to further academic achievement in the United

States.

Oh [my school in Haiti] was the best experience ever! I loved school. School was fun! The level of education I've never experienced it here. That's why I'm so grateful that I did not come here that early because of the foundation that I have back at home I don't think I could ever, ever find that here. Actually school has always been joke for me here because it was so superb [in Haiti]. I'm sure they are probably better in the elite schools [in the US], but not coming from an elite background, that was the best of the best education that I could have ever acquired. I mean awesome education. The foundation was set. It was a building block. I mean you didn't have a choice but to learn anyway, and I was blessed that I love to learn, so it was the best experience in my life. It was very foundational to bring me through where I am and where I'm going, because I'm not there yet. It was awesome education, superb education that I never, even at the college level here, I don't see that kind of education. 
Coralie described what it was like for her as a student in a private school in Portau-Prince. Her school was highly disciplined and high standards were maintained with corporal punishment.

[My school was] a private school. It wasn't religious, but it was a private school. Education was the foundation. You get an education when you got there. If they have to beat you up to learn then that's what they did. Yeah, you didn't have a choice but to learn. You know they spanked ... I think they still do spank kids in Haiti in school.

So you get up early in the morning bathe dress and eat breakfast then, you know, everybody had uniforms back then, so you put your nice uniforms and it has to be ... I'm talking crispy! Yeah, we have to go to school very, very clean and perfect ironed out. I mean you talking starch galore! Yeah it was a very small checkers blue and white uniform you know and it was one piece, you know, open up front all the way and the bottom was all pleated and the top, you know, sleeve and everything. It was nice.

I go to class, and from the second you walk in education, education, they just keep pounding you. I remember when I started in the morning they do the grammar part and in the evening you come back for the math part.

It was maybe a good thirty minutes walk [to school]. Some people did walk hours, but mine was just a thirty minute walk. 
It was given, you come home, everybody's studying, just studying until night time. During the summer we had a blast. I mean it's all playing. But during school time its studying, serious studying. And you know the way the system of schooling is, or was - I cannot speak for now - in Haiti you have to memorize everything by heart and you have a lot of things to study every day, so you have no choice. And the next day you gonna be standing there in front of the teacher and recite it by heart, so you have no choice but to study. And every single day you'll be tested and then you have to remember. If its geography you study the whole thing by heart and you go to school and recite it by heart, even if it's ten pages. And math same concept; you continue practicing and you have a lot of homework, a lot of homework! You doing it at home and its due the next day, so you know you cannot slack off. And you don't bring that homework to school the next day you get beat up very bad. Now that I look back, I think it was even child abuse sometimes because they would rip people's skin off literally. But if that's what they knew how to make it ingrained in you, then that's what they did. Some [teachers were] very kind, very nice, fatherly, motherly figures. And some of them was not friendly, but they were there to educate and that was their primary goal.

Remittances funded a large home for Coralie, her siblings, and many cousins.

There were no parents in the household; they were supervised by their elderly grandmother. But they had maids who took care of the cooking and cleaning, and who made sure the school uniforms met the exacting standards of the schools. When Coralie arrived in the US, her family lived in the kind of cramped and impoverished conditions described by the frontiering migrants. They were densely packed into a small apartment that they shared with other immigrants. By the time Coralie arrived, however, her mother was in the position of having the lease on the apartment and being able to take in additional roomers. This meant that despite the crowded conditions, Coralie, her mother, and her siblings enjoyed the privileged position of sleeping in the bedrooms. Coralie's mother cooked for everyone, and extra roomers brought in more financial resources. Although the neighborhood was poor and the household was crowded, Coralie had the support of her large family. 
When we just got here it was very rough. Mom back then was living in one of the poorest area in Pompano, in an apartment, two bedroom apartment. There was so many of us in the apartment. Before we came there were a lot of people who came here too, had no relatives, so they all kind of commuted together, stayed together. And these people, the majority of them was still with them. My brothers came and then we came, they had two bedroom apartment so my mother and the four children. Four girls are in one bedroom. I remember we even had a guy living... we had a little laundry room...living in the laundry room. So the whole living room was a bed. You know, that's where the guys slept. We had like distant families, close friends, people she was trying to help. A lot of them were men, single men who left the country trying to look for a better life for their families, and they were alone so she would help them with the cooking and different things.

Living in a very poor neighborhood, Coralie attended schools with very low expectations and levels of achievement. The environment was far less structured than her Haitian schools had been. Coralie was very critical of the quality of education she found in the schools she attended in Florida. Although she had to work harder to learn in English, she felt that the curriculum introduced very little that she hadn't already learned in Haiti.

The school system, until today, I am not impressed at all. It has always been a joke for me. I was not impressed at all with the education system. Never, never. I mean higher level, yeah, but not the lower level...middle school, high school.

Actually, when I came in, they started me ninth grade and they realized I wasn't at age yet and they shipped me back, due to age. But it was a joke for me. I could not imagine how easy school was. These are the things I used to do in first, second grade that I was doing in eighth grade. I was like, "Are you serious?" So as a result, I never really took school seriously to give my all to it because it was so easy... So you kind of fell in to the coasting... which didn't help cause I'm like, "That's a piece of cake." You know, it's too easy. The stuff I've been learning since four, five, six, seven years old. 
This experience was quite typical of students who had attended high quality

private schools in Haiti. Not only did these students have a strong academic foundation to help them to overcome the difficulties of transitioning to schools in a new country and classes in an unfamiliar language, but they also had a personal confidence that helped them to get through rough times.

\section{Producing a Middle Class Habitus}

Students who attended schools associated with a higher social class than they had been born into were inculcated with the habitus of that social stratum. They learned to present themselves and think of themselves as persons who would attend college and enter the middle class. Raphaella described some of the ways a middle class habitus was produced in her private school in Port-au-Prince.

\section{Raphaella}

Raphaella was subject to strict monitoring of appearance and behavior at the private school she attended. She explained that the director of the school personally inspected each student as they entered the building, checking that uniforms were clean and crisp, shoes were shined, hair was styled, and personal hygiene was immaculate.

When I went to school, you're in the line before you go to class and the principal - if it's a woman they call her directress; if it's a man they call him director, but they are a principal - has to come to each line to look at your shoes, to look at your uniform ... Yes, they inspect every student. They would come and you would have to lift your card up for them to sign that you were present, and then they would look at you. If you're not fit, then they would take you out of the line and they would put you to go stand somewhere with them, then bop bop bop (pantomimes a beating), they do enforcement or they would send you home. 
Standards of dress, grooming, and comportment were rigidly enforced in the private school Raphaella attended. Haitian students learn that it is important to maintain the appropriate image for their social position. They will project an image that is associated with the social class of their families or, in cases like Rapaella's where schooling is a step toward upward mobility, they will learn to demonstrate a habitus of a higher social position. Through this training, the students learned to recognize the symbolic boundaries of class in their society. Raphaella remembers the way her attempt to put a little individual flair into her style was quickly squashed.

I'm young, you know, I just moved up from primary to secondary school. I want to look nice. My mom was taking a perm out of my hair. She braid my own hair, you know, [as opposed to hair extensions that can be purchased and braided into the hair]. I did my uniform. I told her don't make the uniform too long, to the top of my knee. When I went to school, when I'm in the line - that day I was unlucky. The principal took me out of the line and then she made me - I don't know how to call it - unhem, unhem my uniform. She made me unbraid my hair (laughs), and go to class. I was so mad. My uniform is unhemmed and then I have to go inside the class. They must think I'm crazy. (Laughs) It's either I accept this, or they call my parents to come pick me up. So that was a good session of the class I don't want to miss, I had to stay. So I had to unbraid my hair, and I had to do that for the uniform to fit, and then I had to go back in. Yup.

The results of this boundary enforcement were an embodiment of the habitus of the educated class, which is evident at a glance among Haitians. Not only was a student's appearance carefully monitored to enforce the appropriate class habitus, but proper behavior was expected both inside that school and out in the neighborhood. 
For example, you cannot eat on the street. You have to go to the cafeteria or inside the school, but you can't go eat in the street. The principal would not want to see you eating in the street. In Haiti this does matter. It would show where you're from, what part of Haiti you live. They would categorize you by that. They would rank you or label by that. If you eating on the street they would say oh, you're from lavil (a small town), you're the poor kid, you know, you don't fit with them. So they can talk to you and say they don't want you to do that. And then after school hours, they don't want to see you on the street in your uniform. They would think that you were delinquent. Go home, take your clothes off, yeah. And if you're fighting outside the school and they catch you, you're out.

Raphaella pointed out that being able to go to a good private school allowed her to interact with students who came from higher class families and to absorb their cultural norms. But even though she learned to comport herself in a manner associated with a more privileged status, it was not possible to actually elevate her own place in the Haitian social hierarchy. Raphaella explained the benefit of having proximity to students of a higher class, regardless of the immutable nature of her status.

The school that I went to in Haiti, although I was very smart, it didn't change my status. But socially, it changed my environment. Like, there are people who didn't talk to me before, just because they see my uniform they would talk to me. But I still live in the [poorer] neighborhood. For instance, if I was part of one class, even though I would go to school where the higher-class people come to school, I was still not part of that class. But I would still be engaged with them. The status didn't really matter as long as I was able to get the same education, as long as they were part of my school too.

Part of the habitus she developed included a social distancing from the public school students. She explained that there were clear differences between students from different academic institutions, and by presenting herself in the manner prescribed for students at her more privileged school, she signals her superior education to everyone who sees her. 
It does make a difference. Somebody from [a private Episcopal high school] and somebody from [the public school], they don't have the same education. You can tell by the way you speak. By the way comport yourself. And by the way you are in class, your intelligence.

For instance, in Haiti I would not go to school with my shoes dirty. I would not go to school with my uniform dirty or with my skirt above my knee. Because if the principal sees that, you would go back home and you would be sanctioned. On the contrary, people from lycée, you know from public school, it doesn't matter to them. They would go ashy, they would braid their hair, everything. So that, when they see you in the morning going to school, that would make a difference.

Through the standards of behavior and self-presentation enforced in her school, Raphaella learned the habitus, or appropriate norms, of an educated young woman in Haiti. At the same time she learned to employ these traits or symbolic markers for boundary-work, to draw distinctions between the public school students and herself. She came to think of herself as someone who belonged on the privileged side of the boundary. Raphaella became comfortable drawing boundaries against Haitian youth who did not have the means to attend private schools. Furthermore, through these boundaries, she began to see herself as fundamentally different in terms of intelligence, not simply as someone with greater opportunity. Symbolic boundaries, such as these, serve to justify the established hierarchies, as young people who cannot afford schooling are stigmatized as "delinquents."

\section{Social and Academic Boundaries in American Schools}

When Haitian immigrant youth entered US schools, they were subject to forms of boundary-work that they had not previously encountered. While remittances may have introduced them to a higher class habitus, these symbols did not always carry the same meanings and privileges in their new American social lives. These young migrants 
experienced the boundaries created by racial and ethnic discrimination, prejudices against immigrants, and the quotidian barriers produced by their difficulties with English. I return, first, to Coralie, who came to the United States in 1980, and then to Raphaella, who attended high school in South Florida two decades years later.

\section{Coralie}

Coralie arrived in South Florida to join her mother and other siblings in 1980, when she was 13 years old. Like every contributor to this research, she found that there were boundaries to learning and to fitting in with her peers due to her limited proficiency in English. While bilingual and ESOL (English as a Second Language) programs were intended to help immigrant students to progress in school, many young migrants asserted that these classes produced both social and symbolic boundaries. Students faced great pressure to acculturate to the social norms of their school environments and shed the markers of immigrant status and ethnic characteristics. Student in ESOL classes had little interaction with the general student population, and felt "like second-class citizens."

When I came here I started school right away. Like in the middle of eighth grade ... It was so terrible. They did have the bilingual program there and these kids came from everywhere. It was a disaster! In the bilingual classes a lot of them were concentrating primarily of teaching you English. Started at a much lower level, which I'm sure a majority of the kids were above that. It's just language barrier. It was not really not having the education; it's just the language barrier.

English was not the only impediment to education for Haitian immigrant youth.

Assignment to ESOL classes marked a student for boundary-work from their mainstream schoolmates. African American students taunted new Haitian immigrants with stereotypes such as "Haitians stink" or "Haitians eat cats," defining an ethnic boundary 
by violations of social norms. They mocked the way the Haitian students dressed and the food they ate. Depicting Haitians as the violators of respectable standards of behavior and violators of social taboos, they tainted the immigrants with stigma. By creating boundaries against the Haitian students, African American students enforced a social hierarchy that placed themselves in a superior position to the new immigrants. They were able to reward Haitian students with acceptance or at least relief from torment if the new immigrants respected the social hierarchy.

As Alex Stepick (1998) has documented, Haitian youth in South Florida suffered tremendously in the 1980s from the rampant negative stereotypes and discrimination against Haitians. Some students hid their ethnicity in order to avoid the stigma. Several Haitian contributors recounted the story of a Haitian teen who committed suicide when his Haitian heritage was publicly revealed. Coralie recalls the hostile environment Haitians endured at her school.

There were a lot of social issues going on back then. In the eighties it was terrible. The mistreatment, it's like we're aliens in the school. For some reason they like me ...you know I was one of the blessed one. But the mistreatment around me was amazing. It was a lot of distraction back then to go to school as a Haitian. Every day there used to be a major fight. Haitian against every nationality in the school. They used to tease them so much and beat them up, literally. There was a lot of picking, a lot of bullying, so it was a lot of distraction. Very difficult as a Haitian back then to be in that education system and to learn because you have to be more in defensive mode, survival mode, so you do not get killed, get hurt, 'cause they'll team up and beat you up just because you're Haitian. Very, very, extremely difficult time to go to school back then. 
Everywhere you walk all the other kids would call them (she hisses in a whisper), "Haitian, Haitian!" And I remember from passing by and I would respond. I would say, "Haitian? You calling a Haitian? How can I help you?" They like, "Oh you not Haitian, get out of here, you not Haitian." I'm like, "Yes I am Haitian, you calling Haitian, what can I do for you?" So for whatever reason, I think it was grace of God, I was never picked on. I don't know why. But I was really blessed, let me put it that way. But all the other kids around me, all the other Haitian kids, they really had it rough. Very, very difficult. It was a very hostile environment to earn your education...very difficult. Extremely, and I've always said that I think, every Haitian that went to school here, in particular graduated college here, they deserve a crown of diamond because it's through a very, very difficult, insulting time, hostile environment. A lot of them will drop out they're afraid to come to school cause they get beat up and get picked on. They become very aggressive because of that and I think a lot of [the problems] that we see now probably have resulted because, you know, it's always been a very - even today - a very hostile environment for Haitians to go to school.

Coralie directly identifies the hostile environment that Haitian youth encountered in schools as a boundary to their academic progress. Students were subject to physical and verbal abuse, and they did not feel that school personnel felt compelled to protect them. To continue their educations, students had to find a way to deal with the harassment and violence.

In addition, students perceived that teachers did not have high academic expectations for them. Students in ESOL classes felt that they were in "the dummy class." Some students, like Coralie, who had great confidence in their academic abilities, lobbied school officials to be transferred out of these programs and into classes with the general student population. 
So I, personally, I made a vow. I said I want to learn; I don't want to be in that kind of environment. So I asked them to put me in regular classes. And in the regular classes, of course, you don't speak English that well so they make it very difficult. I had to use dictionaries around class. The teachers, some of them were helpful; some of them were not helpful at all, actually would rather that you were not there at all.

Low expectations of immigrant students are symbolic boundaries that can justify disparate treatment. If school personnel perceive students as unsuited for higher education, they may not receive the necessary preparation to continue their schooling. Coralie recognized that if she stayed in the bilingual classes she would not advance in the subjects she needed to master to be able to attend college. She had to work much harder to succeed in coursework in English, but she was determined to meet the challenge. She noticed that students who stayed in the bilingual classes were not on the path to upward mobility that she believed she could achieve. Coralie had the examples of older siblings who had migrated before her, studied English, and were attending college in the US to reinforce her confidence. They helped her to see that remaining in a bilingual program would create a boundary to her academic progress. But even outside of the ESOL program she felt the boundaries drawn against her and other Haitian students by some of her teachers, as she recalls, "The teachers, ...; some of them were not helpful at all, actually would rather that you were not there at all."

\section{Raphaella}

Like Coralie, Raphaella arrived in the US when she was 13 years old. But although she came 20 years later, after more than 100,000 Haitians had already settled in South Florida, conditions for students who came from Haiti were still quite difficult and hostile. Having to attend classes in a language she didn't understand and couldn't 
communicate in was only part of the frustration Raphaella experienced when she arrived in the US in 2003. Although she loved exploring her new neighborhood in Miami, at school she was shunned, harassed, and threatened.

Oh, I went through a lot! I went through a lot especially with kids here. Even though they're Haitian, but they were born here... It was hell. In school. Outside school I'm happy. I am in a big country and when I'm in the neighborhood, I'm walking, looking at people. I go to the store, buy phone calls to call my friends, people in Haiti. But when it's in school, I'm not happy. Because I'm new to the country, people would not talk to me. Students would accuse me of things that I don't even understand. And sometimes when I go to PE (Physical Education) class some students would want to fight me. I don't know what I do. I don't know the language. It was hell. I went to hell.

Like Coralie and every other contributor who attended high school in South

Florida, Raphaella emphasized the very hostile environment that Haitian immigrants had to contend with. Many recounted that they had been afraid to go to school, and not one felt that school personnel would protect them. As students in Haiti, they were all familiar with harsh tactics used by teachers and school administrators to inculcate the habitus of the school and enforce its requisite hierarchies. They had been relieved to hear that corporal punishment was not used in American schools. But the immigrant teens never expected that it would be their classmates who used humiliation and physical assault to mark and enforce the boundaries within the school population. Learning to speak English and to adopt the dress and behaviors considered appropriate by teens in their schools helped to deflect unwanted attention.

After six months Raphaella was sent to live with another relative and had to change schools. Her situation became even worse. She was subject to constant torment, not only at school, but in the house she shared with her American-born cousins, as well. 
It was worse. Students would want to fight me. I'm walking, they would push me. I don't know, I just can't defend myself. I don't know the language. The American kids mixing with the Haitian American kids would not want me to stay in the classroom in peace.

And the room that I was in, I was living with my auntie in Orlando. Her children born here, and they still didn't like me because I'm from Haiti. So I would just stay in my room. After school, I would just stay in the room, lock the room, until at night when my auntie come, I would go take a shower. As long as they were in the living room, I would not be able to go. My own cousins, but they're born here. They don't know me. Because they're born here. They don't have any clue about the culture. And then they just look at you bad because of what they hear, because you don't speak the language, Haiti's a poor country. When you leave Haiti they just put you like, you're lower than them. It doesn't matter if you're like part of them, part of the family, they would treat you different. They would tell you "Oh go back to Haiti. You're a boat people." "Why did you come here on the boat?" They would treat you different. Unless if they used to go to Haiti and meet you in Haiti, you know in summer they would go to Haiti, then it would be different. But if they've never been in Haiti, it's something else.

Even among her own cousins, Raphaella was subject to the boundary-work carried out against Haitian immigrant youth. They ascribed to Raphaella the stereotyped image of Haitians as impoverished, unintelligent, uncultured, illegally in the US, and unwelcome. Rejecting her was a way of distancing themselves from the stigma of Haitianness. Raphaella's cousins could also be targeted for rejection if they publicly accepted her.

Raphaella succeeded academically although she continued to experience harassment and rejection throughout high school. She was very proud of her scholastic accomplishments, but she never felt that she was accepted socially by her high school peers. Feeling alienated from her classmates, Raphaella avoided the social events that most American teens enjoy. 
I didn't go to prom. I didn't go to grad night. I felt that the students are taking advantage of me because I was smart, but at the same time they did not want to hang out with me because I didn't speak English. So I felt what was the point of going to grad night and to prom with them?

Furthermore, Raphaella felt that some of the teachers and administrators harbored prejudices against Haitian immigrant students. Teachers did not always show the skills or desire to help immigrant students understand and improve. She believed that the school did little to prepare Haitian students for college and, in fact, tended to discourage members of the faculty or staff who made the effort to do so.

When the teacher is giving lessons they would treat us different. Because the Americans are in the same class, the white people are in the same class, Hispanics in the same class, and we just came from Haiti and we're in the same class. So the teacher has to be well-qualified to manage, to balance it. Some teachers are well-qualified teachers. They understand. They manage the class well. But others, they would discriminate against us too and they would just give us any grade.

In my 10th grade year I had a counselor who really understood me. He was very nice. He would get in trouble for helping the Haitian students. They didn't want him to teach us about financial aid in high school. They don't teach you that at all. They don't want you to apply for financial aid. But he would tell us about those things and start making us apply for college in 10th grade. He would help us, but the principal would say you have to let them find this out on their own. He would get in trouble for helping us.

Fortunately Raphaella found that the environment was different when she advanced to college. In college she also felt sometimes that teachers discriminated against Haitian students. But the general social climate was much better than it had been in high school, and it was a relief. Discrimination seemed to be a minor irritant compared to the relentless verbal and even physical abuse Haitian students experienced in high school. 
Compared to high school it's a very, very big difference! You don't have students bothering you. You don't have teachers yelling. It's different. Totally different. It's like a different country. In high school, you have kids fighting, you are around delinquency, groups, like gangs... It was different in college. [In high school] people would fight you if you didn't do what they say. And you would want to do things just so you wouldn't get beat up. Or get jumped. It's different in college.

In college, Raphaella returned to an environment that was more consistent with her middle class habitus. She felt that once again boundaries were drawn on familiar criteria. Her academic success could be deployed in college to demonstrate that she belonged among the educated classes of Americans.

Despite her experiences with racial and ethnic prejudice in school, Raphaella is confident that her education will allow her to advance socioeconomically in the United States. She feels that her academic credentials allow her to compete with people of all races. She does not anticipate that the color of her skin or her national origin will be a boundary to her employment opportunities.

I'm able to get an education just like a white person would. ... I'm able to apply for any position that a white person would apply. I'm able to incorporate in America with my education and I feel good about it. I feel like, well, why not? I'm doing my best. I'm going to school. I'm getting an education. I passed the high school level. I did my college level. Now I'm a senior. I feel great! I feel great. I feel like I'm part of it.

Because I think that in the US education counts more than race. Race, yes, we know about race. But when you have the education, that's not the first factor anymore. You have the education, you're a part of it. It doesn't matter if you're black, white, Hispanic. If I have a PhD, and that person has a PhD or a Masters and she's white, I can apply. So to me it's education. I want to go as high as I could to take race out of my mind and put in the education factor. 
At a certain point, yes, high level people face discrimination; but me, although I know I'm going to face it, I'm not going to let that bother me. I know that you have the education. You can speak; you can write. I have it too. I can speak. I can write. I can talk to you. I'm not going to put myself down. I'm not going to look down. I'm not going to look down and not look at you in the eye. I'm going to look at you too. You're going to talk; I'm going to talk to you. I'm not going to say, "I'm black, I'm this, I'm that," feel inferior... No.

Raphaella does not feel inferior. It was clear that the self-concept and middle class habitus instilled in trailing migrants who had attended high quality schools in Haiti provided resilience against the negative reception they faced in South Florida. They simply did not accept the low expectations of others. Trailing migrants who had been groomed to enter the middle class had already learned to draw boundaries against students who would behave aggressively toward them and defy the norms of student behavior expected in Haiti. Students like Raphaella and Coralie defined themselves and their place in society by their academic accomplishments and aspirations. Rather than accepting the habitus of their classmates, students with successful teen transitions maintained boundaries against behaviors that would undermine their academic success.

Coralie and Raphaella demonstrate teen transitions of students who successfully complete high school and move on to college. Their academic pathways relied on a strong family commitment to their educations and sufficient financial resources from abroad to allow them to attend high quality schools in Haiti. These teens came to the US trailing family members who had been established in South Florida for years. Their families were certainly poor; but by the time these teens migrated to the US, the family had a great deal more security than frontiering migrants had when they first arrived. 
Teens who had attended high quality schools in Haiti were able to cross educational boundaries because of their strong academic foundations. Nevertheless, their school years were extremely difficult. Once they arrived in the US, they were subject to very hostile school environments, where Haitians routinely suffered both physical and verbal abuse. But teen migrants who had attended high quality schools in Haiti had developed a middle class habitus and self-concept that helped them to overcome the challenges of the anti-Haitian environment. They had learned to feel superior to and to maintain their own boundaries against students who Raphaella described as "delinquents."

The stories of teen trailing migrants provide some explanations for the “comparatively more problematic adaptation" Rumbaut's analysis indicated (2005: 1191). These young people must contend with obstacles to their educational opportunities and impediments to their progress. Students with more substantial transnational ties had more resources to cross the boundaries they encountered.

\section{Crossing Boundaries to Higher Education}

The previous sections of this chapter demonstrated incorporation pathways of the transnational generation, the trailing migrants whose educations in Haiti were funded by remittances. In Tipa Tipa, I discussed the boundaries for trailing migrants who must set aside their educational aspirations to provide or care for other family members. When they say "I lost my time," they reflect the Haitian cultural expectation that obligations to others create boundaries to personal advancement. There is a time in life when the family invests in you; there is a time when you invest in others. In Teenage Transitions I 
examined the boundaries encountered by young migrants who entered the United States during middle school or high school. Boundaries to their academic achievement include language limitations, which affected all contributors but were particularly problematic for Haitian immigrants at this age. Not only did students risk falling behind in their academic progress, but they also had to contend with social boundary-work of their classmates. Nearly all contributors who migrated as teens experienced both verbal and physical abuse in their schools. Other students viciously defended boundaries against Haitians who displayed their recent immigrant status through speech, dress, and behavior. But, as Raphaella explained, once they moved on to college Haitian immigrants were still subject to some discrimination but not outright abuse. Not all teen migrants make it to college, though. Insufficient academic preparation, as William had, leaves some teen migrants unable to earn the high school diploma. Lack of this certification becomes a boundary to entering college or a military career. Other students, like Evangelique, may cross academic boundaries only to encounter insurmountable financial obstacles.

In this final section of the chapter on the education of the transnational generation, I discuss the ways that contributors who migrated to the United States after completing high school in Haiti crossed boundaries to higher education. Beginning with their early lives in rural Haiti, I trace the educational trajectories of Daniel and Charline, who first crossed boundaries to education in their homeland and continued to do so after joining their families in South Florida. I analyze these cases juxtaposed against those of the transnational generation migrants who were unable to achieve similar levels of education. 


\section{Daniel}

Growing up in the rural areas of northwestern Haiti, Daniel started school at six or seven years old. He learned to read quickly and began a life-long love of learning. In 1977 his parents brought him to the capital city, Port-au-Prince, while they left to seek work in the United States. They were determined to give their children the chances for education that they never had. Daniel becomes very emotional when he thinks about the sacrifices his parents made for their children to be educated:

In Haiti, most of the parents, they don't want their children to grow up the way they did. My mom always told me. "I didn't have a chance to go to school. It's the time for us really to push you up so you don't have the same issues that we have to deal with. To come and have the lowest job, to have the lowest paying job in the country." But the love, they do it with love. And I respect them for that. They teach me character.

Like many Haitians leaving the country at that time, Daniel's parents had only a few years of schooling, no English, and very little knowledge about what life would be like in the United States. But they felt it was necessary to seek work in the US in order to provide for their children. The children stayed with relatives for a time; but by age 15 , Daniel was left to care for two brothers and a sister. After his mother left Haiti, Daniel would not see her for nearly fifteen years. He remembers, "When she came back and saw me, she didn't recognize me." His parents sent remittances to support the children, but he was always aware of the need to make the money last.

At 15 years old I was like the adult of the house. ... I had to be the head of the house at that time. Fifteen, sixteen years old in Haiti. But it was kind of very tough, because I had to go to school and also if my parents don't send enough money, I have to make sure that I take care of [my siblings]. 
The obligation for a teen-aged boy to become the man of the house was common in households where the parents were abroad or in a single-mother household. Other young men and women had to leave school to help support the younger siblings, particularly in families that received no remittances or had only one family member abroad. Daniel was fortunate to have received enough money to stay in school, but part of what made this possible was his drive to find a way to contribute without cutting his own education short. His parents had made it clear to him that education was the key to a successful future. Daniel pushed himself hard to qualify for the scholarships that were awarded each year to students who excelled at their exams.

At that time I was in the school in Haiti, they have 3 exams for the year. One every three months.... If you average for the first two exams, [a very high score] they skip you for the third one, and you can have a full scholarship for next year. So I always fought to get this. I know the money my mom would send to me, it was in my pocket. Or if she can't I don't have to worry about it. Also since I was pretty much on top of all the courses in the classroom, I used to help my friends and they pay me. So I tutored them and they paid me money, and with this money I take care of my brother and sister.

He was able to fulfill the expectation that older siblings will sacrifice to keep their younger brothers and sisters in school without leaving school himself. Not only did he earn scholarships, but he began to make money himself as a tutor to other students who were also receiving remittances. The transnational funding of their educations helped contribute to his educational expenses, as well.

Daniel completed high school and began to study engineering in college. While trying to complete college, he worked teaching traditional Haitian music to the children 
of wealthy Haitians who had returned to the country after living abroad during the Duvalier years.

By 1990 Daniel had a wife, a daughter, and another on the way. His parents were able to sponsor him for US residency, and in 1991, just after the birth of his second child, he left to join his parents in Florida. The arrival of a family reunification visa created a difficult decision point for many trailing migrants. Their lives had continued and with long backlogs for visas they often had to choose whether to separate from spouses and children, change their status and re-submit immigration petitions, or simply abandon the plan to come to the US.

I had like one week before my visa expired, because when they give you the residency they give an envelope that only the US immigration in here can open. You open it, anything happen to it, any damage, it's cancelled. It's no good. But I wanted to see the child before I left Haiti. I wanted to spend the whole time with my daughter. After she was born and after my wife came from the hospital, I said now it's time for me to go. So she was brand new, after I think 3 or four days she was born, my second child, I left to come to Florida. And it was really tough. I decided I'm not going to wait any more. I had my reservation, I just - boom - I just left. So I came in 1991.

Unlike his parents, who had arrived in Miami in 1977 as frontiering migrants, Daniel came to the US with a place to stay, a family to support him, a good education, and a green card. He had studied English, but needed to take classes to improve his comprehension and speaking ability, which he described as "awful." Soon he was able to continue toward an associate's degree at a local community college in addition to working part-time. 
In 1991 I continued [school]. I went to study English, because I had almost no English. I tried to learn English from Haiti, but when you learn English in Haiti sometimes if you find a good school, American school, there's a great chance where they can learn a lot. But still, the slate was very empty. I had a pretty good knowledge of the rules, the grammar. ... but the pronunciation - awful. So when I came, I went to school to get my English. I went to Miami-Dade Community College.

Although he had some set-backs, and it took a while to complete his courses at the community college, he maintained a high GPA and, in 1998, he was awarded a scholarship to a local university where he completed Bachelor's and Master's degrees. He currently works in the public schools, in addition to pursuing his love of music as a choir director in a local Haitian church. Daniel was eventually able to bring his wife and children to the US. His oldest child has already graduated from college and works as a nurse. His younger daughter is a college student.

As the child of uneducated labor migrants, Daniel's academic achievements in the US have been impressive. If he had migrated at age 12 along with his parents in 1977, he would have been thrust into an American school system that was only beginning to identify the special needs of immigrant children from Haiti. Growing up with poor immigrant parents in Miami, it is possible that he could have accomplished this level of education, but it would have been far from likely. He attributes his success to the sacrifices of his parents and the examples of some excellent teachers in Haiti. Even less likely, had he grown up in Miami, was the possibility of developing the middle class habitus and self-concept produced by his academic advances in Haiti. He had an opportunity, by rising to the level of education that he did in Haiti, to attain a middle class status as a teacher in Haiti. He married an educated woman and saw himself as a professional. Although he struggled to improve his English and to complete college 
courses in this new language, he had the confidence and expectation that he had the educational foundations and intellectual capacity to do so. Migrants with strong educational foundations have a much better chance to succeed academically in the new country.

The transnational generation relied on remittances to exceed the low levels of education achieved by their parents. Access to remittances for children of immigrants like Daniel meant an opportunity to move to the capital city, attend higher quality schools, and stay in school longer and more continuously. In addition, when trailing migrants arrived in the US they could rely on family support for their basic needs. Not only was this a more positive experience on an emotional level than the precarious first months of the frontiering migrants, but having family support when they arrived in the US increased the likelihood that they could attend school. Daniel's parents continued to provide support that allowed him to persist in higher education. Haitian parents regularly pointed out that they were happy to support their children until they were 30 , or even older, particularly if it meant they could continue their educations. Daniel did not lose his time because, with his parents and other relatives already working in the United States, there were sufficient family resources to allow him to work part-time and stay in school.

Daniel's trajectory of upward mobility through educational achievement is by no means a rare case. In fact, this transnational process of improving socioeconomic status in a single immigrant generation was repeated over and over again in the stories of transnational families. Daniel's story demonstrates a dramatic leap in from parental illiteracy to his earning a graduate degree and achieving middle class occupation in the United States. Most of the families who contributed to this research saw more gradual 
progress but all had been able to use transnational resources and opportunities to increase educational attainment and socioeconomic status.

The transnational process of increasing education is an important aspect of contemporary immigrant incorporation. Because educational attainment is an important factor in immigrant incorporation, immigrant families, like Daniel's, have been able to change the nature of their incorporation into the United States through a transnational process of crossing - because of transnational access to resources - or evading - by migrating - boundaries to socioeconomic mobility.

\section{Charline}

Charline tells a similar story of transnational socioeconomic mobility. Born in the central agricultural region of Haiti, Charline was sent at 2 or 3 years of age to be raised by her godmother in a small city on Haiti's northern coast.

My godmother was a little more comfortable financially and then she had no kids. She was probably 21 years old and she was doing ok, so since my mom had two of us she said let me take my godchild and I will take care of her for you.

As discussed in Chapter 5, this child-rearing decision reflects normative practices in Haiti. The primary explanation for sending her to be raised her by godmother was financial. Charline's mother was stretching her resources to care for her growing family and her godmother, who worked as a seamstress, was more financially able to provide for the child. But further, her godmother had no children of her own. Children are both cherished and seen as a necessary part of a woman's life in Haiti. From a young age they can be helpful with household chores. But, perhaps more importantly, they are the 
primary investment for a woman's future security. If she raises the child well, she can expect to receive support as she grows older. Sending a child to be raised by a relative or fictive kin also strengthens the relationship between the adults involved, creating persistent reciprocal obligations. In Haiti, relationships are the foundations of security, and caring for children is an important way that lasting relationships are built.

Charline's mother went to work in the Bahamas, where she would spend most of the next 10 years, leaving her other children in the care of their grandmother. When Charline was six, her godmother enrolled her in a strict Catholic elementary school.

It was a religious school, Catholic, directed by the nuns. It was very, very strict and that was a little traumatizing because you get the paddle. And my godmother was very strict too - very, very strict. She wanted ... She has a little education, but she didn't have much, and she wanted to pour everything into me.

By the early 1970s, Charline's mother had saved up enough money to buy a house in Port-au-Prince where her children and extended family members would all eventually move in order to have access to secondary schooling and other benefits that were not available outside of the capital. This decision also reflects a pattern of rural-tourban migration typical of many Haitian families. By moving from the interior provinces to a small city, Charline had more educational opportunities. But secondary education was available in very few places outside of the capital, so she and many other relatives went to live and attend school in Port-au-Prince.

Although many siblings and cousins lived together in the home Charline's mother purchased, choosing a school and managing educational expenses was primarily the 
responsibility of each child's parent or the guardian who supported them. For Charline, this meant continuing a strict Catholic education.

Not everybody went to the same school. My godmother, she believed a lot in those nuns, religious schools. She wanted to make sure I got the best education. So she put me in those very renowned schools in Haiti by the nuns throughout my whole secondary career and I graduated high school there. The other kids, they went to other schools - good schools too, but not so focused on the religious aspect of it.

After establishing a home in Port-au-Prince, Charline's mom decided not to return to the Bahamas but to make her way to South Florida. Charline was fortunate to have a parent with the ability to travel back to Haiti occasionally. The consumer goods her mother brought when she visited were central to Charline's expectation of what life was like in the United States.

When my mom come back she bring all those good-smelling soap and nice clothes and underwears and everything...I feel like it's a land where things are great! So I wanted to come enjoy it. Yeah! She bring all those nice shoes, nice stuff...I'm like wow! I can't wait to go there one day...

Charline was drawn to the US by the goods sent by the frontiering migrants and by the opportunities for work. When she began to come herself to visit she became determined to migrate to the US to pursue her future here.

Oh, everybody's desire was to go to the United States at one point. And to work, because Haiti wasn't really promising when it comes to a future for young people. There was always uprising, always a problem so everybody wanted ... "Oh god I can't wait for me to leave and go to United States and work for myself." That was a desire. As soon as I finished high school I wanted to... I came here, I used to come here to visit. [My mom] managed to get me a visiting visa so I used to come here and then spend the summer and go back. But at one point when I finished high school, I decided even though I had a visiting visa I'm gonna go and I'm not going back. Because for what? I have no desire to go back. 
Things were not quite the same, of course, when she came to the US for good. Charline realized that she needed to work if she wanted to enjoy all the nice things she had come to associate with life in America. Furthermore, she realized that she had an obligation to make things easier for the family by providing more for herself.

When I first came to visit, it was still nice... Especially when I would come to visit and going back a lot of people would give me money so I would go back with a stash of money. You know, I was excited. But when I came to live, that was a different story...nobody gave me anything and I had to work for it. Reality sets in.

First, I wanted to get a job...make money. First thing was to be independent, working and not having to depend on my mom to give me stuff. That was my first goal. That was very, very important! [My mom] has 8 kids and then I'm older. I need to make room for the other ones that are younger. I am of age to take care of me, you know. And you know how it is when you have to ask for things. You have to wait, you know, take a number. But when I work I can provide my own stuff when I feel like it! I had in the back of my head to get an education, you know do something, because I am a high school graduate and I have the potential of doing everything, but I didn't know what it was and couldn't put my finger to it.

The availability of desirable consumer goods she had come to enjoy while still living in Haiti were a powerful incentive for Charline to go to work right away, rather than to pursue further education immediately. As an older sibling, it was also her role to become less of a burden on the family resources so that more of her mother's income could be directed toward the education of the younger children. She lived with her mother and other siblings and did not have to worry about finding and paying for housing. Although she contributed some of her earnings toward the family expenses, her employment was mostly a way of providing extra amenities for herself. Her way of life was not like that of the frontiering migrants, who allowed themselves very few luxuries. 
She was beginning to pursue a more individualistic lifestyle, typical of American culture, and used consumer goods to display an elevated class orientation.

She began working in a retail store for minimum wage, but her educational foundations allowed her to quickly move into a position working for the county providing refugee resettlement services to other Haitians. As with many other immigrants from the transnational generation, Charline benefitted as the needs of the growing ethnic community provided job opportunities for Haitians who had sufficient education and language skills.

When I first came I was working in a five and ten store, I don't know why they call it that, but it was a store where they sold everything. They had a sewing department and - I hardly spoke English then - but I was playing the role of a translator, too. So I was doing everything, making three dollars and fifteen cents an hour.

I never saw the check...the guy usually cash it for me and give me 95 dollars a week so I, maybe that's what I made. So I work there for about nine months from January to October and after October somebody took me to a job with refugee re-settlement with the government, the county. I graduated from three fifteen to five-something plus. I was a translator too working there, and I spent ten years there at the refugee center.

At that time there was a lot to be done for the Haitian community. Remember the community is green. A lot of refugees and they need help to go to food stamp, they need people to translate, people to recruit them. So they had a center where they were employing a lot of people, a lot of people. They had different programs like that at the time. You would go to the courthouse and translate for them; you would go fill out their forms. There were needs for educated Haitians to help with the group that came. A lot of them needed help, so that's how that was a source of employment.

But with her academic credentials she felt she should try to reach higher for more education and a better career. Having enough education to work for the county also meant that Charline had access to benefits, like tuition reimbursement, that are not 
available to most labor migrants. Being just this small step higher in education and class

orientation than the frontiering migrants provided opportunities that were compounded.

While I was working in the county, I was taking one class at a time. I was working like what they call a "health services worker." That means just a beautiful name they created for gopher! So I was just there, answering the phone, filing, do everything that I could, you know. And I said that's not what I came here for, I can get an education. So I start taking one class at a time. At the time, since the job I was working for was with the county, they had a reimbursement program. You have to pay for the class and then they will reimburse you at the end. So I would do that, and while I was taking the class, one class at a time and a friend of mine listened to the radio and she heard about the scholarship. She said, "I know you want to go to nursing school, here's what I heard today. " I called that number she gave me and one thing led to another and then it was reality. I thought it wasn't true, but when I applied I got it.

So while I was working [for the county], I went to nursing school with a scholarship where they pay for my education, books and all included. It was with the hospital I wanted. They were looking for nurses, they were attracting people to go to school for nursing. Throughout the program you have to maintain at least a $C$ or above, and once you finish, you pass your board, you work for them for two years. And I thought I was only working for 2 years, now I'm going on 20 years. So that's it...that's my working story! 3 places! Isn't that good for 31 years in a country? 3 jobs! That's it!

Charline credits the solid foundations of her schooling in Haiti, as well as the strong value of education instilled in her by her godmother and other family members, for the success she has had. The rigor enforced in the Catholic schools she attended in her youth left her with the disciplined study habits she needed to advance academically in the United States. 
Haitian education at the time was really strong. I remember at one point when I was in nursing school, the Americans were saying, "How do you do it? When I'm studying, I have to have a medical dictionary and an English dictionary." But we learn Latin in Haiti and at certain point English has the same root. So we had really good education at that time. And my kids, sometimes they [ask me to quiz them with flashcards], "Oh mom can you hold this for me, let me see if I know it." And I say, "Go ahead." They say, "How do you know it?" I said, "I know!" And if they make a mistake even without looking I say, "Stop! You made a mistake." "How do you know that stuff?" I said, "I come from Haiti and we had good education...Chemistry, Algebra, and everything. That's good school!"

Charline and her siblings all completed high school - some in Haiti and some in the US - and seven of the eight went on to college or professional training. She married another Haitian immigrant and raised several children, who currently attend college in Florida. Charline's rapid upward mobility in the United States was possible because of the strong academic foundation she had when she migrated. She enjoyed a high-quality education in Haiti because of the investments of her mother and godmother. The women who raised Charline had very limited educations themselves, but they felt strongly that every effort should be made to insure that their children would have more educational opportunities. These opportunities resulted from an extended family support system and transnationally generated funds.

A solid academic foundation was essential to Charline's ability to succeed in higher education in the United States. In addition to the transnational financial support that made her education possible, as a trailing migrant Charline was able to move into a secure home environment that helped to give her the freedom to continue to pursue her education. By attaining a Bachelor's degree in nursing she was able to move fairly 
quickly into the American middle class. Charline is proud of her accomplishments and feels that she is a good example for the young people around her.

When I came to the United States I started working, but that wasn't what I wanted to do. I was working, but I always had it on the back burner that I need to go back to school. So even when I was married with two kids I went to nursing school. I succeeded in being an $R N$, which was very hard for me, but I did it. Now I consider my life not only a good example for my kids, but I consider it a good example for other young people that I meet at my worksite. I'm always telling them, this is how it was for me when I was in nursing school with two kids and a husband and a house. And if I can do it, you can do it. I'm always encouraging people to go to school.

The frontiering generation believed that education was the key to upward mobility, but without the money generated by working abroad they could not have provided it for their children. The transnational process of migration to produce remittances, investments in education for children in Haiti, and the subsequent migration of those children with higher levels of education, produced the upward mobility that these families were able to achieve in the US.

The stories of Daniel and Charline allow us to look back at their transnational paths of academic achievement, the support of the extended families that helped them cross boundaries to education, and their eventual incorporation into the American middle class. Like most of the contributors to this research, Charline and Daniel began their lives in the Haitian countryside with parents who had, at most, a few years of elementary education. Remittances and support from extended family, including godparents, made it possible for them to attend school continuously and to move to urban areas where higher quality schools and secondary education was available. Crossing the significant boundaries to a high school degree in Haiti allowed Daniel and Charline to enter the 
United States on more advantageous terms than the migrants who lacked these academic credentials. Still, having a strong educational foundation and a high school degree is not sufficient to continue with higher education after arriving in the US. Charline and Daniel had enough family in South Florida to be able to continue their academic progress, rather than having to shift their focus toward earning money to support themselves and others. They did not lose their time the way that Jean-Luc had. Still, good educational foundations and family support were not all they needed to complete college degrees. Both Charline and Daniel received substantial financial aid - including scholarships and tuition reimbursement programs - that were essential to their academic achievement. In contrast, Evangelique's story, in Teen Transitions, demonstrated that it is difficult even to begin to take college classes without financial aid. Many students find that even with financial aid they lack the resources necessary to complete their degrees. Many individuals from the transnational generation ended up in the "some college" level of academic attainment, having lacked the financial resources for completing a degree or having lost their time before their slow progress as part-time students resulted in a diploma. But without a higher education credential, having attended college does little to enhance one's job prospects.

The data I presented in this chapter illustrate the transnational process by which Haitian immigrant families cooperate to allow some individuals to cross boundaries to higher education. Family members including parents, siblings, aunts, uncles, cousins, and even unrelated fictive kin may contribute in a variety of ways. Some directly contribute by funding expenses for education, but others participate through childcare, preparing 
meals, arranging for travel or documents for migration, or by providing emotional support, guidance, or prayers.

\section{Haitian Immigrants in South Florida and Education}

The ethnographic approach to this research allowed me to describe and examine the transnational processes utilized by the contributing families to access higher levels of education. But an examination of the educational pathways of Haitian immigrants in 27 transnational families cannot provide an indication of the frequency or magnitude of these processes. To provide a broader context for the ethnographic research, I examined the educational attainment and enrollment of Haitian immigrants in South Florida, using the US Census, 2009-2011 American Community Survey. I define South Florida as including Miami-Dade, Broward, and Palm Beach counties, which comprise the MiamiFort Lauderdale-Pompano Beach, FL Metropolitan Statistical Area in the US Census.

Educational attainment is measured by the US Census among individuals who are 25 years of age or older. While it is not uncommon for older students to continue their educations today, a student who attended school continuously from the age of five could be expected to have completed college or even a Master's degree by age 25 .

Approximately 36,000 Haitian immigrants (13\% of the total Haitian immigrant population) in South Florida are less than 25 years of age. 
Figure 5. Age distribution of Haitian-born persons in South Florida

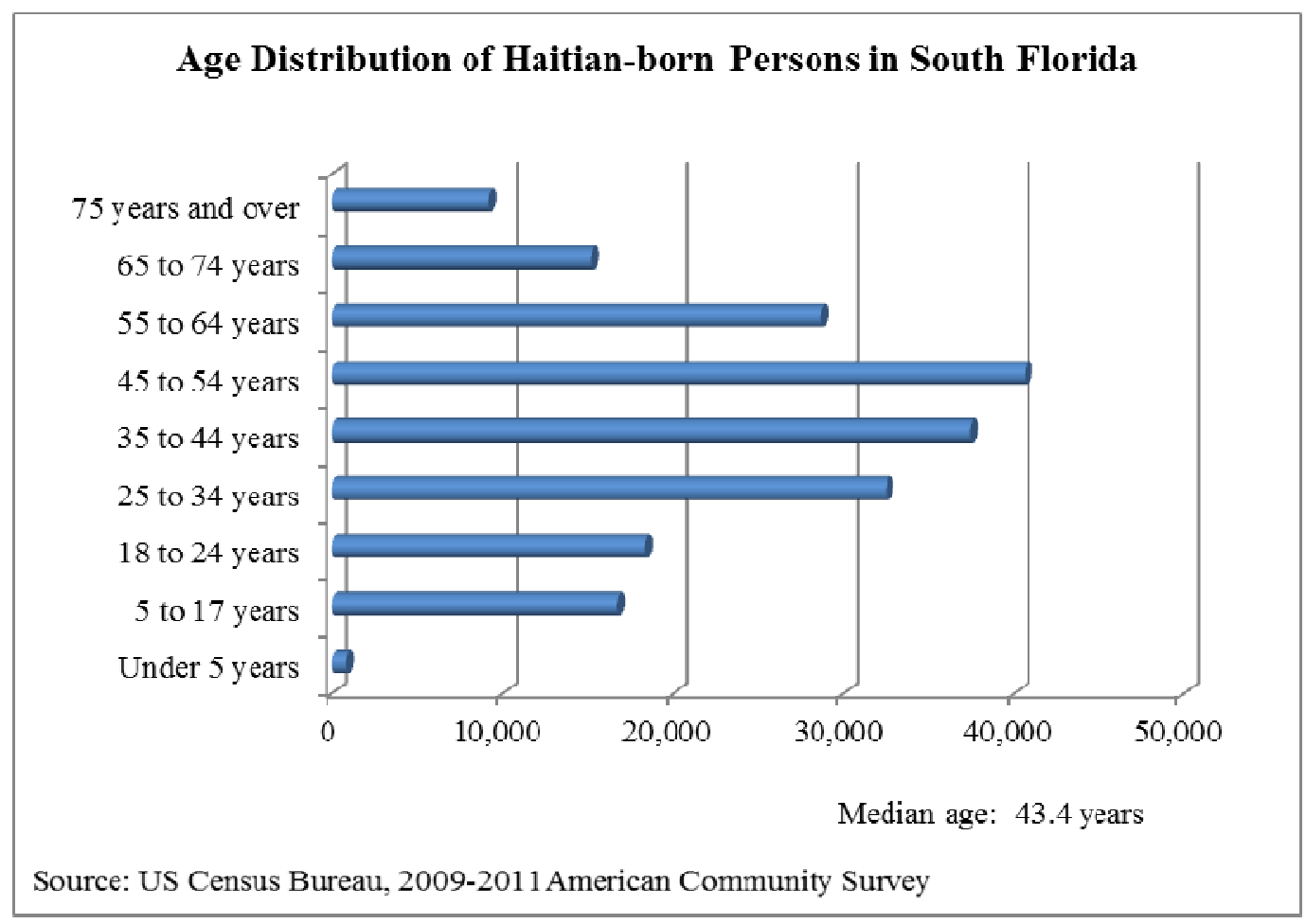

Among Haitian immigrants age 25 or older, although 33\% have not earned a high school diploma, 38\% have attended at least some college and $11 \%$ have earned Bachelor's degrees or higher levels of academic certification. 
Figure 6. Educational attainment of Haitian immigrants in South Florida

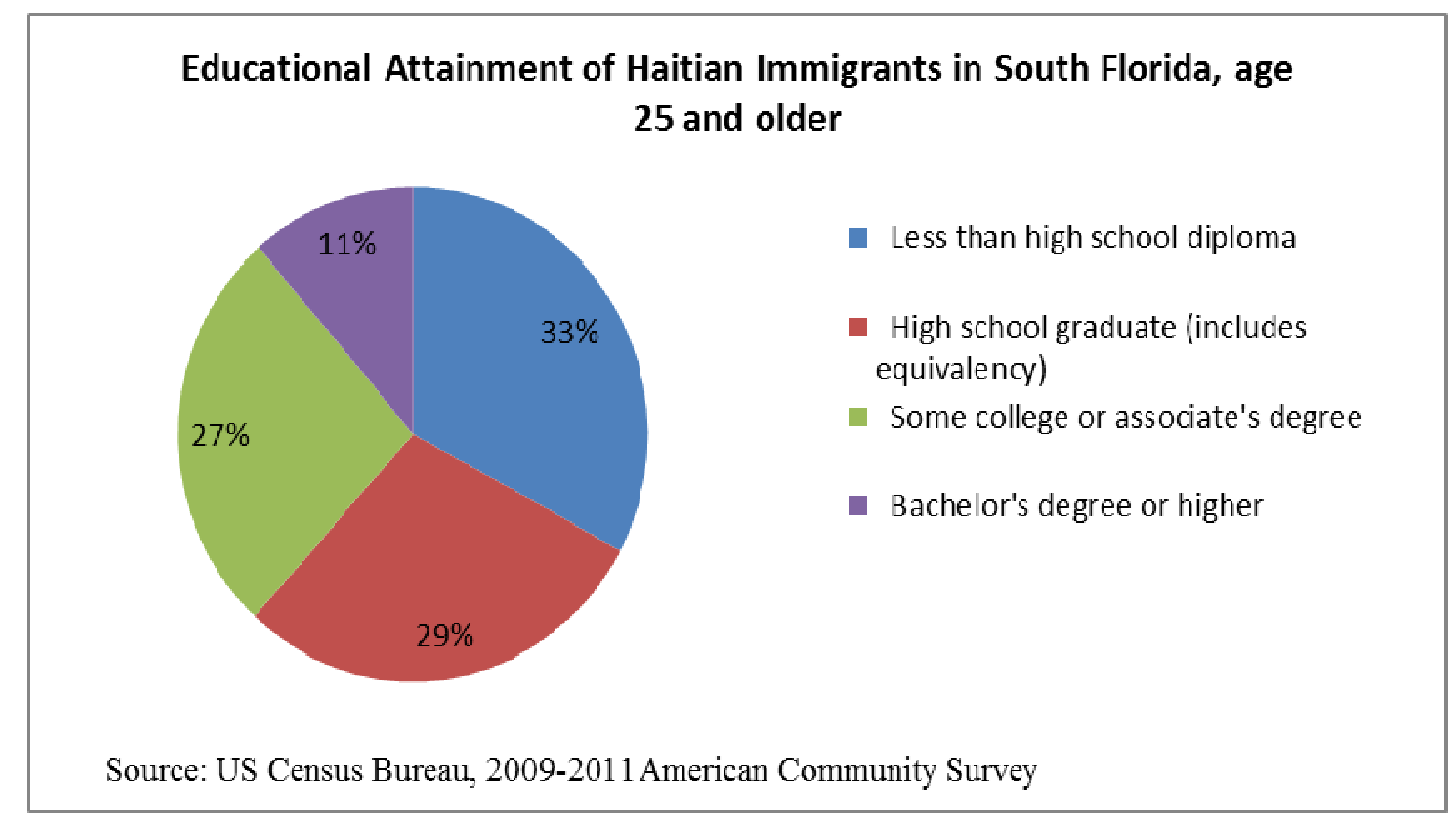

More than 44,000 Haitian immigrants (22\% of Haitian immigrants of all ages) are enrolled in school. This exceeds the population of traditional school-age Haitian immigrants by 8,000 . More than half of Haitian immigrant students are attending college or graduate schools. These numbers indicate that many Haitian immigrants are persisting into higher education. From census data, it is not possible to determine whether the kinds of transnational processes described in this chapter have been part of their academic pathways. Nevertheless, it is clear that substantial numbers of Haitian immigrants are pursuing higher education in the United States. These data align with the very strong commitment to education found among the families who contributed to my dissertation research. 
Figure 7. School enrollment of Haitian immigrants in South Florida

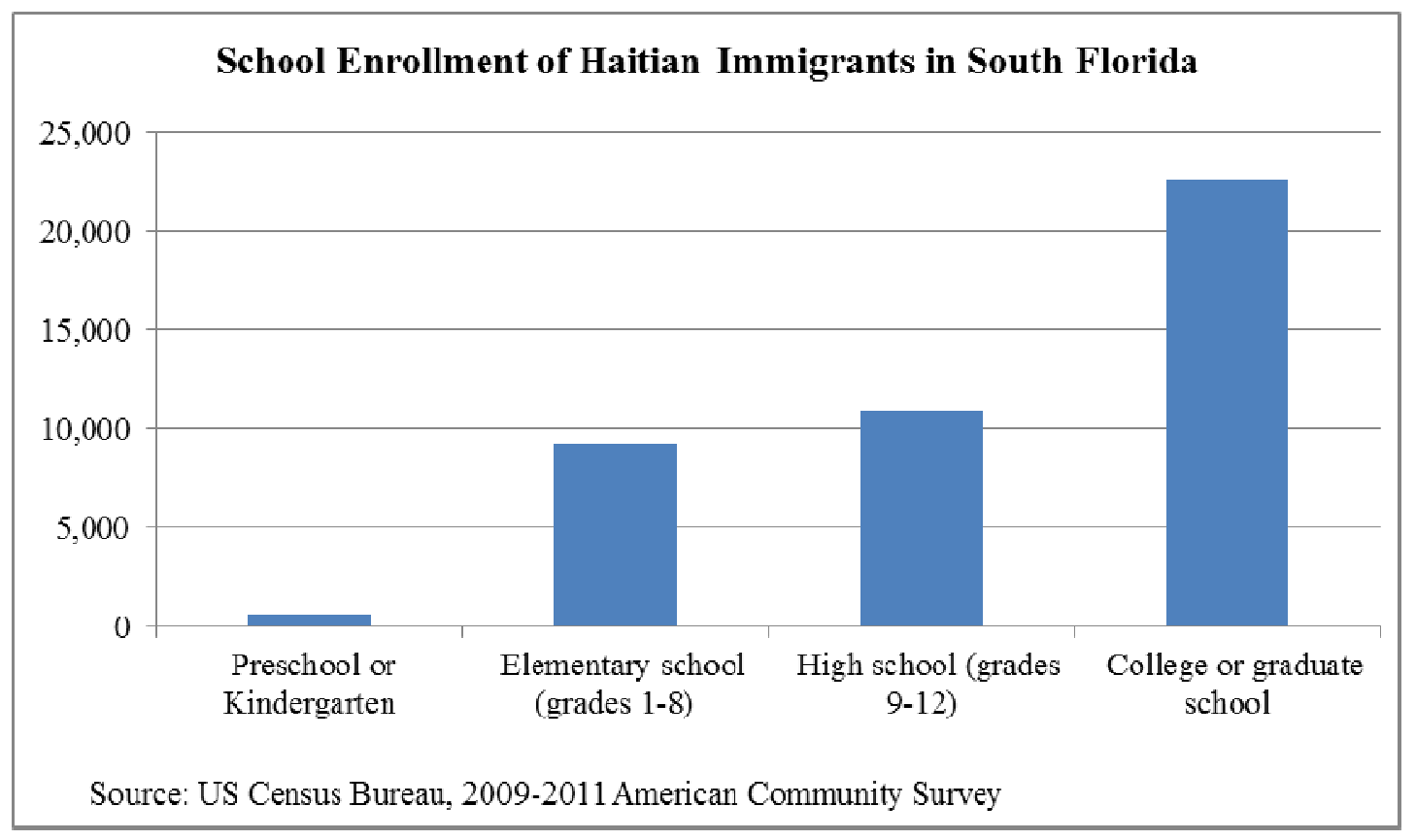

In this dissertation I argue that when Haitian transnational families invest in the education of a child, the benefits will accrue to the family as a whole. The project is expressed as an effort "to raise the family up." In the next chapter, I return to the concept of the lakou as a template for a cultural logic of duties and obligations that structures the distribution of benefits in Haitian families. It is through the logic of the lakou that individual gains in academic achievement become a resource for the extended family. More highly educated individuals raise the family up as they generate a more favorable incorporation into the United States. 


\section{FAMILIAL RELATIONSHIPS AND OBLIGATIONS}

Children when they grow up, they help their parents with everything, everything. That's why we, in Haiti we always say, that's why I give you birth. I give you birth to help me to live. Because I know one day I can't. One day you will do everything I did for you. These are our rules. [Frida]

\section{The Logic of the Lakou}

The previous chapter, Education and the Transnational Generation, described ways that individuals were able to achieve higher levels of education with the support of transnational families and opportunities made available by having access to resources in a transnational field. I argue that education is not simply an asset of the individual; it is a resource that serves to raise the family up. I return to the concept of the lakou as a framework for understanding how the benefits of these transnational efforts accrue to the frontiering migrants and other family members. In this chapter I consider the ways that resources are shared and distributed among the members of the extended family in greater detail. The narratives in previous chapters primarily depict Haitian extended families, the transnational lakou, as solidary, collective entities in which all cooperate and successfully, albeit to varying degrees, produce socioeconomic mobility. Although it is through these cooperative efforts that individual advances raise the family up, the distribution of resources within the family is not without contention. This chapter explores practices of reciprocity as well as some of the inequities and tensions that arise within the transnational family.

The traditional Haitian lakou - a cluster of households sharing a common yard spatially situates family relations and serves as an arena for cooperation, competition, and conflict. Shared responsibility for childcare and eldercare, cooperation for agricultural 
production, and reliance on relatives for economic aid forges networks of intergenerational interdependence. The traditional duties and obligations between family members are reinforced by an understanding that the benefits of these relationships are essential to both individual and collective security. The lakou is also the site of tension and conflict, as resources are not communal; rather, they are disparately held by individuals and households that comprise the lakou.

Large-scale migration - both rural-to-urban and international - has dramatically changed the nature of the Haitian lakou. But as Michel Laguerre (1984) has described, these social practices are re-created in both urban and transnational settings. Along with an adapted version of familial duties and obligations, the tension between participation in the larger collective and obligation to one's own spouse and offspring is recreated in transnational social fields. Nina Glick Schiller and Georges Fouron documented the complexities of maintaining these social ties and navigating the obligations and expectations of the transnational family. In so doing, they explain that the Haitian family is a resource buttressed by a moral code. Some of its essential components are that: "Those who have more are obligated to help those who have less" and "A person's humanity is defined by their acts of helping others" (Glick Schiller and Fouron 2001: 66). Helping others is an obligation, not a gift or a charitable act, in particular, in regard to family. Glick Schiller and Fouron argue that "family can be experienced as a series of 'debts' that must be paid and can be collected" (2001: 77).

Many Haitian immigrants maintain the social safety net created by the familial obligations of the lakou across the transnational field. Among contributing families, webs of disparate social and material ties were generated through remittances and transnational 
childrearing. Children stayed with relatives and fictive kin while relying on remittances from parents they might not see for a decade or more. Caretakers and other relatives in Haiti relied on remittances, as well, to improve their living conditions. And arranging for migration required the pooling of both social and economic resources from relatives both in Haiti and abroad.

The tension between participation in the larger collective and obligation to the natal unit that characterizes the traditional lakou is recreated in transnational social fields. Individual households have access to different levels of income - whether from employment or remittances - and their own personal debts and expenses. Individuals have their own ambitions for increasing their resources and status. In particular, parents prioritize educating their own children, even when they feel obligated to help nieces, nephews, siblings, and godchildren. Still, family members can be counted on to help out those who have less or to pool resources for larger projects like purchasing property or funding a migration. Familial relationships are the source of one's security and they thus must be carefully tended, despite the substantial tension between fulfilling one's own needs and those of others. In the United States social and economic structures are quite different from those in Haiti. Accordingly, while the central logic of the lakou - the tending of interpersonal and inter-household relationships to enhance the security of the extended family as a whole - remains, many of its specific practices change in the American context.

An important concept in the analysis of social relations in a transnational field is what Bryceson and Vuorela (2002) have termed relativizing. This refers to the ways that relationships are selectively tended in transnational families. Specifically, relativizing 
"refers to the variety of ways individuals establish, maintain or curtail relational ties with specific family members" (Bryceson and Vuorela 2002:14). Included in this are material exchanges, such as remittances and child care, but also the maintenance of communications, transmission of ideas and practices, and sponsorship of subsequent migrants. So not only do migrants decide how to distribute resources, but they actively shape the nature of transnational family relationships in a variety of ways.

The concept of relativizing reminds us that family - transnational or otherwise is intentionally constructed, shaped not only by cultural norms, but by the selective inclusion of individuals who comprise the group. My work with Haitian transnational families has revealed many facets of the relativizing process, in particular, the tensions between collectivist and individualist ideologies and practices. This exploration of family includes vastly different experiences depending upon place in family birth order and migration chain, where the individual was raised, whether there are different fathers or mothers among the children of the extended family. While these differences could be dramatic, they were often minimized in the initial version of the family history contributors reported to me. For example, Marie told me about the occupational statuses of her siblings:

Oh yes, we have a doctor, one businessman - he's in Canada, a very big business, two nurses, one pastor - he's still in Haiti, he has a very big congregation, and everyone a Christian, very educated.

This recounting of "we have" followed by a presentation of the most prestigious educational and occupational statuses quickly became recognizable among contributors. Person after person performed a well-established claim to family status. Family migration 
stories were told in great detail, with easy recall of dates of entry into the US, attainment of citizenship, and other important markers of the journey. Clearly these stories had been repeated time and time again, at least in the "official" version that was initially presented.

Only as I pressed for a very detailed migration history did some of the less successful family members come into the story. For example, nearly one hour into our tracing of her family history - much of which was familiar from the less formal conversations we had over the prior five years - Marie suddenly introduced an unfamiliar name. As I probed for more specific details of her siblings' educational attainment Marie revealed:

Bertie didn't finish, ... Francois didn't finish, ... Oh! and there's another one I forgot ... oh my God. How come I forgot him? The third one. I forgot the third one. It's Peterson. He's the third one. But him, he came in a boat. He came in a boat ... maybe that's why I forgot about him.

Peterson did not fit well into the family narrative that emphasized academic achievement, devout Christianity, and claims to a place in the North American middle class. He came on a boat, had no visa, and including him in the story disrupted the image of the family as one that had come to the US legally and in a plane, which is a proxy for an elevated social class among Haitian immigrants.

Through the process of relativizing, choices are made about who fits into the category of "family." Haitians are quite explicit about the need to distance themselves from members of the family who might damage its reputation and undermine the project of status-building. The extended family is described as a tree - a living and growing thing - to which each individual is attached. Each family member is simply a leaf. They will come and go, be born then die, but it is the tree, the intergenerational family whole, that 
is the primary unit of being. This being the case, should any individual threaten the family collective, like a diseased branch on a tree, they should be pruned - cut off from the family tree and the benefits to which he or she would otherwise be entitled. Herskowitz (1971) identified this as a social reality of the lakou, and we see its legacy in this type of relativizing.

Not only can and should threatening individuals be excised from the family, others - not related in any biological sense - can be grafted into the family, where they may both contribute to and benefit from the family collective. As if they were leaves on a tree, each person contributes to the strength of the family, but the leaves have no existence separate from the tree; life without connection to a family is similarly unimaginable.

In the lakou, child-rearing is a critical process for insuring the connections between people. A child in the lakou has a relationship to all family members there, and the community will contribute to her upbringing in various ways. Shared child-care establishes life-long bonds between the child and many adult family members, but also between the adults involved in her care. Haitian children are not infrequently sent to live with others for a variety of economic and social reasons. In fact, because migration has made parent-child separation extremely common in recent decades, very few of the adult immigrants I have interviewed were raised by their biological parents. So this practice of relativizing in this case is creating familial relationships.

Annelle illustrated this concept with the story of her own childhood. Annelle's mother already had ten sons when she was born, and her father had children with other women, as well. They were farmers and were quite poor. When Annelle reached two 
years old, as soon as she could be weaned from her mother's breast, her parents gave her to a missionary couple they admired. As Annelle explains it, her parents never abandoned her; they just wanted to ensure that the relationship with the missionary couple would persist. In her words, "They want the friendship relationship just go, keep on." By giving the missionaries their daughter to raise, Annelle's parents would become part of their family too.

Annelle explained, "In my country family raise anyone ... nephew, niece ... special sometimes your godmother. The family raise anyone, not their own child only." To be sure, children are precious and dearly loved. Haitian women and girls vie to hold babies and mothers easily leave their children in the care of others. They encourage these relationships from birth, cultivating the social networks that will provide resources of various kinds throughout the child's life. Such investments in other people's children may extend for many years. Other than direct care and feeding, the most common form of investment is in a child's education. Aunts, uncles, godparents, and others provide significant subsidies for the school expenses of children who remain in Haiti. And if the child comes to the US, they will likely contribute for the fees and expenses, hosting them in their home or finding them a place to stay.

The children are raised with the clear expectation that they will be responsible for their caretakers as they get old. This was described by all as their "social security." Gina, who was raised in Haiti by an aunt after her mom migrated to the US explained,

My auntie always said, "You my account number. I spend all my time, all my money on you. Now when I grow older you owe me. You owe me back because if I can't work you the one who have to provide for me." 
After migrating to South Florida, Annelle kept her commitments to both her biological parents and the missionary couple who raised her. Annelle declares:

That's my obligation. When somebody raise you not your family, not your biological family, and she take you for two years old, ... she's not your mom and she do something like this for you. Now you have to remember.

When you come here you have to remember your parents. In my country your parents depend on the child. They say, "I spend my money on my child for tomorrow." When the parent spend they say, "I have engineer; I have a doctor; I have a nurse; I have an agronomist." They spend, and they wait for the kids to give back. That's the way my country is.

But although she has two children of her own and has invested in numerous nephews and nieces, Annelle realizes that children who grow up in the United States don't have the same sense of obligation to parents. She continues:

I LOVE America. America do too much for me. I'm not deserve it. But I don't like the way America make the children lost.

American children learn an individualist ethos. Their ties to the lakou are not so strong, and they lack the powerful sense of obligation that children raised in Haiti have. Annelle does not believe she can count on her children to make her future secure. So she continues building her lakou, making strategic investments in others to construct a social safety net. Recognizing that her own resources are too fragile, Annelle has brought others into her home, widening the span of her networks. But these investments - like other insurance policies - are costly. She took a teenage girl, Brigette, into her home when the girl's guardians (an unrelated couple who brought her to the US with them) were suddenly deported. Brigette's mother sends money sometimes, but Annelle insists that Brigette should get just the same care "if her mom send or she don't send. Everything in 
my house, I'm share." Then, after the 2010 earthquake, Annelle took in another child, Karline, whose mother had died. Annelle tells me, "I remember the lady who raised me. She not my family too. So I think I should try to help this girl." Raising Karline is another repayment of the debt she owes to her own adoption mom.

Annelle's family is expanding now through bonds of caretaking and obligation. She hopes that the lakou she has grown will flourish, that the two girls in her care will become well educated and eventually get good jobs. She is looking out for them, sacrificing for them, and investing for her future.

Similarly, Frida, who has no children of her own, is building her lakou in the US by arranging the migrations of young relatives that she raises as if they were her own. She feeds and houses them, supervises their homework, and visits their schools for parent-teacher conferences.

I love the children and that's why I help with them. It is my responsibility to help them. As long as I'm alive, I can help push them. To help them, to feed them. To help them until they can take responsibility for themselves, I have to help them.

Frida's sister passed away several years ago. Now Frida sees it as her responsibility to help provide for her nieces. But she also explains that, according to the cultural norms of the Haitian family, they will have an obligation to help her as she gets older. 
Yes, in my country it's like ... You raise the children; you give them an education to be nurses, lawyers, teachers. As long as they stay in school. They have to [help when you get old]. In my country, this is their responsibility. I have a child, [or] I help you raise a child to grow up, to give an education so tomorrow you can be a nurse, a doctor, or whatever. Tomorrow I'm old. I can't work; then you have to help me. You have to pay for my house, pay for what I need. That's the way we are. Children when they grow up, they help their parents with everything, everything. That's why we, in Haiti we always say, that's why I give you birth. I give you birth to help me to live. Because I know one day I can't. One day you will do everything I did for you. These are our rules. You understand? To help us when we can't do. Yes, that's the way it is.

Nevertheless, Frida, like Annelle, recognizes that things are very different in the United States. The American social security system allows her to have some income to count on in her old age. But, on the other hand, the cultural environment of the US undermines the sense of familial obligation that Haitian children are raised with. She cannot be certain that her nieces will reciprocate her caretaking.

I pay my Social Security here. That will help me too! And family... If they have a good heart. Because sometimes you do something, even for your own child, you do something for tomorrow and they grow up, some of them forget you, they go away from you, you don't hear from them. If you have a good child, with a good heart, you say thanks God. Because I see that here.

Very, very different in Haiti. Children and their parents very different in Haiti. In this country, I don't understand. Like here I saw some children, they don't respect their parents. They tell them I can't wait till I turned 18 years old so I can leave your house and do whatever I want to do. In Haiti can't do that. It's a big difference. If you're lucky, you can have a good child, good children who will help you when you can't. But if you're not lucky... Like, I help them out today but maybe tomorrow I can have only one who will think about me. They can forget about me. They can say forget about her, she's not my mom. What can I do? Yeah, they can say that. Only God knows. If they have a good hearts to be grateful, but if they're ungrateful... 
But anyway, I don't think they're like that. Because I say okay, they are my nieces, my sister's children, I have no children so it is my responsibility to help them. As soon as they can, even if they do something for me tomorrow or even if they forget me, I don't say I don't care as long as I help them, that's what I say.

Frida strongly feels the moral imperative to help her relatives, regardless of whether she can count on a return on her investment. She loves to be surrounded by family and enjoys taking care of them. But she does hope that by raising them in her household and sending them to American schools, the girls will become well-educated and will help to raise the family up.

Jean-Luc suggests that the incorporation into American society and assimilation into America cultural norms erodes the Haitian practices of intergenerational obligations that sustain the lakou. "In America," he explains, "you can do whatever you want. Even your parents cannot choose, "Oh you have to live with me, or you have to live closer to me." Parents do not exercise the kind of authority in the United States that is common in Haiti. The interdependence the family experienced in Haiti was not only a cultural norm, it was a necessity. Where there is no work to be had, and the family relies upon its own garden for subsistence, there is nothing to be gained by moving away even if you could. Although he currently has his father living with him and has frequent contact with other relatives in South Florida, Jean-Luc explains that the regular interdependence grounded in childcare cannot develop in the US the way it does in Haiti because of the pressures of employment obligations.

Many Haitian parents expressed the difficulty of raising children in the US, where parents frequently shoulder the responsibility of raising their kids alone. Parents must make arrangements for child care while they are at work, and often it is quite expensive. 
In Haiti there was always someone to watch your kids, Jean-Luc explained; you didn't even have to think about it.

It's different in Haiti. If you have little kids and you have something to do, you can say let me leave my kids over there [with a family member]. It's different than here. Here everybody's busy. They're doing their own thing. You can't just think you're going to leave your kids at their home. You have to put them in daycare or something like that. And if you have no money to pay, then you have to stay with them. It's different.

Because employment for wages is scarce in Haiti, family members are usually available. If they are working at small business enterprises of their own, children may be incorporated into those tasks. But in the US, as Jean-Luc says, "everyone is busy." They are working or attending school and children are not welcome to come along. Economic pursuits structure both time and spatial patterns. Once in the US, the family is not the hub of economic life. A person's employment is the central organizing fact of life in America, determining the time each of us wakes up, eats dinner, and goes to sleep, where we live, or if we will be free to spend a holiday with our families. In Haiti, relationships provide economic security and this is where time is invested. In the US, time must be invested in work - or in education that will enhance employment prospects - in order to pursue economic security.

Relationships are the foundation of financial security in Haiti. The logic of the lakou creates an economic safety net for a broad group of family members and fictive kin. It prioritizes security over upward mobility and, in fact, tends to discourage displays of accumulated wealth. When an individual or nuclear family advances economically, the expectation of their ability to help others in their social network increases, too. Individual 
success should be shared to some extent by all those who are linked by webs of obligation.

Simply migrating to the United States is enough to raise expectations, as many Haitians assume that it is very easy to make money in America. But the expense of migrating often means that Haitian immigrants arrive with substantial debts to repay to the people who financed them. Contributing to the travel expenses of a migrant is often seen as an investment. Contributors expect returns in the form of remittances, help with tuition expenses, or assistance in the future for their own migrations or those of their children.

The logic of obligations can vary but the inviolate expectation is that between mother and child. A mother will quite literally do anything to support her children, and they are duty-bound to reciprocate. A mother's efforts to support her children are viewed as "sacrifices." There is an acknowledgement that she "gave up her life" in order to provide better opportunities for her children. But because her children are viewed as her "account" these sacrifices are part of a long-term investment strategy for her future. Michael explained: 
One thing you have to understand, the concept in Haiti, whenever you have children you have children to help you when you're getting old. The better profession that the kids can learn, you have a better future. In Haiti we call our children "social security." So we do not rely on the government in Haiti. That's why they have so many kids. And if all of them are doing good, you got a good retirement. And even here you will see the same mentality. If the kids is making good money, you as a parent, your retirement is secure. Then that's really what they invest all their lives in children. From Haiti to here, in order to make them something, when they get old they can get something back from the children. We never rely on government because in Haiti we did not have any help from the government. Coming here, they do not rely on social security. They rely on their children. And the children is their social security. The better you do in life, the better it is for them. And they will push you to do better.

The relationships between fathers and their children are a little less clear cut. I observed many fathers who equaled Haitian mothers in their dedication to providing a better life for their children. However, often I would learn that these men also had children from prior relationships for whom they provided little support. Sometimes they had lost all contact with children they had fathered as young men. On the other hand, they may have been reliable providers for children their wives brought with them from a previous relationship. The pattern seemed to indicate that men tended to withdraw from parenting when they lacked the resources to meet their financial obligations. But this was not a topic the men were willing to discuss in greater depth. "That's just the way it is," Carleton stated when I asked why he had so little contact with his son. My attempts to probe this topic with other contributors yielded similar responses. Many children in contributing families grew up in Haiti without the presence of a father. Some fathers had died when the children were young, others simply left the family or prioritized relationships with other women. In contrast, most of the contributors raising children in 
the US maintained two-parent households in which fathers were actively engaged parents.

The most consistent category of obligation after that of mother-child was between siblings. This was often expressed as an extension of the obligation to one's mother. In particular, older siblings saw their responsibilities to help provide for younger children as a way to make their mother's life easier or to repay her for the sacrifices she had made for the family. As the sibling cohort got older and had children of their own, obligations to help one's brothers and sisters often took the form of childcare and helping to fund the educations of nieces and nephews in Haiti.

There is a recognized potential for a multiplier effect when making investments in others. For example, if an older sister drops out of school to help finance a brother's education she is aware that he might be able to migrate to the United States after he graduates from high school and earn enough to help her children attend private schools in Haiti. If her children get good educations then her future will be more secure.

The offspring of a frontiering migrant usually put a high priority on financing a comfortable retirement for their mother as soon as they were able to do so. But when one of the siblings led the family's migration they did not receive the same level of financial reciprocity. In the next section of the chapter I will discuss the ways that various relationships structured the distribution of resources in the transnational families I studied. First, I will contrast the patterns of reciprocity found in mother-led and siblingled family migrations. Then I will discuss some of the tensions that developed over familial obligations and expectations. 


\section{Family Obligations}

In this section I compare two families. While every family migration story is unique, these illustrate patterns of reciprocity that differ depending upon the relationship of the frontiering migrant to the trailing family members her or she supported. Like many of the stories of Haitian immigrants, each of these begins with a tragedy.

"After my father died ..." The loss of the primary provider brought each family to a breaking point. Who would support the family now? Since the 1970 s, that decision was often that someone would go to the United States to work. Jobs were expected to be more plentiful and much better-paid than the meager opportunities to earn a living in Haiti. It did not start out as a family migration strategy, but rather as a necessary step to support the family. But one aspect of this decision was focused on the longer term - that was to keep the children in school. Sacrifices would be made to educate as many children as possible. In families with very young children, it was usually the parent who left Haiti to make a living.

\section{Fanmi Dorvil}

This was the case for the Fanmi Dorvil (Dorvil Family). From the age of 5 or 6 the children had to leave their family home in the northwest region of Haiti to live with relatives in the city where they could attend school. The eldest was 9 when their father died. Manmi Dorvil could not support the family on her own, so in 1971 she left for the Bahamas. Evens Dorvil explained that the priority of his parents was to see that their children were educated. 
I left my home really when I was 6 years old. Because we were living in the countryside, I had to go down to the city to go to school at 6. I only spent like the vacation time with my parents. They were farmers. My father was a farmer. And so my mother was a housewife. After my father died, '69, then my mother left the country. She went to the Bahamas in '71, and so I was living with relatives until I get here in 1980.

They did believe in education, because they did everything to send all of their kids to school. To them, like most Haitian families, they believe in education. They always tell their kids "I don't want you to grow up like me. I don't want you to go through what I went through." And they know the only way you can succeed in life is with a good education. So, I mean every Haitian family, that's what they believe in. To give their kids a good education.

All seven children were sent to live with their elderly grandmother in a large 2story house in Port-au-Prince. The house was purchased with remittances and became a hub for family migration from the countryside. Many relatives sent children there, and, eventually, two dozen young people were living there - girls on the first floor and boys on the second. Their parents had all migrated in order to provide the best education they could. Education was seen as the only avenue for advancement and escape from poverty. Although she remembers a lot of fun and laughter in that house, Elsie Dorvil explained, "Life was not easy. If your parents do not send, you do not eat." Some of the other parents had been able to migrate with visas. They earned more money and could send more back to Haiti. Not only that, the legal migrants could bring their children to Florida to visit them from time to time. Elsie and her siblings could feel the difference. "We were second-class citizens," she said. Although the household was composed of extended family, each sibling cohort was the financial responsibility of their own parents. Elsie remembered, "If your parents didn't send, you could feel it. There would be less food, and it was clear from your treatment that your mom had not sent the money." 
Manmi Dorvil was able to go from the Bahamas to the United States in 1973. She lived in crowded homes with other migrants who scrimped to save every penny to send back to Haiti. She worked in factories and restaurants, always in the hardest and leastpaid jobs - janitor, dishwasher - and proudly asserts that she could work as hard as any of the men. She was not at all ashamed to do this kind of work. She was proud to support her family and give her kids the education she never had. In 1978, when her oldest son graduated from high school, she borrowed money and had him "smuggled" to the US. Two years later her next son graduated, and more money was borrowed to bring him as well. It was clear to Elsie that more family in the US meant a better quality of life and more opportunities for all of them.

When my two older brothers left we knew life gonna keep getting better. Life will get better, cause they gonna start working and helping Mom and we can get better opportunities and more opening doors for us to come.

It was general mentality back at home that [the United States is] the land of milk and honey. I guess everybody that's their hope and dream that they'll even visit some day or come and live here, you know. Particularly when you had parents abroad, you know here the ultimate goal was for you to eventually someday reunited with them; and it wasn't them coming to you, you'll come to the land of milk and honey.

In 1982 the earnings of Manmi Dorvil and the two boys were enough to bring the rest of the children to the US. Elsie remembers the journey by boat as "very scary" and "traumatizing." When she and her sisters arrived in Miami, her mother crushed Elsie in her arms and rocked her, calling her by her older sister's name. Manmi Dorvil had not seen the girls in 10 years - Elsie was only 3 when her mom left Haiti - and she could not tell which girl was which. The girls were also meeting, for the first time, two siblings who had been born during the years Manmi Dorvil had lived abroad. 
It was an experience. We were reuniting with my mom. I remember we arrived to Miami and she was living here at the time. She come and pick us up and when she saw me, she thought I was my older sister. Because we didn't do a lot of picturing back and forth and she just took me and grab me and start hugging me and kissing me, calling me my older sister's name. She thought I was my older sister because I was so grown. Which was very sad. I remember that all the time. Yes, it was a big reunion. She was happy to see us after ten years.

You know, she never seen us ... Never really talk to us, so it was a great reunion. And at that time, my mother had two other children here. I've known about them. I've seen the pictures, yeah. But we never spoke. We just know we had a brother and sister here. I knew their names and everything but we never really had any contact. I just knew they were there with my mom, you know, and they're siblings. You know they're brothers and sisters but I didn't know them.

In fact, there had been very little communication at all over the years except in the form of material goods or money that Manmi Dorvil would send to the family in Haiti.

So actually she was absent in my life for ten years and then we were reunited again finally when she was able to send for us to come here.

But there was barely any communication at all. Very very seldom. She barely, barely ever called but she'll send things every opportunity that she had. She'll send material things for us but we barely, barely ever communicated.

When the family reunited in the United States, they lived together in one room of a two-bedroom apartment that they shared with five Haitian men. In addition to attending school Elsie started working at 14, just months after she arrived in Florida. She didn't want to be a burden on her mom, who had worked so hard to support them all.

All of Manmi Dorvil's children were now in the US. Every child completed high school and attended at least some college. As soon as they were able, they pooled together enough money to buy a house. Once they purchased a home, the siblings made their mother's retirement their next financial goal. Elsie explained: 
We all worked. Even myself. I started working full time since I was fourteen until today, so we kind of pitch in together. We all worked, so through all those different credits and income, whatever that it was, because it wasn't much then, so we were able to pull it through. My mother was able to buy a house which she still living in now. We had a four bedroom home with two bathrooms, which was heavenly. I think we bought the house in eighty two or eighty three. So we bring all the income in and I don't remember, probably she get support from somebody else, so from all of us put together. And it wasn't that expensive back then, four bedroom, brand new house actually 48,000 or, I can't remember, 38,000. Whatever that it was, wasn't that expensive.

But salaries were a lot lower too. Oh yeah! My mother wasn't making much at all. Factory work...Assembly... And the beauty of it all, since we move there, we ensure that she stop working at a very young age. Actually, my mother retired very early, then we took over and we've been taking care of her since until now. We felt that she work too hard for us and it's time to repay her back. So [we told her], "Just stay home." And we've been all pitching in and helping her since then.

In Haitian culture a parent's children are her social security. She invests in their upbringing and education, and they become her "account" to provide for her in old age. To summarize this parent-led family migration model: When her husband died Manmi Dorvil left Haiti. None of her children were old enough yet to contribute significantly to the family income. She left them in Haiti where their job was to get an education and "raise the family up." As soon as they were old enough, each child began to work and contribute to the family's needs.

Manmi Dorvil was not able to attend school as a child, but she insured that all of her children were educated. Several of the Dorvil children have earned college degrees. They have been able to provide their mom with a secure and satisfying retirement. Although Manmi Dorvil was not physical present while most of her children were growing up, she invested in them and they became her "account." The Dorvil children 
honor their mother for sacrificing so much and making possible the comfortable middleclass livestyle the whole family now enjoys in the United States.

For the Dorvil family there were no options in the decision of who would migrate. Manmi Dorvil had many children, and they were all too young to be sent to support the family. But when a crisis point that stimulates migration hits a family with older children, it is likely that one of them will migrate to support the family. The Fanmi Bertin illustrates this migration pattern.

\section{Fanmi Bertin}

Lucy was 15 when her father died. She had four older half-siblings from her mother's first marriage to an abusive man. None of those children had gone beyond sixth grade and they were already starting families of their own. But Lucy's father had been a kind man and a much better provider. She and the younger children were enrolled in good schools. But by the time Lucy graduated from high school it was becoming too difficult for her widowed mother to keep up with all the expenses. So, having the most education and no family of her own yet, Lucy decided to go to the US to help support the family. She took out a loan on a piece of property her father had owned and bought a visa for \$3000. Like Manmi Dorvil, Lucy worked in menial, low-wage jobs. She found a job in a sewing factory and lived in a crowded apartment with other Haitian immigrants, saving

all the money she could to send home. Her sister remembers with great pride and affection the way Lucy took care of the family. 
She always send enough to keep us going. She sent enough to pay for the school for me and my little brother and for food. She sent food. She sent clothes. Anybody we know ... anybody she knew going [to Haiti] she send, you know, big suitcase of clothes and everything. So she really provide for us ... for everybody.

When Lucy met a man she thought she would like to marry, she made it clear that her responsibilities to her family in Haiti would always be a priority for her. She told him,

If you accept me you got to accept my family because I came here to the country because of my family. So if my family gonna be a problem for you, just leave me alone.

He agreed and they married. True to his word, he has continued to help support Lucy's large extended family.

Lucy has provided the mobility resources for family members - applying for visas, organizing travel, buying tickets or rallying others to contribute - as well as providing financial support. Because she came with a visa, Lucy was able to go through official channels to bring other family members to the US, but the process moved so slowly that some chose other routes. In 1982 she was able to arrange a student visa for her brother Wisley to attend college in Canada. She got him a room with a Haitian family and paid his tuition and rent. He was treated badly by the family he stayed with, but he excelled in school and eventually became a medical doctor.

Two years later another sister, Marie, came to live with Lucy. She attended community college and worked as well. Together the sisters brought their mother to the United States. Lucy insisted that her mother be allowed to retire as soon as they brought her the US. With the support of her children, Manmi Bertin did not have to work. But that meant the sisters had to agree to fulfill their mother's obligations to her siblings and their 
children. Manmi Bertin traveled regularly between Miami and Haiti bringing money and goods to her older brothers and sisters.

[My mom] didn't work when she came here because my sister [Lucy\} refuse for her to work. Because she work all her life to take care of us. God she was a hard working woman!

And the thing is she really did a good job. She take care of us, she put us in the best school in Port-au-Prince. She did good! And the house, it wasn't big, but she keep it clean. We always clean, we always eat on time. Yes, she always provide.

All her sisters and brothers the same. Yeah, she take care of them too. Send money for uncles, sisters, aunties. My mom have five sisters and one brother. My mom is the baby and her child was the first family who came here [to the United States]. So we have to take care of everybody. Think of them too, send them money. None of them have a chance to came! We help the children came, like cousins, we help them come here. They take care of their family but none of [my mom's siblings] ever had a chance to come.

The migration of other adult relatives produces a larger pool from which remittances are sent. Additional migrants can be expected to share a portion of these obligations or they can divert the obligation from the frontiering migrant by taking on the needs of certain relatives as their own responsibility. In the quote above, Marie indicates that after she and her siblings in the US helped cousins to migrate, certain responsibilities would shift to them. A cousin could count on extended family in the US for assistance in the migration process, but once she became established she would be expected to take on the financial needs of her own parents and siblings. She would also become the provider of mobility resources for her close relatives, as well. As this process continues, the burden on the frontiering migrant usually is reduced.

Marie felt a responsibility to share some of her older sister's obligations. Even though she soon had a husband and children of her own, once Marie came to the US she 
felt that she should help Lucy with the burden of assisting the extended family who remained in Haiti.

We managed, because I said, "If she can do it, I can do it." Yeah, because she did wonderful. So I was thinking that's not fair to her. She sacrificed. She spend so much to bring everybody here on her own ... just her and her husband ... So I said if I can do something I should do it. So I always put together with her. Until now, whatever she is doing I put together with her.

By 1989, Lucy had arranged for all her full siblings to migrate to the United States or to Canada. They had all graduated from good schools in Haiti and continued with college. All this time, she and her siblings sent money to Haiti for the education of various cousins, nieces, and nephews. Manmi Bertin had passed away but her children felt a responsibility to continue to send remittances for her remaining siblings and their families.

Finally in 2004 the visas for all of Lucy's half-siblings and their minor children came through. But Kerson, the oldest, had children over 21 who were therefore not eligible to come to the US on the family visa. They reapplied and Kerson, his wife, and their nine children waited in Haiti until they all received visas to come to the United States. They migrated together in 2008 - 30 years after Lucy had arrived as the original migrant of the family.

But while the Dorvil children retired their mother as soon as they were able, Lucy's siblings have not done the same for her. She was never able to return to school herself. She continues to work in a low-wage position at the Miami airport and lives in a home much more modest than those of the siblings whose educations she funded. Her husband is sick now and can no longer work. Still, she receives no supplemental income 
from her family. In fact, she continues to send remittances to extended family in Haiti and makes a place in her home for new migrants to the US. Marie laments that while the siblings are all aware that they should do something for Lucy, they never follow through.

[My mom] said if you guys want to make me happy, don't ever turn your back on each other. And if you guys want me to die happy, you stick together. Whatever it is, stick together. Don't ever turn your back on each other. Because she raised us without no father - my father died very early - and then she did all this by herself until the fifth child left the country and help her out. She always said Lucy sacrifice her life, her education. She left her education. She forget about herself and everything to help you guys, so I wish that you understand and then stick with her.

But till now nobody do anything for [Lucy]. She's still doing for family. Still. She came here, she doesn't care you got a beautiful house, better than her house, she doesn't care you have a million dollars, if she have only $\$ 20$ she'll give it to you. That's how she is.

She never get to go back to school. Never, never. She works at the airport. And then her husband getting sick. He don't work anymore. For almost ten years, her husband don't work. So her responsibility still a lot. She's like a godsend to the family.

We should do something. I think of that all the time. Any I time I sit down with all of them, and say this is what I want to do, and I need help, I can't do it alone, I need everybody's help, this is what we want to do for her. They say yes, and then when they're back home everybody forget about it.

The Haitian cultural ideology that children should be their parents' "account" and provide for them as they age continues to be strong in children raised transnationally, even when they barely knew the parent who sent the remittances. But for migrants like Lucy who sacrificed for decades to support her many siblings and extended family, there is great respect but little material reciprocity. Despite her substantial investment, her brothers and sisters are not her "account." 
Portes and Sensenbrenner (1986) have referred to this as negative social capital, arguing that "freeriders" undermine more successful individuals in such circumstances. Lucy's own socioeconomic advancement has been curtailed by unreciprocated support she has extended to others. But Lucy doesn't view it that way at all. Taking care of the family is simply an extension of the obligation she still owes to her late mother. Lucy honors Manmi Bertin by serving the family well. She has advanced herself because she has "raised the family up." The upward mobility her siblings have been able to achieve elevates the status of the family as a whole. It has expanded the pool of resources available to the family and, as they use those resources to help others, extends and reinforces social ties in Haiti and the US.

\section{Family Tensions}

Transnational families engage in projects of maximizing access to resources in more than one country, but the benefits and costs of migration are not equally shared among individuals within the family and often produce disparate outcomes. The transnational and intergenerational strategies used to achieve socioeconomic mobility often create a tension between consanguinal and affinal responsibilities, and between familial obligations and individual desires and aspirations, as well.

Marie explained how she managed to provide for her many relatives in Haiti while three raising children of her own in South Florida. 
You just make a schedule. This week it's for this; next week it's for that. You know you just manage. When things hard you just call another family member. So, next month I can't do this; so next month you take care of them. So there's a certain amount you know somebody needs to put it together. If I can't afford to do it this month, then I call you, I said OK, I'm gonna be stuck, I'm gonna be broke, I'm not going to have money to send next month. Would you please if you be able to do it? And they always agree or say I'll do it.

I asked Marie if there was ever any tension between brothers and sisters or the different families when they had to organize these financial contributions. She stressed that they always tried to cooperate with one other and to be sensitive to each other's feelings.

Umm, not really. Not with us. We always try to work things out. And hurting each other's feelings ... that's something we don't do. If I know that something you don't like to hear, or you don't want to hear it, if it's going to hurt your feelings, I don't say it. And if I hurt your feelings, I call you and I said I'm sorry, I didn't mean it this way. And then we work it out, and we get over it.

The siblings feel a commitment to help each other but not all of their spouses feel the same way. For Lucy, the obligations to her family were so important that she made sure her potential husband was willing to accept this condition before she agreed to marry him. Marie also gets full cooperation from her husband.

My husband helps. He helps a lot. Like if I'm doing something[to help a family member migrate], somebody coming, and then he said OK, I pay the tickets. Or I pay for the visa. Like when my brother Felix coming, it was a group of five people coming and he say I pay for two. And he pay [my sister] Guerda's ticket and [her daughter] Eunide's ticket. He help, yeah. Like when my mom died, and everybody put together, I give my own, he give his own.

Marie's husband is a willing participant in the efforts to support her family in Haiti. He pays a share, just like the siblings, in addition to his wife's contribution. Marie does acknowledge, however, that her husband has few living relatives in Haiti and so, in 
comparison, his financial obligations are not too great. In some Haitian immigrant families tensions arise because of the competing obligations of a husband and wife. Other spouses - particularly if they are not Haitian themselves - may resist the idea of financially supporting a vast extended family. Marie's brother is married to a woman who feels that nuclear families should be financially independent.

Oh we have one! One very upset. There's one, she's always upset about how we do things in our family. She's always upset: "Everybody growing up now. Everybody's got their own family. Why can't they take care of themselves? Why you have to do this? Why you have to do that?" But my brother don't listen, because that's how my mom raised us. To take care of each other.

\section{Fanmi Pierre}

There is always a tension in families with sprawling networks of obligations between the needs of the extended family and the desire to provide the best possible lifestyle for one's own spouse and children. Haitian immigrants who marry outside of their ethnic group sometimes find that their family obligations cause tension with a spouse who does not share their cultural understanding of familial duties and obligations. In the Fanmi Pierre, as discussed in previous chapters, Grandma Pierre was the original frontiering migrant. Later, her son, Antoine, joined her and he played an important role in facilitating the migrations of the rest of the family. After an older male sibling died, as the only remaining male of the family, Antoine felt a special obligation to provide for the others. As his sisters married, their husbands would take primary responsibility for the needs of their children. Antoine continued to play an important role in all of their lives.

He had a special relationship with Raphaella. When he was younger and his mom was away in the US, Antoine lived with Raphaella's mother and her husband and relied 
on them for support. Raphaella's father died when she was only an infant. From that time,

Antoine has treated her as his own child and once he migrated to the United States he provided most of the financial support for her education.

The thing is, when he was in Haiti, since my mom is older than him, when my mom was with my father my mom used to take care of [Antoine]. When he was in Haiti she used to support him because he was younger. But my father died when I was one. So even though he used to stay in my mom's house, then he would be like father from now on, since Haiti. Yes because I was one year old and he was the only man around.

My uncle, he feels like, since he is the guy in the family - he's the only guy - he felt like since he is the only brother all of his sister's children are his children. When he left Haiti he did not have any kids. So we were his children. So he would take care of us, especially me because I didn't have a father. Because I didn't have a father it was like I get all the love, all the father's support from him. I even used to call him father when I was little. If I needed money he would send it. When he comes [back to Haiti from the US], he would buy me clothes. He was there for us. And then when we came here I was still calling him father.

Raphaella explained that her cousin, who had a father working in the United

States, had financial benefits that she lacked. Her uncle filled this void for her, providing material support but also giving Raphaella a sense of emotional support and security.

The challenge for me is that... compare two cousins: My mom and her sister, they have two daughters - me and my cousin. We have the same age; we're growing up in the same house together. Her father was living in the US while she was in Haiti, so she got to have everything that she wanted, everything that she needed. On the contrary, I couldn't. So living together, seeing her have more opportunity, like having a cell phone... I did not have access to any phone... It was very tough for me. But my uncle always, you know, when he comes then I get to show off too. Okay, I have a father now. My dad is here now. But even though I know he's not my biological father, it was a relieffor me when he comes to Haiti. It's like, well you can do all that with your father; I have my dad. He would not push me away. Like always if he's going to a restaurant, he would buy for me. He would make me feel like, well you have me. 
After the family came to the United States Antoine continued to play the important role of the male of the family. He married an African American woman, who was accepting of his obligations to his sisters and their children. With her help, he provided a home for all of them as they came to the US.

[My uncle] married an American. That woman was a nice woman and she helped support him. She was a teacher. And when we came here she used to live in a two-bedroom house and she took 14 of us into her house. So it was like two bedrooms, 14 of us, plus her, my uncle, her son, almost 20 of us. She was a black American, African-American. She was very nice. She understood.

Antoine's first wife accepted his obligation to his family and understood the role he played in their lives. But when they divorced and he later married a Hispanic woman, his role as a father figure to his nieces was unacceptable to his wife. Since that marriage it has been difficult for Antoine to juggle the competing familial expectations. Raphaella feels that his wife tries to pull her uncle away from the extended family. He has to hide his continuing material support and their contact has become much more limited.

With his African-American wife, she was cool with that. She was very understanding. But they got a divorce. He remarried to a Hispanic woman. That's when the problem started. The wife did not understand. He said, "Well, that's how it is in the family." He's our uncle, and we still, even my other cousins who have fathers, they still look to him, you know, for everything. So even though he has children, he does not consider his children more than us. So it's like you would not know which one is which. We are the same. He would take them shopping; he would take us shopping. 
The woman did not accept that. She said in her culture it's different. She didn't want that. So we had to avoid going to his house because of that. Now the relationship started to be less. But he would still give us money, without her knowing. He would still be a part of us, but not like the way it used to when she was not around. Now, because he married a Hispanic lady she wanted everything to be her and her kids. It was very difficult for him because it was totally different for him. He was not like that. Even when he married the African-American woman, he was still able to keep the connection with the family. But when he married the Hispanic woman everything changed. Yes. Although he was my uncle, he still considers us as his children. So the wife can't say anything because we were here first.

The process of relativizing becomes apparent in the choices Antoine must make.

He has both cultural obligations and emotional attachments to his sisters and their children. But he must choose how to distribute his financial and emotional resources within a new sociocultural context. Through the economic logic of the lakou, Antoine's investments in his sisters and their children would become resources for his own children. The extended family could be relied upon to help care for his children, contribute for major expenses, and eventually help with any connections they might have for schooling or employment. But as the boundary for family inclusion is understood differently by his wife, Antoine's children may not become members of his Haitian-American lakou.

\section{Fanmi Baptiste}

Even the central obligation to one's mother can become a source of tension. If there are not many children to contribute to a mother's support, her offspring may have a difficult task balancing her needs against their responsibilities to their spouses and their own children. While visiting the Fanmi Baptiste I observed the reaction of a mother who felt she had been slighted when her son, Denis, purchased new furnishings for his home. 
Grann Baptiste arrived from New York to visit her son and his family. As she entered the living room and found that he had purchased a new set of living room furniture for his wife, she became furious. "Where is my new furniture?" she cried. "If he buys for her, he is supposed to buy for me too." Although a son has an obligation to support his wife and children, he should not forget his mother. This mother did not have a good relationship with her daughter-in-law and resented what she considered to be Denis's excessive spending on luxury items for his wife. Grann Baptiste felt that these expenses were unfairly reducing the financial support Denis owed to her. Grann Baptiste cut her visit short and returned to New York, leaving her son extremely upset. Denis was working three jobs to try to meet all his financial obligations, and his mother's reaction to the new furniture that he bought to make the house look nice for her visit was very painful for him. He does not want to fall short in has obligations to her.

For Denis to provide more for his mother, he must allocate less to his spouse and to his children. He is torn between the obligation to repay his mother for her sacrifices, the desire to enjoy some of the fruits of his labor himself by spending on consumer goods and entertainment, and the need to invest in his own future through spending for his children. The distribution of financial resources is a zero-sum proposition. To share more, one must keep less. Social resources, however, may be shared more widely without becoming depleted. Family members share information, such as how to enroll children in school or apply for citizenship. Others provide their skills to help with reading mail, translating for parent-teacher conferences, preparing tax statements or resumes. Although it may become burdensome to provide this type of assistance to a large number of 
relatives, these social resources are available to any family member in need. Another type of asset, status, is a resource that can be enjoyed by all members of the family.

\section{Status}

While a few relatives may enjoy the economic benefits of having a family member with a college education, and even more may benefit from the social resources they generate, all family members may enjoy status as a member of a highly educated family. Earlier in this chapter, Marie recounted the most prestigious educational and occupational accomplishments of her siblings, making her claim to membership in a highly educated family. These claims to status, which Michael described as "bragging chips," are available to the entire extended family. It is a symbolic resource that can affect the way that a person is treated. Haitians in the US are well aware of the stereotype that they are unintelligent; therefore, a symbolic resource of this type can be deployed to counter these negative perceptions. Educated family members raise the family up by giving all a claim to this status.

Even those who have not crossed the boundaries to education themselves are elevated by having well-educated children or siblings. Grandma Pierre, who was also discussed earlier in this chapter, demonstrated this when she was insulted at her local pharmacy. The pharmacist's assistant, who was also Haitian, became frustrated when Grandma Pierre came to him with questions. As she struggled to be understood, he lashed out at her: "Ou sot! (You dumb peasant!) Learn to speak English!" Grandma Pierre grabbed her granddaughter by the arm and, pointing at her, responded "My daughter FIU! My daughter university!" She claimed her status as the matriarch of a family that had 
made it to the level of university education. For her, this meant she could not be defined any longer by her own illiteracy. She was the proud grandma of an educated family. Grandma Pierre dramatically changed the educational outcomes of her children and grandchildren when she migrated to the US. She never learned to read or write, but because she came to South Florida in 1981 she was able to earn enough to support her children in Haiti. With remittances earned by planting and picking beans in the hot Florida sun, Grandma Pierre invested in education for her children. She developed the value of her lakou, as most of the children finished high school in Haiti before she brought them to join her in the United States. The strength of these investments increased as more family members joined the workforce in the US. Grandma Pierre enjoys her retirement now, with her children contributing to support her, in addition to the Social Security she earned from her years of employment in the US. She benefits from the social resources of family members who have achieved higher levels of education and incorporation into American society. But she takes the greatest pride in seeing her grandchildren attending college. The status of her lakou will be defined by their academic achievements and the careers that lie ahead. This is Grandma Pierre's life accomplishment and the reward for her determination to raise the family up. 


\section{CONCLUSION}

\section{Immigrant Incorporation through a Transnational Lens}

The direst predictions for the children of Haitian immigrants suggested that because their parents were poor and had limited educations and English language skills, these young people would be unlikely to achieve socioeconomic mobility. They were headed for dead-end working class jobs, discouraged and disaffected by the unmet promises of the American Dream. At worst they risked incorporation into a persistent underclass, having adopted an adversarial stance toward American middle-class values and norms (Gans 1992, Portes and Zhou 1993).

These gloomy and depressing scenarios, however, fail to account for the transnational process of incorporation that characterizes the experience of many Haitian immigrant families. Immigrants today cannot be understood as "the uprooted" or even as the transplanted. Their incorporation into the US can be understood as part of a transnational and intergenerational process through which family members contribute in varied ways to a quest for upward mobility that plays out in the disparate social fields and economic structures of more than one country.

In this dissertation I have described and analyzed the transnational process I observed among many Haitian immigrant families in South Florida. As demonstrated in this study of Haitian immigrant families, the transnational relationships, as well as the social and economic contexts of both homeland and host country, affect the incorporation of immigrants. In this analysis, I focused on education as an important dimension of contemporary immigrant incorporation into the United States, and one about which there 
has been substantial research and theorizing. I argue that because so many immigrant families in the United States live transnational lives, theories of immigrant incorporation must employ an analytic frame broad enough to consider transnational phenomena. My findings suggest that a transnational perspective helps explain some of the factors involved in the academic achievement of immigrant children that are obscured in analyses that consider the receiving context only.

\section{The Transnational Family, Incorporation Processes, and Outcomes}

The transnational processes described in this dissertation are shaped by global structures of inequality and the Haitian cultural understandings of family and its duties and obligations. Global structures of economic inequality create incentives for immigrant families (as they do for multinational corporations) to purchase goods and services in poorer homelands. Modest remittances can purchase vast improvements in lifestyle for family members still in Haiti. Many Haitian immigrant families are using remittance dollars to provide better education for their children. The lowest wage in the US is much higher than most Haitians are able to earn, as described by contributors. Jobs simply were not available for them, even if they had completed the equivalent of a high school education.

The Haitian cultural expectation that families work together to pursue socioeconomic mobility - to raise the family up - and to provide a social safety net is the basis for the transnational processes described in this dissertation. Parents - particularly mothers - struggle to provide for their children and keep them in school as long as possible. This investment will be returned by children who will strive to provide a 
comfortable retirement for their parents and "bragging chips" to elevate the family's social status. Each member of the family plays a role in the pursuit of socioeconomic mobility. Older siblings often must curtail individual aspirations to allow their younger brothers and sisters to advance.

In the traditional lakou, land was the basis of wealth and security. Family relationships were structured on this resource base. Parcels of the family land were individually allotted from parent to child, but cooperative effort made the land productive and created resources for acquiring additional parcels of land or other productive resources such as livestock. Helping a brother to advance meant building social and economic resources that could benefit the entire family.

In contemporary Haitian families, education is essential to family strategies for socioeconomic mobility. While upward mobility was achieved in the traditional lakou by investing in land and expanding the capacity for agricultural production, today a family's resource base is comprised of academic credentials that can lead to middle class or professional employment. Some family members will sacrifice to invest in the educations of others. Although the desire for more schooling remains, parents, older siblings, or other caretakers recognize that "I lost my time," when familial resources are diverted to younger relatives. More specifically, parents tell the beneficiaries of their sacrifice "I lost my time for you." They remind their children that this is a debt that is expected to be repaid in the future. Children owe their parents financial security for their old age, and they have a responsibility to become an asset to the family as a whole. In transnational 
Haitian families, these cultural ideologies and practices combine with a pattern of chain migration that affects the incorporation outcomes of individual Haitian immigrants.

Frontiering migrants, the first in their families to come to the United States, who arrived with low levels of human and social capital, tend to live in immigrant neighborhoods, work in low-paying manual labor jobs, and have little interaction with Americans outside of their ethnic group. Crossing the boundary to the US, with or without legal documents, meant entering a field where jobs were available. Because the boundaries to upward mobility are quite different in the US and Haiti, resources can be applied to the best advantage by utilizing multiple fields. Opportunities for jobs, access to schools and housing, legal protections, bureaucratic obstacles, racial, ethnic, class, and linguistic barriers are construed differently in each country. These disparities afford transnational families opportunities to advance in a variety of ways. Haitian immigrants clearly did face disadvantages as they sought employment and housing in South Florida. But the employment opportunities, poor as they might have been, were a step up from the contributors' experiences in Haiti where they had not been able to find sufficient income to sustain their families and keep their children in school.

Haitian immigrants with low levels of education were rarely able to advance academically or occupational status after arriving in the United States, but they could advance the family. Strategies to raise the family up included sending for other family members who could also produce income and additional mobility resources, bringing children or other relatives to be educated in the US where public schools were free, or remitting money to Haiti to send children to school, start businesses, invest in homes and 
property, or spend on consumer goods to improve quality of life and status. Remittances from frontiering migrants, when invested in the educations of younger relatives who will later come to the US themselves, allow trailing migrants to enter the US on more favorable terms. Trailing migrants were more likely to have legal status as a consequence of family preference visas. They had social resources and support that frontiering migrants lacked. And they entered the US with the benefits of having a better education than the frontiering migrants who preceded them. Depending on family resources, this better education might simply mean more years of schooling or more consistent enrollment. Some trailing migrants still lacked the educational background necessary to enter the American economic system on par with the native-born population. Others encountered boundaries of discrimination and legal status. But when remittances were plentiful enough to provide for high quality schooling, trailing migrants were able to be incorporated into the US on a path that led to higher education and the potential for middle class economic status.

Furthermore, these individuals had an obligation to raise the family up. Educated and upwardly mobile family members became a resource for other relatives, both in the United States and in Haiti. They became a financial resource for parents, often helping them to purchase a home in a secure and comfortable neighborhood. While there was less direct financial support for frontiering migrants who were not parents of a trailing migrant, these relatives could still count on more educated family members for many other benefits such as job referrals, translation, filling out forms, child care, and other forms of assistance. Through these familial exchanges, many frontiering migrants who 
could not advance socioeconomically as individuals experience the benefits of social capital through relatives who enter the American middle class.

\section{Do the Transnational Endeavors of Haitians Create Boundary Blurring?}

The quest to raise the family up is a transnational endeavor for the contributors to this dissertation research. Taking advantage of global structures of inequality and cultural ideologies of family obligation, Haitian immigrant families were able to cross boundaries to equitable incorporation in the United States. This dissertation has been focused on the boundaries to education. Academic achievement, however, is necessary (for most people) but not sufficient for socioeconomic mobility. Haitian immigrants and their children, even when well educated, contend with racial and ethnic prejudices - symbolic boundaries - to equitable incorporation. But throughout American history, boundaries have shifted, albeit slowly, creating a place in the mainstream for a broader demographic.

Race and ethnicity were once clear boundaries to socioeconomic opportunity in the US. National origin was the basis for targeted exclusion from immigration beginning with the 1882 Chinese Exclusion Act. Ethnic groups were barred from employment, with blatant messages such as No Irish Need Apply. Colored Towns and segregated schools excluded blacks from white residential neighborhoods and schools. Even American citizenship was once restricted to free, white persons. In the United States today, such discrimination is illegal. Yet patterns of socioeconomic mobility in the US reflect persistent disparities along racial and ethnic lines.

The argument that these differences reflect unequal intellectual or cultural capacities between ethnic and racial groups has arisen repeatedly; however, this argument 
is accepted by few social scientists. Instead social scientists have focused on the ways that social inequities are produced and maintained. In the realm of immigrant incorporation, the framework of boundaries and the processes by which boundaries are established, policed, and resisted is one I find particularly useful. A great benefit of boundary perspective is that it can be applied to many different scales of interaction. Boundary work is regularly carried out by individuals, families, ethnic groups, social classes, and also by nation-states. The boundaries drawn at all these levels affect the incorporation of immigrants. Boundaries are not drawn against all differences; they mark the differences that make a difference (to adapt Bateson's 1972 definition of information), those that are associated with disparate value or power.

Educational parity among ethnic groups, historically, has opened the way for the blurring of boundaries. As Raphaella stated "I'm able to get an education just like a white person would. ... I'm able to apply for any position that a white person would apply. I'm able to incorporate in America with my education and I feel good about it." Many of the educated trailing migrants reported that people they go to school or work with are surprised to learn they are Haitian. "You don't seem like a Haitian" Charline was told. The symbolic meaning of "Haitian" for many Americans still reflects a stereotyped image of poverty, illiteracy, sorcery, and disease that is entangled with resilient prejudices toward all darker-skinned people. The persistent association of black Americans with an "underclass" taints African Americans as well as Haitian and other black immigrants with this stigma. But education undermines this symbolic boundary. When Haitians cross the boundaries to higher education and middle class or professional occupations, the 
boundary begins to blur. Blurry boundaries, of course, are not a guarantee of an impending shift. Such blurring is equally likely to generate a nativist backlash; and this response is clearly evident in current racialized anti-immigrant discourse.

Education, however, is not just a symbolic resource that can change the mental framing of what "Haitian" is or what the intellectual capacity of black people might be. It is also a social resource that can be wielded in material ways to generate tangible economic and political gains. Education creates opportunities for amassing power in meaningful ways in American society. The transnational process of increasing access to education among Haitian immigrant families changes the terms of their incorporation into the United States. As individual Haitian immigrants cross boundaries to higher education and socioeconomic mobility, they are beginning to blur ethnic boundaries - stereotypes that make sense of and justify discrimination against this national origin group. Blurring boundaries creates the potential for the eventual shifting of the boundaries to full inclusion and equitable incorporation of Haitian immigrants into American society.

In this dissertation, I have focused on the dimension of educational attainment as an indicator of the incorporation outcomes of Haitian immigrants in South Florida. My contributors are keenly aware that despite their educational advances, racism and antiHaitian prejudices still present boundaries to their socioeconomic mobility in the US. They are neither naïve nor irrationally optimistic about their futures. Their struggles over decades, overseas, and over generation have left no illusion that progress in their new country is guaranteed. They found that there is no tree that grows money; to enjoy the material benefits of the US they have had to work very, very hard. Life is harder still 
because in the US it is difficult to maintain the solidarity of the lakou. Yet, little by little, step by step, they cross boundaries to their educational goals and raise the family up. 


\section{REFERENCES}

Adler, Rachel H.

2000 The Maintenance of Transnational Social Fields by Yucatecan Migrants in a

Southwestern City. Mexican Studies/EstudiosMexica 16(1): 165-187.

Alba, Richard

1999 Immigration and the American Realities of Assimilation and Multiculturalism.

Sociological Forum 14(1): 3-25.

Alba, Richard

2005 Bright vs. Blurred Boundaries: Second-generation Assimilation and Exclusion in

France, Germany, and the United States. Ethnic and Racial Studies 28(1): 20-49.

Alba, Richard

2006 On the Sociological Significance of the American Jewish Experience: Boundary

Blurring, Assimilation, and Pluralism. Sociology of Religion 67(4): 347-358.

Alba, Richard and Nancy Denton

2004 Old and New Landscapes of Diversity: The Residential Patterns of Immigrant

Minorities. In Not Just Black and White: Historical and Contemporary Perspectives on Immigration, Race, and Ethnicity in the United States. Nancy Foner and George M.

Fredrickson, eds. Pp. 237-261. New York: Russell Sage Foundation.

Alba, Richard and Victor Nee

1997 Rethinking Assimilation Theory for a New Era of Immigration. International

Migration Review 31(4):826-874.

Alba, Richard and Victor Nee

2003 Remaking the American Mainstream: Assimilation and Contemporary

Immigration. Cambridge: Harvard University Press.

Alicea, Marixsa

1997 “A Chambered Nautilus": The Contradictory Nature of Puerto Rican Women's

Role in the Social Construction of a Transnational Community. Gender and Society

11(5): 597-626.

Andreasen, Robin O.

2000 Race: Biological Reality or Social Construct? Philosophy of Science 67

(Supplement): S653-S666.

Barth, Fredrik

1996 Ethnic Groups and Boundaries. In Theories of Ethnicity. Werner Sollors, ed. Pp. 294-225. New York: New York University Press. 
Basch, Linda Nina Glick Schiller, and Cristina Szanton Blanc

1994 Nations Unbound: Transnational Projects, Postcolonial Predicaments, and Deterritorialized Nation-States. Langhorne, PA: Gordon and Breach.

Bateson, Gregory

Steps to the Ecology of the Mind: Collected Essays in Anthropology, Psychiatry,

Evolution, and Epistemology. Chicago: University of Chicago Press.

Bauböck, Rainer

2005 Citizenship Policies: International, State, Migrant, and Democratic Perspectives.

Global Migration Perspectives. No.19, January 2005.

Bodnar, John

1976 Immigration and Modernization: The Case of Slavic Peasants in Industrial America. Journal of Social History 10(1): 44-71.

Borjas, George J.

1985 Assimilation, Changes in Cohort Quality, and the Earnings of Immigrants. Journal of Labor Economics 3(4): 463-489.

Bourdieu, Pierre

1984 Distinction: A Social Critique of the Judgement of Taste. Cambridge, MA: Harvard University Press.

1986 The Forms of Capital. In The Sociology of Economic Life. 2nd edition. Mark S. Granovetter and Richard Swedburg, eds. Pp. 96-111. Boulder, CO: Westview Press.

Bourdieu, Pierre and Jean-Claude Passeron

Reproduction in Education, Society and Culture. London: Sage Publications.

Brown, Karen McCarthy

1991 Mama Lola: A Vodou Priestess in Brooklyn. Berkley: University of California Press.

Bryceson, Deborah Fahy and Ulla Vuorela, eds.

2002 Transnational Families in the Twenty-first Century. In The Transnational Family:

New European Frontiers and Global Networks. Deborah Fahy Bryceson and Ulla

Vuorela, eds. Pp. 3-30. Oxford: Berg.

Cadet, Jean-Robert

1998 Restavec: From Haitian Slave Child to Middle-Class American. Austin: University of Texas Press. 
Carling, Jørgen

2008 The Human Dynamics of Migrant Transnationalism. Ethnic and Racial Studies 31(8): 1452-1477.

Castles, Stephen

2002 Migration and Community Formation under Conditions of Globalization.

International Migration Review 36(4): 1143-1168.

Catanese, Anthony V.

1999 Haitians: Migration and Diaspora. Boulder, CO: Westview Press.

Charles, Carolle

2006 Political Refugees or Economic Immigrants?: A New "Old Debate" within the Haitian Immigrant Communities but with Contestations and Division. Journal of American Ethnic History 25(2):190-208.

Chiswick, Barry

1978 The Effect of Americanization on the Earnings of Foreign-born Men. The Journal of Political Economy 86(5): 897-921.

Cornell, Stephen and Douglass Hartmann

2004 Conceptual Confusions and Divides: Race, Ethnicity, and the Study of Immigration. In Not Just Black and White: Historical and Contemporary Perspectives on Immigration, Race, and Ethnicity in the United States. Nancy Foner and George M. Fredrickson, eds. Pp. 23-41. New York: Russell Sage Foundation.

DeWind, Josh and Kasinitz, Philip

1997 Everything Old Is New Again? Processes and Theories of Immigrant

Incorporation. International Migration Review 31(4): 1096-1111.

Dinnerstein, Leonard, Roger L. Nichols, and David M. Reimers

1996 Natives and Strangers: A Multicultural History of the Americas. New York:

Oxford University Press.

Dinnerstein, Leonard and David M. Reimers

1999 Ethnic Americans. New York: Columbia University Press.

Dreby, Joanna

2009 Negotiating Work and Parenting Over the Life Course: Mexican Family

Dynamics in a Binational Context. In Across Generations: Immigrant Families in

America. Nancy Foner, ed. Pp. 190-218. New York: New York University Press. 
2005 Beneficiaries of Sacrifice: Educational Repercussions for Mexican Children whose Parents Work in the US. Paper presented at the annual meeting of the American Sociological Association. Philadelphia, PA. All Academic Inc. Available at: http://www.allacademic.com/one/www/research/index.php?click_key=1 [Accessed June 14, 2009].

Erel Umut

2002 Reconceptualizing Motherhood: Experiences of Migrant Women from Turkey Living in Germany. In The Transnational Family, Deborah Fahy Bryceson and Ulla Vuorala, eds. Oxford: Berg. Pp. 127-146.

Espiritu, Yen Le and Thom Tran

2002 "Việt Nam, Nước Tôi" (Vietnam, My Country): Vietnamese Americans and Transnationalism. In The Changing Face of Home: The Transnational Lives of the Second Generation. Peggy Levitt and Mary C. Waters, eds. Pp. 367-398. New York: Russell Sage Foundation.

Esser, Hartmut

2004 Does the "New" Immigration Require a "New" Theory of Intergenerational Integration? International Migration Review 38(3): 1126-1159.

Evergeti, Venetia and Elisabetta Zontini

2006 Introduction: Some Critical Reflections on Social Capital, Migration and

Transnational Families. Ethnic and Racial Studies 29(6):1025-1039).

Farley, Reynolds and Richard Alba

2002 The New Second Generation in the United States. International Migration Review 669-701.

Feliciano, Cynthia, and Rubèn G. Rumbaut

2005 Gendered Paths: Educational and Occupational Expectations and Outcomes among Adult Children of Immigrants. Ethnic and Racial Studies 28(6): 1087-1118.

Fjellman, Stephen and Hugh Gladwin

1985 Haitian Family Patterns of Migration to South Florida. Human Organization 44: 301- 312 .

Foner, Nancy, ed. 2009 Across Generations: Immigrant Families in America. New York: New York University Press.

2005 In a New Land: A Comparative View of Immigration. New York: New York University Press. 
1997 The Immigrant Family: Cultural Legacies and Cultural Changes. International Migration Review Special Issue: Immigrant Adaptation and Native-Born Responses in the Making of Americans 31(4):961-974.

Fouron, Georges E. and Nina Glick Schiller 2002 The Generation of Identity: Redefining the Second Generation Within a Transnational Social Field. In The Changing Face of Home: The Transnational Lives of the Second Generation. Peggy Levitt and Mary C. Waters, eds. Pp. 168-208. New York: Russell Sage Foundation.

Gans, Herbert

1979 Symbolic Ethnicity: The Future of Ethnic Groups and Cultures in America. Ethnic and Racial Studies 2(1): 1-20.

1992 Second-generation Decline: Scenarios for the Economic and Ethnic Futures of the Post-1965 American Immigrants. Ethnic and Racial Studies 15(2):173-192.

1997 Toward a Reconciliation of "Assimilation" and "Pluralism": The Interplay of Acculturation and Ethnic Retention. International Migration Review. Special Issue: Immigrant Adaptation and Native-Born Responses in the Making of Americans 31(4): 875-892.

2007 Discussion Article: Acculturation, Assimilation, and Mobility. Ethnic and Racial Studies 30(1): 164.

George, Sheba Mariam

2005 When Women Come First: Gender and Class in Transnational Migration.

Berkeley, CA: University of California Press.

Gibson, Campbell J. and Emily Lennon

1999 Historical Census Statistics on the Foreign-born Population of the United States: 1850-1990. Population Division Working Paper No. 29. US Census Bureau.

Gibson, Margaret

1987 The School Performance of Immigrant Minorities: A Comparative View. Anthropology \& Education Quarterly 18(4): 262-275.

1988 Accommodation without Assimilation: Sikh Immigrants in an American High School. Ithaca, NY: Cornell University Press.

Gjerde, Jon

1999 New Growth on Old Vines - The State of the Field: The Social History of Immigration to and Ethnicity in the United States. Journal of American Ethnic History 18(4): 40-65. 
Glazer, Nathan

2000 On Beyond the Melting Pot, 35 Years After. International Migration Review 34(1): 270-279.

1997 Is Assimilation Dead? Annals of the American Academy of Political and Social Science 530: $122-136$.

Glazer, Nathan and Daniel P. Moynihan

1970 Beyond the Melting Pot: The Negroes, Puerto Ricans, Jews, Italians, and Irish of New York City. $2^{\text {nd }}$ edition. Cambridge, MA: The MIT Press.

Glick Schiller, Nina

2003 The Centrality of Ethnography. In American Arrivals: Anthropology Engages the New Immigration. Nancy Foner, ed. Pp. 99-128.Santa Fe, NM: School of American Research Press.

Glick Schiller, Nina and Georges Eugene Fouron

2001 Georges Woke Up Laughing: Long-distance Nationalism and the Search for Home. Durham, NC: Duke University Press.

1999 Terrains of Blood and Nation: Haitian Transnational Social Fields. Ethnic and Racial Studies 22(2): 340-366.

Glick Schiller, Nina, Linda Basch, and Cristina Szanton Blanc 1995 From Immigrant to Transmigrant: Theorizing Transnational Migration. Anthropological Quarterly 68(1): 48-63.

Goldring, Luin

1998 The Power of Status in Transnational Social Fields. In Transnationalism from Below, Michael Peter Smith and Luis Eduardo Guarnizo, eds. Pp. 165-194. New Brunswick, NJ: Transaction Publishers.

Gordon, Milton M.

1964 Assimilation in American Life: The Role of Race, Religion, and National Origins. New York: Oxford University Press.

Grieco, Elizabeth M., Yesenia D. Acosta, G. Patricia de la Cruz, Christine Gambino, Thomas Gryn, Luke J. Larsen, Edward N. Trevelyan, and Nathan P. Walters 2012 The Foreign-born Population in the United States: 2010. American Community Survey Reports, U. S. Census Bureau.

Gualtieri, Sarah

2001 Becoming"White": Race, Religion, and the Foundations of Syrian/Lebanese Ethnicity in the United States. Journal of American Ethnic History 20(4): 29-58. 
Guarnizo, Luis Eduardo and Michael Peter Smith

1998 The Locations of Transnationalism. In Transnationalism from Below, Michael

Peter Smith and Luis Eduardo Guarnizo, eds. Pp. 3-34. New Brunswick, NJ:

Transaction Publishers.

Hadjadj, Bernard

2000 Education for All in Haiti Over the Last 20 Years: Assessment and Perspectives. Lynda Quamina-Aiyejina, ed. Education for All in the Caribbean: Assessment 2000. UNESCO.

Haggerty, Richard A., ed.

1989 Haiti: A Country Study. Washington: GPO for the Library of Congress, Handlin, Oscar

2002 [1951] The Uprooted: The Epic Story of the Great Migrations That Made the American People. $2^{\text {nd }}$ edition. Philadelphia: University of Pennsylvania Press.

Hao, Lingxin and Melissa Bonstead- Bruns

1998 Parent-Child Differences in Educational Expectations and the Academic

Achievement of Immigrant and Native Students. Sociology of Education 71(3): 175198.

Herskovits, Melville J.

1971[1937] Life in a Haitian Valley. Garden City, NY: Doubleday \& Company, Inc.

Hintzen, Percy C.

2004 Imagining Home: Race and the West Indian Diaspora in the San Francisco Bay Area. Journal of Latin American Anthropology 9(2): 289-318.

Hirschmann, Charles

2005 Immigration and the American Century. Demography 42(4): 595-620.

Hoefer, Michael, Nancy Rytina, and Bryan C. Baker

2010 Estimates of the Unauthorized Immigrant Population Residing in the United

States: January 2009. Office of Immigration Statistics, Policy Directorate, UD

Department of Homeland Security.

http://www.dhs.gov/xlibrary/assets/statistics/publications/ois_ill_pe_2009.pdf

Accessed 5/25/10.

Hondagneu-Sotelo, Pierrette

1994 Gendered Transitions: Mexican Experiences of Immigration. Berkeley: University of California Press.

Ignatiev, Noel

1995 How the Irish Became White. New York: Routledge. 
Isajiw, Wsevolod W.

1974 Definitions of Ethnicity. Ethnicity 1: 111-124.

Itzigsohn, Jose and Silvia Giorguli Saucedo

2002 Immigrant Incorporation and Sociocultural Transnationalism. International Migration Review 36(3): 766-798.

Jacobson, Matthew Frye

1998 Whiteness of a Different Color: European Immigrants and the Alchemy of Race.

Cambridge, MA: Harvard University Press.

Jaynes, Gerald

2004 Immigration and the Social Construction of Otherness: "Underclass" Stigma and Intergroup Relations. In Not Just Black and White: Historical and Contemporary Perspectives on Immigration, Race, and Ethnicity in the United States. Nancy Foner and George M. Fredrickson, eds. Pp. 100-116. New York: Russell Sage Foundation.

Jeffries, Kelly and Randall Monger

2008 US Legal Permanent Residents: 2007. Annual Flow Report. US Department of Homeland Security, Office of Immigration Statistics.

Johnson, James H., Walter C. Farrell, and Chandra Guinn

1997 Immigration Reform and the Browning of America: Tensions, Conflicts and Community Instability in Metropolitan Los Angeles. International Migration Review 31(4): 1055-1095. Special Issue: Immigrant Adaptation and Native-Born Responses in the Making of Americans

Joppke, Christian

1999 Immigration and the Nation-State: The United States, Germany, and Great

Britain. Oxford: Oxford University Press.

Kasinitz, Philip

2004 Race, Assimilation, and "Second Generations," Past and Present. In Not Just Black and White: Historical and Contemporary Perspectives on Immigration, Race, and Ethnicity in the United States. Nancy Foner and George M. Fredrickson, eds. Pp. 278-300. New York: Russell Sage Foundation.

Kasinitz, Philip, John Mollenkopf, and Mary C. Waters.

2002 Becoming American/Becoming New Yorkers: Immigrant Incorporation in a Majority Minority City. International Migration Review 36:1020-1036.

Kazal, R.A. 1995. "Revisiting Assimilation: The Rise, Fall, and Reappraisal of a Concept in American Ethnic History." The American Historical Review 100:437-471. 
Kearney, Michael

1995 The Local and the Global: The Anthropology of Globalization and

Transnationalism. Annual Review of Anthropology 24:547-565.

1991 Borders and Boundaries of State and Self at the End of Empire. Journal of Historical Sociology

King, Desmond

2000 Making Americans: Immigration, Race, and the Origins of the Diverse

Democracy. Cambridge, MA: Harvard University Press.

Kiviso, Peter

1990 The Transplanted Then and Now: The Reorientation of Immigration Studies from the Chicago School to the New Social History. Ethnic and Racial Studies 13(4): 456481.

Konczal, Lisa, and William Haller

2008 Fit to Miss, but Matched to Hatch: Success factors among the Second

Generation's Disadvantaged in South Florida. Annals of the Academy of Political and Social Sciences 620(1): 161-176.

Kyle, David

2000 Transnational Peasants: Migrations, Networks, and Ethnicity in Andean Ecuador.

Baltimore, MD: The Johns Hopkins University Press.

Laguerre, Michel S.

1984 American Odyssey: Haitians in New York City. Ithaca, NY: Cornell University Press.

1982 Urban Life in the Caribbean: A Study of a Haitian Urban Community.

Cambridge, MA: Schenkman Publishing Company, Inc.

Landolt, Patricia and Wei Wei Da

2005 The Spatially Ruptured Practices of Migrant Families: A Comparison of Immigrants from El Salvador and the People's Republic of China. Current Sociology 53(4):625-653.

Lawless, Robert

1992 Haiti's Bad Press: Origins, Development, and Consequences. Rochester, NY:

Schenkman Books.

1986 Haitian Migrants and Haitian-Americans: From Invisibility into the Spotlight. Journal of Ethnic Studies 14(2): 29-70. 
Lee, Erika

2004 American Gatekeeping: Race and Immigration Law in the Twentieth Century. In Not Just Black and White: Historical and Contemporary Perspectives on Immigration, Race, and Ethnicity in the United States. Nancy Foner and George M. Fredrickson, eds. Pp. 119-144. New York: Russell Sage Foundation.

Levitt, Peggy

2002 The Ties That Change: Relations to the Ancestral Home over the Life Cycle. In

The Changing Face of Home: The Transnational Lives of the Second Generation.

Peggy Levitt and Mary C. Waters, eds. Pp. 123-144. New York: Russell Sage

Foundation.

2001 The Transnational Villagers. Berkeley: University of California Press.

1998 Social Remittances: Migration Driven Local-Level Forms of Cultural Diffusion. International Migration Review 32(4): 926-948.

Levitt, Peggy and Nina Glick Schiller

2004 Conceptualizing Simultaneity: A Transnational Social Field Perspective on

Society. International Migration Review 38(3): 1002-1039.

Leyburn, James G.

1966 The Haitian People. New Haven: Yale University Press.

Logan, Rayfort W.

1930 Education in Haiti. The Journal of Negro History 15(4):401-460.

Lowenthal, Ira Paul

1987 "Marriage is 20, Children are 21": The Cultural Construction of Conjugality and Family in Rural Haiti. Ph.D. dissertation, Johns Hopkins University.

Mahler, Sarah J

2001 Transnational Relationships: The Struggle to Communicate Across Borders. Identities 7(4): 583-619.

1998 Theoretical and Empirical Contributions: Toward a Research Agenda for Transnationalism. In Transnationalism from Below. M.P. Smith and L.E. Guarnizo, eds. Pp. 64-100. New Brunswick NJ: Transaction Publishers.

1995 American Dreaming: Immigrant Life on the Margins. Princeton, NJ: Princeton University Press.

Mahler, Sarah J. and Patricia R. Pessar

2006 Gender Matters: Ethnographers bring Gender from the Periphery toward the Core of Migration Studies. International Migration Review 40(1):27-63. 
Massey, Douglas S.

2007 Categorically Unequal: The American Stratification System. New York: Russell Sage Foundation.

1995 The New Immigration and Ethnicity in the United States. Population and Development Review 21(3): 631-652.

1990 American Apartheid: Segregation and the Making of the Underclass. The American Journal of Sociology 96(2): 329-357.

Massey, Douglass S. and Katherine Bartley

2005 The Changing Legal Status Distribution of Immigrants: A Caution. International Migration Review 39(2): 469-484.

Matthei, Linda Miller and David A. Smith

1998 Belizean "Boyz 'n the 'Hood"?: Garifuna Labor Migration and Transnational Identity. In Transnationalism from Below, Michael Peter Smith and Luis Eduardo Guarnizo, eds. Pp. 270-290. New Brunswick, NJ: Transaction Publishers.

McKay, Ramah

2003 Family Reunification. Migration Policy Institute. March 2003.

http://www.migrationinformation.org/USfocus/display.cfm?ID=122. Accessed $10 / 28 / 2008$.

Miller, Errol

1992 Education for All: Caribbean Perspectives and Imperatives. Washington, D. C.: Inter-American Development Bank.

Mitchell, Christopher

1994 U. S. Policy toward Haitian Boat People, 1972-93. Annals of the American Academy of Political and Social Science 534: 69-80.

Moldenhawer, Bolette

2005 Transnational Migrant Communities and Education Strategies Among Pakistani Youngsters in Denmark. Journal of Ethnic and Migration Studies 31(1):51-78.

Monger, Randall

2010 US Legal Permanent Residents: 2009. Annual Flow Report. US Department of Homeland Security, Office of Immigration Statistics.

Moran-Taylor, Michelle J.

2008 When Mothers and Fathers Migrate North: Caretakers, Children, and Child Rearing in Guatemala. Latin American Perspectives 35: 79-95. 
Morawska, Ewa

2003 Disciplinary Agendas and Analytic Strategies of Research on Immigrant

Transnationalism: Challenges of Interdisciplinary Knowledge. International Migration Review 37(3): 611-640.

Nagel, Joane

1994 Constructing Ethnicity: Creating and Recreating Ethnic Identity and Culture.

Social Problems 41(1):152-179.

Neckerman, Kathryn M., Prudence Carter, and Jennifer Lee

1999 Segmented Assimilation and Minority Cultures of Mobility. Ethnic and Racial

Studies 22(6): 945-964.

Nicholas, Tekla

2008 Family, Obligation, and Educational Outcomes: Unraveling the Paradox of High Aspirations and Low Academic Achievement among the Children of Haitian Immigrants. Master's Thesis, Department of Anthropology, Florida Atlantic University.

Nicholas, Tekla, Alex Stepick, and Carol Dutton Stepick

2008 Here's Your Diploma, Mom! Family Obligation and Multiple Pathways to

Success. Annals of the Academy of Political and Social Sciences 620(1): 237-252.

Olorunnipa, Touluse

2011 Foreclosure Crisis Hits Home for All. Miami Herald, January, 9, 2011.

http://www.miamiherald.com/2011/01/09/2008157/foreclosure-crisis-hits-home.html. Accessed March 1, 2014.

Olwig, Karen Fog

2003 "Transnational" Socio-Cultural Systems and Ethnographic Research: Views from an Extended Field Site. International Migration Review 37(3):787-811.

1999 Narratives of the Children Left Behind: Home and Identity in Globalised

Caribbean Families. Journal of Ethnic and Migration Studies 25(2): 267-284.

Omi, Michael and Howard Winant

1986 Racial Formation in the United States: From the 1960s to the 1980s. New York:

Routledge \& Kegan Paul Inc.

Orellana, Marjorie Faulstich, Barrie Thorne, Anna Chee, Wan Shun Eva Lam 2001 Transnational Childhoods: The Participation of Children in Processes of Family Migration. Social Problems 48(4): 572-591. 
Oropesa, R.S. and Nancy Landale

1997 In Search of the New Second Generation: Alternative Strategies for Identifying

Second Generation Children and Understanding their Acquisition of English.

Sociological Perspectives 40(3): 429-455.

Orozco, Manuel

2006 Understanding the Remittance Economy of Haiti. Inter-American Dialogue.

Commissioned by the World Bank.

Pamphile, Leon D.

1985 America's Policy-Making in Haitian Education 1915-1934. The Journal of Negro

Education 54(1):99-108.

Paquin, Lyonel

1983 The Haitians: Class and Color Politics. Brooklyn, NY: Multitype.

Parreñas, Rhacel

2005 Long Distance Intimacy: Class, Gender, and Intergenerational Relations between

Mothers and Children in Filipino Transnational Families. Global Networks 5(4):14702266.

Perlmann, Joel and Roger Waldinger

1997 Second Generation Decline? Children of Immigrants, Past and Present - A

Reconsideration. International Migration Review 31(4): 893-922.

Perriera, Krista M., Kathleen Mullan Harris, and Dohoon Lee

2006 Making It In America: High School Completion by Immigrant and Native Youth.

Demography 43(3): 511-536.

Pessar, Patricia R., and Sarah J. Mahler

2003 Transnational Migration: Bringing Gender In. International Migration Review 37(3): 812-846.

Pierre, Jemima

2004 Black Immigrants in the United States and the "Cultural Narratives" of Ethnicity. Identities: Global Studies in Culture and Power 11: 141-170.

Placide, Sharon E.

2010 Navigating Racial Boundaries: The One-Drop Rule and Mixed-Race Jamaicans in South Florida. Ph.D. dissertation, Department of Global and Sociocultural Studies, Florida International University.

Portes, Alejandro

2003 Conclusion: Theoretical Convergencies and Empirical Evidence in the Study of Immigrant Transnationalism. International Migration Review 37(3): 874-892. 
1998 Social Capital: Its Origins and Applications in Modern Sociology. Annual Review of Sociology 24: 1-24.

Portes, Alejandro, Patricia Fernandez-Kelly, and William Haller.

2005 Segmented Assimilation on the Ground: The New Second Generation in Early Adulthood. Ethnic and Racial Studies 28(6): 1000-40.

Portes, Alejandro, Luis E. Guarnizo, and Patricia Landolt

1999 The Study of Transnationalism: Pitfalls and Promise of an Emergent Research

Field." Ethnic and Racial Studies 22(2): 217-237.

Portes, Alejandro and Dag MacLeod

1996 Educational Progress of Children of Immigrants: The Roles of Class, Ethnicity, and School Context. Sociology of Education 69(4): 255-275.

Portes, Alejandro and Ruben G. Rumbaut

1996 Immigrant America: A Portrait. Second Edition. Berkeley: University of California Press.

2001 Legacies: the Story of the Immigrant Second Generation. Berkley: University of California Press.

2005 Introduction: The Second Generation and the Children of Immigrants Longitudinal Study. Ethnic and Racial Studies 28(6).

Portes, Alejandro and Julia Sensenbrenner

1998 Embeddedness and Immigration: Notes on the Social Determinants of Economic Action. In The Sociology of Economic Life. $2^{\text {nd }}$ edition. Mark S. Granovetter and Richard Swedburg, eds. Pp. 112-135. Boulder, CO: Westview Press.

Portes, Alejandro and Min Zhou

1993 The New Second Generation: Segmented Assimilation and its Variants. The Annals of the American Academy of Political and Social Science 530: 74-96.

Pribilsky, Jason

2004 "Aprendemos a Convivir": Conjugal Relations, Co-parenting, and Family Life Among Ecuadorian Transnational Migrants in New York City and the Ecuadorian Andes. Global Networks 4(3): 313-334.

2001 Nervios and Modern Childhood: Migration and Shifting Contexts of Child Life in the Ecuadorian Andes. Childhood 8(2):251-273. 
Putnam, Robert

2000 Bowling Alone: The Collapse and Revival of American Community. New York:

Simon and Schuster.

Richman, Karen E.

2005 Migration and Vodou. Gainesville: University Press of Florida.

2003 Miami Money and the Home Gal. Anthropology and Humanism 27(2): 119-132.

Roediger, David R.

2005 Working Toward Whiteness: How America's Immigrants Became White. New

York: Basic Books.

Roediger, David and James Barrett

2004 Making New Immigrants “Inbetween”: Irish Hosts and White Panethnicity, 1890 to 1930. In Not Just Black and White: Historical and Contemporary Perspectives on Immigration, Race, and Ethnicity in the United States. Nancy Foner and George M. Fredrickson, eds. Pp. 167-196. New York: Russell Sage Foundation.

Rogers, Reuel R.

2006 Afro-Caribbean Immigrants and the Politics of Imcorporation: Ethnicity, Exception, or Exit. New York: Cambridge University Press.

Romero, Mary

2008 Crossing the Immigration and Race Border: A Critical Race Theory Approach to Immigration Studies. Contemporary Justice Review 11(1): 23-37.

Rumbaut, Ruben G.

1994 The Crucible Within: Ethnic Identity, Self-esteem, and Segmented Assimilation among Children of Immigrants. International Migration Review 28(4): 748-794.

1997a Paradoxes (and Orthodoxies) of Assimilation. Sociological Perspectives 40(3): 483-511.

1997b Assimilation and Its Discontents: Between Rhetoric and Reality. International Migration Review 31(4): 923-960.

2004 Ages, Life Stages, and Generational Cohorts: Decomposing the Immigrant First and Second Generations in the United States. International Migration Review 38(3): 1160-1205.

Rumbaut, Ruben G. and Alejandro Portes, eds.

2001 Ethnicities: Children of Immigrants in America. Berkeley: University of California Press. 
Ryan, Louise

2004 Family Matters: (E)migration, Familial Networks and Irish Women in Britain.

The Sociological Review 351-370.

Ryang, Sonia

2002 A Long Loop: Transmigration of Korean Women in Japan. International

Migration Review 36(3): 894-911.

Sanjek, Roger

1994 The Enduring Inequalities of Race. In Race. Steven Gregory and Roger Sanjek, eds. Pp. 1-17. New Brunswick, NJ: Rutgers University Press.

Sanders, Jimy M.

2002 Ethnic Boundaries and Identity in Plural Societies. Annual Review of Sociology 28:327-357.

Sassen, Sakia

2000 Spacialities and Temporalities of the Global:Elements for a Theorization. Public Culture 12:215-232

Schmalzbauer, Leah

2008 Family Divided: The Class Formation of Honduran Transnational Families.

Global Networks 8(3): 329-34.

2004 Searching for Wages and Mothering from Afar: The Case of Honduran

Transnational Families. Journal of Marriage and Family 66:1317-1331.

Schmid, Carol L.

2001 Educational Achievement, Language-Minority Students, and the New Second Generation. Sociology of Education 74(Extra Issue): 71-87.

Schwartz, Timothy T.

2003 "Children are the Wealth of the Poor": Pronatalism and the Economic Utility of Children in Jean-Rabel, Haiti. In Anthropological Perspectives on Economic Development and Integration. Research in Economic Anthropology 22: 61-105.

Shibutani, Tomatsu and Kian Kwan

1965 Ethnic Stratification: A Comparative Approach. New York: The Macmillan Co. Smith, Robert C.

2006 Mexican New York: Transnational Lives of New Immigrants. Berkeley:

University of California Press. 
2002 Life Course, Generation, and Social Location as Factors Shaping SecondGeneration Transnational Life. In The Changing Face of Home: The Transnational Lives of the Second Generation. Peggy Levitt and Mary C. Waters, eds. Pp. 145-167. New York: Russell Sage Foundation.

1998 Transnational Localities: Community, Technology and the Politics of Membership within the Context of Mexico and US Migration. In Transnationalism From Below, Michael Peter Smith and Luis Eduardo Guarnizo, eds. Pp. 196-238. New Brunswick, NJ: Transaction Publishers.

Stepick, Alex

1982 Pride Against Prejudice: Haitians in the United States. Needham Heights, MA: Allyn \& Bacon.

1982b Haitian Boat People: A Study in the Conflicting Forces Shaping US Immigration Policy. Law and Contemporary Problems 45(2): 163-196.

1992 The Refugees Nobody Wants: Haitians in Miami. In Miami Now! Pp. 57-82. . Guillermo J. Grenier and Alex Stepick III, eds. Gainesville: University Press of Florida.

Stepick, Alex, Guillermo Grenier, Max Castro, and Marvin Dunn 2003 This Land is Our Land: Immigrants and Power in Miami. Berkeley: University of California Press.

Stepick, Alex and Alejandro Portes 1986 Flight into Despair: A Profile of Recent Haitian Refugees in South Florida. International Migration Review 20(2):329-350.

Stepick, Alex, Carol Dutton Stepick

2010 The Complexities and Confusions of Segmented Assimilation. Ethnic and Racial Studies 33(7): 1149-1167.

Stepick, Alex, Carol Dutton Stepick, Emmanuel Eugene, Deborah Teed, and Yves Labissiere

2001 Shifting Identities and Intergenerational Conflict: Growing Up Haitian in Miami. In Ethnicities: Children of Immigrants in America. Berkeley: University of California Press.

Stepick, Alex, Carol Dutton Stepick, and Philip Kretsedemas 2001 Civic Engagement of Haitian Immigrants and Haitian Americans in Miami-Dade County. Immigration \& Ethnicity Institute, Florida International University, Miami. 
Suarez-Orozco, Carola and Marcelo M. Suarez-Orozco

2001 Children of Immigration. Cambridge, MA: Harvard University Press.

Suarez-Orozco, Carola, Irina L.G. Todorova, and Josephine Louie

2002 Making Up for Lost Time: The Experience of Separation and Reunification among Immigrant Families. Family Process 41(4):625-643.

Thompson, Richard H.

1989 Ethnicity and Human Nature. In Theories of Ethnicity: A Critical Appraisal. New York: Greenwood Press.

US Department of State. "Visa Bulletin for March 2009.” Available at:

http://travel.state.gov/visa/frvi/bulletin/bulletin_4427.html [Accessed June 9, 2009].

US Department of Homeland Security

2003 "Estimates of the Unauthorized Immigrant Population Residing in the United States: 1990 to $2000 "$.

http://www.dhs.gov/xlibrary/assets/statistics/publications/Ill_Report_1211.pdf [Accessed June 9, 2009].

Vaughan, Jessica

2009 Five Million waiting on Family Visas. Center for Immigration Studies. http://cis.org/Vaughan/FamilyImmigrantWaitingList [Accessed June 9, 2009].

Vecoli, Rudolph J.

1993 An Inter-Ethnic Perspective on American Immigration History. Mid America 75: 223-235.

Waldinger, Roger

2007 The Bounded Community: Turning Foreigners into Americans in Twenty-first Century L.A. Ethnic and Racial Studies 30(3): 341-374.

Waldinger, Roger

2007 Did Manufacturing Matter? The Experience of Yesterday's Second Generation: A Reassessment. International Migration Review 41(1): 3-39.

Waldinger, Roger and Cynthia Feliciano

2004 Will the New Second Generation Experience 'Downward Assimilation'?

Segmented Assimilation Re-assessed. Ethnic and Racial Studies 27(3): 376- 402.

Wasem, Ruth Ellen

2007 US Immigration Policy on Haitian Migrants. CRS Report for Congress.

http://www.ilw.com/immigdaily/news/2007,0628-crs.pdf. 
2010 US Immigration Policy on Haitian Migrants. CRS Report for Congress. http://www.fas.org/sgp/crs/row/RS21349.pdf

Waters, Johanna L.

2005 Transnational Family Strategies and Education in the Contemporary Chinese Diaspora. Global Networks 5(4): 359-377.

Waters, Mary C.

1994 Ethnic and Racial Identities of Second-Generation Black Immigrants in New

York City. International Migration Review 28(4): 795-820.

Waters, Mary C. and Tomas R. Jimenez

2005 Assessing Immigrant Assimilation: New Empirical and Theoretical Challenges.

Annual Review of Sociology 31:105-125.

Whitehouse, Bruce

2009 Transnational Childrearing and the Preservation of Transnational Identity in Brazzaville, Congo. Global Networks 9(1): 82-99.

Wierzbicki, Susan

2004 Beyond the Immigrant Enclave: Network Change and Assimilation. New York: LFB Scholarly Publishing LLC.

Wimmer, Andreas

2008 The Making and Unmaking of Ethnic Boundaries: A Multilevel Process Theory. American Journal of Sociology 113(4): 970-1022.

Wimmer, Andreas, and Nina Glick Schiller

2003 Methodological Nationalism, the Social Sciences, and the Study of Migration: An

Essay in Historical Epistemology. International Migration Review 37(3): 576-610.

Wolf, Diane L.

2002 There's No Place Like "Home": Emotional Transnationalism and the Struggles of Second-Generation Filipinos. In The Changing Face of Home: The Transnational Lives of the Second Generation. Peggy Levitt and Mary C. Waters, eds. Pp. 255-294. New York: Russell Sage Foundation.

Zhou, Min

1997 Growing Up American: The Challenge Confronting Immigrant Children and Children of Immigrants. Annual Review of Sociology 23: 63-95.

Zhou, Min and Xiong Yang Sao

2005 The Multifaceted American Experiences of the Children of Asian Immigrants: Lessons for Segmented Assimilation. Ethnic and Racial Studies 28(6): 11191152. 
Zolberg, Aristede and Long Litt Woon

1999 Why is Islam like Spanish: Cultural Incorporation in Europe and the United States. Politics \& Society 27(1): 5-38.

Zolberg, Aristide R.

2006 A Nation By Design: Immigration Policy in the Fashioning of America. New York: Russell Sage Foundation. 


\section{APPENDIX}

\section{Sample Interview Guide}

\section{Interview process:}

Interviews will be semi-structured. This sample interview guide is intended to detail areas to be probed following very open questions posed to begin each segment of the interview. Questions will vary depending on the circumstances of the individual participant's migration and family history. Interviews of the initial, frontiering migrants and the first trailing migrants interviewed in each family are expected to be quite detailed and may require several interview sessions. As a core of information regarding the family history is established, the remaining family members will be interviewed to provide varied perspectives for triangulation of the data, but these interviews may be briefer and more narrowly focused on the participants' own experiences and outcomes rather than a full family history. The interview guide will be adapted to respond to themes that emerge during data collection.

\section{Migration overview}

Before I ask for the full story, I would like to make a chart of everywhere you have lived. After that, we will go through your history in detail and I will ask more about the places you lived, your family, education, employment, and why you and other family members came to the US.

Let's start with where you were born - What year was that? Who lived in that household with you?

(Proceed through life history, charting place and year of each move and with whom participant lived)

\section{Childhood}

Now let's go back to your childhood.

Tell me about the place you lived then. (This section may be repeated if the participant moved during childhood)

Household:

What was home like? (general lifestyle \& material conditions)

Household composition?

Parents'/guardians' occupations?

Extended family:

Were there other family members living nearby?

How often did you see them? What kinds of things did you do together?

Did your families help each other? If so, how? 


\section{Education (in Haiti)}

Tell me about your education. Did you go to school?

How old were you when you started school?

How many years did you go?

Were you able to go every year?

How many grades did you complete?

Why did you stop attending school when you did?

What were your schools like?

How did you get to school?

How did your family pay for school or school expenses?

Did your brothers and sisters go to school?

How many years did they go to school or what grade did they complete?

Impacts of Family Migration (trailing migrants)

Let's talk some more about your family's migration to the US.

Who was the first to come?

Do you remember why they migrated? How did they decide to go?

\section{Family Separation:}

How did their leaving affect your life?

Did you move, or was your household changed in other ways because of this?

Did your responsibilities change? (child- or elder-care, household chores, employment)

Did this have an impact on your schooling? (positive or negative effects on school enrollment, attendance, or grades)

How did you feel about this separation?

\section{Communication \& Remittances:}

What happened after they left? Did they stay in touch or visit? How? How often?

Did they send money or other things back to Haiti?

Describe: What? How much? How often?

Who received money or gifts from them? How were they distributed?

How did the money or things you received affect your life in Haiti?

What did you learn about the US from that person?

How did the information about the US affect you? Did it make you think about migrating yourself? Did it change your ideas about school or how you should prepare for your life?

(Ask about subsequent family migrants \& the impacts of their migrations in terms of family separation, communication, money \& material goods, ideas \& information) 


\section{Personal Migration}

How did you decide to come to the US? Why did you migrate?

Why did you come at that time?

Did you have a visa? Did someone else make arrangements for you to come?

How did you travel? Alone or with others?

Who did you leave behind in Haiti when you came?

Where did you settle? Why there?

Did you receive any assistance when you arrived - financial, place to live or eat, advice

$\&$ information - from family or others?

\section{Incorporation into the US}

What was your life like when you first got here?

Did you speak English? How did you communicate?

Did you get a job? What kind? How did it pay?

Did you go to school? What level? Did you earn degrees or certifications in the US?

Did you face any problems getting work or in school because you were an immigrant?

\section{Transnational Ties}

Did you stay in touch with people still in Haiti? How? How often?

Did you send money or other things back to Haiti?

Describe: What? How much? How often?

Who received money or gifts from you?

What did you tell people back in Haiti about life in the US?

Have you helped anyone else to come to the US? (visa, money, hospitality, information)

Who did you help and why?

How did you help them?

\section{On-going Family Interdependence}

Tell me about your current family relationships.

Do you currently help family members in the US, Haiti, or elsewhere with money, material goods, childcare, elder-care, transportation, finding jobs, a place to stay or eat?

Do other relatives help you or others with these things?

When do you feel a responsibility to help other family members?

Who decides what to do when someone in the family needs help?

Are there certain family members who are expected to help more than others?

Are there certain family members that you feel a special obligation to help? 


\section{VITA}

\section{TEKLA C. NICHOLAS}

2008

MA, Anthropology

Florida Atlantic University

Boca Raton, Florida

2008

MA, Comparative Sociology

Florida International University

Miami, Florida

$2010-2014$

Adjunct Lecturer

Florida International University

Miami, Florida

$2010-2013$

Research Associate

Florida International University

Miami, Florida

2013

Research Specialist

Florida International University

Miami, Florida

\section{PUBLICATIONS AND PRESENTATIONS}

Nicholas, Tekla. "Shifting Boundaries of the Land of God and Shrines to the Anti-Christ: Haitian Protestantism across National Borders," American Anthropological Association Annual Meeting, San Francisco, November 2012.

Nicholas, Tekla. "Clearing the Pathway to Graduation: Revealing Institutional Impediments to College Persistence," Society for Applied Anthropology, Baltimore, March 2012.

Nicholas, Tekla. "Legacies of the Lakou: Cooperation and Conflict in Transnational Haitian Families," American Anthropological Association Annual Meeting, Montreal, November 2011.

Nicholas, Tekla. "Taking the Long View: Haitian Transnational Families and the Adult Outcomes of Children Left Behind," American Anthropological Association Annual Meeting, New Orleans, November 2010. 
Nicholas, Tekla. "'Betwixt and Between': Transformations in Transnational Spaces." American Anthropological Association Annual Meeting, Philadelphia, December 2009.

Nicholas, Tekla. 2008. Family, Obligation, and Educational Outcomes: Unraveling the Paradox of High Aspirations and Low Academic Achievement among the Children of Haitian Immigrants. Master's Thesis, Department of Anthropology, Florida Atlantic University.

Nicholas, Tekla. "Remittances, Education, and Family Reunification: The Transnational Strategies of Haitian Immigrant Families," Transnational Parenthood and Children-LeftBehind, Oslo, Norway, November 2008.

Nicholas, Tekla. "Building Human Capital Transnationally: Remittances, Education, and Migration among Haitian Immigrants in South Florida," Conference of the Working Group on Childhood and Migration, Philadelphia, June, 2008.

Nicholas, Tekla. "Family, Community, and Education: Academic Outcomes among Second Generation Haitian-Americans," Haitian Studies Association Annual Conference. Boca Raton, Florida. October, 2007.

Nicholas, Tekla, and LéTania Severe. 2008. "School Segregation, Educational Disparities, and Impacts on Haitian Youth in South Florida," Proceedings of the Seventh Annual College of Education Research Conference, Florida International University College of Education, Maria S. Plakhotnik and Sarah M. Nielsen, eds. Pp, 98-104. http://coeweb.fiu.edu/research_conference/COERC\%202008\%20Proceedings.pdf.

Nicholas, Tekla, and LéTania Severe . 2008 "The Invisible Borders of School Segregation: Educational Disparities and Haitian Youth in South Florida," Society for the Study of Social Problems Annual Meeting, Boston, August 2008.

Nicholas, Tekla, and LéTania Severe. "School Segregation and the Education of Haitian Immigrants" American Anthropological Association Annual Meeting, Washington DC, December 2007.

Nicholas, Tekla, Alex Stepick and Carol Dutton Stepick. 2008. "Here's Your Diploma, Mom!" Family Obligation and Multiple Pathways to Success, Annals of the American Academy of Political and Social Science 620: 237-252. 